\title{
Atrial fibrillation begets atrial fibrillation : an experimental study in chronically instrumented goats
}

Citation for published version (APA):

Wijffels, M. C. E. F. (1996). Atrial fibrillation begets atrial fibrillation : an experimental study in chronically instrumented goats. [Doctoral Thesis, Maastricht University]. Universiteit Maastricht. https://doi.org/10.26481/dis.19961220mw

Document status and date:

Published: 01/01/1996

DOI:

10.26481/dis.19961220mw

Document Version:

Publisher's PDF, also known as Version of record

\section{Please check the document version of this publication:}

- A submitted manuscript is the version of the article upon submission and before peer-review. There can be important differences between the submitted version and the official published version of record.

People interested in the research are advised to contact the author for the final version of the publication, or visit the DOI to the publisher's website.

- The final author version and the galley proof are versions of the publication after peer review.

- The final published version features the final layout of the paper including the volume, issue and page numbers.

Link to publication

\footnotetext{
General rights rights.

- You may freely distribute the URL identifying the publication in the public portal. please follow below link for the End User Agreement:

www.umlib.nl/taverne-license

Take down policy

If you believe that this document breaches copyright please contact us at:

repository@maastrichtuniversity.nl

providing details and we will investigate your claim.
}

Copyright and moral rights for the publications made accessible in the public portal are retained by the authors and/or other copyright owners and it is a condition of accessing publications that users recognise and abide by the legal requirements associated with these

- Users may download and print one copy of any publication from the public portal for the purpose of private study or research.

- You may not further distribute the material or use it for any profit-making activity or commercial gain

If the publication is distributed under the terms of Article $25 \mathrm{fa}$ of the Dutch Copyright Act, indicated by the "Taverne" license above, 
Atrial Fibrillation Begets Atrial Fibrillation 
(C) M.C.E.F. Wijffels, Maastricht 1996 ISBN 9090101241

Vormgeving en druk: Datawyse I Universitaire Pers Maastricht 


\section{Atrial Fibrillation Begets Atrial Fibrillation An Experimental Study in Chronically Instrumented Goats}

\section{PROEFSCHRIFT}

ter verkrijging van de graad van doctor aan de Universiteit Maastricht, op gezag van de Rector Magnificus, Prof. mr. M.J. Cohen, volgens het besluit van het College van Dekanen, in het openbaar te verdedigen op vrijdag 20 december 1996 om $10 .(0)$ uur

door

Maurits Christoffel Emile Franciscus Wijliels geboren te Maastricht op 4 november 1967 


\section{Promotor:}

Prof.dr. M.A. Allessie

\section{Beoordelingscommissie:}

Prof.dr. H.J.J. Wellens (voorzitter)

Dr. H.J.G.M. Crijns (Rijksuniversiteit Groningen)

Prof.dr. M.J. Janse (Universiteit van Amsterdam)

Prof.dr. R.S. Reneman

Prof.dr. H.A.J. Struijker Boudier

This study was supported by a grant of the Netherlands Organization for Scientific Research (N.W.O).

Grant number 900-516-318.

Financial support by the Netherlands Heart Foundation for the publication of this thesis is gratefully acknowledged.

Additional support was granted by the Netherlands Foundation of Scientific Research and Stichting RESCAR Maastricht. 
Dankzij mijn Ouders Aan Marieke 
efnslno 


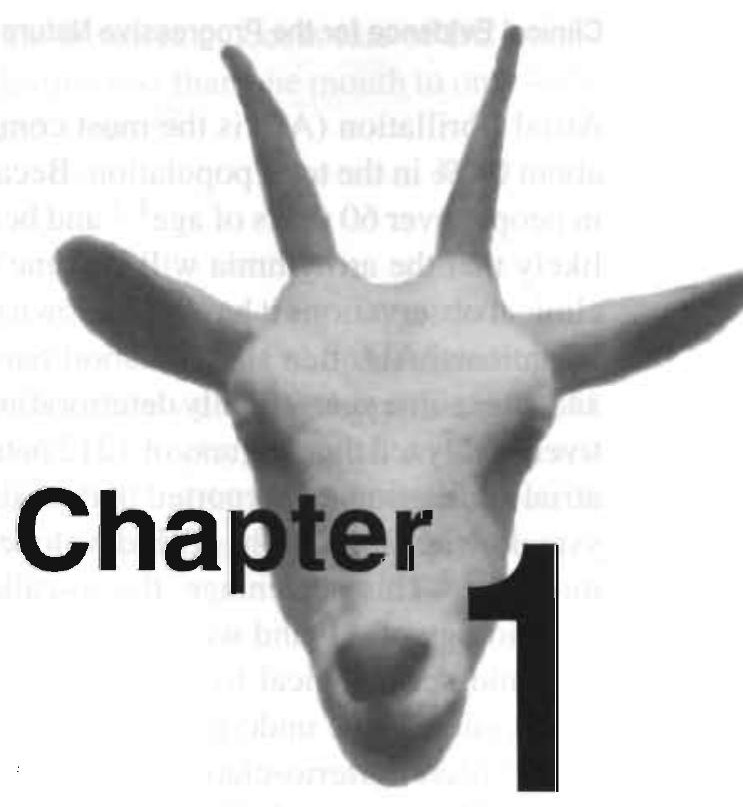

Introduction 


\section{Clinical Evidence for the Progressive Nature of Atrial Fibrillation}

Atrial fibrillation (AF) is the most common arrhythmia in man with a prevalence of about $0.4 \%$ in the total population. Because its prevalence increases with age to $2-4 \%$ in people over 60 years of age ${ }^{1-5}$ and because of the aging of our population, it is very likely that the arrhythmia will become even more common in the near future. From clinical observations it has been known that atrial fibrillation has a progressive nature. In patients, AF often starts as short paroxysms which gradually increase in duration and after some years, finally deteriorating into chronic $\mathrm{AF}^{2}{ }^{2,6.7}$ Godtfredsen retrospectively analyzed the progress of 1212 patients with electrocardiographically confirmed atrial fibrillation and reported that of all patients who initially presented with paroxysmal atrial fibrillation, 33\% developed chronic AF after a median duration of 34 months. ${ }^{2,7}$ This percentage, the so-called 'transition rate', varied considerably with the etiology of $\mathrm{AF}$ and was as high as $66 \%$ in patients with rheumatic heart disease. It would seem logical to explain the transition of paroxysmal to chronic AF by a progression of the underlying heart disease (e.g. rheumatic heart disease, congestive heart failure, arteriosclerotic/ischemic heart disease, degenerative changes due to aging). However, in $2-32 \%$ of the AF-patients, the arrhythmia occurs in the presence of an apparently healthy heart (lone atrial fibrillation). ${ }^{2-4,7-11}$ Even in this group of patients with lone $\mathrm{AF}$ a transition from paroxysmal to chronic $\mathrm{AF}$ is seen in $4-24 \%$ of cases, which by definition can not be attributed to a worsening of an underlying cardiovascular disease. ${ }^{2,9}$

Additional evidence for the progressive nature of AF is provided by the observation that the success rate of cardioversion by anti-fibrillatory drugs diminishes when $\mathrm{AF}$ has persisted for a considerable time. ${ }^{12-21}$ Both Crijns et al. and Suttorp et al. compared the effects of intravenous flecainide in patients with recent onset $\mathrm{AF}$ (duration $<24$ hours) and in those with AF of longer duration. ${ }^{15-17}$ The results of these studies are given in Table 1 , and show that drug efficacy clearly diminished from $86 \%$ for recent onset AF to only $39 \%$ for chronic AF.

Similarly, the success rate of electrical defibrillation and subsequent maintenance of sinus rhythm depend strongly on the previous history of atrial fibrillation. ${ }^{22-26}$ For

Table 1. The diminishing efficacy of necainide in patients with chronic AF

Efficacy of intravenous flecainide

Study

Recent onset AF ( $<24 h)$

Chronic AF $(>24 h)$

Crijns et al., $1988^{15}$

Suttorp et al., $1989^{16}$

$77 \%(10 / 13)$

$0 \%(0 / 7)$

Suttorp et al., $1990^{17}$

$86 \%(19 / 22)$

$40 \%(4 / 10)$

$93 \%(13 / 14)$

$83 \%(5 / 6)$

Overall efficacy

$86 \%(42 / 49)$

$39 \%(9 / 23)$ 
instance, Resnekov and McDonald reported that the direct success rate of DC-countershock diminished from nearly $100 \%$ in AF lasting less than one month to only $48 \%$ when the arrhythmia had been present for over 5 years. ${ }^{22}$

\section{Aim of the Present Study}

A possible explanation for the progressive nature of $\mathrm{AF}$ is the deterioration in underlying heart disease with time. However, a completely different hypothesis would be that atrial fibrillation itself causes progressive electrophysiological and/or structural changes to the atrial myocardium, which favor the initiation and perpetuation of the arrhythmia. The aim of the present study was to test this altemative hypothesis.

\section{Evaluation of the Hypothesis: The Chronically Instrumented Goat}

In order to evaluate the hypothesis that atrial fibrillation begets atrial fibrillation, an animal model was developed in which, in a completely healthy heart, the effects of repetitive paroxysms of $\mathrm{AF}$ on the duration of subsequent $\mathrm{AF}$-episodes could be studied. For this model we needed an animal 1) with atria big enough to allow the induction and perpetuation of AF, 2) which could be instrumented with multiple atrial recording and stimulation electrodes for chronic electrophysiological measurements and 3) which could be connected to the equipment used for the continuous maintenance of AF ( 24 hours a day).

Their was extensive experience in our laboratory with a model of chronically instrumented conscious dogs. This model was used to study the role of the atrial wavelength in the induction of atrial tachyarrhythmias and for the evaluation of anti-fibrillatory drugs. ${ }^{27-29}$ Although at first sight this dog model seemed adequate for our study, a number of disadvantages were evident. Since dogs are very lively animals, it is almost impossible to connect them to a cable for 24 hours a day. Therefore and because of additional reasons such as housing of the animals and financial considerations, the goat $(40-60 \mathrm{~kg}$ ) was chosen for the present study. Because male (billy) goats are known to have an unpleasant smell and are more difficult to handle we used only female (nanny) goats.

\section{The Effects of Repetitive Induction of AF in the First Instrumented Goat}

In September 1991 the first goat was successlully instrumented with multiple epicardial atrial electrodes. Following recovery from surgery, the implanted electrodes and the so-called 'automatic external atrial fibrillator' were tested. This device, consisting of a personal computer and a stimulator, continuously monitored a bipolar 


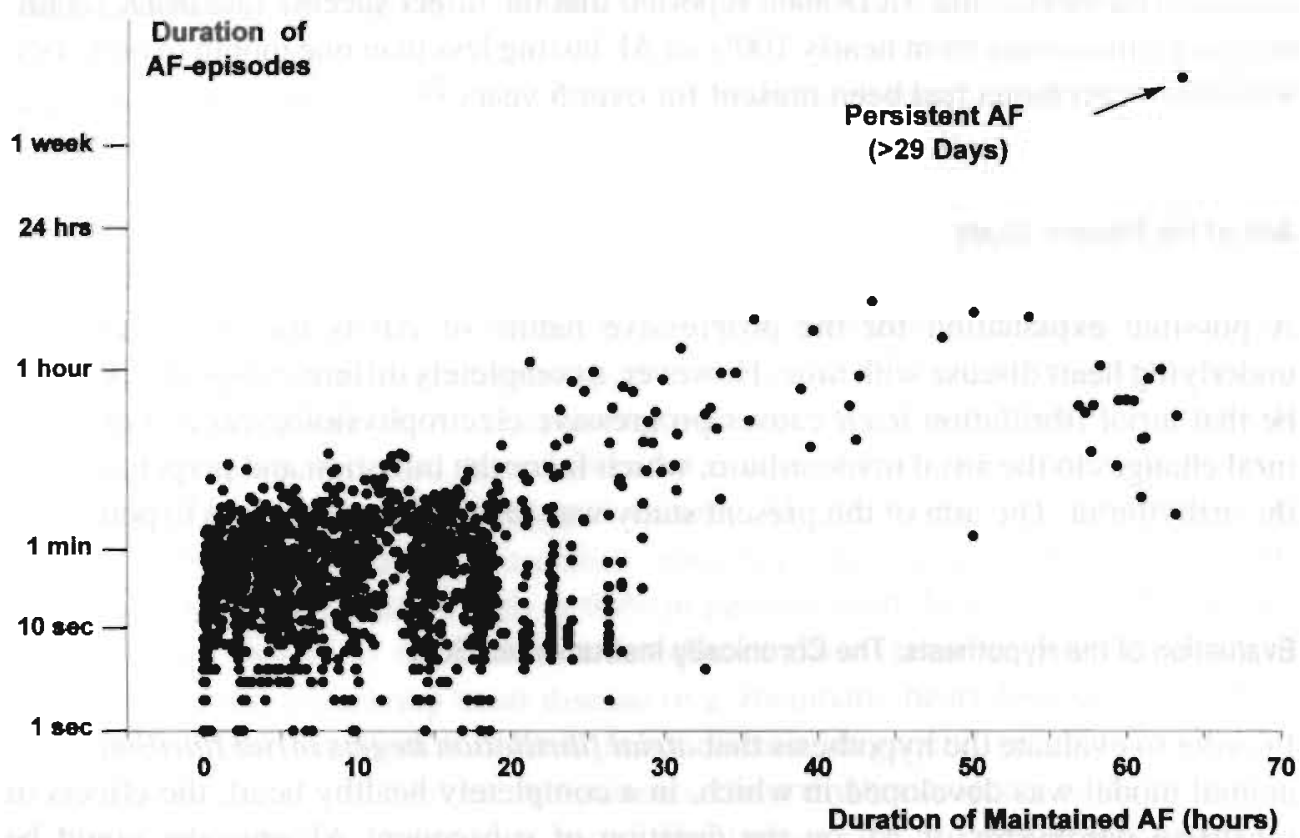

Figure 1. The effects of repetitive induction of atrial fibrillation on the duration of AF-episodes. On the horizontal axis the duration of maintained AF is given, on the vertical axis the duration of AF-episodes is plotted on a logarithmic scale. Each episode of AF was calculated from the time between two stimuli and plotted as an individual point. When at $\mathrm{t}=0$ hours the automatic atrial fibrillator was switched on, the fibrillation episodes were short-lasting and usually terminated within less than 10 seconds. Due to the repetitive induction of AF, the duration of fibrillation episodes gradually prolonged and after 24 hours the average duration was already 5 minutes. On the second day the duration of AF-episode further increased to about 1 hour and finally within 3 days of pacing AF became chronic (duration 24 hours) (arrow).

atrial electrogram and was able to distinguish between $\mathrm{AF}$ and sinus rhythm. Each time that $\mathrm{AF}$ spontaneously converted, the resumption of sinus rhythm was detected by the atrial fibrillator and AF was immediately reinduced by a burst of rapid atrial stimuli. In this way, AF was automatically maintained by the fibrillator for 24 hours a day. The moments of reinduction of AF were stored on the hard-disk of the computer, allowing off-line analysis of the duration of the individual fibrillation episodes.

On the $4^{\text {th }}$ of November 1991 the first goat was connected to the external atrial fibrillator and the automatic detection was switched on. In Fig 1 the effects of the artificial maintenance of AF by the atrial fibrillator on the duration of the individual subsequent episodes of AF can be seen. The duration of each episode was calculated from the time between two consecutive bursts of atrial stimuli and is plotted as an individual data point. As can be seen, when the stimulator was switched on $(t=0)$, the fibrillation episodes were short-lasting and usually terminated within less than 10-20 seconds. Due to the repetitive induction of AF, the duration of fibrillation episodes gradually prolonged and after 24 hours the average duration was already 5 minutes. 
On the second day the duration of the AF-episode further increased to about 1 hour and finally AF became chronic (duration $>24$ hours) (arrow) after 64 hours of being connected to the atrial fibrillator. This episode of AF lasted for more than 29 days and was successfully converted to sinus rhythm by intravenous administration of Cibenzoline (Cipralan ${ }^{\circledR}$ ).

This single observation, was the starting point for this thesis, testing the hypothesis whether 'Atrial Fibrillation begets Atrial Fibrillation.'

Some historical aspects of atrial fibrillation are discussed in chapter 2, together with the current knowledge concerning the mechanisms and determinants of AF. In chapter 3 the effects of the repetitive induction of AF on the duration and activation rate of fibrillation are described, together with the effects on the electrophysiological properties of the atria. We describe how AF causes a marked decrease in the atrial effective refractory period (electrical remodeling) and discuss how this contributes to the perpetuation of AF. Chapter 4 reports on the role of some possible triggers which might cause this process of atrial electrical remodeling. The AF-induced changes in refractory period are related to changes in the shape and duration of epicardially recorded Monophasic Action Potentials in chapter 5. In chapter 6, the pharmacological conversion of chronic AF by drugs with class IA, IC and III actions is studied, while in chapter 7 the effects of these drugs on the circuit size, wavelength and excitable gap during AF is reported. In chapter 8, the spontaneous and Cibenzoline facilitated termination of atrial fibrillation are described. Finally, in chapter 9 a general discussion and some possible implications of this thesis are given.

\section{References}

1 Ostrander LD, Brandt RL, Kjelsberg MO, Epstein FH: Electrocardiographic findings among the adult population of a total natural community, Tecumseh, Michigan. Circulation 1965;31:888-898

2 Godtfredsen J: Atrial fibrillation: etiology, course and prognosis. A follow-up study of 1212 cases. Copenhagen Denmark: University of Copenhagen, 1975;(Thesis)

3 Önundarson PT, Thorgeirsson G, Jonmundsson E, Sigfusson N, Hardarson T: Chronic atrial fibrillation - epidemiologic features and 14 year follow-up: A case control study. Eur Heari $J$ 1987:8:521-527

4 Kannel WB, Abbott RD, Savage DD, McNamara PM: Epidemiologic features of chronic atrial fibrillation: the Framingham study. N Engl J Med 1982;306: 1018-1022

5 Petersen P, Godtfredsen J: Atrial fibrillation: a review of course and prognosis. Acta Med Scand 1984:216:5-9

6 Parkinson J, Campbell M: Paroxysmal auricular fibrillation. A record of two hundred patients. $Q J$ Med 1930;24:67-100

7 Godtfredsen J: Atrial fibrillation: course and prognosis. A follow-up study of 1212 cases, in Kulbertus HE, Olsson SB, Schlepper M (eds): Atrial Fibrillation. Mölndal, Sweden, Lindgren and Söner, 1982, pp 134-145

8 Evans W. Swann P: Lone auricular fibrillation. Br Heart J 1954;16:189-194

9 Kopecky SL, Gersh BJ. McGoon MD, Whisnant JP, Holmes DR, Ilstrup DM, Frye RL: The natural history of lone atrial tihrillation: a population based study over three decades. $N$ Engl J Med 1987:317:669-674 
10 Davidson E, Rotenberg Z, Weinberger I, Fuchs J, Agmon J: Diagnosis and characteristics of lone atrial fibrillation. Chest 1989;95:1048-1050

11 Brand FN, Abbott RD, Kannel WB, Wolf PA: Characteristics and prognosis of lone atrial fibrillation. 30-Year follow-up in the Frarningham study. JAMA 1985;254:3449-3453

12 Borgeat A, Goy JJ, Maendly R, et al: Flecainide versus quinidine for conversion of atrial fibrillation to sinus rhythm. Am . Cardiol 1986:58:496-498

13 Fenster PE, Comess KA, Marsh R, Katzenberg C. Hager D: Conversion of atrial fibrillation to sinus rhythm by acute intravenous procainamide infusion. Am Heart J 1983;106:501-504

14 Crozier IG, Ikram H, Kenealy M, Levy L: Flecainide acetate for conversion of acute supraventricular tachycardia to sinus rhythm. Am J Cardiol 1987;59:607-609

15 Crijns HJGM, Wijk van LM, Gilst van WH, Kingma HJ, Van Gelder IC, Lie KI: Acute conversion of atrial fibrillation to sinus rhythm: clinical efficacy of flecainide acetate. Comparison of two regimes. Eur Heart J 1988:9:634-638

16 Suttorp MJ, Kingma JH, Lie-A-Huen L, Mast EG: Intravenous flecainide versus verapamil for acute conversion of paroxysmal atrial fibrillation or flutter to sinus rhythm. Am J Cardiol 1989;63:693-696

17 Suttorp MJ, Kingma HJ, Jessurun ER, Lie-A-Huen L, van Hemel NM, Lie KI: The value of class IC antiarrhythmic drugs for acute conversion of paroxysmal atrial fibrillation or flutter to sinus rhythm. J Am Coll Cardiol 1990;16:1722-1727

18 Vita JA. Friedman PL. Cantillon C, Antman EM: Efficacy of intravenous Propafenone for the acute management of atrial fibrillation. Am J Cardiol 1989;63:1275-1278

19 Bianconi L, Boccadamo R, Pappalardo A, Gentili C, Pistolese M: Effectiveness of intravenous propafenone for conversion of atrial fibrillation and flutter of recent onset. Am J Cardiol 1989;64:335-338

20 Teo KK, Harte M, Horgan JH: Sotalol infusion in the treatment of supraventricular tachyarrhythmias. Chest 1985;87:113-118

21 Gold RL, Haffajee CI, Charos G. Sloan K. Baker S, Alpert JS: Amiodarone for refractory atrial fibrillation. Am J Cardiol 1986:57:124-127

22 Resnekov L, McDonald L: Appraisal of electroconversion in treatment of cardiac dysrhythmias. $\mathrm{Br}$ Heart J 1968:30:786-811

23 Bjerkelund C, Orning O: An evaluation of DC shock treatment of atrial arrhythmias. Acta Med Scand 1968:184:481-491

24 Van Gelder IC. Crijns HJGM. Gilst van WH, Verwer R, Lie KI: Prediction of uneventful cardioversion and maintenance of sinus rhythm from direct-current electrical cardioversion of chronic atrial fibrillation and flutter. Am J Cardiol 1991:68:41-46

25 Morris JJ, Jr., Peter RH, McIntosh HD: Electrical conversion of atrial fibrillation. Immediate and long-term results and selection of patients. Ann Intern Med 1966;65:216-231

26 Waris E, Kreus K. Salokannel J: Factors influencing persistence of sinus rhythm after DC shock treatment of atrial fibrillation. Acta Med Scand 1971;189:161-166

27 Rensma PL, Allessie MA, Lammers WJEP, Bonke FIM, Schalij MJ: Length of excitation wave and susceptibility to reentrant atrial arrhythmias in normal conscious dogs. Circ Res 1988;62:395-410

28 Rensma PL: Atrial arrhythmias and measurement of the wavelength in a chronic dog model. Maastricht. The Netherlands: University of Limburg, 1987;(Thesis)

29 Kirchhof CJHJ, Wijffels M, Brugada J, Planellas J. Allessie MA: Mode of action of a new class IC drug (ORG 7797) against atrial fibrillation in conscious dogs. J Cardiovasc Pharmacol 1991:17:116-124 


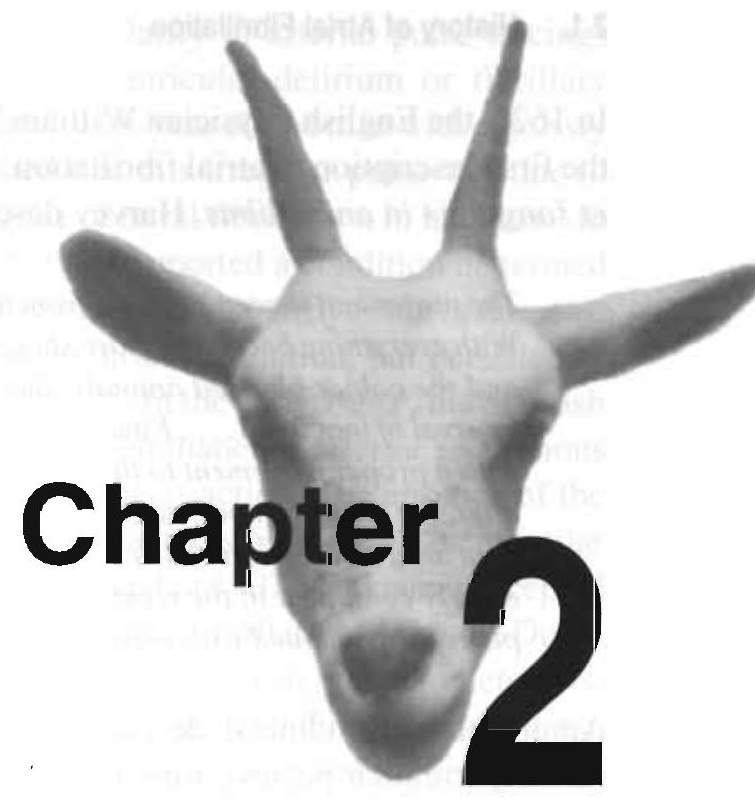

\section{Historical Overview and Determinants of Atrial Fibrillation}

2.1 History of Atrial Fibrillation

2.2 History of the Mechanism of Atrial Fibrillation

- The Circus Movement Theory

- The Ectopic Focus Theory

- The Multiple Wavelet Hypothesis

2.3 The Atrial Wavelength

- Intra-Atrial Conduction

- Atrial Refractory Period

2.4 The Atrial Tissue Mass

2.5 Inhomogeneity in Electrophysiological Properties

2.6 The Autonomic Nervous System

2.7 Atrial Dilatation

2.8 Atrial Ischemia 


\subsection{History of Atrial Fibrillation}

In 1628 , the English physician William Harvey (1578-1657) gave what was probably the first description of atrial fibrillation. ${ }^{1}$ In his Exercitatio anatomica de motu cordis et sanguinis in animalibus, Harvey describes his observations:

The movement is seen to begin from the auricles and to pass on to the ventricles. With everything becoming more sluggish as the heart lies dying, and also in fishes and the colder blooded animals, these two movements become separated by an interval of inactivity.... Finally as it sinks to death (the ventricle) ceases to reply with a proper movement to the pulsating auricle... But 1 .... have noticed, that after the heart proper, and even the right auricle were ceasing to beat and appeared on the point of death, an obscure movement, undulation/palpitation had clearly continued in the right auricular blood itself for as long as the blood was perceptibly imbued with warmth and spirit.

Among the first clinical descriptions of patients suffering from atrial fibrillation (grossly irregular pulses), were those from the French physician Jean Baptiste Senac (1693-1770). ${ }^{1}$ Senac was inspired by the work of Harvey and repeated his animal experiments confirming the origin of the heart beat. Senac's Traité de la Structure du Coeur de son action et de ses maladies (1749) was the first textbook on cardiology, later followed by his Traité des Maladies du Coeur (1774). By accurate linking clinical observations to post-mortem findings he correlated mitral valve disease and distension of the atria with marked irregularity of the pulse. Although some of his pathophysiological explanations did not survive the ages, his febrifugal mixture of rubarb and quinidine with a light purgative (palpitations could be provoked by stomach distention) is still very "up to date".

A relationship between irregularity of the pulse in humans and atrial fibrillation as seen in animals was also suggested by the Scottish physiologist Arthur Cushny (1866-1926). In an effort to fill in the gap between clinical observations and physiological experiments, Cushny compared clinical sphygmographic tracings taken in cases of irregularity of the pulse with arterial sphygmographic tracings from dog experiments. ${ }^{2}$ Although, in this paper must of his attention was directed towards atrial and ventricular extrasystoles as a cause of irregularity of the pulse, he was clearly aware of the "extreme irregularity of the heart known clinically as delirium cordis"

It is unnecessary to explain that in physiology this term (delirium cordis) is used to indicate fibrillary contractions of the heart, which arrest the circulation and prove immediately fatal. The clinical sphygmogram in these cases resembles exactly that obtained from dogs when the auricle is undergoing fibrillary contractions, which may be continued for a long time without proving fatal. I do not wish to assert that the clinical delirium cordis is identical with the physiological delirium auriculae, but the resemblance is certainly striking. 
About 7 years later Cushny again showed the similarity of arterial pulse tracings recorded from dogs with a condition known as "auricular delirium or fibrillary contraction in the auricle" and pulse tracings from a 64-year old woman with a grossly irregular pulse. In this study, Cushny suggested that this irregular pulse was due to atrial fibrillation thereby claiming the occurrence of atrial fibrillation in humans. ${ }^{3}$ In the same time, Heinrich Edwald Hering (1866-1948) reported a condition he termed "pulsus irregularis perpetuus" claiming that this was a distinct arrhythmia in humans. However. Hering did not attribute his findings to atrial fibrillation, but persisted to think that the arrhythmia was based on extrasystoles. ${ }^{4}$ In the early $1890^{5}$, the Scottish physician James Mackenzie (1853-1925) recorded simultaneous arterial and venous pulse tracing in hundreds of patients with irregular heart action. The absence of the atrial activity in the jugular pulse and the predominant systolic wave ("ventricular form of venous pulse") were very common findings and in 1907 Mackenzie accepted Cushny's hypothesis that these findings represented atrial fibrillation. After the Dutch physiologist Willem Einthoven (1860-1927) introduced the string-galvanometer, ${ }^{5}$ he was the first to publish an electrocardiogram depicting atrial fibrillation in 1906 although he did not correlate this tracing with the arrhythmia. In 1909 Rothberger and Winterberg were the first to use this new technique to prove that atrial fibrillation existed in humans. They compared electrocardiograms recorded from animals with electrically induced atrial librillation with those from patients with what they believed had "pulsus irregularis perpetuus" and showed that these shared three common distinctive features: 1) a totally irregular ventricular rate 2) an absence of P-waves and 3) the presence of baseline oscillations of the string galvanometer representing fibrillary waves. ${ }^{6}$ Almost simultaneously with the work of Rothberger, the British physician Thomas Lewis (1881-1945) 7 independently reported his studies of electrocardiogram recordings of patients with completely irregular heart rhythm. Lewis's conclusion, that the irregular pulse seen in patients with mitral stenosis or general cardiovascular degeneration ("pulsus irregularis perpetuus") was due to atrial fibrillation, was based on the following evidence: 1) the clinical irregularity of the arterial pulse and heart apex is a specific finding and can be mimicked by experimentally induced atrial fibrillation, 2) electrocardiograms from patients with irregular heart beats show irregular waves between the ventricular curves, that disappear when the irregularity vanishes (paroxysmal form). The "diastolic waves" are identical to those seen in experimental fibrillation. 3) the venous curves recorded both from patients with an irregular pulse and from experimental atrial fibrillation, show a prominent ventricular systolic wave and an absent normal atrial contraction wave. With this Lewis concluded that the well known auricular fibrillation (first described by Harvey in 1628) was a common condition in humans thereby stressing its clinical importance. 7.8 


\subsection{History of The Mechanism of Atrial Fibrillation}

Ever since atrial fibrillation (AF) has been recognized, people have been intrigued by the possible mechanism for the rapid irregular atrial activations which are characteristic for the arrhythmia. Currently, the 'Multiple Wavelet' hypothesis, as formulated by Moe around 1960 and experimentally confirmed by Allessie in 1985, is the most generally accepted hypothesis to explain AF. In the decades preceding the formulation of Moe's multiple wavelet hypothesis, the scientific world had roughly been divided into those advocating the circus movement theory and those supporting the ectopic focus theory to explain atrial fibrillation.

\section{The Circus Movement Theory}

In 1906 Mayer $^{9}$ was the first to demonstrate the occurrence of circus movement in the jelly-fish. By cutting out the center of the medusa and removing the marginal sense organs, Mayer was left with a ring of paralyzed tissue. If this preparation was stimulated at any point, a circulating contraction wave started that could continue for days. Although Mayer himself never understood the clinical relevance of his findings, Mines and Garrey fortunately did. Mines was inspired by the work of Mayer and repeated his experiments in ring preparations of tortoise atrium connected to ventricular tissue.$^{10}$ Mines showed that in this ring preparation, a reciprocating rhythm between atrium and ventricle could be started. He reasoned that it was very likely that the rhythm was caused by circulating excitation, because it occurred in the presence of slow conduction and a short refractory period and furthermore could be initiated and terminated by a single extra-systole. Mines not only suggested that these observations could explain some cases of paroxysmal tachycardia, but also suggested that circus mowement could be involved in fibrillation (reciprocating thythm between different portions of a single chamber):

It is capable of further extension to explain the condition of fibrillation, which arises under precisely those circumstances which produce the conditions in heart muscle essential for the manifestation of circulating excitation, namely, a slow and short wave of excitation. Once started the high frequency of repetition of the excitations tends to maintain the condition.

In the same year that Mines died probably as a result of an experiment he performed on himself, Garrey confirmed his findings in a ring cul from the base of a fibrillating turtle ventricle. ${ }^{11}$ Although fibrillary contractions usually continued in a ring of two centimeters wide, Garrey found that marked changes occurred when this ring was narrowed to one centimeter.

As soon as this narrawing was completed it was found that the incoordinated fibrillary contractions had resolved themselves into a number of contraction 
waves which followed each other successively and repeated around and around the ring, all progressing in the same direction, an exhibition to which we may apply the term "circus contractions".

Together with his observation that fibrillation immediately ceased in small pieces of atrial or ventricular tissue that were cut from the fibrillating heart, Garrey showed that circus movement seemed to underlie the fibrillatory process, and also highlighted the importance of conduction block and tissue mass for the perpetuation of the arrhythmia. In his discussion about the nature of the fibrillary process, 45 years before Moe developed 'his' multiple wavelet hypothesis, Garrey already stated that multiple wavelets were underlying the process of atrial fibrillation:

The existence of such blocks, and especially of blocks of transitory character and shifting location, has been noted in the experiments detailed above. These conditions make possible the propagation of the contraction wave in a series of ringlike circuits of shifting locations and multiply complexity. It is in these "circus contractions" determined by the presence of blocks, that we see the essential phenomena of fibrillation. In small masses of tissue blocks may exist, but the time necessary for the impulse to traverse all available circuits is within the refractory period and the mass contracts as a unit and fibrillation is thus impossible. In larger masses this is not true for the larger the mass the greater the possible number and length of circuits, and the greater the probability that each impulse will circulate until it reaches tissue which has once contracted but has passed out of the refractory state; thus a continuous circulation of impulses is inaugurated, which is fibrillation. Such a mechanism would account for the greater liability of large hearts to fibrillate and for the greater persistence of the fibrillary state in large tissue masses.

In 1920 Lewis et al, inspired by the experimental observations of Mines and Garrey, partly reconstructed the activation pattern of experimentally induced atrial flutter in dogs, and showed that this arrhythmia was based on a single reentrant circuit around the caval veins. ${ }^{12}$ One year later Lewis et al. ${ }^{13}$ reconstructed the atrial activation pattern in a case of human atrial flutter by detailed examination of the auricular electrical axis. In three different planes, he showed that during each flutter cycle this ax is revolved through 360 degrees allowing a rough three-dimensional reconstruction of the activation pattern. It wals concluded that similar to observations in animals, the flutter wave was running around both caval veins. Directly thereafter, Lewis used exactly the same method for the demonstration of circus movement in a case of clinical fibrillation. ${ }^{14}$ In this paper, Lewis states:

A study of the movements of the electrical axis of the auricle confirms in a siriking manner the conclusion which has been drawn from experiments on animals, namely that in fibrillation a single circulating wave controls the beating of the auricles. But this central or circulatory wave does not run the constant course which it pursues in flutter. 


\section{The Ectopic Focus Theory}

Although the circus movement theory as advocated by Lewis was easily accepted in the English speaking world, the German scientific workers were more difficult to convince and held on to the ectopic focus theory as first proposed by Engelmann 15 and later confirmed by Scherf. ${ }^{16}$ Scherf strongly opposed the circus movement theory as proposed by Lewis. He showed that tying off the taenia terminalis, a muscle bundle which by Lewis was found to be part of the circuit, terminated atrial flutter in only 1 out of 17 dogs. ${ }^{17}$ Some years later, Scherf's believe was further strengthened by his observation that aconitine injection into the myocardial wall resulted in rapid and irregular atrial activations similar to those present during AF. ${ }^{16,18}$ In addition, he reported that cooling of the aconitine spot immediately abolished AF which reappeared when the cooling was interrupted. He concluded that:

These results cannot be explained by the circus movement theory of Lewis. They can only be explained by assuming that auricular flutter and fibrillation are initiated by rapid impulse formation in a single center.

The Multiple Wavelet Hypothesis

Around 1960, Moe and co-workers developed the multiple wavelet hypothesis to explain the mechanism of atrial fibrillation. ${ }^{19-21}$ Inspired by the work of others, opposing either the ectopic focus or the circus movement theory. Moe argued that both phenomena had been produced experimentally, and found it conceivable that these could also occur in patients. However, Moe found it very hard to believe that either one of them could be responsible for the self-sustained nature of AF. Focusing on the mechanism that could be responsible for the perpetuation of the arrhythmia, he performed an additional set of experiments in which he separated the stimuli involved in initiation and perpetuation of atrial fibrillation. In anesthetized dogs during openchest experiments, atrial fibrillation was induced either by rapid pacing or by aconitine injection. After the stimulator was turned off, fibrillation immediately terminated in the absence of vagal stimulation, but persisted as long as vagal stimulation was continued. The remote possibility that pacing itself had initiated a ectopic focus at the site of stimulation, was excluded by demonstrating the continuation of the arrhythmia despite clamping off the site of stimulation during vagally maintained AF. Aconitine injection at the site of the appendage resulted in persistent atrial fibrillation which seemed to be independent of vagal stimulation. Isolation of the aconitine spot usually terminated fibrillation in the body of the atrium while in the clamped off appendage it was replaced by a more regular arrhythmia. However, and similar to the pacing experiments, fibrillation once induced was self-perpetuating in the body of the atrium as long as the vagus was stimulated. Based on these observations and on the early considerations by Garrey, Moe and coworkers formulated the 'Multiple Wavelet' 
hypothesis to explain the characteristics of "true" self-perpetuating atrial fibrillation as follows:

Orderly spread of excitation will no longer be possible; the grossly irregular wave front becomes fractionated as it divides about islets or strands of refractory tissue, and each of the daughter wavelets may now be considered as independent offspring. Such a wavelet may accelerate or decelerate as it encounters tissue in a more or less advanced state of recovery. It may become exinguished as it encounters refractory tissue; it may divide again or combine with a neighbor; it may be expected to fluctuate in size and change in direction. Its course though determined by the excitability or refractoriness of surrounding tissue, would appear to be as random as Brownian motion. Fully developed fibrillation would then be a state in which many such randomly wandering wavelets coexist. The likelihood of persistence of this process should depend upon the number of wavelets present. If the number is large, there is little chance that all elements will fall into phase (i.e., be refractory or excitable simultaneously), but if the number is small there is a considerable probability that they may fuse and permit resumption of sinus rhythm. The average number, in turn, will depend upon (1) the atrial mass, (2) the mean duration of the refractory period, and (3) the mean conduction velocity.

Although at that time Moe and co-workers were not able to test their hypothesis in living tissue experimentally, they developed a mathematical computer model in which they showed that self-sustained turbulent activity, having many similarities to atrial fibrillation, could be induced. ${ }^{21}$

About 25 years after Moe had refined Garrey's thoughts and formulated the 'Multiple Wavelet' hypothesis, Allessie and colleagues were able to confirm it experimentally, by reconstruction of the atrial activation pattern during acetylcholine induced atrial fibrillation in isolated Langendorff perfused canine hearts. ${ }^{22}$ During sustained atrial fibrillation, they showed that each atrium was activated by multiple wavelets which usually reentered each other in a random way (random reentry). In addition to this, the lifetime of the individual wavelet was found to be rather short and the number of waves varied considerably from time to time. In the presence of an average of three wavelets per atrium the chances for simultaneous die out of wavelets in one atrium were rather high and new impulses originating from the other atrium were considered necessary for the perpetuation of AF. It was concluded that the critical number of wandering wavelets for the perpetuation of AF was higher than three and less than or equal to six (three in each atrium).

\subsection{The Atrial Wavelength}

Already in their early descriptions of circus movement, Mines (1913) and Garrey (1914) formulated prerequisites for the occurrence of reentry. ${ }^{10,11}$ In the auricular- 
ventricular ring, Mines suggested that a small difference in the rate of recovery between the two A-V connections caused a conduction block of a ventricular extrastimulus over one of the two connecting parts (unidirectional block). In addition, after activation of the atrium, the wave could only return to the ventricle in the presence of a slow conduction and/or a short refractory period. Only under these circumstances is the length of the excitation wave shorter than the anatomical pathway around the obstacle (short wavelength). In this type of circus movement around an anatomical obstacle (anatomical reentry) the size of the pathway is usually longer than the wavelength leaving a part of the circuit fully excitable (excitable gap).

As shown by Allessie et al. ${ }^{23-25}$ circus movement can also be induced in preparations in which no anatomical obstacle is present (functional reentry). In small pieces of rabbit atrial myocardium, the excitation wave was found to circulate around an area of functional conduction block. In contrast to reentry around anatomical obstacles, in this type of reentry (leading circle) no excitable gap was present and the size of the circuit was equal to the length of the excitation wave. Small areas of conduction block, which were related to local differences in refractoriness, again were a prerequisite for the onset of reentry. The length of the line of conduction block needed for the production of reentry was inversely related to the length of the excitation wave. In the presence of a short wavelength (slow conduction and/or short refractory period) already a small area of conduction block was sufficient to serve as a functional obstacle for the premature impulse to circumvent, and reentrant activity was started.

During atrial fibrillation, the atrium is activated by multiple randomly reentering functional circuits (multiple wavelet hypothesis). ${ }^{11,19-22}$ These circuits are thought to have a small or absent excitable gap and their size is thus about equal to the atrial wavelength. Because the stability of AF is determined by the number of wavelets that can be present simultaneously, the stability of AF is inversely related to the wavelength of the atrial impulse. The shorter the wavelength the more waves can fit into the atria and the more sustained is AF. The important role of the atrial wavelength for the induction of atrial reentrant arrhythmias has been extensively studied by Smeets et al. and Rensma et al. ${ }^{26-29}$ More recently several studies also showed the importance of the atrial wavelength for the stability of atrial fibrillation. Kirchhof et al. ${ }^{30}$ showed that the anti-fibrillatory effects of ORG 7797 were caused by a prolongation of the minimal wavelength during rapid pacing rates. Similarly. Wang and Nattel et al. showed that drugs like flecainide, propafenone, $d \mathrm{l}$-sotalol and ambasilide prolonged the atrial wavelength at ultra-rapid rates thereby explaining the anti-fibrillatory action of these drugs. ${ }^{31-33}$ Because the wavelength (the distance that the excitation wave travels during the refractory period) is determined by the product of the refractory period and the conduction velocity (WL $=\mathrm{CV} \times \mathrm{RP}$ ) changes in these parameters are likely to determine the inducibility and stability of atrial fibrillation. 
The observation that atrial fibrillation is more easily induced at rapid heart rates and by early premature stimuli can partly be explained by a rate dependent slowing of the intra-atrial conduction velocity. In human atria, Plumb et al reported a significant and progressive prolongation of conduction times at increasing pacing rates. ${ }^{34}$ In isolated rabbit atria and in chronically instrumented conscious dogs it has been shown that during rapid atrial pacing and premature stimuli the conduction velocity is progressively depressed (and the refractory period shortened), thereby shortening the atrial wavelength and favoring the occurrence of reentrant arrhythmias. ${ }^{26-29}$ In patients, long or biphasic P-waves, inter-atrial conduction block, fragmented atrial electrograms and intra-atrial conduction delay by premature stimuli and depressed atrial action potentials are all associated with a high atrial vulnerability and occur more frequently in patients with a history of (paroxysmal) atrial fibrillation. ${ }^{35-49}$

\section{Atrial Refractory Period}

Many studies have shown that the atrial refractory period progressively decreases at shorter coupling intervals. ${ }^{26-29,50-53}$ In combination with a depression of the conduction velocity at high rates, this physiological rate adaptation of the refractory period decreases the atrial wavelength at rapid rates considerably. This explains the high inducibility of reentrant arrhythmias at rapid pacing rates and short premature stimuli. ${ }^{26-29,52}$ The pro-fibrillatory effects of vagal stimulation, acetylcholine or adenosine administration are well known and are also thought to be based on a shortening of atrial refractoriness and atrial wavelength. ${ }^{19,22,26-29,54-58}$ The important role of a short refractory period in the genesis of clinical arrhythmias is supported by several studies in which a high atrial vulnerability and a history of atrial fibrillation showed a good correlation with short atrial refractory periods. ${ }^{36,39,41.59-61}$

Besides the importance of a short atrial refractory period, other studies have indicated that a loss of the physiological rate adaptation of atrial refractoriness is also correlated with a high vulnerability and stability of atrial fibrillation. ${ }^{62-65}$ In 1982 Attuel et al. measured the atrial refractory period in patients during pacing at intervals between 280 and $1500 \mathrm{~ms}$ and reported that an absent or poor rate adaptation of the atrial refractory period was related to a history of and a high vulnerability to atrial arrhythmias. ${ }^{62,63}$ It was suggested that a poor or absent rate adaptation of the atrial refractory period may constitute a clinical entity and might be a marker of atrial pathology causing the propensity to atrial fibrillation. A few years later, these observations were extended by Boutjdir and Le Heuzey et al. who measured the effects of changes in heart rate on the duration of the action potential and refractory period in isolated strips of human atrial myocardium. ${ }^{64.65}$ Atrial samples from patients with chronic AF showed a short action potential duration and effective refractory period, a poor rate adaptation and an increased dispersion in atrial refractoriness and were considered to be an important factor for the arrhythmia. 


\subsection{The Atrial Tissue Mass}

The role of tissue mass for fibrillation has been recognized since McWilliam (1887) who reported that fibrillation recovered less quickly in dogs than in hearts of smaller species like cat, rabbit, rat, mouse, hedgehog and fowl. ${ }^{66}$ Based on these observations and the knowledge that fibrillation in the thin walled atria is less stable than in the thick ventricle, Garrey (1914) was one of the first to recognize the important role of tissue mass for the induction and perpetuation of fibrillation and tested this subject systematically. After cutting or clamping off a small portion of the wall of fibrillating atrium (cat, rabbit, dog), fibrillation immediately ceased in the separated portion while the rest continued to fibrillate. The cessation of fibrillation could not be explained by a loss of the physiological properties of the isolated portion and was reversible by release of the clamp. By cutting away pieces from fibrillating dog ventricles Garrey reported that larger pieces fibrillated sometimes for seconds or even half a minute after removal whereas small bits ceased immediately. By subsequent division of pieces of rabbit atria, West and Landa (1962) determined the minimal tissue mass for the induction of atrial arrhythmias, ${ }^{67}$ while again others related the total body weight to the incidence, inducibility and stability of atrial fibrillation. ${ }^{68,69}$ Boswell et al. determined the duration of atrial fibrillation in dogs of different size and reported a clear relation between both parameters. ${ }^{68}$ Similarly, Bohn et al. reported a prevalence of spontaneous chronic AF of only $0.2 \%$ in dogs (55 out of 30.663 ), but found that the arrhythmia was much more common in giant breeds than in smaller ones. ${ }^{69}$ Moore et al. induced atrial fibrillation in adult cattle and mules and compared the duration of AF in these animals with the duration in calves and adult goats who have smaller atria. ${ }^{70}$ Whereas in the adult cows AF was persistent and episodes lasted for 95 minutes to over 8 weeks, AF usually terminated within one minute in calves and adult goats.

\section{Relation between Atrial Wavelength and Atrial Surface Area}

As discussed previously, according to Moe's multiple wavelet hypothesis, the stability of AF is determined by the number of waves that can be present simultaneously in the atria. This is determined by both the atrial tissue mass and the atrial wavelength. Rensma, ${ }^{28,29}$ estimated the maximal number of wavelets that can be present simultancously in atria of different species by relating the wavelength of the earliest premature beat to the atrial surface area. It was found that the wavelength does not prolong in proportion with the increase in atrial size in larger mammals thereby explaining the increased propensity for atrial fibrillation in these animals. Rensma estimated the atrial wavelength of the earliest premature beat to be about $3.5 \mathrm{~cm}$ in rabbit. $8 \mathrm{~cm}$ in dog, $12 \mathrm{~cm}$ in man, $20 \mathrm{~cm}$ in horse, $30 \mathrm{~cm}$ in elephant and $45 \mathrm{~cm}$ in whale. The atrial surface areal was cstimated at about $3 \mathrm{~cm}^{2}$ in rabbit, increasing to $35,60,300,1000$ and 300() $\mathrm{cm}^{2}$ in dog, man, horse. elephant and whale respectively. Because the maximal number of wavelets is given by the total atrial surface area divided by the 
area of the individual wavelets (number of wavelets $=$ atrial surface $\mathrm{WL}^{2} / 4 \pi$ ), this would allow only 3 wavelets to be present in the rabbit atrium. This is below the critical number of 4- 6 waves needed for sustained AF as reported by Allessie. ${ }^{22}$ The estimated maximal number of wavelets in dog and man was about 6 and 5 and increased further to 10,13 and 19 in horse, elephant and whale respectively. These correlated well with the observation that in rabbits atrial fibrillation is very difficult to induce and usually of short duration. ${ }^{71.72}$ On the other hand, AF is not uncommon in dog ${ }^{69}$ and man ${ }^{73,74}$ and seems to occur frequently and is usually of sustained nature in cows and horses $70.75-78$

\subsection{Inhomogeneity in Electrophysiological Properties}

Inhomogeneities in electrophysiological properties are important both for the inducibility (vulnerability) and the stability for AF. Dispersion in atrial refractoriness is associated with the occurrence of temporal/functional conduction block, which is one of the prerequisites for the initiation of reentrant arrhythmias. ${ }^{10.24}$ In areas with depressed conduction the wavelength will be shortened locally which might promote the occurrence of microreentry. On the other hand, areas of conduction block will force the wavefront to fractionate, thereby increasing the number of waves and thus AF stability. The important role of local conduction disturbances in the initiation of reentrant atrial arrhythmias were demonstrated by Lammers et al. ${ }^{79,80}$ Depression of conduction can be caused by different mechanisms related to either the active or passive membrane properties.

Conduction disturbances which occur during rapid pacing or after short premature stimuli are usually related to local differences in refractory period. ${ }^{24}$ This nonuniform recovery of excitability is naturally present in the atria, and may be enhanced by 1) changes in heart rate, ${ }^{81}$ 2) by a high vagal tone, ${ }^{82-84}$ or 3 ) by various stimuli which can affect atrial refractoriness locally such as stretch or ischemia. In patients an increased dispersion in atrial refractoriness has been associated with a higher vulnerability, or a positive history of AF. ${ }^{59.61,64,65}$ In 1986, Boutjdir and Le Heuzey et al measured the effective refractory period in superfused strips of human right atrial appendage. They reported that patients with chronic AF had a shorter refractory period which poorly adapted to changes in heart rate and showed a significantly greater dispersion in atrial refractory period. ${ }^{64,65}$ Similar results were found by Ramdat et al. who used the local AF-interval as an index of atrial refractoriness. ${ }^{61}$ Patients with idiopathic paroxysmal atrial fibrillation had shorter AF-intervals and a significantly larger dispersion in atrial refractoriness.

Local conduction disturbances can also be related to the direction of wave propagation and in that case are most likely caused by tissue anisotropy ${ }^{85,86}$ Locally depressed action potentials as found in fibers from diseased or dilated atria are another cause of increased heterogeneity in conduction properties and have been related to a 
positive history of atrial fibrillation. ${ }^{47-49}$ Progressive fibrosis of the atrial myocardium, as may occur due to the natural process of aging, is also likely to be very important for the development of AF. Especially in the absence of any another underlying cardiovascular disease, these degenerative changes can explain the increasing prevalence of $\mathrm{AF}$ in the elderly population. ${ }^{73,74}$

While the atrial mass, the length of the excitation wave and the inhomogeneity in electrophysiological properties all are thought to have a direct effect on the stability (number of wavelets) and vulnerability of AF, other factors like the autonomic nervous system, atrial dilatation and atrial ischemia may only affect the substrate for fibrillation by modulation of these three "true" determinants.

\subsection{The autonomic Nervous system}

A number of studies have indicated the important role of the autonomic nervous system in the occurrence and the stability of AF. Based on the activity of the autonomic nervous system Coumel at al. described two different subgroups of patients with paroxysmal $\mathrm{AF} .87,88$ Most frequently, $\mathrm{AF}$ was associated with a high vagal tone and paroxysms occurred typically at night, during rest, after extensive meals or alcohol absorption. In the second group of patients an opposite trend was noticed and AF episodes were dependent on a high sympathetic tone. This less common type of AF typically occurred during the daytime (morning), at exercise or during emotional stress. Frequently, in patients with this type of AF the increased adrenergic state is caused by hyperthyroidism or phaeochromocytoma.

Experimentally, the pro-fibrillatory effects of a high vagal tone are well established and often even a necessary ingredient for stable AF. 19,22,31,71 The effects of high vagal activity or acetylcholine are thought to be based on the strong shortening of atrial refractoriness and the atrial wavelength due to activation of the $I_{K A c h}$ channel. ${ }^{26-}$ $29,31,54,89$ In addition to the short refractory period, some of the pro-fibrillatory effects can also be attributed to an increase in dispersion of atrial refractoriness during high vagal activity. ${ }^{82-84}$

The effects of increased sympathetic activity are less clear. Some studies report a shortening of the atrial refractory period and/or action potential duration, $28,55,90-92$ while others found no change ${ }^{93-94}$ or even a lengthening in refractoriness. ${ }^{27,91,92}$ The discrepancy in effects can be explained by the fact that adrenergic stimulation can enhance both inward currents $\left(\mathrm{Na}^{+} \text {or } \mathrm{Ca}^{2+}\right)^{95}$ and outward currents $\left(\mathrm{K}^{+}\right) .{ }^{96} \mathrm{Kass}$ and Quadbeck showed that the effects of adrenergic stimulation are concentration dependent. While at lower doses of noradrenaline the action potential prolonged, it shortened when higher dosages of the drug were given. Thus, the net effect of adrenergic stimulation will depend on the relative contribution of $\mathrm{Na}^{+}, \mathrm{Ca}^{2+}$ and $\mathrm{K}^{+}$-channels and on the amount of sympathetic stimulation. 


\subsection{Atrial Dilatation}

Although the relation between atrial dilatation and atrial fibrillation is well established, ${ }^{97-105}$ there has been considerable controversy as to whether the atrial enlargement is the cause or the consequence of AF. The observation that patients with mitral stenosis and/or mitral insufficiency frequently develop atrial fibrillation strongly suggests that atrial dilatation can cause atrial fibrillation in these patients. ${ }^{97,98}$ As reported by Braunwald, AF seems almost inevitable when mitral valve insufficiency is very severe and has led to a marked atrial enlargement. ${ }^{100}$ In the Framingham study the presence of rheumatic heart disease increased the risk ratio for the development of chronic AF to 8.3 in men and 15.3 in women. ${ }^{106}$ Additional evidence for the hypothesis that atrial enlargement increases the stability of AF is given by studies from Resnekov and others showing that patients with dilated atria are less likely to be cardioverted by DC-countershock and more likely to revert to atrial fibrillation afterwards. ${ }^{101,107-109}$ Experimental atrial dilatation, produced by mitral insufficiency or acute volume expansion, clearly increases the propensity for atrial fibrillation in otherwise normal hearts. ${ }^{110-1} 12$

While these studies indicate that atrial dilatation is a potential cause of AF, other studies have shown that atrial enlargement can also be the result of AF. 104,105,113 Although in some of these studies, progression of underlying heart disease could not be excluded, Sanfillipo et al. selected a group of 15 patients with lone AF and with normal atrial dimensions and no mitral valve or left ventricular pathology. ${ }^{113}$ During a follow-up period of 12-28 months (average 20.6 months), the diameter of the left and right atria increased with approximately $10-15 \%$ while right and left atrial volume increased by $35 \%$ and $42 \%$ respectively. Other evidence for the hypothesis that AF causes atrial dilatation is given by the observations of Gosselink et al. and Van Gelder et al. who showed that after successful cardioversion the dimensions of the atria decreased by $5-10 \% .114,115$

According to the multiple wavelet hypothesis of atrial fibrillation, the inducibility and stability of AF are determined by 1) the tissue mass (atrial surface area), 2) the wavelength (refractory period and conduction velocity) and 3) the dispersion of electrophysiological properties. Although atrial dilatation will not directly increase the atrial mass, the atrial surface area will certainly do so which might allow a larger number of wavelets during AF.

Their is some discrepancy in the literature concerning the effects of acute dilatation on atrial refractoriness. While some studies describe a lengthening or no change in refractoriness, $116-118$ others report a clear shortening of atrial refractoriness in response to acute atrial stretch. ${ }^{11,112,119}$ Recently, Le Grand et al. determined the refractory period and duration of the atrial action potential in specimens taken from chronically dilated human atria. ${ }^{120}$ Although no changes in atrial refractory periods were found, the action potentials recorded from dilated atria showed a depressed or 
absent plateau phase, and at slow pacing intervals the duration of the action potential, measured at $50 \%$ and $90 \%$ repolarization, was as much as $31 \%$ and $13 \%$ shorter. The ionic basis for the shortened action potential was provided by voltage clamp measurements revealing that the L-type calcium current was reduced by $75 \%$.

Atrial dilatation can not only shorten wavelength by decreasing the atrial refractory period but may also depress atrial conduction properties. Hordof ${ }^{48}$ and others, 47,49 recorded action potentials in samples from diseased/dilated human atria and related these with clinical and pre-operative ECG data. A good correlation was found between a low resting membrane potential ( -50 to $-60 \mathrm{mV}$ versus $-80 \mathrm{mV}$ ), a markedly reduced maximal upstroke of the action potential $(<20 \mathrm{~V} / \mathrm{sec}$ versus $200 \mathrm{~V} / \mathrm{sec})$ and atrial dilatation, a prolonged P-wave and a clinically history of atrial arrhythmias (e.g. atrial fibrillation). It was suggested that the occurrence of these depressed action potentials favors the initiation and perpetuation of reentrant arrhythmias. ${ }^{47-49}$

Atrial stretch may also be pro-fibrillatory by increasing the spatial inhomogeneity in electrophysiological properties. Clinically, in patients with mitral stenosis or insufficiency dilatation will primarily occur in the left atrium thereby increasing the non-unitormity in electrophysiological properties between the two chambers. On the other hand, it is likely that the thin parts of the atrium like the free walls are stretched to a much larger extend than thicker structures like the crista terminalis, Bachmann's bundle or the interatrial septum. Although little is known about this subject, some studies indeed reported an increased dispersion in refractory periods in response to stretch of the atrial myocardium. ${ }^{121,122}$

\subsection{Atrial Ischemia}

Coronary artery or ischemic heart disease is a well known risk factor for atrial fibrillation and has been reported to occur in $19-43 \%$ of all patients with AF. ${ }^{72,73,106.123}$ In the Framingham study coronary heart disease was a significant precursor to atrial fibrillation and was present in $25 \%$ of men and $14 \%$ of women who developed AF. 106,123 Atrial fibrillation is observed in the setting of an acute myocardial infarction, and has been reported in 3-44\% of the cases. ${ }^{124-126} \mathrm{~A}$ number of potential reasons may explain this phenomenon: 1) ischemia of the atrial myocardium, 2) changes in autonomic tone (high vagal or sympathetic tone) following a myocardial infarction, 3) atrial dilatation due to pump failure (extensive infaret) or valvular insufficiency (papillary infarct) or 4) pericarditis in case of a transmural infarction.

Hod et al. observed that $3 \%$ of the patients with acute myocardial infarction, developed atrial fibrillation within 3 hours of the onset of pain. ${ }^{127}$ The occurrence of early AF was usually seen in patients with an occluded left circumflex artery and was associated with left atrial ischemia. Atrial ischemia can favor fibrillation by modifying the electrophysiological properties of the atria. In 1954 Trautwein et al. reported that during myocardial ischemia the action potential became markedly shortened. ${ }^{128}$ 
About 30 years later, Noma showed that the shortening of the action potential during ischemia was caused by activation of the ATP-regulated potassium channels. ${ }^{129} \mathrm{On}$ the other hand, the pro-fibrillatory effects may be related to a depression of the membrane potential and the concomitant slowing of the conduction velocity in the ischemic area. ${ }^{130-132}$ Besides a short refractory period and a slow conduction velocity, an increased dispersion in electrophysiological properties between the ischemic and non-ischemic atrial parts might add to the increased propensity for AF.

Atrial ischemia might not only be the cause but also the consequence of AF. In anesthetized dogs, White et al. ${ }^{133}$ studied the acute effects of electrically induced atrial fibrillation on the balance between blood supply and energy demand. They found that atrial fibrillation caused a 2-3 fold increase in atrial blood flow and oxygen consumption. The resulting reduction in the atrial flow reserve makes it conceivable that a further increase in metabolic demands during AF might lead to atrial ischemia. So, similar to atrial dilatation, atrial ischemia might be a cause as well as a consequence of $\mathrm{AF}$, favoring the self-perpetuation of the arrhythmia.

\section{References}

1 McMichael J, Harvey W, Laennec RT, de Senac JB: History of atrial fibril]ation 1628-1819. Br Heart $J$ 1982;48:193-197

2 Cushny AR: On the interpretation of pulse-tracings. J Exp Med 1899:4:327-347

3 Cushny AR, Edmunds CW: Paroxysmal irregularity of the heart and auricular fibrillation. Am JMed Sci 1907; 133:67-77

4 Hering HE: Analyse des pulsus irregularis perpetuus. Prag Med Wchnschr 1903:38:377-381

5 Einthoven W: Un nouveau galvanomètre. Arch N Sc Ex Nat 1901;6:625-633

6 Rothberger CJ, Winterberg H: Vorholflimmern und arrhythmia perpetua. Wien Klin Wochenschr 1909:22:839-844

7 Lewis T: Auricular fibrillation: a common clinical condition. BrMedJ 1909;2:1528

8 Lewis T: Auricular fibrillation and its relationship to clinical irregularity of the heart. Heart $1910 ; 1: 306-372$

9 Mayer AG: Rhythmical pulsation in scyphomedusa, in Anonymous Carnegie Institution of Washington. 1906,

10 Mines GR: On dynamic equilibrium in the heart. J Physiol 1913;46:349-383

11 Garrey WE: The nature of fibrillation contraction of the heart; its relation to tissue mass and form. Am J Physiol 1914;33:397-414

12 Lewis T, Feil S, Stroud WD: Observations upon flutter and fibrillation. Part 2. The nature of auricular flutter. Heart 1920;7:191-246

13 Lewis T, Drury AN. !liescu CC: A demonstration of circus movement in clinical flutter of the auricles. Heart 1921:8:341-359

14 Lewis T, Drury AN, Iliescu CC: A demonstration of circus movement in clinical fibrillation of the auricles. Heart 1921;8:361-379

15 Engelmann TW: Über den einfluss der systole auf die motorische leitung in der herzkammer, mit bemerkungen zur theorie allorhythmischer herzstörungen. Arch $f d$ ges Physiol 1896:62:543

16 Scherf D: Studies on auricular tachycardia caused by aconitine administration. Proc Soc Exp Biol Med 1947;64:233-239

17 Scherf D: Versuche zur Theorie des Vorhofflatterns und Vorhofflimmerns. Z Gesamte Exp Med 1928:61:30-44 
18 Scherf D, Romano FJ: Experimental studies on auricular flutter and auricular fibrillation. Am Heart J 1948;36:241-251

19 Moe GK, Abildskov JA: Atrial fibrillation as a self-sustaining arrhythmias independent of focal discharge. Am Heart $J$ 1959;58:59-70

20 Moe GK: On the multiple wavelet hypothesis of atrial fibrillation. Arch Int Pharmacodyn Ther 1962;140:183-188

21 Moe GK, Rheinboldt WC, Abildskov JA: A computer model of atrial fibrillation. Am Heart J 1964:67:200-220

22 Allessie MA, Lammers WJEP, Bonke FIM. Hollen SJ: Experimental evaluation of Moe's multiple wavelet hypothesis of atrial fibrillation. in Zipes DP. Jalife J (eds): Cardiac Electrophysiology and Arrhythmias. NY, Grune \& Stratton, 1985, pp 265-275

23 Allessie MA, Bonke FIM, Schopman FJG: Circus movement in rabbit atrial muscle as a mechanism of tachycardia. Circ Res 1973;32:54-62

24 Allessie MA, Bonke FIM, Schopman FJG: Circus movement in rabbit atrial muscle as a mechanism of tachycardia. II. The role of nonuniform recovery of excitability in the occurrence of unidirectional block, as studied with multiple microelectrodes. Circ Res 1976;39:168-177

25 Allessie MA, Bonke FIM, Schopman FJG: Circus movement in rabbit atrial muscle as a mechanism of tachycardia. III. The "leading circle" concept: A new model of circus movement in cardiac tissue without the involvement of an anatomical obstacle. Circ Res 1977;41:9-18

26 Smeets JLRM: Wave length of the cardiac impulse and reentrant arrhythmias. Maastricht. The Netherlands: University of Limburg, 1983;(Thesis)

27 Smeets JLRM, Allessie MA, Lammers WJEP, Bonke FIM, Hollen SJ: The wavelength of the cardiac impulse and reentrant arrhythmias in isolated rabbit atrium. The role of heart rate, autonomic transmitters, temperature, and potassium. Circ Res 1986;58:96-108

28 Rensma PL: Atrial arrhythmias and measurement of the wavelength in a chronic dog model. Maastricht, The Netherlands: University of Limburg, 1987;(Thesis)

29 Rensma PL, Allessie MA, Lammers WJEP, Bonke FIM, Schalij MJ: Length of excitation wave and susceptibility to reentrant atrial arrhythmias in normal conscious dogs. Circ Res 1988;62:395-410

30 Kirchhof CJHJ, Wijffels M, Brugada J, Planellas J, Allessie MA: Mode of action of a new class IC drug (ORG 7797) against atrial fibrillation in conscious dogs. J Cardiovasc Pharmacol 1991;17:116-124

31 Wang Z, Page PL, Nattel S: Mechanism of flecainide's antiarrhythmic action in experimental atrial fibrillation. Circ Res 1992:71:271-287

32 Wang J, Bourne GW, Wang Z, Villemaire C, Talajic M, Nattel S: Comparative mechanisms of antiarrhythmic drug action in experimental atrial fibrillation. Circulation 1993:88:1030-1044

33 Wang J, Feng J. Nattel S: Class III antiarrhythmic drug action in experimental atrial fibrillation. Differences in reverse use dependence and effectiveness between d-Sotalol and the new antiarrhythmic drug Ambasilide. Circulation 1994;90:2032-2040

34 Plumb VJ, Karp RB, James TN, Waldo AL: Atrial excitability and conduction during rapid atrial pacing. Circulation 1981:63:1140-1141

35 Bayes de Luna A, Cladellas M, Oter R. Torner P, Guindo J, Marti V, Rivera I, Iturralde P: Interatrial conduction block and retrograde activation of the left atrium and paroxysmal supraventricular tachyarrhythmias. Eur Heart $J$ 1988;9:1112-1118

36 Cosio FG, Palacios J, Vidal JM, Cocina EG, Gomez-Sanchez A, Tamargo L: Electrophysiologic studies in atrial fibrillation. Slow conduction of premature impulses: A possible manifestation of the background for reentry. Am J Cardiol 1983;51:122-130

37 Cosio FG, Arribas F: Role of conduction disturbances in atrial arthythmias, in Attuel P. Cournel P. Janse M.I (eds): The atrium in Health and Disease. Mount Kisco, NY, Futura Publishing Co, 1989. pp 133

38 Cosio FG: Intra-atrial conduction and atrial fibrillation. in Olsson SB, Allessie MA, Campbell RWF (eds): Atrial Fibrillation. Mechanisms and Therapeutic Strategies. Armonk, NY, Futura Publishing Co.. Inc. 1994, pp 51-65 
39 Pop T, Fleischmann D. Effert S: The vulnerability of the right atritum. III. Electrophysiologic correlates of atrial vulnerability. Klin Wochenschr 1979:57:31-36

40 Tanigawa M, Fukatani M, Konoe A, Isomoto S, Kadena M. Hashiba K: Prolonged and fractionated right atrial electrograms during sinus rhythm in patients with paroxysmal atrial fibrillation and sick sinus node syndrome. J Am Coll Cardiol 1991:17:403-408

41 Kumagai K, Akimitsu S, Kawahira K, Kawanami F, Yamanouchi Y, Hiroki T, Arakawa K: Electrophysiological properties in chronic lone atrial fibrillation. Circulation 1991:84:1662-1668

42 Buxton AE. Waxman HL, Marchlinski FE, Josephson ME: Atrial conduction: effects of extrastimuli with and without atrial dysrhythmias. Am J Cardiol 1984:54:755-761

43 Simpson RJ, Jr.. Foster JR, Gettes LS: Atrial excitability and conduction in patients with interatrial conduction defects. Am J Cardiol 1982;50:1331-1337

44 Ohe T, Matsuhisa M, Kamakura S, Yamada J, Sato I, Nakajima K, Shimomura K: Relation between the widening of the fragmented atrial activity zone and atrial fibrillation. Am $J$ Cardiol 1983;52:1219-1222

45 Stafford PJ, Tumer I. Vincent R: Quantitative analysis of signal-averaged P waves in idiopathic paroxysmal atrial fibrillation. Am J Cardiol 1991;68:751-755

46 Yamada T, Fukunami M, Ohmori M, Kumagai K, Sakai A, Minamino T, Hoki N: Characteristics of frequency content of atrial signal-averaged electrocardiograms during sinus rhythm in patients with paroxysmal atrial fibrillation. J Am Coll Cardiol 1992;19:559-563

47 Ten Eick RE, Singer DH: Electrophysiologic properties of diseased human atrium. I.Low diastolic potential and altered cellular response to potassium. Circ Res 1979;44:545

48 Hordof AJ, Edie R, Malm JR, Hoffman BF, Rosen MR: Electrophysiologic properties and response to pharmacologic agents of fibers from diseased human atria. Circulation 1976;54:774-779

49 Mary-Rabine L, Albert A, Pham TD, Hordof AJ, Fenoglio JJ, Jr., Malm JR, Rosen MR: The relationship of human atrial cellular electrophysiology to clinical function and ultrastructure. Circ Res 1983:52:188-199

50 Mendez C, Grunzit CC, Moe GK: Influence of cycle length upon refractory period of auricles, ventricles and AV node in the dog. Am.J Physiol 1956;184:287

51 Denes P, Delon W, Dhingra R, Pietras RJ, Rosen KM: The effects of cycle length on cardiac refractory periods in man. Circulation 1974;49:32-41

52 Wyndham CRC, Amat-y-Leon F, Wu D, Denes P, Dhingra RC, Simpson RJ, Jr., Rosen KM: Effects of cycle length on atrial vulnerability. Circulation 1977;55:260-267

53 Wiener I, Kunkes S, Rubin D, Kupersmith J, Packer M, Pitchon R. Schweitzer P: Effects of a sudden change in cycle length on human atrial, atrioventricular nodal and ventricular refractory periods. Circulation 1981;64:245-248

54 Hoffman BF. Suckling EE: Cardiac cellular potentials: Effect of vagal stimulation and acetylcholine. Am J Physiol 1953:173:312-320

55 Farges JP, Ollagnier M. Faucon G: Influence of acetylcholine. isoproterenol, quinidine and ouabain on effective refractory periods of atrial and ventricular myocardium in the dog. Arch Int Pharmacodyn 1977;227:206-219

56 Ortiz J, Niwano S, Abe H, Rudy Y, Johnson NJ, Waldo AL: Mapping the conversion of atrial flutter to atrial fibrillation and atrial fibrillation to atrial flutter. Circ Res 1994:74:882-894

57 Kabell G, Buchanan LV, Gibson JK, Belardinelli L: Effects of adenosine on atrial refractoriness and arrhythmias. Cardiovasc Res 1994:28:1385-1389

58 O Nunain S, Garrat C. Paul V, Debbas N, Ward DE, Camm AJ: Effect of intravenous adenosine on human atrial and ventricular repolarisation. Cardiovasc Res 1992;26:939-943

59 Michelucci A, Padeletti L, Fradella GA: Atrial refractoriness and spontaneous or induced atrial fibrillation. Acta Cardiol 1982:37:333-344

60 Michelucci A, Padeletti L, Porciani C, Mezzani A. Salvi S. Bamoshmoosh M, Gensini GF: Dispersion of refractoriness and atrial fibrillation. in Olsson SB. Allessie MA, Campbell RWF (eds): Atrial Fibrillation. Mechanisms and Therapeutic Strategies. Armonk, NY. Futura Publishing Co., Inc. 1994, pp 81-107 
61 Ramdat Misier AR, Opthof T, Hemel van NM, Defauw JJAM. Bakker de JMT, Janse MJ, Capelle van FJL: Increased dispersion of 'refractoriness' in patients with idiopathic paroxysmal atrial fibrillation. J Am Coll Cardiol 1992;19:1531-1535

62 Attuel P, Childers RW, Cauchemez B, Poveda J, Mugical J, Coumel P: Failure in the rate adaptation of the atrial refractory period: its relationship to vulnerability. Int J Cardiol 1982:2:179-197

63 Attuel P. Childers RW, Haissaguerre M. Leclercq J, Mugica J, Coumel P: Failure in the rate adaptation of the atrial refractory periods: new parameter to assess atrial vulnerability. Pace 1984;7:1382

64 Boutjdir M, Le Heuzey J, Lavergne T, Chauvaud S, Guize L, Carpentier A, Peronneau P: Inhomogeneity of cellular refractoriness in human atrium: factor of arrhythmia? Pace 1986:9:1095-1 100

65 Le Heuzey J, Boutjdir M. Gagey S, Lavergne T, Guize L: Cellular aspects of atrial vulnerability, in Attuel P. Olsson SB, Schlepper M (eds): The atrium in Health and Disease. Mount Kisco, Futura Publishing, 1989, pp 81-94

66 McWilliam JA: Fibrillar contraction of the heart. J Physiol 1887;8:296-310

67 West TC, Landa JF: Minimal mass required for induction of a sustained arrhythmia in isolated atrial segments. Am J Physiol 1962;202:232-236

68 Boswell SH, Hoff HE, Geddes LA: Body size in the maintenance of experimental atrial fibrillation in the dog. Cardiovasc Res Cent Bull 1968;6:99-116

69 Bohn FK, Patterson DF, Pyle RL: Atrial fibrillation in dogs. Br Vet $J$ 1971:127:485-496

70 Moore EN. Spear JF: Natural occurrence and experimental initiation of atrial fibrillation in different animal species, in Kulbertus HE, Olsson SB, Schlepper M (eds): Atrial fibrillation. Mölndal, Sweden, 1982, pp 33-41

71 Holland WC, Burn JH: Production of fibrillation in isolated atria of rabbit heart. $\mathrm{Br} \mathrm{Med} \mathrm{J}$ 1957:1:1031-1033

72 Holland WC. Tinsley b: Factors affecting the incidence of atrial fibrillation. Am $J$ Physiol 1958:193:235-238

73 Godtfredsen J: Atrial fibrillation: etiology, course and prognosis. A follow-up study of 1212 cases. Copenhagen, Denmark: University of Copenhagen, 1975:(Thesis)

74 Godtfredsen J: Atrial fibrillation: course and prognosis. A follow-up study of 1212 cases, in Kulbertus HE, Olsson SB, Schlepper M (eds): Atrial Fibrillation. Mölndal, Sweden, Lindgren and Soner, 1982, pp 134-145

75 McGuirk SM, Muir WW, Sams RA, Rings DM: Atrial fibrillation in cows: clinical findings and therapeutic considerations. JAm Vet Med Assoc 1983;182:1380-1386

76 Constable PD, Muir WW, Bonagura JD. Rings DM, St.Jean G: Clinical and electrocardiographic characterization of cattle with atrial premature complexes. J Am Vet Med Assoc 1990;9:1163-1169

77 Glendinning SA: The use of quinidine sulphate for the treatment of atrial fibrillation in twelve horses. Vet Rec 1965:77:951-960

78 Deem DA. Fregin GF: Atrial fibrillation in horses: a review of 106 clinical cases, with consideration of prevalence, clinical signs and prognosis. I Am Vet Med Assoc 1982;180:261-265

79 Lammers WJEP, Schalij MJ, Kirchhof CJHJ, Allessie MA: Quantification of spatial inhomogeneity in conduction and initiation of reentrant atrial arrhythmias. Am J Physiol 1990;28:H1254-H1263

80 Lammers WJEP, Kirchhof CJHJ, Bonke FIM, Allessie MA: Vulnerability of rabbit atrium to reentry by hypoxia. Role of inhomogeneity in conduction and wavelength. Am JPhysiol 1992;262:H47-H55

81 Han J, Millet D, Chizzonitti B, et al: Temporal dispersion of recovery of excitability in atrium and ventricle as a function of heart rate. Am Heart $J$ 1966:71:481

82 Alessi R, Nusynowitz M, Abildskov JA, et al: Nonuniform distribution of vagal effects on the atrial refractory period. Am J Physiol 1958;194(20:406

83 Zipes DP, Mihalick MJ, Robbins GT: Effects of selecrive vagal and stellate ganglion scimulation on atrial refractoriness. Cardiovasc Res 1974;8:647-655

84 Ninomiya I: Direct evidence of nonuniform distribution of vagal effects on dog atria. Circ Res $1966 ; 19: 576-583$ 
85 Spach MS, Dolber PC: Relating extraceliular potentials and their derivatives to anisotropic propagation at a microscopic level in human cardiac muscle. Evidence for electrical uncoupling of side-to -side fiber connections with increasing age. Circ Res 1986;58:356-371

86 Spach MS, Kootsey JM, Sloan JD: Active modulation of electrical coupling between cardiac cells of the dog. A mechanism for transient and steady state variations in conduction velocity. Circ Res 1982;51:347-362

87 Coumel P, Attuel P, Lavallee J, Flammang D, Leclercq JF, Slama R: Syndrome d'arythmie auriculaire d'origine vagale. Arch Mal Coeur 1978:71:645-656

88 Coumel P: Neurogenic and humoral influences of the autonomic nervous system in the determination of paroxysmal atrial fibrillation, in Attuel P, Olsson SB, Schlepper M (eds): The atrium in Health and Disease. Mount Kisco, NY, Futura Publishing Co, 1989, pp 213-232

89 Hoffman BF, Siebens AA, McBrooks C: Effect of vagal stimulation on cardiac excitability. Am J Physiol 1952;169:377-383

90 Farges JP, Faucon G, Lievre M, Ollagnier M: Relationship between atrial and ventricular rates of fibrillation and cardiac contractile tissue effective refractory periods in the dog. $\mathrm{Br} J$ Pharmacol 1978;63:587-591

91 Quadbeck J, Reiter M: Cardiac action potential and inotropic effects of noradrenaline and calcium. Naunyn-Schmiedeberg's Arch Pharmacol 1975;286:337-351

92 Kass RS, Wiegers SE: The ionic basis of concentration-related effects of noradrenaline on the action potential of calf cardiac Purkinje fibres. J Physiol 1982:322:541-558

93 Hoffman BF, PF Cranefield: Electrophysiology of the heart. New York, McGraw-Hill, 1960,

94 Allessie MA, Bonke FIM, Lammers WJEP: The effects of carbamylcholine, adrenaline, ouabain, quinidine and verapamil on circus movement tachycardia in isolated segments of rabbit atrial myocardium. in Kulbertus HE (ed): Reentrant arrhythmias. Mechanisms and treatment. Lancaster, MTP Press Limited, 1977, pp 63-71

95 Pelzer D, Pelzer S, McDonald TF: Properties and regulation of calcium channels in muscle cells. Rev Physiol Biochem Pharmacol 1990;114:107-207

96 Yazawa K, Kameyama M: Mechanism of receptor-mediated modulation of the delayed outward potassium current in guinea-pig ventricular myocytes. $J$ Physiol 1990;421:135-150

97 Selzer A, Cohn KE: Natural history of mitral stenosis: a review. Circulation 1972;45:878-890

98 Selzer A, Katayama F: Mitral regurgitation: clinical patterns, pathophysiology and natural history. Medicine 1972;51:337-366

99 Davies MJ, Pomerance A: Pathology of atrial fibrillation in man. Br Heart J 1972;34:520-525

100 Braunwald E, Awe WC: The syndrome of severe mitral regurgitation with normal left atrial pressure. Circulation 1963;27:29-35

101 Henry WL, Morganroth J, Pearlman AS, Clark CE, Redwood DR, Itscoitz SB, Epstein SE: Relation between echocardiographically determined left atrial size and atrial fibrillation. Circulation 1976;53:273-279

102 Petersen P, Kastrup J, Brinch K, Godtfredsen J. Boysen G: Relation between left atrial dimension and duration of atrial fibrillation. Am J Cardiol 1987;60:382-384

103 Takahashi N, Imataka K., Seki A, Fujii J: Left atrial enlargement in patients with paroxysmal atrial fibrillation. Jpn Heart J 1982;23:677-683

104 Keren G, Etzion T, Sherez J, Zelcer AA, Megidish R, Miller HI, Laniado S: Atrial fibrillation and atrial enlargement in patients with mitral stenosis. Am Heart J 1987; 1 14:1146-1 155

105 Probst P, Goldschlager N, Selzer A: Left atrial size and atrial fibrillation in mitral stenosis: ficturs influencing their relationship. Circulation 1973:48:1282-1287

106 Kannel WB, Abbott RD, Savage DD, McNamara PM: Epidemiologic features of chronic atrial fibrillation: the Framingham study. N Engl J Med 1982:306:1018-1022

107 Resnekov L, McDonald L: Appraisal of electroconversion in treatment of cardiac dysrhythmias. $\mathrm{Br}$ Heart $J$ 1968;30:786-811

108 Morris JJ, Jr., Peter RH, McIntosh HD: Electrical conversion of atrial fibrillation. Immediate and long-term results and selection of patients. Ann Intern Med 1966:65:216-231 
109 Brodsky MA, Allen BJ: Factors determining maintenance of sinus rhythm after chronic atrial fibrillation with left atrial dilatation. Am J Cardiol 1989;63:1065-1068

110 Cox J, Canavan TE, Schuessler RB, Cain ME, Lindsay BD, Stone CM, Smith PK, Corr PB. Boineau JP: The surgical treatment of atrial fibrillation. II. Intraoperative electrophysiologic mapping and description of the electrophysiologic basis of atrial flutter and atrial fibrillation. $J$ Thor Card Surg 1991;101:406-426

111 Solìi F, Vecsey T, Kekési V, Juhász-Nagy A: The effect of atrial dilatation on the genesis of atrial arrhythmias. Cardiovasc Res 1989;23:882-886

112 Ravelli F, Allessie MA: Atrial stretch decreases refractoriness and induces atrial fibrillation in the isolated rabbit heart. Circulation 1995;92:1-754(Abstract)

113 Sanfilippo AJ, Abascal VM, Sheehan M, Oertel LB, Harrigan P, Hughes RA, Weyman AE: Atrial enlargement as a consequence of atrial fibrillation. Circulation 1990;82:792-797

114 Gosselink MAT. Crijns HJGM, Hamer HPM, Hillege H, Lie KI: Changes in left and right atrial size after cardioversion of atrial fibrillation: Role of mitral valve disease. $J$ Am Coll Cardiol 1995:22:1666-1672

115 Van Gelder IC. Crijns HJGM, Gilst van WH. Hamer HPM, Lie KI: Decrease of right and left atrial sizes after direct-current electrical cardioversion in chronic atrial fibrillation. Am $J$ Cardiol 1991:67:93-95

116 Calkins H, El-Atassi R, Leon A, Kalbfleisch SJ, Borganelli M, Langberg JJ. Morady F: Effect of the atrioventricular relationship on atrial refractoriness in humans. Pace 1992;15:771-778

117 Kaseda S. Zipes DP: Contraction-excitation feedback in the atria: a cause of changes in refractoriness. J Am Coll Cardiol 1988;11:1327-1336

118 Klein LS, Miles WM, Zipes DP: Effect of atrioventricular interval during pacing or reciprocating tachycardia on atrial size, pressure, and refractory period. Contraction-excitation feedback in human atrium. Circulation 1990:82:60-68

119 Calkins H, El-Atassi R, Kalbfleisch S, Langberg J. Morady F: Effects of an acute increase in atrial pressure on atrial refractoriness in humans. Pace 1992:15:1674-1680

120 Le Grand B. Hatem S, Deroubaix E, Couétil JP, Coraboeuf E: Depressed transient outward and calcium currents in dilated human atria. Cardiovasc Res 1994:28:548-556

121 Isobe F. Schuessler RB, Mitsuno M. Nitta T, Cronin CS, Boineau JP, Cox JL: High atrial pressure directly affects the dispersion of refractoriness and the inducibility of atrial fibrillation. Circulation 1993:88:1-326(Abstrac1)

122 Satoh T. Zipes DP: The duration of atrial refractoriness in the thin region of the canine right atrium exceeds refractoriness in the thick region. Circulation 1996;92:I-755(Abstract)

123 Kannel WB, Abbott RD. Savage DD, MeNamara PM: Coronary heart disease and atrial fibrillation: the Framingham study. Am Heart J 1983;106:389-396

124 Cristal N. Peterburg I, Szwarcberg J: Atrial fibrillation developing in the acute phase of myocardial infarction: prognostic implications. Chest 1976:70:8-11

125 Cristal N. Szwareberg J, Gueron M: Supraventricular arrhythmias in acute myocardial infarction prognostic importince of clinical setting: mechanism of production. Ann Intem Med 1975:82:35-39

126 Liberthson RR. Salisbury KW, Hutter AM. DeSanctis RW: Atrial tachyarrhythmias in acute myocardial infarction. Am J Med 1976:60:956-960

127 Hod H. Lew AS. Keltai M. Cercek B. Geft IL. Shah PK. Ganz W: Early atrial fibrillation during evolving myocardial infarction: a consequence of impaired left atrial perfusion. Circulation 1987:75:146-150

128 Trautwein W, Gottstein U. Dudel J: Der aktionsstrom der myocardfaser im sauerstoffmangel. Pflïgers Arch Ges Physiol 1954;260:40-60

129 Noma A: ATP-regulated $\mathrm{K}^{+}$channels in cardiac muscle. Nature 1983;305:147-148

130 Wit AL. Hoffman BF. Cranefield PF: Slow conduction and reentry in the ventricular conduction system. Circ Res 1972:30:1-10

131 Cranefield PF. Wit AL. Hoffman BF: Genesis of cardiac arrhythmias. Circulation 1973:47:190-204 
132 Janse MJ, Wit AL: Electrophysiological mechanisms of ventricular arrhythmias resulting from myocardial ischemia and infarction. Physiol Rev 1989;69:1049-1169

133 White CW, Kerber RE, Weiss HR, Marcus ML: The effects of atrial fibrillation on atrial pressurevolume and flow relationships. Circ Res 1982;51:205-215 


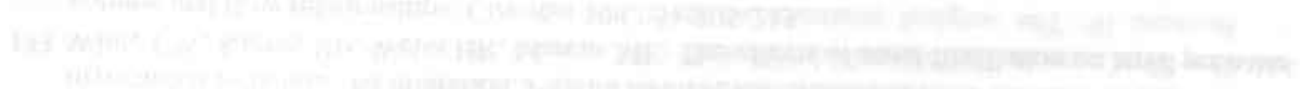

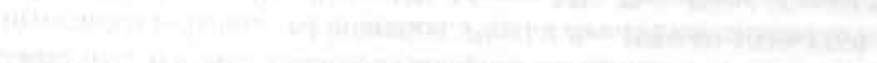




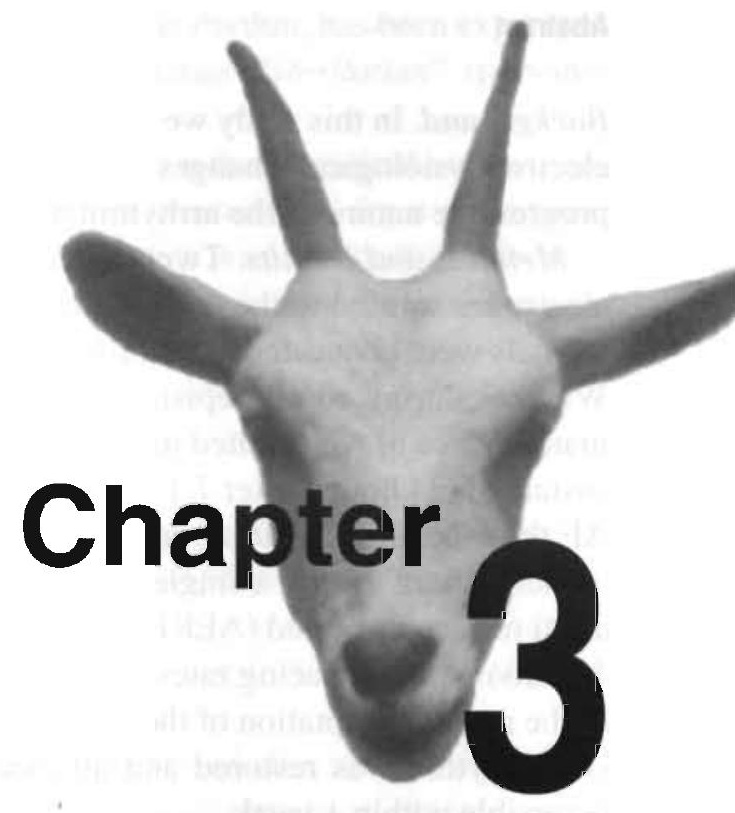

\section{Atrial Fibrillation Begets Atrial Fibrillation}

A Study in Awake Chronically Instrumented Goats

Maurits C.E.F. Wijffels

Charles J.H.J. Kirchhof

Rick Dorland

Maurits A. Allessie

Circulation 1995;92:1954-1968 


\section{Abstract}

Background. In this study we tested the hypothesis that atrial fibrillation (AF) causes electrophysiological changes of the atrial myocardium which might explain the progressive nature of the arrhythmia.

Methods and Results. Twelve goats were chronically instrumented with multiple electrodes sutured to the epicardium of both atria. 2-3 Weeks after implantation, the animals were connected to a fibrillation pacemaker which artificially maintained AF. Whereas during control episodes of AF were shortlasting ( $6 \pm 3$ seconds), artificial maintenance of $\mathrm{AF}$ resulted in a progressive increase in the duration of AF to become sustained ( 24 hours) after $7.1 \pm 4.8$ days ( 10 of 11 goats). During the first 24 hours of AF the median fibrillation interval shortened from $145 \pm 18$ to $108 \pm 8 \mathrm{~ms}$ and the inducibility of $\mathrm{AF}$ by a single premature stimulus increased from $24 \%$ to $76 \%$. The atrial refractory period (AERP) shortened from $146 \pm 19$ to $95 \pm 20 \mathrm{~ms}(-35 \%)\left(\mathrm{S}_{1} \mathrm{~S}_{1}\right.$ : $400 \mathrm{~ms})$. At high pacing rates the shortening was less (-12\%) pointing to a reversion of the normal adaptation of the AERP to heart rate. In 5 goats, after 2-4 weeks of AF, sinus rhythm was restored and all electrophysiological changes were found to be reversible within 1 week.

Conclusions: Artificial maintenance of AF leads to a marked shortening of AERP, a reversion of its physiological rate adaptation, and an increase in rate, inducibility and stability of AF. All these changes were completely reversible within 1 week of sinus rhythm.

\section{Introduction}

Atrial fibrillation (AF) is a common arrhythmia in man with an overall prevalence of $0.4 \%$ to $0.9 \%$. Its incidence increases with age with about 0.1 to $0.2 \%$ per year over the age of 40 , resulting in a prevalence of $2-4 \%$ in the population over 60 years of age. ${ }^{1-3}$ Rheumatic and ischemic heart disease, hypertension and congestive heart failure are important risk factors for the development of AF leading to a prevalence of as high as $40 \%$ in patients with overt congestive heart failure. ${ }^{4}$ On the other hand, in $3-31 \%$ of documented AF no underlying cardiovascular disease can be detected (lone AF). ${ }^{2,5-8}$

Paroxysmal atrial fibrillation often progresses to chronic atrial fibrillation, the transition rate varying considerably with the underlying etiology. ${ }^{1}$ However $18 \%$ of patients with lone paroxysmal atrial fibrillation also develop sustained fibrillation. ${ }^{7}$ The duration of the paroxysms of AF was found to be of importance, transition to chronic fibrillation occurring in $31 \%$ of patients with paroxysms shorter than two days, versus $46 \%$ if the episodes of $A F$ were of longer duration. ${ }^{1}$ From these epidemiological data thus it seems that, independent of the underlying etiology, atrial fibrillation in itself is a progressive disease. The clinical experience that with time it becomes 
more and more difficult to keep a patient with AF in sinus rhythm, has been expressed by M. Rosenbaum by the term "Domestication of Atrial Fibrillation" (personal communication 1992).

Other evidence that AF promotes AF is the observation that chemical or electrical defibrillation has a higher success rate when AF has existed only for a short time. Cardioversion by intravenous administration of flecainide was successful in 76-93\% of patients with recent onset $\mathrm{AF}$ ( $<24$ hours) compared to $0-83 \%$ in patients with $\mathrm{AF}$ of longer duration. ${ }^{9-12}$ Amiodarone cardioverted $\mathrm{AF}$ in $85 \%$ if lasting for $<1$ year versus $57 \%$ in patients who had $\mathrm{AF}$ for than 1 year. In patients with long-lasting $\mathrm{AF}$ the chances of maintaining sinus rhythm after cardioversion with amiodarone were also less. ${ }^{13}$

The success rate of electrical atrial defibrillation also depends on the duration of AF. ${ }^{14.15}$ In 186 patients whom were successfully defibrillated, the mean duration of atrial fibrillation was $16 \pm 27$ months compared to $28 \pm 45$ months in the total study group of 246 patients. ${ }^{16}$ The recurrence rate after successful DC countershock was also higher in patients with a longer history of AF. ${ }^{14,15,17-19}$

A possible explanation for all these epidemiological and clinical observations is that, apart from the progressive changes due to an underlying heart disease, atrial fibrillation itself causes progressive electrophysiological and/or structural changes to the atria, which promote the initiation or perpetuation of atrial fibrillation. The present study was designed to test the hypothesis that atrial fibrillation begets atrial fibrillation and to explore the electrophysiological changes which may be responsible for this phenomenon.

\section{Methods}

A Conscious Goat Model of Sustained Atrial Fibrillation.

Twelve goats weighing between 46 and $68 \mathrm{~kg}(55.3 \pm 7.4 \mathrm{~kg})$ were used for this study. Animal handling was performed according to the guiding principles of the American Society of Physiology and approved by the Animal Investigation Committee of the University of Limburg. The goats were anaesthetized with Nesdonal ${ }^{\circledR}$ (Thiopental, $10-15 \mathrm{mg} / \mathrm{kg}$ ) and ventilated by Halothane ${ }^{\circledR}(1-2 \%)$ and a 1:2 mixture of $\mathrm{O}_{2}$ and $\mathrm{N}_{2} \mathrm{O}$. A left intercostal thoracotomy was made and the pericardium was opened to expose the heart. A silicon strip (Silastic $\left.{ }^{(}\right)$, Dow Corning) of $10 \times 1.2 \mathrm{~cm}$, containing 15 unipolar platinum recording electrodes (diameter $1.5 \mathrm{~mm}$, inter-electrode distanci 6-10 $\mathrm{mm}$ ) was guided through the anterior transverse sinus between the atria and the aortic root and sutured to the tips of both atrial appendages. In addition, two smaller silicon strips of $3 \times 1.2 \mathrm{~cm}$, each containing 6 electrodes, were sutured to the lateral walls of the right and left atria (Fig 1) After approximation of the pericardium and closure of the thorax, the electrode leads were tunneled subcutaneously to the neck and exteriorized by a 30 -pin connector (Lemosa ${ }^{\circledR}$, outer diameter $10 \mathrm{~mm}$ ). Three silver 


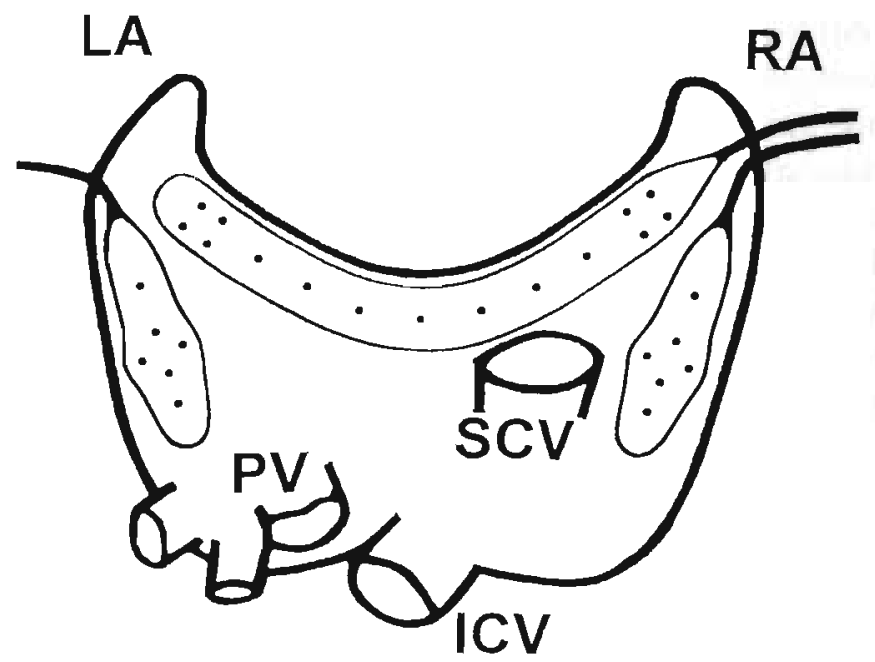

Figure 1. Diagram showing the localization of the 27 chronically implanted electrodes on the atria. Three silicon strips were sutured on the epicardium. One strip with 15 electrodes was pulled through the sinus transversus between the aorta and the atria and fixed to both atrial appendages. The distance between the quadruple of electrodes at each end of the silicon strip at the aortic surface of the atrial appendages was $6 \mathrm{~mm}$, the distance between the row of electrodes along Bachmann's bundle being $10 \mathrm{~mm}$. The two other strips each containing 6 electrodes were sutured to the free wall of the right and left atria. The interelectrode distance of these electrodes was $6 \mathrm{~mm}$ between the quadruple of electrodes and $10 \mathrm{~mm}$ to the distal electrodes. RA, right atrium; L.A. left atrium; $P V$, pulmonary veins; $S C V$, superior caval vein; $I C V$, inferior caval vein.

plates (diameter $25 \mathrm{~mm}$ ) were left subcutaneously to serve as grounding and indifferent electrodes and to record a precordial electrocardiogram. Post-operatively the animals received buprenorfine (Temgesic ${ }^{\circledR}$, Reckitt \& Colman, Hull England) for 1-3 days. Ampicillin (1000 mg) was given prophylactically once before and once after surgery.

\section{Automatic Induction of Atrial Fibrillation}

About 2-3 weeks after surgery the goats were connected to an external automatic atrial fibrillator. The goats were kept in separate boxes (size $1.5 \times 0.7$ meter) with free access to food and water. A cable from the ceiling was plugged into the connector in the neck of the animals and the atrial electrodes were connected to a multi-channel recording unit (gain 200-400; bandwidth $\mathrm{l}-500 \mathrm{~Hz}$ ). $20 \mathrm{~A}$ spring between the cable and the fixation point at the ceiling allowed free movements of the goats in their boxes. The atria could be stimulated through any of the epicardial electrodes. The automatic fibrillator consisted of a personal computer ( 386 processor) connected to a stimulator (Medtronic, SP3084). The computer program continuously analyzed one of the recorded bipolar atrial electrograms and determined the maximal length of the 

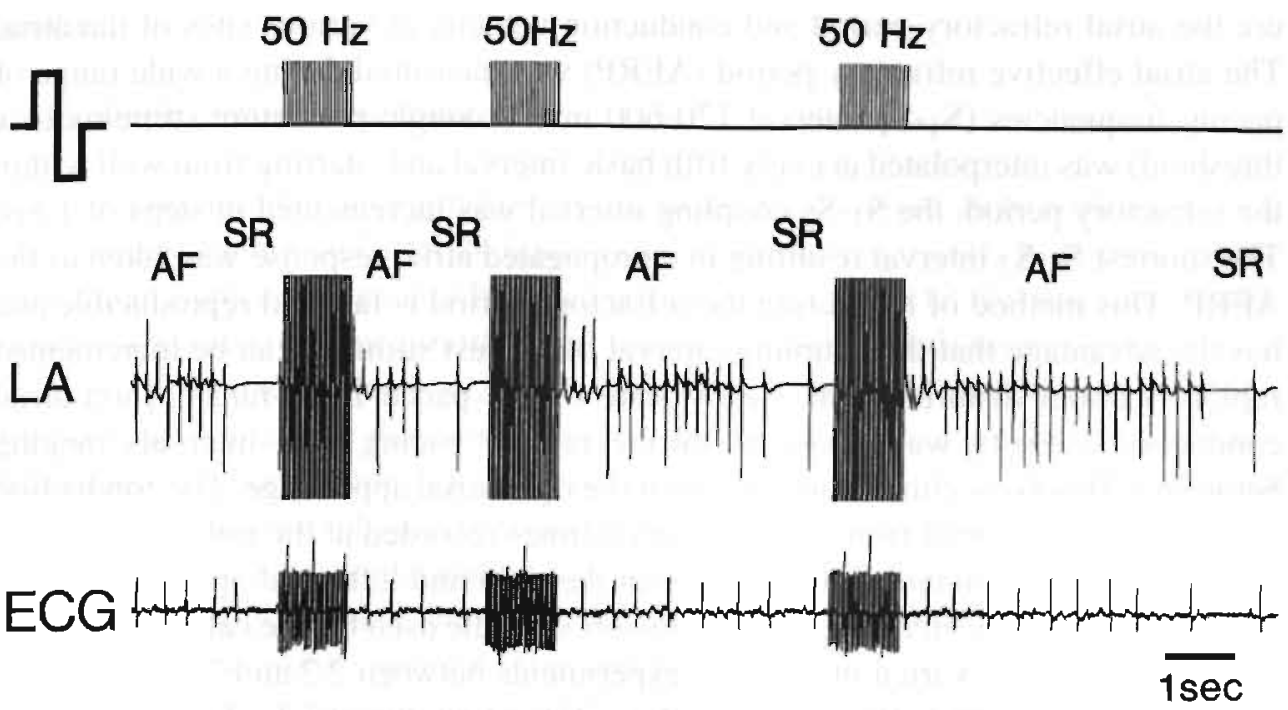

Figure 2. The functioning of the automatic fibrillation pacemaker. A single bipolar left atrial electrogram (LA) was sensed continuously for the occurrence of an iso-electrical segment of longer than $300 \mathrm{~ms}$. As soon as a long iso-electrical segment was detected (sinus rhythun) the pacemaker automatically delivered a 1 second burst of stimuli (interval $20 \mathrm{~ms}, 4 \mathrm{x}$ threshold) and atrial fibrillation was promptly reinduced. In this example the fibrillation pacemaker had just been turned on and only short episodes of self-terminating atrial fibrillation were produced. LA, left atrial bipolar electrogram; ECG, precordial surface electrocardiogram recorded from one of the subcutaneous electrodes; $A F$, atrial fibrillation; $S R$, sinus rhythm.

iso-electrical segment in consecutive time-windows of 1 second. During sinus rhythm the duration of the iso-electrical segment was always longer than $300-400 \mathrm{~ms}$, whereas during atrial fibrillation it was shorter than $80-120 \mathrm{~ms}$. Because of this large difference this proved to be a simple and reliable criterion to automatically distinguish between sinus rhythm and atrial fibrillation. When the automatic fibrillator was turned on, a 1-second burst of biphasic stimuli (interval $20 \mathrm{~ms}, 4$ times diastolic threshold) was delivered as soon as sinus rhythm was detected. As can be seen in Fig 2 this promptly induced atrial fibrillation in a reproducible way. By giving automatic bursts of stimuli immediately after atrial fibrillation converted to sinus rhythm, atrial fibrillation could be maintained continuously during 24 hours a day, 7 days a week. All moments of induction of $\mathrm{AF}$ were stored in the computer and the duration of each episode was calculated. During the maintenance of AF, the atrial fibrillation interval was measured on line from a single bipolar atrial electrogram. Additionally, at regular time intervals all electrograms were stored on magnetic tape and atrial fibrillation interval histograms were made from the unipolar electrograms recorded at different sites.

\section{Experimental Protocol}

After the goats had recovered from surgery and before they were connected to the automatic fibrillator, first an extensive electrophysiological study was done to meas- 
ure the atrial refractory period and conduction velocity at various sites of the atria. The atrial effective refractory period (AERP) was measured during a wide range of pacing frequencies $\left(\mathrm{S}_{1}-\mathrm{S}_{1}\right.$ interval $\left.120-600 \mathrm{~ms}\right)$. A single premature stimulus ( $4 \mathrm{x}$ threshold) was interpolated at every fifth basic interval and, starting from well within the refractory period, the $S_{1-} S_{2}$ coupling interval was incremented in steps of $1 \mathrm{~ms}$. The shortest $S_{1}-S_{2}$ interval resulting in a propagated atrial response was taken as the AERP. This method of measuring the refractory period is fast and reproducible and has the advantage that the coupling interval of the test stimulus can be incremented rapidly without disturbing the steady state of the paced heart rate. ${ }^{21}$ Intra-atrial conduction velocity was measured during regular pacing with intervals ranging between 120-600 ms either from the left or the right atrial appendage. The conduction velocity was calculated from the conduction times recorded at the row of electrodes positioned on Bachmann's bundle between the right and left atrial appendages. The distance between the electrodes on Bachmann's bundle used for the calculation of the conduction velocity varied in different experiments between 2.2 and $7.2 \mathrm{~cm}$.

After the fibrillation pacemaker had been turned on, the atrial refractory periods and conduction velocities were measured again after respectively 6 and 24 hours of maintained AF. In some goats these measurements could also be repeated after 2-4 days.

The vulnerability of the atria to fibrillation was compared during control and after 24 hours of AF. During regular pacing with a fixed interval of $400 \mathrm{~ms}$ single early premature stimuli of 4 times threshold were administered through the same stimulating electrodes as used for regular pacing. Atrial fibrillation was considered to be induced if the single premature stimulus was followed by rapid irregular atrial activity lasting for more than 1 second.

In 5 goats the reversibility of effects was studied after conversion of long-lasting AF (2-4 weeks) to sinus rhythm. In 4 goats AF converted spontaneously and in 1 goat $\mathrm{AF}$ was terminated by an infusion of Cibenzoline (Cipralan ${ }^{\circledR}, 1.5 \mathrm{mg} / \mathrm{kg}$ ). Measurements were made 6 hours, 24 hours, 1 week and 2 weeks after conversion to sinus rhythm.

Data are presented as mean \pm standard deviation. Statistical analysis of the obtained data was performed by using the paired Student's $t$-test or when the data did not have a normal distribution by the Wilcoxon matched pairs signed ranks test. In case of multiple statistical comparisons (e.g. control versus 6 hours and 24 hours of AF) the $\mathrm{p}$ value was corrected by multiplying it with the number of comparisons (Boferroni's correction). A corrected $\mathrm{p}$ value of less than 0.05 was considered to be statistically significant. 


\section{Results}

Development of sustained atrial fibrillation

In Fig 3 a representative example is shown of the induction of atrial fibrillation in a goat in sinus rhythm and after 24 hours and 2 weeks of electrically maintained atrial fibrillation. Typically in goats which had been in sinus rhythm all the time, electrically induced AF lasted only for a short period and usually terminated spontaneously within seconds (upper trace). However, as shown by the second and third tracing recorded from the same goat, the duration of paroxysms of AF increased after AF had been maintained for some time. In this case after 24 hours of AF the bouts of atrial fibrillation lasted for about 20 seconds (middle trace), and after 2 weeks atrial fibrillation became sustained and no longer terminated spontaneously (bottom trace). Actually, the bottom trace shows induction of AF the last time it had converted spontaneously to sinus rhythm. The repetitive induction of fibrillation not only resulted in a dramatic prolongation of the duration of fibrillation but also the rate of fibrillation increased significantly. This is illustrated in Fig 4 in which a single unipolar electrogram is shown recorded from the left atrial appendage during various stages of AF. While during acute fibrillation (upper tracing) the median fibrillation interval was $149 \mathrm{~ms}$, already after 6 hours of AF the interval had shortened to $132 \mathrm{~ms}$. After 24 hours of maintained AF the median fibrillation interval had further decreased to $117 \mathrm{~ms}$ to become as short as $91 \mathrm{~ms}$ after 2 weeks when AF had become sustained (lower tracing). Also the configuration of the atrial electrograms changed during the development of chronic fibrillation. While during the first days of AF most activations still showed a single steep negative deflection of high amplitude separated by an iso-electric segment, after 2 weeks of AF single steep deflections were less common and many electrograms now were of low amplitude with a high degree of fragmentation and no clear iso-electric segment (lower tracing). This suggests that during recent onset fibrillation the atrium is still activated uniformly by broad activation waves (type I fibrillation) and that after 2 weeks of $\mathrm{AF}$, activation of the atrium had become more complex by the development of multiple arcs of intra-atrial conduction block (type II or type III fibrillation) 22,23

Fig 5 shows the time course of the prolongation of episodes of AF during the first two weeks of fibrillation in 4 different goats (panels A-D). As can be seen there existed a large inter-individual variation in the time course of development of sustained atrial fibrillation, defined as $\mathrm{AF}$ lasting longer than 24 hours. In panel $\mathrm{A}$, sustained fibrillation occurred already after 3 days. In contrast, in goat $D$ the time course of prolongation of AF was much slower and after 2 weeks the average duration of AF was still not longer than 50 minutes. Panels $B$ and $C$ show two examples of an intermediate time course in which sustained $A F$ was reached after about 8 and 12 days.

In Fig 6 (panels A-D) the time course of changes in fibrillation interval is given for the same 4 goats as in Fig 5. Compared to the time course in AF duration, the time course of changes in fibrillation interval showed much less inter-individual variation. 

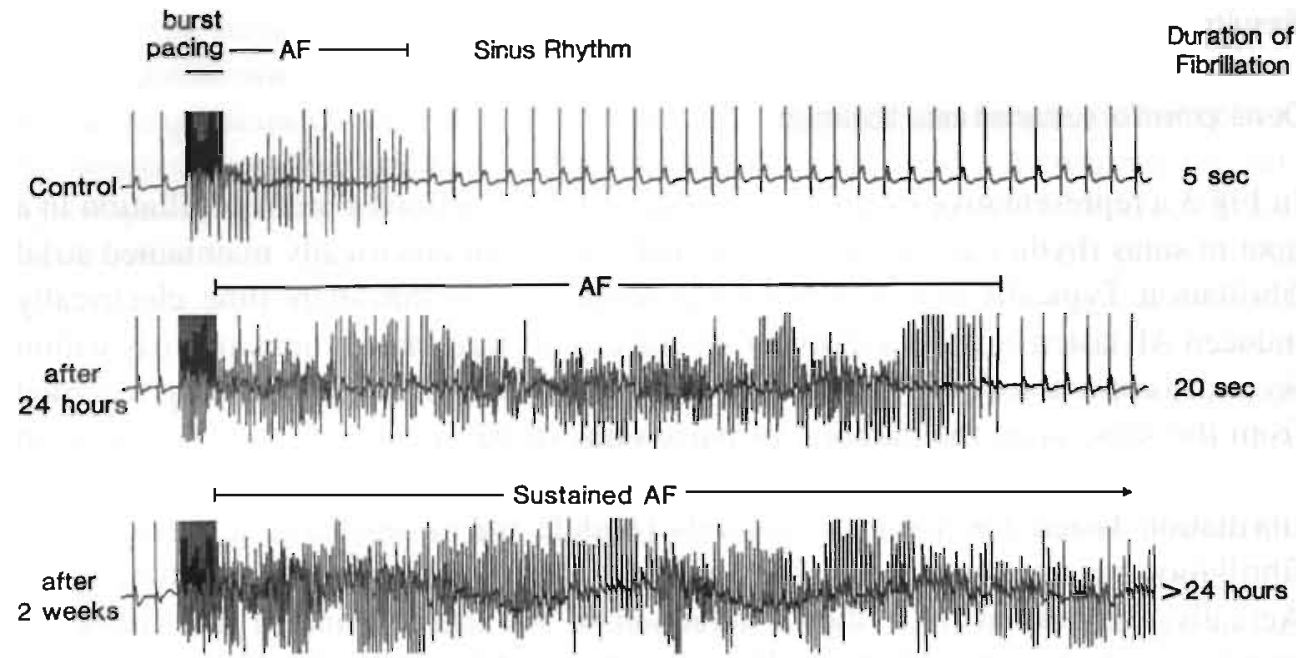

$2 \mathrm{sec}$

Figure 3. Prolongation of the duration of episodes of electrically induced atrial fibrillation after maintaining AF for respectively 24 hours and 2 weeks. The three tracings show a single atrial electrogram recorded from the same goat during induction of AF by a 1 second burst of stimuli $(50 \mathrm{~Hz}, 4 \times$ threshold). In the upper tracing the goat has been in sinus rhythm all the time and atrial fibrillation self-terminated within 5 seconds. The second tracing was recorded after the goat had been connected to the fibrillation pacemaker for 24 hours showing a clear prolongation of the duration of AF to 20 seconds. The third tracing was recorded after 2 weeks of electrically maintained atrial fibrillation. After induction of AF this episode became sustained and did not terminate spontaneously anymore.

In all goats the fibrillation interval decreased rapidly within the first 24 hours with a time course of about $2 \mathrm{~ms}$ per hour. The atrial fibrillation interval continued to shorten more slowly during the next days with only a few milliseconds per day to reach a steady state after about 6 days.

Table 1 gives the median duration of the episodes of induced AF and the fibrillation intervals of all goats both during sinus rhythm and after respectively 24 hours, 48 hours, 1 week and 2 weeks of atrial fibrillation. During sinus rhythm the episodes of electrically induced atrial fibrillation were very short and terminated already after 6 \pm 3 seconds. The median interval of these short runs of AF ranged from 113 to 176 $\mathrm{ms}$ (mean $1+5 \pm 18 \mathrm{~ms}$ ). After 24 hours of atrial fibrillation the average duration of $\mathrm{AF}$ had increased to $2.2 \pm 3.0$ minutes and the fibrillation interval had shortened to $108 \pm 8 \mathrm{~ms}$. After 48 hours in two goats AF had become sustained (lasting 24 hours) while in the remaining 10 goats fibrillation lasted for $7.8 \pm 9.7$ minutes. The mean fibrillation interval wals $105 \pm 8 \mathrm{~ms}$. After 1 week, in 5 of 11 goats AF had become sustained and in the 6 other animals fibrillation lasted for $241 \pm 459$ minutes. The fibrillation interval was $100 \pm 5 \mathrm{~ms}$ (one goat (\#8) dropped out due to the development of a serious sepsis after 4 days of AF). After 2 weeks, in 9 of 11 goats and within 3 weehs in 10 of 11 goats fibrillation lasted longer than 24 hours. In the goat in which 


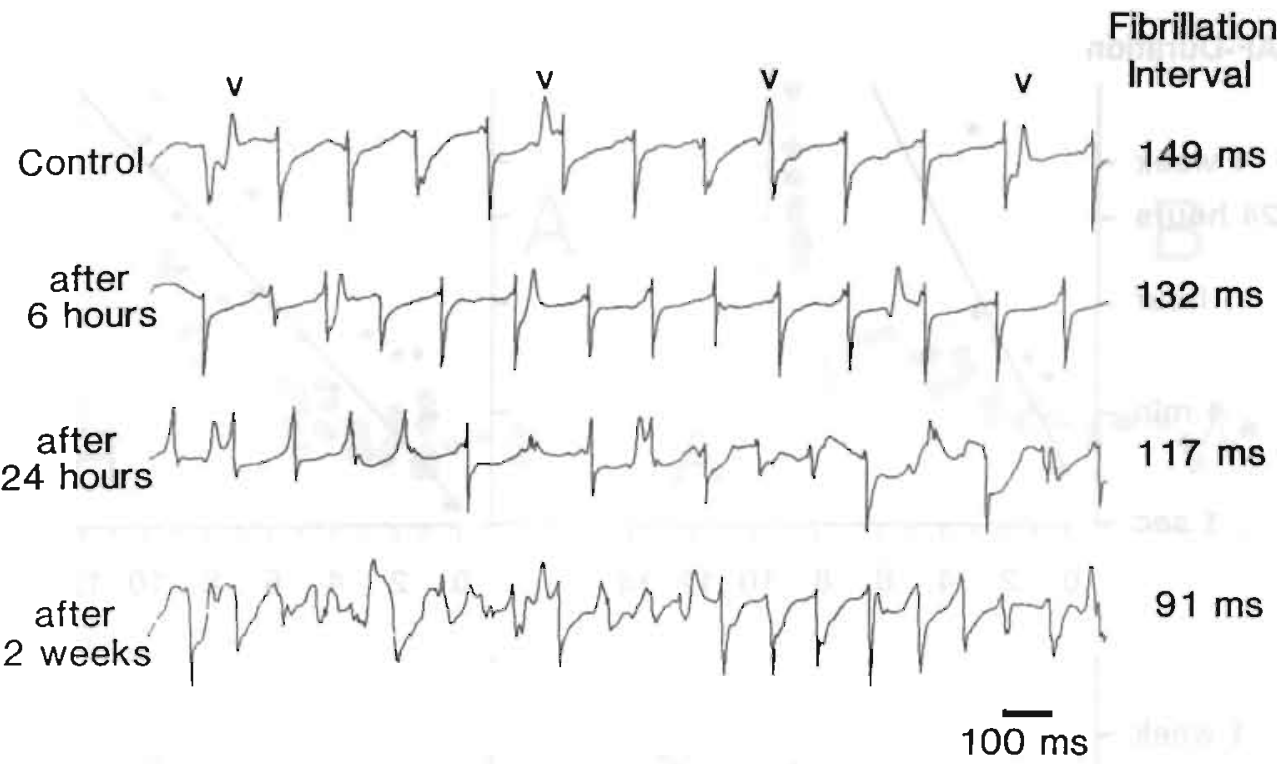

Figure 4. A single unipolar atrial electrogram recorded from the lefi atrial appendage during different stages of atrial fibrillation. At the right hand side of the tracings the corresponding median fibrillation intervals, as measured from these short samples of AF, are plotted. As can be seen from the electrograms and the calculated median fibrillation intervals, the atrial rate clearly increased during the initial phase of atrial fibrillation. Also the morphology of the atrial electrograms changed in the course of atrial fibrillation. Whereas during recent onset fibrillation the electrograms mostly showed single deflections of high amplitude separated by an iso-electric segment (upper tracing). after 2 weeks of AF the electrograms were of lower amplitude and showed a higher degree of fragmentation (lower uracing). V. ventricular complex.

AF did not become sustained the longest episode of AF lasted for 13.5 hours. During sustained atrial fibrillation ( 24 hours) the average AF interval was $99 \pm 10 \mathrm{~ms}$ compared to $145 \pm 18 \mathrm{~ms}$ for the short lasting episodes of AF induced during sinus rhythm.

Correlation Between Rate and Duration of Atrial Fibrillation

Although the development of chronic fibrillation was accompanied by a progressive increase in the rate of fibrillation, there was a discrepancy in the time course of these changes. This is illustrated in Fig 7 in which the changes in both parameters in goat \#3 are plotted during the first 24 hours of electrically maintained AF. As usual fibrillation started as short paroxysms lasting for only a few seconds (upper panel) with a fibrillation interval between $150-164 \mathrm{~ms}$ (lower panel). However, while the average fibrillation interval already commenced to shorten within the first hours of maintained AF. it was not until after 15 hours of repetitive induction of $\mathrm{AF}$ that also the duration of the episodes of AF started to get longer. At that time the average fibrillation interval had already shortened to $123 \mathrm{~ms}$. At the end of the first 24 hours 


\section{AF-Duration}
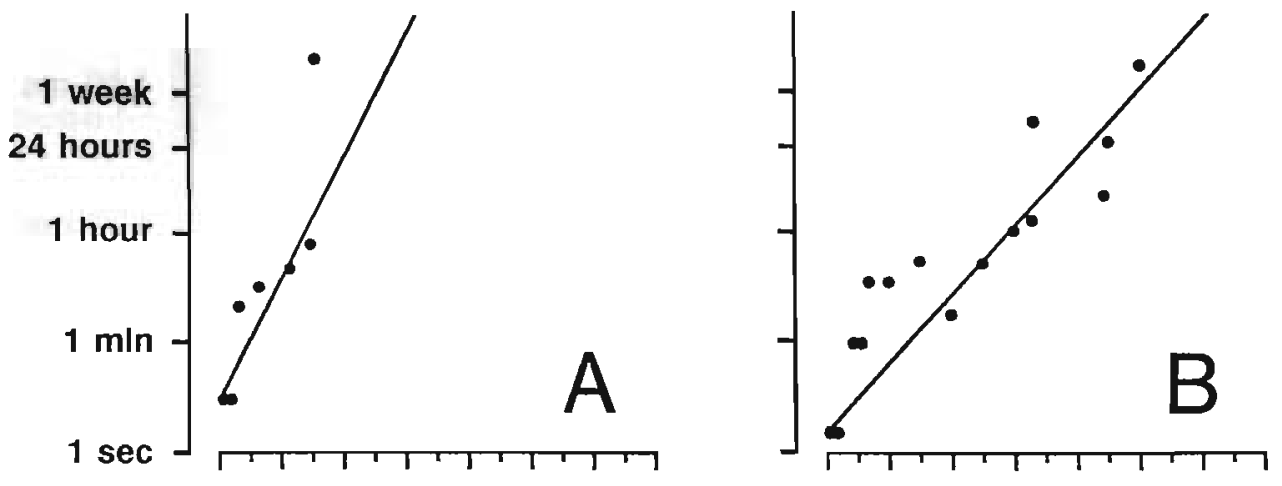

$\begin{array}{llllllll}0 & 2 & 4 & 6 & 8 & 10 & 12 & 14\end{array}$
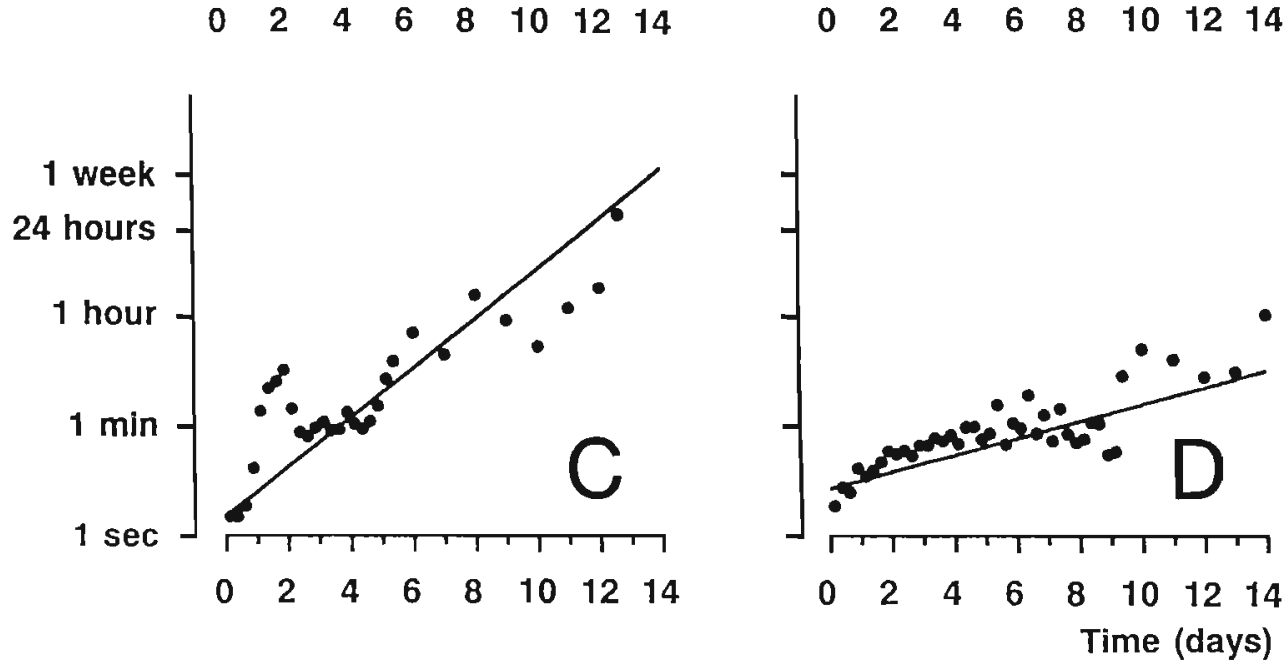

Figure 5. The time course of development of chronic fibrillation in 4 different goats (panels A-D). On the ordinate the duration of the episudes of induced AF is plotied on a logarithmic scale. The data points represent the median duration of all episodes of AF during either a time period of 6 hours (AF shorter than 30 minutes) or 24 hours (AF longer than 30 minutes). If less than 5 episodes vecurred within 24 hours the duration of the episodes of AF are plotted individually. After logarithmic transformation of all individual data points. linear regression lines were calculated. The correlation coefficients were $0.65,0.74,0.79$ and 0.65 respectively. There was considerable interindividual variation in the time course of development of chronic AF. In panel A (goat \#1, table 1), atrial fibrillation became chronic (24 hours) already after 3 days. In goats B and C (goats \#6 and 3) atrial fibrillation was chronic after respectively 8 and 12 days, whereas in goat D (goat \# 4), after 2 weeks of AF the episodes of AF still lasted for only 50 minutes.

of atrial fibrillation the duration of AF had increased to an average of 1.5 minutes and the fibrillation interval had shortened to $100 \mathrm{~ms}$. In Fig 8. for 6 goats the duration of the episodes of AF is plotted against the corresponding fibrillation intervals. From this plot it appears that at fibrillation intervals longer than about $120 \mathrm{~ms}$, fibrillation was shortlasting and usually terminated spontaneously within less than ten seconds. However when the median fibrillation interval became shorter than $120 \mathrm{~ms}$ an 

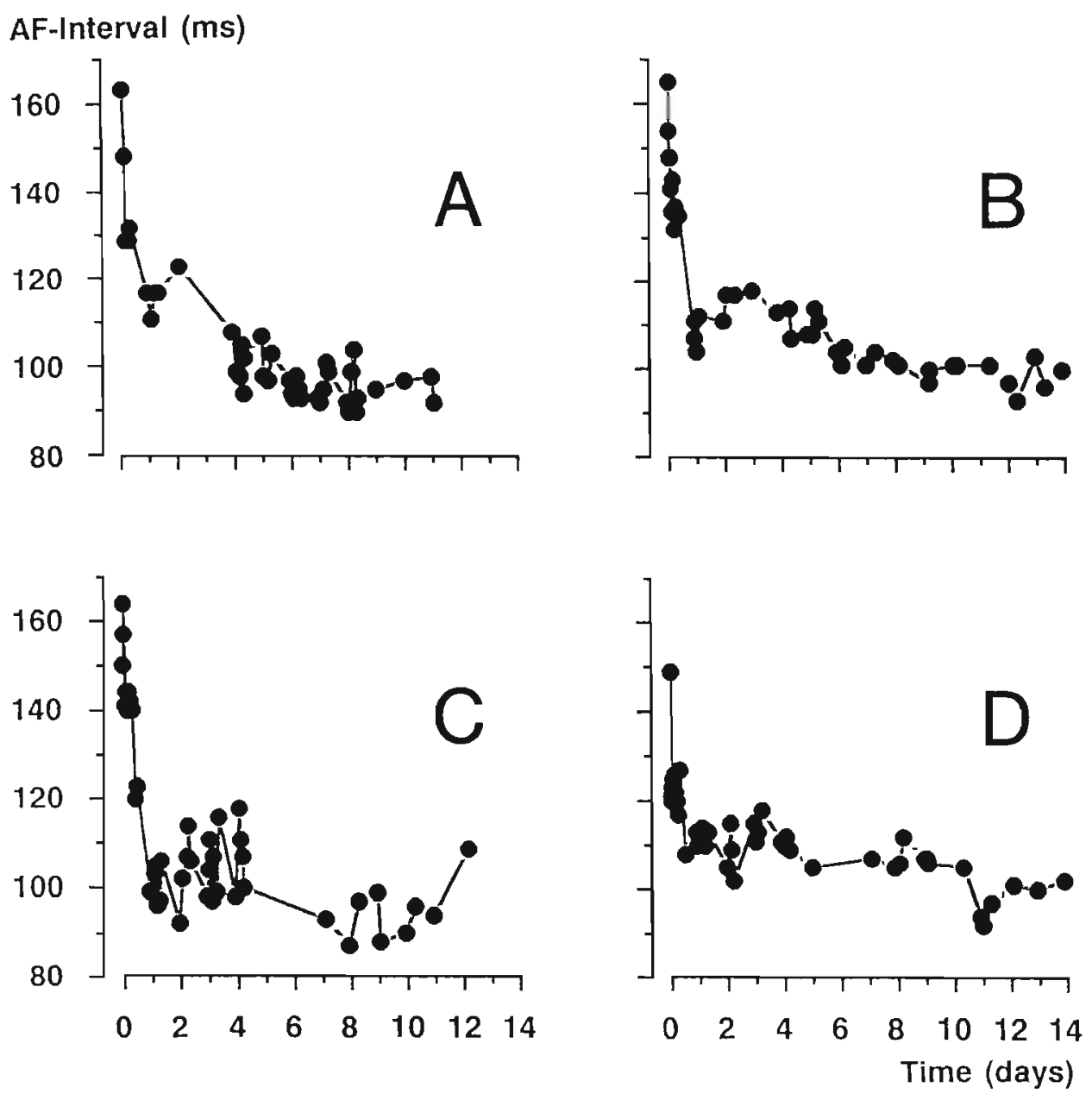

Figure 6. The time course of changes of atrial fibrillation interval during the development of chronic atrial fibrillation in 4 goats. The data in panel A-D are from the same goats as in figure 5. Compared to the large inter-individual variation in the duration of AF seen in figure 5, the time course of changes in fibrillation interval was more uniform. In all four goats (panels A-D), during the first 24 hours of AF the fibrillation interval shortened rapidly and continued to shorten more gradually during the following days. Data points represent the average atrial fibrillation interval as measured on line from a bipolar atrial electrogram (sample size $5-20$ seconds).

exponential rise in the duration of $\mathrm{AF}$ was found. From these data thus it seems that the cascade of cause and effect, finally leading to chronic atrial fibrillation, is started by a shortening of the fibrillation interval. As soon as the fibrillation interval passes a critical threshold of $120 \mathrm{~ms}$, obviously atrial fibrillation becomes more stable and the duration of AF starts to increase. This in turn will further shorten the fibrillation interval which will prolong the duration of AF again, etc. Such a positive feedback mechanism will continue until a new steady state is reached in which atrial fibrillation has become the predominant atrial rhythm (domestication of atrial fibrillation). 
Do Table 1. Median duration and interval of episodes of induced atrial fibrillation.

\begin{tabular}{|c|c|c|c|c|c|c|c|c|c|c|}
\hline \multirow[b]{2}{*}{ Goat \# } & \multicolumn{2}{|c|}{ Sinus Ahythm } & \multicolumn{2}{|c|}{24 Hours of AF } & \multicolumn{2}{|c|}{48 Hours of AE } & \multicolumn{2}{|c|}{1 Week of AF } & \multicolumn{2}{|c|}{2 Weeks of $A F$} \\
\hline & $\begin{array}{l}\text { Duration } \\
\text { (sec) }\end{array}$ & $\begin{array}{l}\text { Interval } \\
\text { (ms) }\end{array}$ & $\begin{array}{l}\text { Duration } \\
\text { (sec) }\end{array}$ & $\begin{array}{l}\text { Interval } \\
\text { (ms) }\end{array}$ & $\begin{array}{l}\text { Duration } \\
\text { (sec) }\end{array}$ & $\begin{array}{l}\text { Interval } \\
\text { (ms) }\end{array}$ & $\begin{array}{l}\text { Duration } \\
\text { (sec) }\end{array}$ & $\begin{array}{l}\text { Interval } \\
\text { (ms) }\end{array}$ & $\begin{array}{l}\text { Duration } \\
\text { (sec) }\end{array}$ & $\begin{array}{l}\text { Interval } \\
\text { (ms) }\end{array}$ \\
\hline 1 & 5 & 163 & 672 & 117 & 1006 & 123 & $>24 h$ & 92 & $>24 h$ & - \\
\hline 2 & 5 & 139 & 11 & 110 & 71 & 102 & 2614 & - & 6453 & 115 \\
\hline 3 & 4 & 164 & 98 & 99 & 117 & 101 & 1186 & 93 & $>24 h$ & 89 \\
\hline 4 & 3 & 142 & 20 & 109 & 8 & 110 & 113 & 106 & 2950 & 91 \\
\hline 5 & 5 & 150 & 264 & 105 & $>24 h$ & 110 & $>24 h$ & 102 & $>24 h$ & 113 \\
\hline 6 & 4 & 157 & 57 & 115 & 1845 & 110 & $>24 h$ & 110 & $>24 h$ & 109 \\
\hline 7 & 5 & 176 & 24 & 112 & 25 & 106 & 6331 & 101 & $>24 h$ & 100 \\
\hline 8 & 4 & 151 & 13 & 106 & 195 & 99 & $\dagger$ & $\dagger$ & $t$ & $t$ \\
\hline 9 & 9 & 132 & 228 & 122 & 971 & $=$ & $>24 h$ & 98 & $>24 h$ & 105 \\
\hline 10 & 1 & 129 & 128 & 108 & $>24 h$ & 105 & $>24 h$ & 104 & $>24 h$ & 91 \\
\hline 11 & 15 & 113 & 53 & 95 & 410 & 91 & 75831 & 97 & $>24 h$ & 89 \\
\hline 12 & 8 & 125 & 21 & 100 & 21 & 98 & 721 & 98 & $>24 \mathrm{~h}$ & 87 \\
\hline Mean & 6 & 145 & $132^{5 \S}$ & $108^{* *}$ & $467^{69}$ & $135^{\mathrm{w*}}$ & $14466^{\S}$ & $100^{\cdots *}$ & $4702^{\S}$ & $99^{\circ}$ \\
\hline Sd & 3 & 18 & 182 & 8 & 584 & 8 & 27519 & 5 & 1752 & 10 \\
\hline SAF & $0 / 12$ & & $0 / 12$ & & $2 / 12$ & & $5 / 11$ & & $9 / 11^{\ddagger}$ & \\
\hline
\end{tabular}

AF, atrial fibrillation; Sd, standard deviation; SAF, sustained atrial fibrillation ( $>24$ hours); ${ }^{\cdots \cdots} p<0.00$ compared to control (paired Student's t-test; corrected for multiple comparisons); ${ }^{\S} p<0.05$, ${ }^{5 \varsigma} p<0.01$ compared to control (Wilcoxon matched pairs signed ranks test; corrected for multiple comparisons; ; $\uparrow$ goal dropped out due lo the development of a serious sepsis; $\ddagger$ alter 3 weeks $S A F$ had developed in 10 of 11 goats. 


\section{AF-Duration}
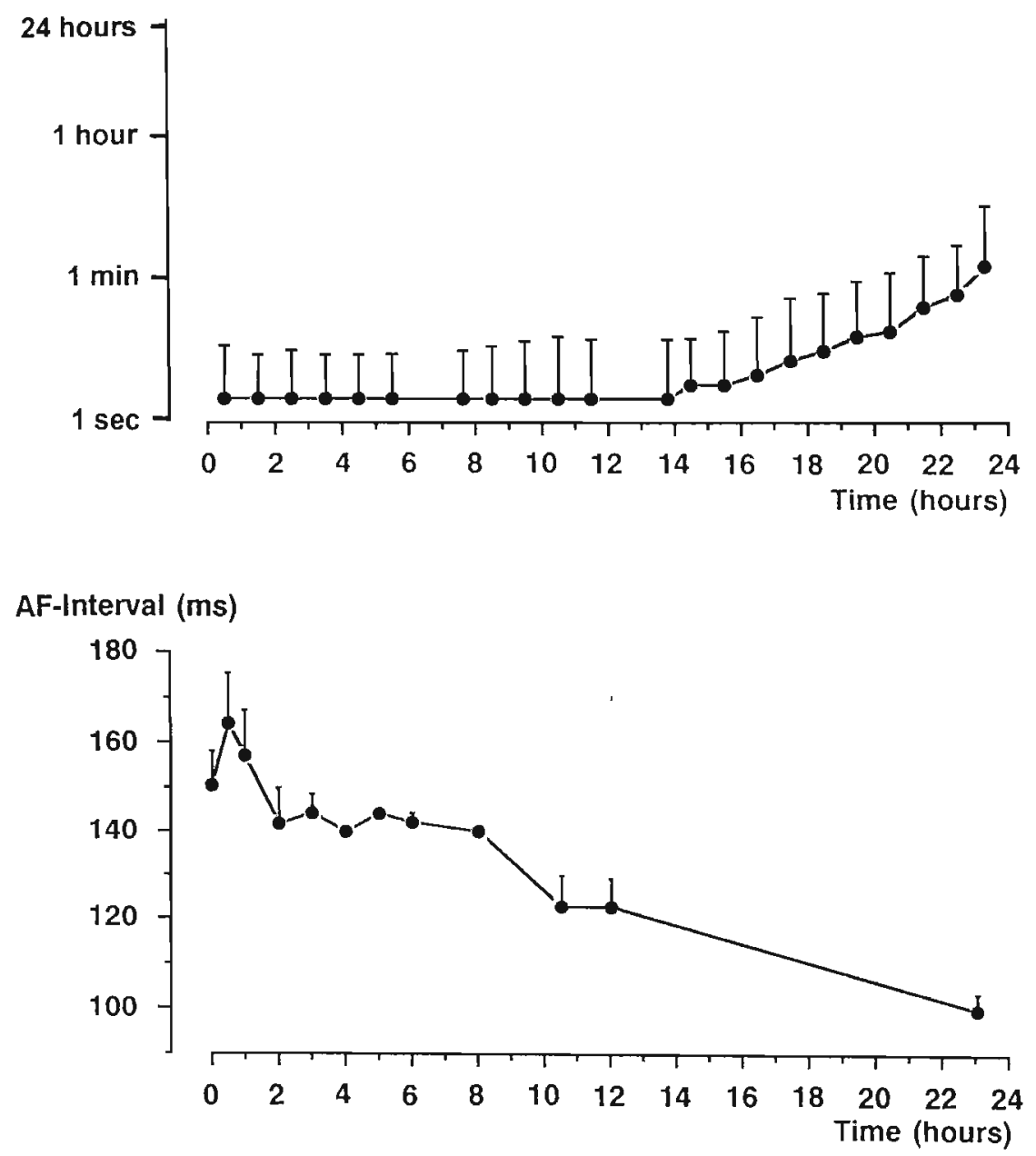

Figure 7. An example of the different time course of changes in duration of AF (upper panel) and atrial fibrillation interval (lower panel) (goat \#3). During the first hours of repetitive induction of AF the duration of AF did not change while the fibrillation interval already shortened considerably. It was not until after about 15 hours of maintained AF that also the duration of AF started to change. At the end of the first day of atrial fibrillation the episodes of AF lasted for 1.5 minutes at an average AF interval of $100 \mathrm{~ms}$. The bars in the upper panel represent the 95th percentile of the durations of induced episodes of $\mathrm{AF}$ and in the lower panel they indicate the standard deviation of the average fibrillation interval.

\section{Effects of Fibrillation on Intra-Atrial Conduction}

To test whether the prolongation of AF was caused by disturbances in intra-atrial conduction, the intra-atrial conduction velocity was determined both during sinus rhythm and after 6 and 24 hours and 2-4 days of atrial fibrillation. As soon as an episode of induced atrial fibrillation terminated spontaneously the atria were paced regularly at various pacing rates either from the left or the right atrial appendage and 


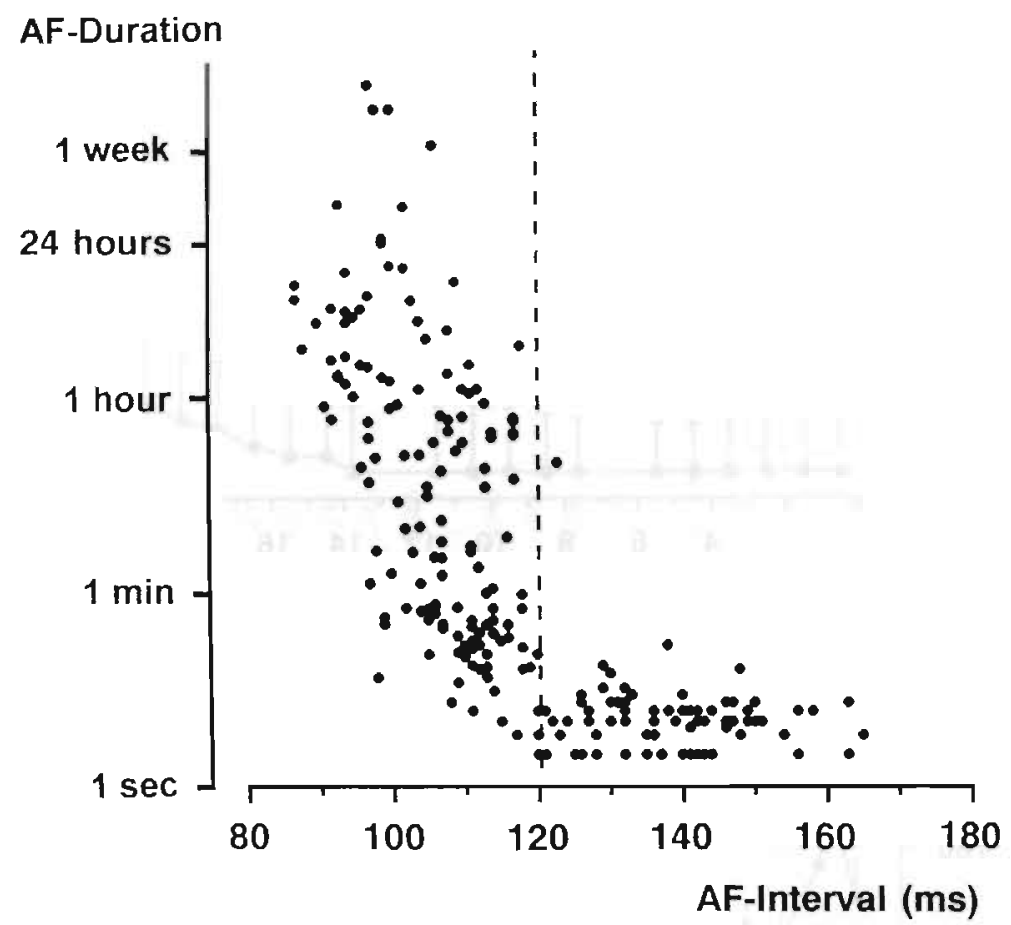

Figure 8. Correlation between AF intervals and the duration of atrial fibrillation. Data are from 6 goats (\#1, \#3, \#4, \#5, \#6 and \#7). The duration of the episodes of electrically induced AF is plotted on a logarhimic scale. At fibrillation intervals longer than $120 \mathrm{~ms}$ there was no comelation with the duration of $\mathrm{AF}$ and atrial fibrillation was usually shortasting. However as soon as the fibrillation interval became shorter than this critical value fvertical dashed line) the duration of AF inereased exponentially.

the conduction times along the row of electrodes sutured on Bachmann's bundle were measured over a distance varying between 2.2 and $7.2 \mathrm{~cm}$. In Fig 9 an example is given (goat \#4). At a pacing interval of $500 \mathrm{~ms}$ the conduction velocity was $143 \mathrm{~cm} / \mathrm{s}$. Pacing at shorter intervals first resulted in a slight slowing of the conduction velocity whereas at pacing intervals of less than $250 \mathrm{~ms}$ conduction velocity was depressed more markedly resulting in a velocity of less than $110 \mathrm{~cm} / \mathrm{s}$ at the maximum pacing rate. During the first days of $\mathrm{AF}$ no depressive effect on the intra-atrial conduction velocity could be found. The slight shift of the velocity curve to the left was due to a shortening of the atrial refractory period (see below). As can be seen from table 2, actually this resulted in an increase in conduction velocity during pacing with short intervals ( 250 and $200 \mathrm{~ms}$ ).

\section{Effects of Fibrillation on the Atrial Refractory Period}

In contrast to the intra-altrial conduction velocity which did not seem to be affected during the first days of atrial fibrillation, marked changes in the atrial refractory period 


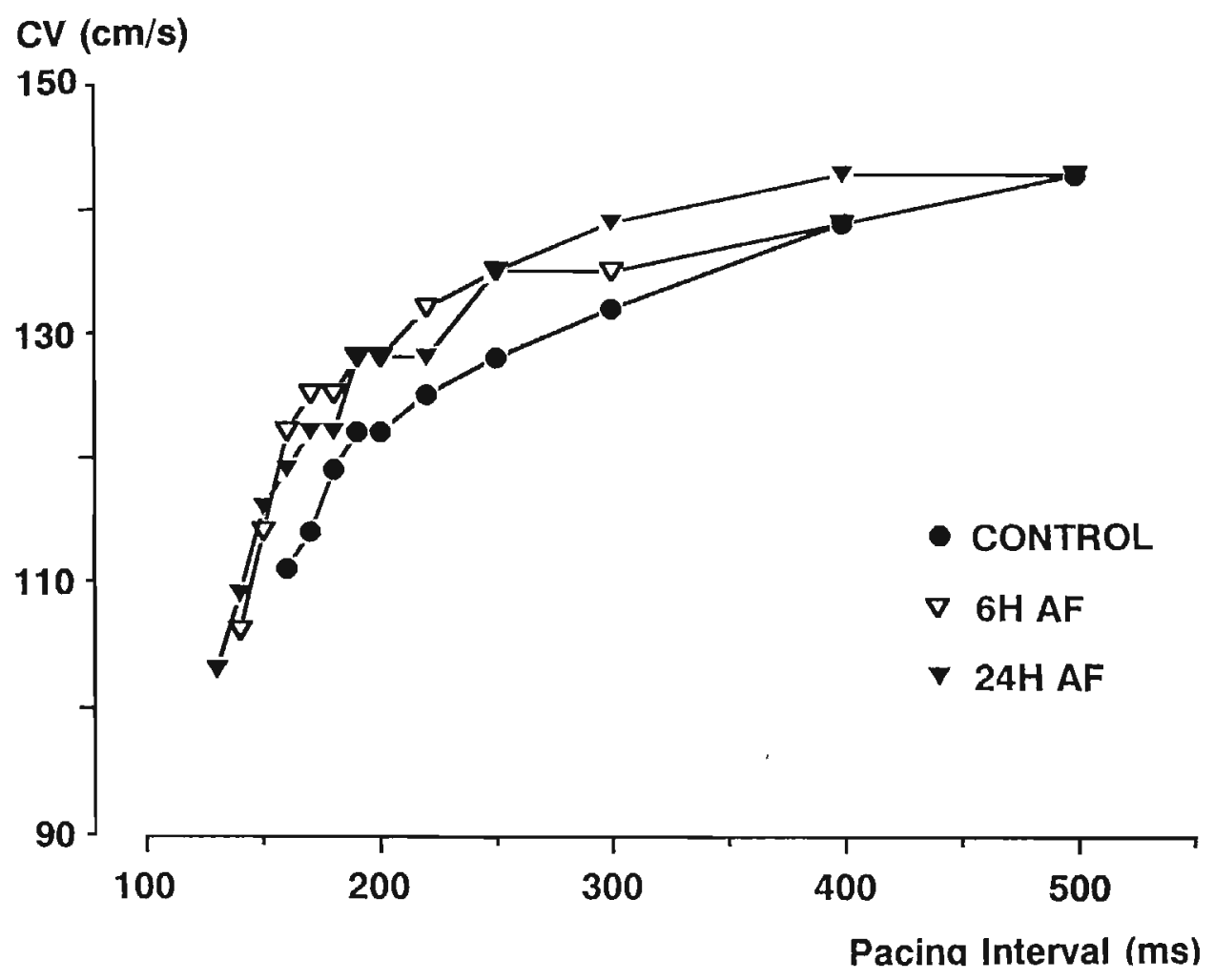

Figure 9. Intra-atrial conduction velocity along the bundle of Bachmann at various pacing intervals during sinus rhythm and after 6 and 24 hours of atrial fibrillation. Intra-atrial conduction was not affected during the first 24 hours of atrial fibrillation. The slight shift of the curve to the left is caused by a shortening of atrial refractoriness (see figure 10 and 11).

occurred within the first 24 hours of AF. Fig 10 gives a representative example. During pacing with a fixed interval of $400 \mathrm{~ms}$, the atrial refractory period was measured by giving an early interpolated stimulus $\left(S_{2}\right)$ after every fifth basic stimulus $\left(S_{1}\right)$. During control (upper two tracings), the shortest $S_{1}-S_{2}$ coupling interval that resulted in an atrial response was $127 \mathrm{~ms}$. Already after 6 hours of AF (middle tracings) the atrial refractory period had shortened considerably and a premature stimulus of $104 \mathrm{~ms}$ elicited a premature beat which started a short run of rapid atrial responses. After 24 hours of AF, the AERP had shortened to $90 \mathrm{~ms}$ and a single early premature beat now induced a short run of AF.

In Fig 11 four examples of the changes in AERP at different pacing intervals are shown (panels A-D). In panel A (goat \#6), due to the physiological rate adaptation of the refractory period, during control the refractory period shortened from $150 \mathrm{~ms}$ during slow pacing to $132 \mathrm{~ms}$ at a pacing interval of $180 \mathrm{~ms}$. Already after 6 hours of fibrillation, the adaptation curve had clearly shifted downwards indicating a general 
IN Table 2. Effects of Atrial Fibrillation on Atrial Conduction Velocity $(\mathrm{cm} / \mathrm{s})$.

Sinus Phythm

Pacing Intervals

Goat

\#

$400250 \quad 200 \quad F \max$

$\begin{array}{llll}150 & 143 & 128 & 111\end{array}$

$\begin{array}{llll}122 & 118 & 107 & 98\end{array}$

$\begin{array}{llll}139 & 128 & 122 & 111\end{array}$

$113 \quad 105 \quad 100 \quad 86$

$\begin{array}{llll}133 & 125 & 113 & 109\end{array}$

$\begin{array}{llll}140 & 129 & 122 & 96\end{array}$

$\begin{array}{llll}129 & 113 & 105 & 69\end{array}$

$\begin{array}{llll}117 & 106 & 106 & 102\end{array}$

$\begin{array}{llll}103 & 102 & 101 & 96\end{array}$

$\begin{array}{llll}120 & 109 & 103 \quad 99\end{array}$

$\begin{array}{llll}122 & 118 & 114 & 105\end{array}$

$\begin{array}{lllll}\text { Mean } & 126 & 118 & 111 & 98\end{array}$

$\begin{array}{lrrrr}\text { Sd } & 13 & 12 & 9 & 12\end{array}$
After 6 Hours of AF

Pacing Interval

$400250200 \quad$ Fmax

- $\quad-\quad-$

- $\quad-\quad$ -

$\begin{array}{llll}139 & 135 & 128 & 106\end{array}$

$\begin{array}{llll}115 & 109 & 106 & 92\end{array}$

$\begin{array}{llll}128 & 122 & 118 & 105\end{array}$

$\begin{array}{llll}140 & 135 & 132 & 108\end{array}$

$\begin{array}{llll}138 & 122 & 116 & 105\end{array}$

$\begin{array}{llll}122 & 119 & 119 & 111\end{array}$

$\begin{array}{lll}105 & 100-\end{array}$

$122 \quad 118-$

$120 \quad 118-$

$125120120^{* *} 105$
After 24. Hours of $A F$

Pacing Intervals

$400 \quad 250 \quad 200 \quad F \max$

$\begin{array}{llll}140 & 136 & 125 & 109\end{array}$

$\begin{array}{llll}128 & 122 & 115 & 102\end{array}$

$\begin{array}{llll}143 & 135 & 128 & 103\end{array}$

$\begin{array}{llll}118 & 115 & 111 & 102\end{array}$

$\begin{array}{llll}133 & 125 & 120 & 109\end{array}$

$\begin{array}{llll}143 & 138 & 135 & 102\end{array}$

$\begin{array}{llll}138 & 129 & 116 & 105\end{array}$

$\begin{array}{llll}124 & 117 & 117 & 108\end{array}$

$\begin{array}{llll}102 & 100 & 97 & 94\end{array}$

$\begin{array}{llll}129 & 123 & 122 & 106\end{array}$

$\begin{array}{llll}122 & 116 & 116 & 114\end{array}$

$\begin{array}{rrrr}129 & 123 & 118^{*} & 105 \\ 12 & 11 & 9 & 5\end{array}$
After 2-4 Days of AF

Pacing Intervals

$400 \quad 250 \quad 200 \quad F \max$

$\begin{array}{llll}133 & 130 & 130 & 113\end{array}$

$\begin{array}{llll}122 & 118 & 113 & 112\end{array}$

$\begin{array}{llll}132 & 128 & 128 & 104\end{array}$

$\begin{array}{llll}122 & 120 & 115 & 112\end{array}$

$\begin{array}{llll}- & - & - & - \\ 138 & 132 & 127 & 108\end{array}$

$\begin{array}{llll}116 & 105 & 100 & 79\end{array}$

- - - -

- $-\quad$ -

$\begin{array}{llll}129 & 124 & 123 & 114\end{array}$

$\begin{array}{llll}124 & 118 & 117 & 117\end{array}$

$\begin{array}{rrrr}127 & 122 & 119 & 107 \\ 7 & 8 & 9 & 11\end{array}$

Numbers indicate conduction velocity along Bachmann's bundle in $\mathrm{cm} / \mathrm{s}$; Fmax, maximal pacing ftequency with 1:1 response. Sd, standard deviation; " $p<0.05$. $" p<0.01$ compared to control (paired Studeni's t-lest: corrected for multiple comparisons). 

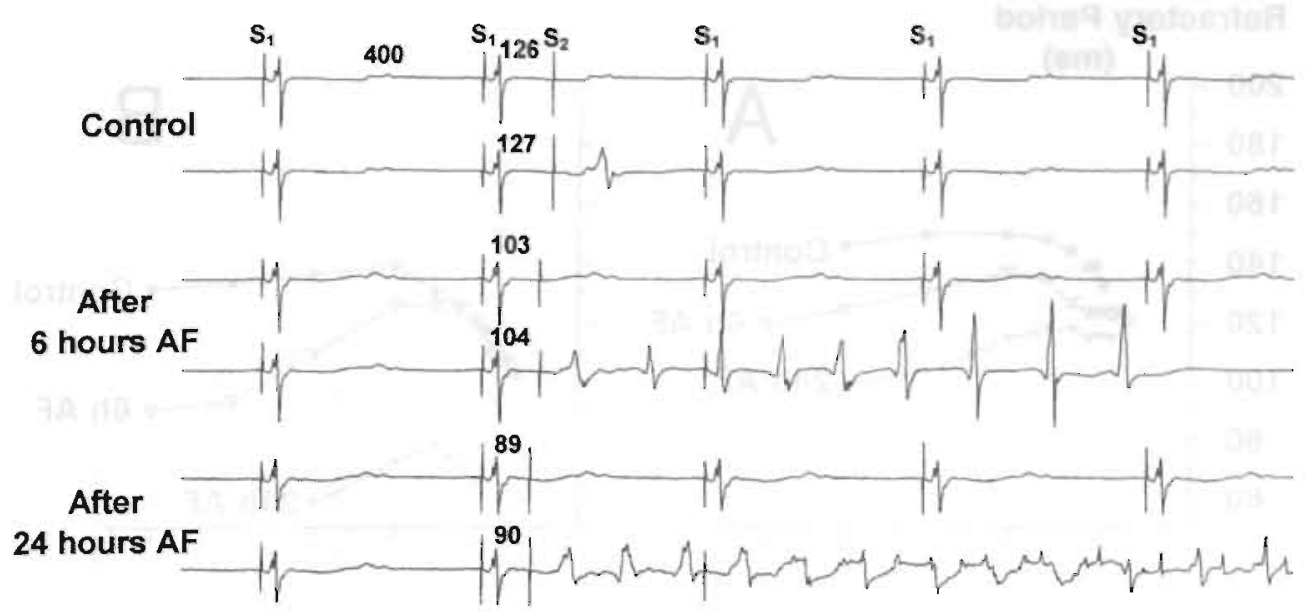

$100 \mathrm{~ms}$

Figure 10. Illustration of the shortening of the atrial effective refractory period during the first 24 hours of electrically maintained atrial fibrillation. The AERP was determined by an interpolated stimulus during pacing at a fixed interval of $400 \mathrm{~ms}$. While during control (upper two tracings) a premature stimulus given after $126 \mathrm{~ms}$ still fell in the refractory period, a stimulus with a coupling interval of $127 \mathrm{~ms}$ evoked a premature atrial response. After 6 hours of AF (middie tracings) the AERP already had decreased to $104 \mathrm{~ms}$. After 24 hours of AF (lower tracings) the AERP had become as short as $90 \mathrm{~ms}$. While during control no arrhythmias were induced by a single premature stimulus, after 6 and 24 hours of AF short runs of atrial fibrillation were induced. $S_{1}$, basic stimulus; $S_{2}$ extra stimulus; $A F$, atrial fibrillation.

shortening of the refractory period. After 24 hours of AF the curve was further shifted downwards and the refractory period at $500 \mathrm{~ms}$ pacing interval had shortened by about $50 \mathrm{~ms}$ to less than $100 \mathrm{~ms}$. At the higher pacing rates the curve had become flat and the normal prolongation of the refractory period upon slowing of the heart rate was abolished. At the slower heart rates (right part of the curve), now the refractory period actually became shorter when the pacing interval was prolonged. In goat \#5 (panel B) after 6 hours of AF only the right part of the curve had shifted downwards and the refractory period during higher pacing rates was not yet changed. However after 24 hours the whole curve was shifted downwards and at all heart rates the refractory period had become shorter than $80 \mathrm{~ms}$. Also in this case the rate adaptation was reversed and the refractory period during slow pacing was shorter than at higher pacing rates. In goats \#4 and \#7 (panel C and D) already during control a slight inversed adaptation of the AERP was present at slow heart rates. Again, atrial fibrillation shortened the refractory period markedly and in these cases the rate adaptation of the refractory was maintained. As a result the AERP was short, both at very short and at long pacing intervals. Whereas in panel $\mathrm{C}$ after 24 hours of AF the refractory period at short and long cycle length was similar (about $110 \mathrm{~ms}$ ), in panel $\mathrm{D}$ the atrial refractory period at slow heart rates was shorter $(94 \mathrm{~ms})$ compared to fast heart rates ( $107 \mathrm{~ms}$ ). In summary, within 24 hours of atrial fibrillation the atrial refractory period 

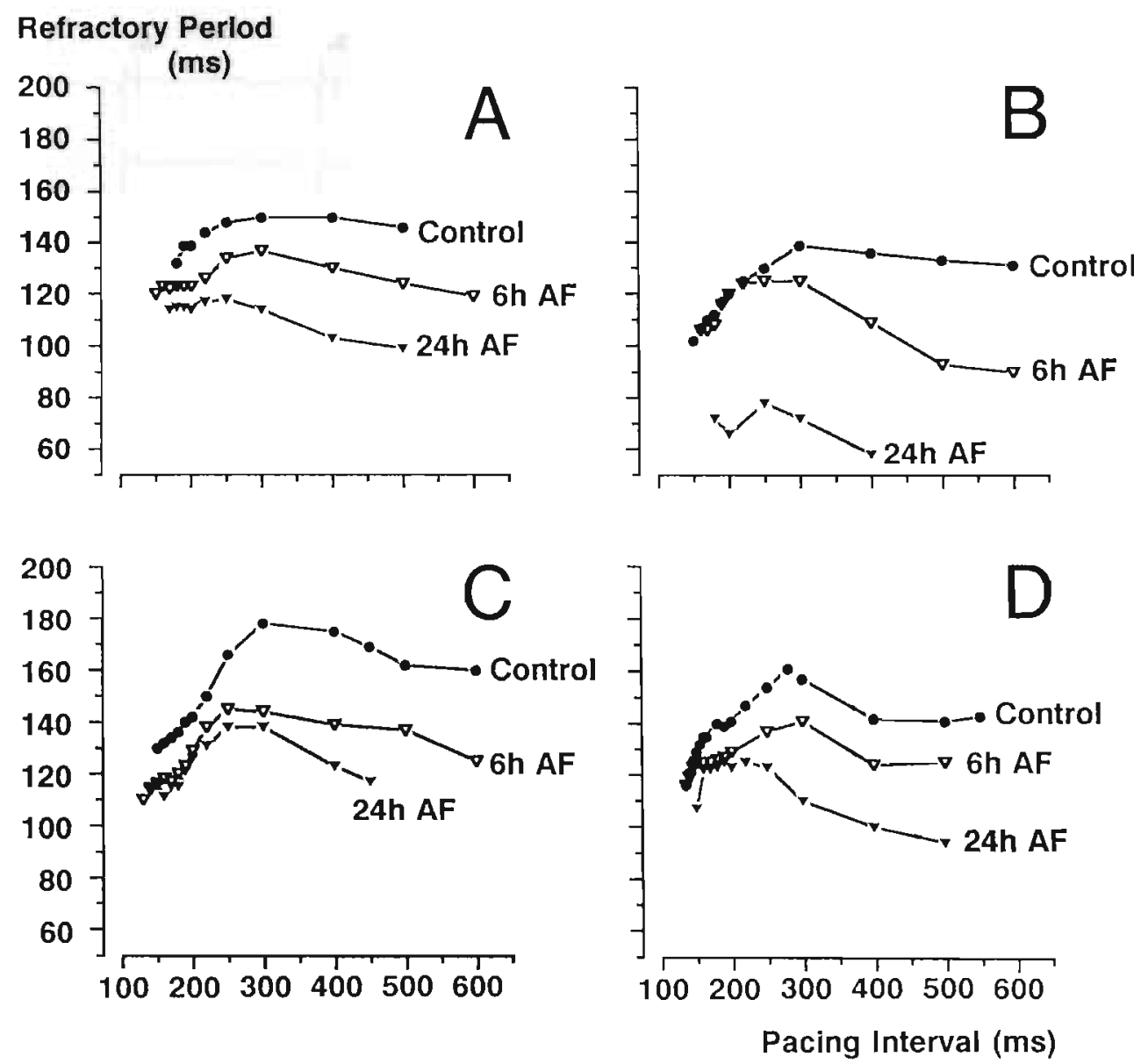

Figure 11. Four examples (panels A-D; goats \#6, \#5, \#4, \#7) of changes in atrial refractoriness in the course of the first 24 hours of fibrillation. In all goats the refractory period shortened markedly at all pacing intervals. In general the amount of shortening was higher at slow heart rates. As a result, the normal physiological rate adaptation of the refractory period was either reversed (panels $A$ and $B$ ) or attenuated (panel D).

became markedly shortened at all heart rates. Because this shortening was more pronounced at slower heart rates the physiological adaptation of the refractory period to changes in heart rate was attenuated or even inversed.

In table 3 the average values of the atrial refractory period at different pacing rates are given for all experiments. Within 24 hours of atrial fibrillation, during pacing at $400 \mathrm{~ms}$ the refractory period shortened from $146 \pm 19 \mathrm{~ms}$ to $95 \pm 20 \mathrm{~ms}(-35 \%)$ $(\mathrm{p}<0.001)$. At a pacing interval of $200 \mathrm{~ms}$ it shortened from $131 \pm 11 \mathrm{~ms}$ to $106 \pm 17$ ms $(-19 \%)(p<0.001)$, whereas during the maximal pacing rate (Fmax) the refractory period changed from $117 \pm 12 \mathrm{~ms}$ to $103 \pm 14 \mathrm{~ms}(-12 \%)(\mathrm{p}<0.01)$. Due to the abnormal (reversed) adaptation of the refractory period to changes in heart rate, after 24 hours of fibrillation the refractory period during slow heart rates actually had 
Table 3. Effects of Atrial Fibrillation on Atrial Effective Refractory Period.

\begin{tabular}{|c|c|c|c|c|c|c|c|c|c|c|c|c|c|c|c|c|}
\hline \multirow{2}{*}{$\begin{array}{l}\text { Goal } \\
\#\end{array}$} & \multicolumn{4}{|c|}{$\begin{array}{l}\text { Sinus Rhythm } \\
\text { Pacing Intervals }\end{array}$} & \multicolumn{4}{|c|}{$\begin{array}{l}\text { After } 6 \text { Hours of AF } \\
\text { Pacing Intervals }\end{array}$} & \multicolumn{4}{|c|}{$\begin{array}{l}\text { After } 24 \text { Hours of AF } \\
\text { Pacing Intervals }\end{array}$} & \multicolumn{4}{|c|}{$\begin{array}{l}\text { After 2-4 Days of AF } \\
\text { Pacing Intervals }\end{array}$} \\
\hline & 400 & 250 & 200 & Fmax & 400 & 250 & 200 & Fmax & 400 & 250 & 200 & Fmax & 400 & 250 & 200 & $F \max$ \\
\hline 2 & 137 & 151 & 135 & 125 & - & - & - & - & 70 & 87 & 89 & 92 & 73 & 82 & 8 & 81 \\
\hline 3 & 135 & 141 & 124 & 115 & 126 & 130 & 124 & 109 & 98 & 104 & 112 & 118 & 71 & 78 & 84 & 87 \\
\hline 4 & 175 & 166 & 142 & 130 & 139 & 145 & 129 & 110 & 123 & 138 & 126 & 115 & 105 & 125 & 124 & 104 \\
\hline 5 & 136 & 130 & 120 & 102 & 109 & 125 & 120 & 106 & 58 & 78 & 66 & 72 & 56 & 59 & 62 & 62 \\
\hline 6 & 150 & 148 & 139 & 132 & 130 & 134 & 123 & 120 & 103 & 118 & 114 & 114 & - & - & - & - \\
\hline 7 & 142 & 154 & 141 & 116 & 124 & 137 & 129 & 116 & 100 & 123 & 123 & 107 & 86 & 101 & 108 & 102 \\
\hline$B$ & 111 & 115 & 109 & 112 & 111 & 113 & 108 & 104 & 89 & 92 & 93 & 99 & 77 & 86 & 76 & 90 \\
\hline 9 & 131 & 153 & 127 & 112 & 116 & 128 & 125 & 109 & 92 & 109 & 109 & 104 & - & - & - & - \\
\hline 10 & 150 & 147 & 133 & 116 & 118 & 120 & - & - & 104 & 112 & 111 & 109 & - & - & - & - \\
\hline 11 & 159 & 139 & 119 & 94 & 109 & 115 & - & - & 84 & 93 & 101 & 87 & 59 & 69 & 78 & 81 \\
\hline 12 & 177 & 155 & 148 & 135 & 150 & 139 & - & - & 129 & 127 & 122 & 114 & 124 & 127 & 117 & 116 \\
\hline Mean & 146 & 145 & 131 & 117 & $123^{* *}$ & $129^{* * *}$ & 123 & 111 & $95^{\prime \prime}$ & $107^{\star \star * *}$ & $106^{* k i}$ & $103^{* *}$ & $81^{\ldots}$ & $91^{\cdots}$ & $91^{* * *}$ & $90^{\prime *}$ \\
\hline Sd & 19 & 13 & 11 & 12 & 13 & 10 & 7 & 5 & 20 & 18 & 17 & 14 & 22 & 23 & 21 & 16 \\
\hline
\end{tabular}

Numbers indicate atrial effective refractony period in ms; Fmax, maximal pacing frequency with $1: 1$ response; Sd, standard deviation; ${ }^{* *} p<0.01,{ }^{* \cdots} p<0.001$ compared to control (paired Student's t-test; corrected for multiple comparisons). 


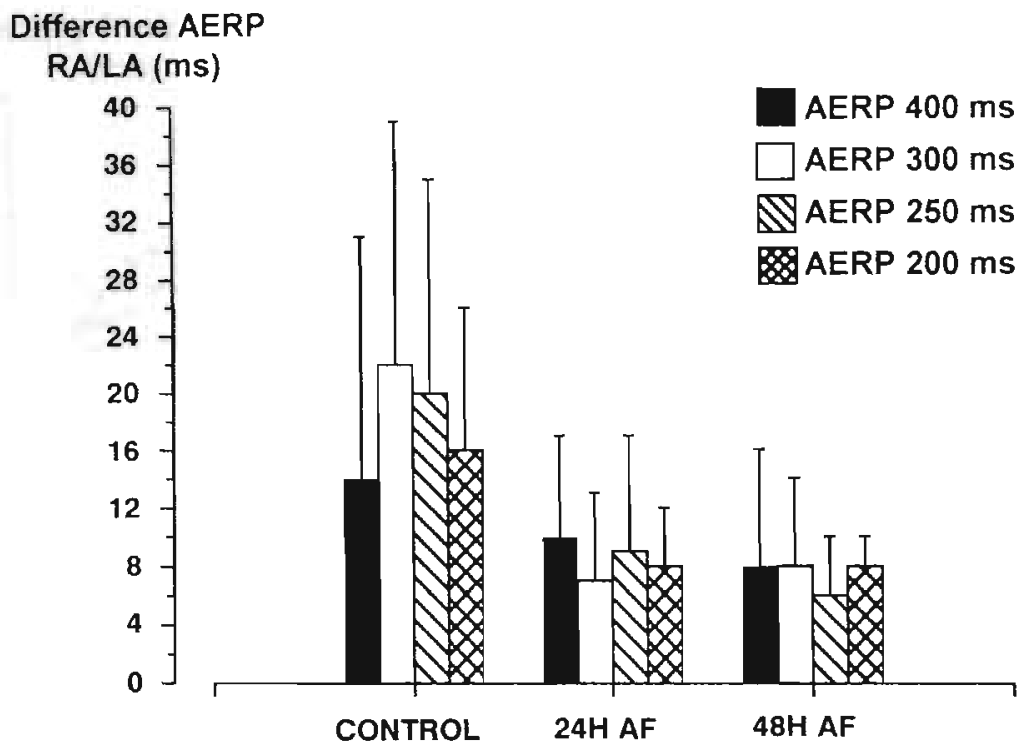

\begin{abstract}
Figure 12. The difference in atrial effective refractory period between the right and left atrial appendage during regular pacing $(400,300,250$ and $200 \mathrm{~ms}$ intervals) during control (sinus hythm) and after 24 and 48 hours of maintained atrial fibrillation. Data are the average values \pm standard deviation as measured in 4 goats. No increase in the dispersion of atrial refractoriness by AF was observed. The slight not statistically significant decrease in dispersion in AERP might be due to a general shortening of the atrial refractory period by AF.
\end{abstract}

become shorter than during the maximum pacing rate $(95 \pm 20$ ms versus $103 \pm 14$ $m s)$. Because the atrial vulnerability to fibrillation progressively increased and also the duration of the induced episodes of AF became longer, after 24 hours of maintained AF in some goats it was no longer possible to measure the adaptation curve of the atrial refractory period. In 8 goats in which the changes in atrial refractoriness could be followed for a longer period of time (2-4 days) the atrial refractory period shortened further to $81 \pm 22$ during slow pacing and $90 \pm 16$ during fast pacing (Fmax)(table 3 ).

\title{
Spatial Dispersion of Atrial Refractoriness
}

To assess whether an increased spatial dispersion in atrial refractoriness may play a role in the increased stability of fibrillation, in four goats the differences in effective refractory period between the right and left atrial appendage was measured during the first two days of AF. In Fig 12 the differences in AERP are given during pacing at various intervals during control (sinus rhythm) and after 24 and 48 hours of AF. During sinus rhythm the average differences between right and left atrial refractory period during pacing with intervals of $400,300,250$ and $200 \mathrm{~ms}$, were $14,22.20$, and $16 \mathrm{~ms}$ respectively. After 48 hours of AF these values were $8,8,6$, and $8 \mathrm{~ms}$. This decrease 

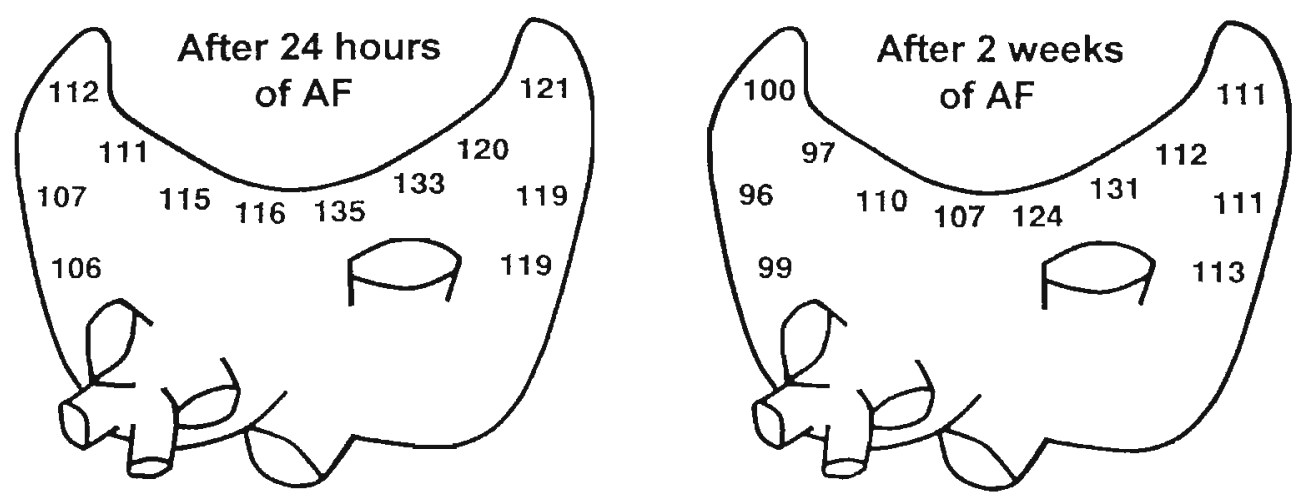

Figure 13. A representative example (goat \#7) of the spatial distribution of local fibrillation intervals after 1 day and 2 weeks of maintained AF. The numbers indicate the median fibrillation interval measured from a 12 seconds sample of $\mathrm{AF}$ at 12 different atrial sites. After 1 day of AF the shortest local median fibrillation interval was $106 \mathrm{~ms}$ (free wall of left atrium) and the longest was $135 \mathrm{~ms}$ (at Bachmann's bundle). After 2 weeks of fibrillation these values were 96 and $131 \mathrm{~ms}$ respectively. The slight increase in the maximal spatial dispersion of the median fibrillation interval from 29 to $35 \mathrm{~ms}$ was not statistically significant (see table 4)

in the spatial difference in atrial refractoriness may be explained by the general shortening of the atrial refractory period during the first 48 hours of $\mathrm{AF}$.

In addition, in six goats the spatial differences in median atrial fibrillation interval at 10-13 atrial sites were measured after respectively 1 and 14 days of maintained AF. An example of the spatial distribution of median AF intervals is given in Fig 13 (goat \# 7). In this case the fibrillation interval was measured at 12 sites located at the right and left atrial free wall, the right and left atrial appendages and the bundle of Bachmann. After 24 hours of AF the largest difference in fibrillation interval was 29 $\mathrm{ms}$. Ait the bundle of Bachmann the median AF interval was $135 \mathrm{~ms}$ compared to 106 $m s$ at the free wall of the left atrium. After 2 weeks of AF the spatial dispersion in AF interval was $35 \mathrm{~ms}$ ( $131 \mathrm{~ms}$ at Bachmann's bundle and $96 \mathrm{~ms}$ at the left atrial free wall). In all 6 goats the longest fibrillation interval was mostly found at Bachmann's bundle. After 24 hours of maintained AF in all 6 goats the shortest fibrillation interval was found in the left atrium. Differences in fibrillation intervals between the left and the right atrium varied between 4 and $24 \mathrm{~ms}$. After 2 weeks of AF still in 4 of 6 goats the shortest AF interval was found in the left atrium (differences between right and left atrium 11-15 ms). In the other 2 goats AF intervals were similar in both atria. In table 4 the data of all goats are listed. No statistically significant differences in spatial distribution of the median fibrillation intervals were found between 24 hours and 2 weeks of atrial fibrillation. Thus, the measurements of spatial differences in refractory period as well as the spatial distribution of median AF intervals, do not support the hypothesis that the increase in stability of $\mathrm{AF}$ is due to an increased spatial dispersion in atrial refractoriness. 
Table 4. Effects of Maintained AF on the Spatial Dispersion of AF-Intervals

\begin{tabular}{|c|c|c|c|c|c|c|}
\hline \multirow[b]{2}{*}{ Goat \# } & \multicolumn{3}{|c|}{ After 24 hours of AF } & \multicolumn{3}{|c|}{ After 2 weeks of AF } \\
\hline & $\begin{array}{l}\text { Mean of } \\
\mathrm{P}_{50}\end{array}$ & $\begin{array}{l}\text { Spatial } \\
\text { Dispersion }\end{array}$ & $\begin{array}{l}\text { Range of } \\
P_{50}\end{array}$ & $\begin{array}{l}\text { Mean of } \\
\mathrm{P}_{50}\end{array}$ & $\begin{array}{l}\text { Spatial } \\
\text { Dispersion }\end{array}$ & $\begin{array}{l}\text { Range of } \\
P_{50}\end{array}$ \\
\hline 2 & 113 & 13 & $107-120$ & 113 & 24 & $101-125$ \\
\hline 3 & 112 & 29 & $96-125$ & 101 & 30 & $88-118$ \\
\hline 4 & 116 & 16 & $107-123$ & 96 & 17 & $86-103$ \\
\hline 5 & 112 & 23 & $103-126$ & 114 & 28 & $106-134$ \\
\hline 6 & 116 & 25 & $104-129$ & 109 & 20 & $100-120$ \\
\hline 7 & 118 & 29 & $106-135$ & 109 & 35 & $96-131$ \\
\hline Mean & 114 & 23 & $104-126$ & 107 & 26 & $96-122$ \\
\hline $\mathrm{Sd}$ & 2 & 6 & & 7 & 6 & \\
\hline
\end{tabular}

Mean of $P_{50}$, average median fibrillation interval measured at 10-13 different sites during 12 seconds of AF. Spatial dispersion, difference between the site with the shortest and the longest median fibrillation interval. Range of $P_{50}$, the values of the shortest and longest local median fibrillation interval. No significant changes between control and 24 hours were found (paired Student's test).

Inducibility of Atrial Fibrillation

The inducibility of atrial fibrillation by single premature stimuli was tested in 11 goats at a total of 17 pacing sites (1-2 sites in each goat). During control, at 4 of 17 sites (24\%) (in 3 of 11 goats) the application of a single early premature stimulus induced short paroxysms of atrial fibrillation. After 24 hours of maintained AF, single premature stimuli produced atrial fibrillation at 13 of 17 sites $(76 \% ; \mathrm{p}<0.01)$ (9 of 11 goats) (table 5). Thus already after 24 hours of AF the vulnerability of the atria to fibrillation was clearly increased.

After a total period of $19 \pm 5$ days of maintained AF, in 5 goats the inducibility of AF was tested again after conversion to sinus rhythm. 6 Hours after conversion the inducibility of AF was still very high (100\%). However after 24 hours the vulnerability to AF had already clearly decreased (43\%), whereas after 1 week of sinus rhythm the inducibility of AF was comparable to control (29\%).

Reversibility of Fibrillation-Induced Electrophysiological Changes

In 5 goats in which atrial fibrillation was maintained for 2-4 weeks the reversibility of the electrophysiological changes by atrial fibrillation was studied. In 4 goats sinus rhythm restored spontaneously, whereas in 1 goat (goat \#6) AF was terminated by intravenous infusion of Cibenzoline (Cipralan ${ }^{\circledR} 1.5 \mathrm{mg} / \mathrm{kg}$ ). In table 6 the duration and interval of the paroxysms of electrically induced atrial fibrillation are given together with the intra-atrial conduction velocity and refractory period as measured 
Table 5. Inducibility of Atrial Fibrillation by a Single Early Premature Stimulus,

\begin{tabular}{|c|c|c|c|c|c|c|c|}
\hline Goat \# & $\begin{array}{l}\text { Pacing } \\
\text { Site }\end{array}$ & $\begin{array}{l}\text { Sinus } \\
\text { Rhythm }\end{array}$ & $\begin{array}{l}\text { After } \\
24 \text { Hours } \\
\text { of AF }\end{array}$ & $\begin{array}{l}\text { Duration } \\
\text { of AF } \\
\text { (Days) }\end{array}$ & $\begin{array}{l}6 \text { Hours } \\
\text { After } \\
\text { Conversion }\end{array}$ & $\begin{array}{l}24 \text { Hours } \\
\text { After } \\
\text { Conversion }\end{array}$ & $\begin{array}{l}1 \text { Week } \\
\text { After } \\
\text { Conversion }\end{array}$ \\
\hline \multirow[t]{2}{*}{2} & RA & - & + & 18 & + & + & - \\
\hline & $\llcorner A$ & - & + & & & - & - \\
\hline 3 & LA & - & + & 14 & $*$ & - & - \\
\hline \multirow[t]{2}{*}{4} & RA & - & - & 20 & + & - & - \\
\hline & $L A$ & - & - & & + & - & - \\
\hline \multirow[t]{2}{*}{5} & RA & + & + & 14 & + & & \\
\hline & $L A$ & + & + & & + & & \\
\hline \multirow[t]{2}{*}{6} & RA & - & - & 27 & & + & + \\
\hline & $L A$ & - & + & & + & + & + \\
\hline \multirow[t]{2}{*}{7} & RA & + & + & & & & \\
\hline & LA & - & - & & & & \\
\hline \multirow[t]{2}{*}{8} & RA & - & + & & & & \\
\hline & $L A$ & + & + & & & & \\
\hline 9 & LA & - & + & & & & \\
\hline 10 & LA & - & + & & : & & \\
\hline 11 & RA & - & + & & & & \\
\hline 12 & RA & - & - & & & & \\
\hline \# Goats & & $3 / 11(27 \%)$ & $9 / 11(81 \%)^{\S}$ & & $5 / 5(100 \%)$ & $2 / 4(50 \%)$ & $1 / 4(25 \%)$ \\
\hline$\#$ Sites & & $4 / 17(24 \%)$ & $13 / 17(76 \%)^{\xi \S}$ & & $7 n(100 \%)$ & $3 / 7(43 \%)$ & $277(29 \%)$ \\
\hline
\end{tabular}

$\mathrm{AA}$, right atrium; $\mathrm{LA}$, left atrium. AF was induced by a single premature stimulus during pacing at $400 \mathrm{~ms}$; Atter 14-2.7 days, of $\mathrm{AF}$; in 4 goats sinus rhythm was restored spontaneously, in 1 goat ( $/ \overline{6} 6)$ AF was converted by infusion of Cibenzoline; ${ }^{5} p<0.05,{ }^{55} p<0.01$ sinus inythm compared to 24 hours of atrial fibrillation (Wilcoxon matched pairs signed ranks test).

during control (before AF was chronically maintained) and 6 hours, 24 hours, 1 week and 2 weeks after conversion of AF to sinus rhythm.

6 Hours after conversion to sinus rhythm the median duration of electrically induced paroxysms of atrial fibrillation was already back to normal and lasted only 7 $\pm 2 \mathrm{sec}$. Also the atrial fibrillation interval was significantly prolonged from $105 \pm 10$ to $139 \pm 7 \mathrm{~ms}$. However in all goats some of the induced episodes of AF were still long-lasting (the 95th percentile of AF duration was 49.1 minutes compared to 13 seconds during control). In 2 goats an episode of AF was induced still lasting longer than 1 and 6 hours respectively. After 24 hours of sinus rhythm only short-lasting episodes of AF could be induced, terminating spontaneously within $6 \pm 4$ seconds. After 24 hours also the fibrillation interval was normalized to $151 \pm 25 \mathrm{~ms}$.

6 Hours after restoration of sinus rhythm, the AERP400 and the AERP200 were still shorter than during control, the atrial refractory period still showing a clear reversed adaptation to heart rate. 24 Hours after conversion the AERP200 had returned to control values, but at slower pacing rates (AERP400) the refractory period was still 
8 Table 6. Reversibility of Fibrillation-Induced Changes.

Control (Sinus Rhythm)

\begin{tabular}{|c|c|c|c|c|c|c|c|c|c|}
\hline \multirow{3}{*}{$\begin{array}{l}\text { Goat } \\
\#\end{array}$} & \multirow{3}{*}{$\begin{array}{l}\text { Duration } \\
\text { of } \mathrm{AF} \\
\text { (sec) }\end{array}$} & \multirow{3}{*}{$\begin{array}{l}\text { Interval } \\
\text { of AF } \\
\text { (ms) }\end{array}$} & \multirow{3}{*}{$\begin{array}{l}\text { AERP } \\
400 \\
(\mathrm{~ms})\end{array}$} & \multirow{3}{*}{$\begin{array}{l}\text { AERP } \\
200 \\
\text { (ms) }\end{array}$} & \multirow{3}{*}{$\begin{array}{l}C V \\
400 \\
(\mathrm{~cm} / \mathrm{s})\end{array}$} & \multirow{3}{*}{$\begin{array}{l}\mathrm{CV} \\
200 \\
(\mathrm{~cm} / \mathrm{s})\end{array}$} & \multirow{3}{*}{$\begin{array}{l}\text { Duration } \\
\text { of } \mathrm{AF} \\
\text { (sec) }\end{array}$} & \multirow{3}{*}{$\begin{array}{l}\text { Interval } \\
\text { of AF } \\
\text { (ms) }\end{array}$} & \multirow{3}{*}{$\begin{array}{l}\text { AERP } \\
400 \\
\text { (ms) }\end{array}$} \\
\hline & & & & & & & & & \\
\hline & & & & & & & & & \\
\hline 2 & 5 & 139 & 137 & 135 & 150 & 128 & 6 & 170 & 123 \\
\hline 3 & 4 & 164 & 135 & 124 & 122 & 107 & 4 & 181 & 104 \\
\hline 4 & 3 & 142 & 175 & 142 & 139 & 122 & 12 & 124 & 125 \\
\hline 5 & 5 & 150 & 136 & 120 & 113 & 100 & - & - & - \\
\hline 6 & 4 & 157 & 150 & 139 & 133 & 113 & 2 & 130 & 116 \\
\hline Mean & 4 & 150 & 147 & 132 & 131 & 114 & 6 & 151 & 117 \\
\hline \multirow[t]{2}{*}{ Sd } & 1 & 9 & 15 & 9 & 13 & 10 & 4 & 25 & 8 \\
\hline & \multicolumn{3}{|l|}{ Chronic AF } & \multicolumn{6}{|c|}{24 hours after Conversion to Sinus Rhythm } \\
\hline Goat & Total & Last & Interval & Duration & Interval & AERP & AERP & $\mathrm{CV}$ & $\mathrm{CV}$ \\
\hline$\#$ & Duration & Episode & of $\mathrm{AF}$ & of $\mathrm{AF}$ & of $\mathrm{AF}$ & 400 & 200 & 400 & 200 \\
\hline & (days) & (hours) & (ms) & (sec) & $(\mathrm{ms})$ & (ms) & (ms) & $(\mathrm{cm} / \mathrm{s})$ & $(\mathrm{cm} / \mathrm{s})$ \\
\hline 2 & 18 & 40 & 114 & 6 & 177 & 130 & 129 & 125 & 111 \\
\hline 3 & 14 & 36 & 89 & 5 & 174 & 150 & 126 & 107 & 98 \\
\hline 4 & 20 & 2 & 98 & 4 & 147 & 177 & 127 & 122 & 115 \\
\hline 5 & 14 & 195 & 113 & - & - & - & - & - & - \\
\hline 6 & 27 & 411 & 111 & 2 & 155 & 130 & $\uparrow 17$ & 113 & 100 \\
\hline Mean & 19 & 137 & $105^{\circ}$ & 4 & 163 & 147 & 125 & $117^{\circ}$ & 106 \\
\hline Sd & 5 & 152 & 10 & 2 & 13 & 19 & 5 & 7 & 7 \\
\hline
\end{tabular}


Table 6. Reversibility of Fibrillation-Induced Changes (Continued).

6 Hours After Conversion to Sinus Rhythm

$\begin{array}{lllllll}\text { Goal } & \text { Duration } & \text { Interval } & \text { AERP } & \text { AERP } & \text { CV } & \text { CV } \\ \# & \text { of AF } & \text { of AF } & 400 & 200 & 400 & 200 \\ & (\mathrm{sec}) & (\mathrm{ms}) & (\mathrm{ms}) & (\mathrm{ms}) & (\mathrm{cm} / \mathrm{s}) & (\mathrm{cm} / \mathrm{s})\end{array}$

$\begin{array}{rrrrrrrr}2 & 10 & 153 & 87 & 106 & - & - & - \\ 3 & 5 & 131 & 80 & 98 & 118 & 105 & 5 \\ 4 & 5 & 140 & 82 & 103 & 122 & 116 & 2 \\ 5 & 6 & 136 & 68 & 94 & 112 & 106 & - \\ 6 & 8 & 137 & 98 & 103 & - & - & 2\end{array}$

$\begin{array}{lrrrrrrr}\text { Mean } & 7 & 139 & 83^{* \prime} & 101^{n *} & 117 & 109 & 3 \\ \text { Sd } & 2 & 7 & 10 & 4 & 4 & 5 & 1\end{array}$

Sd 2

$7 \quad 10$
4

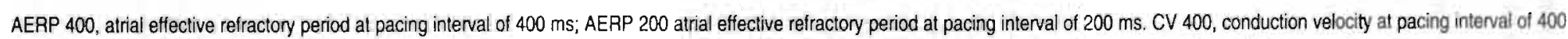
ms; CV 200. conduction velocity at pacing interval of $200 \mathrm{~ms}$; " $p<0.05, " * p<0.01, " * * 0<0.001$ compared to control (paired Student's t-test; corrected for multiple comparisons).

2 Weeks After Conversion to Sinus Rhythm

\begin{tabular}{llllll}
\hline Duration & Interval & AERP & AERP & CV & CV \\
of AF & of AF & 400 & 200 & 400 & 200 \\
$(\mathrm{sec})$ & $(\mathrm{ms})$ & $(\mathrm{ms})$ & $(\mathrm{ms})$ & $(\mathrm{cm} / \mathrm{s})$ & $(\mathrm{cm} / \mathrm{s})$
\end{tabular}

$\begin{array}{rrrrr}- & - & - & - & - \\ 151 & 146 & 131 & 109 & 102 \\ 148 & 157 & 126 & 125 & 114 \\ - & - & - & - & - \\ 154 & 130 & 118 & 113 & 102 \\ 151 & 144 & 125 & 116 & 106 \\ 2 & 11 & 5 & 7 & 6\end{array}$


shortened. After 1 week of sinus rhythm the rate adaptation of the atrial refractory period was full normalized and also at slow heart rates the refractory period was normal again.

After conversion of AF to sinus rhythm the conduction velocity along Bachmann's bundle remained slightly slower than it was before chronic atrial fibrillation.

Although from these observations no exact time constant for the reversibility of the various electrophysiological changes can be derived, they show that after cardioversion of $\mathrm{AF}$, all electrophysiological changes induced by atrial fibrillation are completely reversible within a few days.

\section{Discussion}

\section{Mechanisms of Chronic Atrial Fibrillation}

Burst pacing between two closely spaced atrial electrodes induces atrial fibrillation which in normal goats terminates spontaneously within a few seconds. In this study we showed that, when atrial fibrillation is maintained artificially, the duration of these paroxysms progressively increases, until after 1-3 weeks atrial fibrillation becomes sustained. Around 1960 Moe and coworkers ${ }^{24-26}$ introduced the multiple wavelet hypothesis, postulating that the persistence of atrial fibrillation depends on the average number of wavelets being present in the atria. If the number of wavelets is high, the statistical probability that they will all extinguish at the same time will be small and atrial fibrillation will persist. On the other hand, when only a small number of wavelets is present, the chance that they will die out simultaneously is higher and atrial fibrillation will self-terminate. In 1985, Moe's multiple wavelet hypothesis was experimentally confirmed by mapping of the atrial activation pattern of atrial fibrillation in isolated canine hearts and the critical number of wavelets required to sustain $\mathrm{AF}$ was estimated to be between four and six. ${ }^{27}$ More recently high density mapping has been applied clinically and the presence of random reentry ${ }^{28}$ of multiple wandering wavelets during electrically induced AF could also be demonstrated in man. ${ }^{22,29}$

The number of wavelets that can coexist in the atria is determined both by the atrial tissue mass (or surface area), and the wavelength of the atrial impulse ${ }^{30.31}$ It is well known that in larger hearts atrial fibrillation is more stable and of longer duration, ${ }^{32}$ and that in humans atrial dilatation is an important risk factor for atrial fibrillation. ${ }^{33}$ This can be easily understood by realizing that the number of circuits in the atria increases with the square of the atrial diameter and that in larger mammals the wavelength of the atrial impulse does not increase proportionally to the size of the atria. ${ }^{34}$ The well known profibrillatory effects of vagal stimulation, acetylcholine and adenosine are generally ascribed to a shortening of the atrial action potential without a noticeable effect on conduction velocity. Since the wavelength of atrial refractoriness is the product of conduction velocity and refractory period, the wavelength will become considerably shorter, thus allowing more wavelets to co-exist in a given tissue 
mass. On the other hand drugs that prolong the wavelength of the atrial impulse have been shown to prevent or terminate atrial fibrillation. $31,35,36$ In patients with atrial fibrillation the wavelength may be shortened, at least locally, by the existence of intra-atrial conduction defects. Several clinical studies have indicated that long or biphasic $\mathrm{P}$-waves, late potentials, fragmented atrial electrograms, or increased conduction delays of premature beats are all associated with a higher vulnerability to atrial fibrillation. ${ }^{37-46}$ In addition to this pathophysiologic triad of chronic fibrillation (atrial dilatation, shortened refractoriness and depressed conduction), also increased heterogeneity, either in intra-atrial conduction (enhanced nonuniform anisotropy, ${ }^{47,48}$ locally depressed action potentials ${ }^{49-51}$ ), or in recovery of excitability (increased spatial dispersion in atrial refractory periods) $)^{52-55}$ may be of crucial importance.

\section{Shortening of Atrial Refractoriness by Atrial Fibrillation}

In the present study we found no changes in atrial conduction velocity during the first days of atrial fibrillation. In contrast marked changes were observed in the atrial refractory period which, during the first 24 hours of fibrillation, depending on the pacing rate, shortened by as much as $12 \%-35 \%$. Since the conduction velocity was not affected, the wavelength of the atrial impulse must have been shortened by a similar amount. This progressive shortening of the wavelength by atrial fibrillation provides a good explanation for the observed stabilization of AF with time (domestication of AF). Previous studies have shown that a high correlation exists between the refractory period as measured by programmed electrical stimulation and the average cycle length during fibrillation, suggesting that the local fibrillation interval might be used as an index of local refractoriness. ${ }^{53,56,57}$ The advantage of such an index of local refractoriness is that one can follow the time course of changes in refractory periods during fibrillation without the need for extensive pacing protocols, which are not only time limited but may also disturb the experimental conditions. The relationship between the atrial refractory period and the local fibrillation interval was confirmed in our present study by the observation that the progressive shortening of the fibrillation interval during the development of chronic fibrillation was associated with a concomitant shortening of the atrial refractory period as measured by programmed electrical stimulation. However we want to emphasize that this does not mean that the median fibrillation interval is equal to the local refractory period. On the contrary we believe that during AF the refractory period is somewhat shorter than the median fibrillation interval and that a small partially excitable gap exists during atrial fibrillation. ${ }^{58.59}$ Nevertheless, with these limitations in mind, in our opinion the median fibrillation interval can be used to estimate changes in atrial refractory period by atrial fibrillation. During the first 24 hours of atrial fibrillation the median cycle length of AF progressively shortened with a time course of about $2 \mathrm{~ms}$ per hour. During the following days this shortening of the atrial "refractory period" continued at a much slower rate of only a few milliseconds per day. A steady state in atrial fibrillation interval was reached after about 6 days of AF. 


\section{Correlation Between Atrial Fibrillation Cycle Length and Stability of AF}

Immediately after the fibrillation pacemaker was turned on and atrial fibrillation was maintained artificially, the refractory period of the atria slowly started to shorten. Initially, this did not increase the stability of fibrillation and the episodes of induced $\mathrm{AF}$ remained short and self-terminating. The atrial refractory period had to be shortened to a certain critical value before atrial fibrillation got more stable and the paroxysms of AF started to last for a longer period of time. On the average, atrial fibrillation started to last longer after the median fibrillation interval had shortened to about $120 \mathrm{~ms}$. The median fibrillation interval continued to shorten up to $99 \pm 10 \mathrm{~ms}$ during sustained atrial fibrillation (see table 1 and Fig 8). At this point we can only estimate the critical changes in wavelength associated with (or as we think partly responsible for) the development of chronic AF. If we assume that the atrial refractory period is $10 \%$ shorter than the median fibrillation interval, and if we take an average conduction velocity of $61 \mathrm{~cm} / \mathrm{s}$ as recently measured during type $\mathrm{IAF}^{22}$ the wavelength during the short episodes of acute AF would be in the order of $8-9 \mathrm{~cm}$. The critical wavelength at which AF starts to prolong would then be around 6-7 cm, whereas during chronic atrial fibrillation the wavelength should be $5-6 \mathrm{~cm}$. However when atrial conduction during chronic atrial fibrillation in reality is slower than 61 $\mathrm{cm} / \mathrm{s}$, the wavelength actually might be smaller. At a conduction velocity of $50 \mathrm{~cm} / \mathrm{s}$ the wavelength during sustained $A F$ would be $4-5 \mathrm{~cm}$, whereas at $40 \mathrm{~cm} / \mathrm{s}$ the multiple wavelets would be as short as $3-4 \mathrm{~cm}$. At such short wavelengths the diameter of intra-atrial reentrant circuits could be as small as $1 \mathrm{~cm}$.

There is reason to believe that besides the shortening of refractoriness also other factors may play a role in the development of chronic fibrillation. This is supported by the observation that the time course of changes in atrial refractoriness does not completely run parallel with the time course of development of sustained fibrillation. Whereas the median fibrillation interval usually already reached a steady state within a couple of days, it often took an additional 1-2 weeks for atrial fibrillation to become persistent. Possible candidates of additional changes in the atria requiring a longer time period to develop, might be atrial dilatation, 60 a general depression of atrial conduction velocity, or the development of local areas of structural intra-atrial conduction block. ${ }^{37}$

\section{Maladaptation of the atrial refractory period}

In 1982 Attuel et al. 1,62 measured the atrial refractory period in 39 patients during pacing at three or more basic cycle lengths. They found that in patients in which sustained alrial tachyarrhythmias could be provoked with 1-3 premature stimuli, the atrial refractory period either failed to adapt or adapted poorly to changes in heart rate. ( nn the basis of these observations they suggested that a poor or absent rate adaptation of the atrial refractory period may constitute a clinical entity and might be a marker of atrial pathology causing a propensity to atrial fibrillation. These observations were 
extended by Le Heuzey et al. who measured the effects of changes in heart rate on the duration of the action potential recorded from isolated strips of human atrial myocardium. ${ }^{54,55}$ From these studies it was suggested that a maladaptation of refractoriness might be the cause of atrial fibrillation in man. In our present study we made a similar observation that maintenance of AF was associated with maladaptation of the atrial refractory period to changes in heart rate. While normal goats in sinus rhythm showed a clear shortening of the atrial refractory period at shorter pacing intervals, goats which had been artificially kept in atrial fibrillation, after one or more days lost this physiological adaptation and showed either a constant duration of the refractory period at different pacing rates or an inverse adaptation curve, i.e. instead of lengthening, the atrial refractory period actually now shortened at slower heart rates. After cardioversion to sinus rhythm the normal adaptation to changes in heart rate was restored within a couple of days. From these experiments thus it seems that the maladaptation of the atrial refractory period rather is the result of atrial fibrillation than the cause of it. However it can not be excluded that the changes in rate adaptation of the refractory period is one of the factors that cause atrial fibrillation to become sustained.

\section{What Causes the Shortening of the Refractory Period During AF?}

The mechanisms of the shortening of atrial refractoriness by AF are as yet unclear and require further study. Possible causes are: 1) Long term changes in activity or sensitivity of the autonomic nervous system, 2) Stretch of the atrial wall due to the increased intra-atrial pressure, 3) Ischemia of the atrial myocardium, 4) An increase in plasma atrial natriuretic factor (ANF) levels and 5) The high rate of electrical activation of the atrial cells per se.

Several studies have emphasized the importance of the autonomic nervous system for the initiation and perpetuation of atrial fibrillation. Coumel et al. ${ }^{63}$ have described two different subgroups of patients with atrial fibrillation. In one group the initiation of atrial fibrillation was dependent on a high vagal tone, whereas in another group the occurrence of atrial fibrillation seemed to be related to adrenergic stimulation of the heart. ${ }^{6+}$ Indeed it is well known that a high vagal tone or the administration of acetylcholine is profibrillatory because it shortens the atrial action potentials and the wavelength ${ }^{31}$ due to activation of the $\mathrm{I}^{\text {KAch }}$ channel.

There is disagreement in the literature about the effect of stretch on the refractory period, some studies reporting a shortening whereas others have found no change or even a lengthening of the refractory period. ${ }^{65-70}$ So far, nobody has measured the effect of prolonged changes in atrial wall stress on atrial refractoriness. Therefore, although a greater than twofold acute increase in atrial pressure was found to have no effect on the human atrial refractory period, it remains to be seen whether a chronic increase in atrial pressure above a certain value does exert important electrophysiological changes. ${ }^{70}$

When the atria become ischemic, activation of ATP-regulated potassium channels may result in a shortening of the atrial action potential. In 1982 White et al. ${ }^{71}$ showed 
that immediately after induction of AF both atrial perfusion and oxygen consumption rise sharply. The oxygen consumption increased more than 3 -fold while the blood supply increased with a factor of 2-3, actually resulting in a higher flow per gram in the fibrillating atria than in the pumping left ventricle. Since the reactive hyperemia response was significantly attenuated and in some dogs nearly abolished, the flow reserve during atrial fibrillation is clearly decreased. A further increase in atrial metabolism, for instance by adrenergic stimulation, could lead to a further increase in oxygen demand which now can no longer be met by the already maximally dilated coronary arteries. Whether AF actually causes atrial ischemia is at present unknown.

The increase in the production of ANF by the atrial cells when the atria are thrown into fibrillation is well documented. ${ }^{72}$ Recently, Stambler et al. have demonstrated that the infusion of ANF in dogs may give rise to a shortening of the AERP and the monophasic action potential. ${ }^{73}$ If in the goat the plasma concentration of ANF increases by atrial fibrillation and if the ANF levels become high enough to shorten the AERP, this mechanism might be involved in the process of domestication of AF. The fifth most intriguing possibility that the shortening of atrial refractoriness is mediated by the high rate of depolarization itself will be discussed below.

\section{T Wave 'Memory'}

In 1982 Rosenbaum et al. described that rapid atrial or ventricular pacing in humans could induce $T$ wave changes which developed to a maximum in about 24 hours of pacing. Because repeated rapid pacing caused the repolarization changes to appear after a shorter period of time, they concluded that "the myocardial cells involved in this process seem to keep a 'memory' of the previous effect...". 74 As reviewed by Katz ${ }^{75}$ primary repolarization abnormalities can be caused by three fundamentally different causal mechanisms taking place at different levels in the heart: altered structure (organ), altered metabolism (cell), or altered ion channels (genes). A distinction between these three different mechanisms can be made on the basis of the time course and reversibility of the changes. While structural changes are generally irreversible and may take weeks or even years to develop, metabolic changes occur virtually instantaneously and are rapidly reversible. It has been postulated that the changes in repolarization referred to as cardiac 'memory', which develop more slowly and persist longer than the transient changes mediated by changes in cellular metabolism but are still reversible and not associated with obvious organ damage, "arises from molecular replacements involving the channel proteins of the heart's plasma membrane". ${ }^{75}$ Similarly to the posttachycardia $T$ wave changes, the shortening in atrial refractory period by atrial fibrillation might be based on alterations in synthesis and assembly of the potassium channels that control atrial repolarization. As shown by Agnew $^{76}$ and Aldrich ${ }^{77}$ cells posses the ability to synthesize a rich variety of potassium channels by "mixing and matching" different subunits which can be expressed by a large family of genes. Recent studies of Rosen et al. ${ }^{78,79}$ have demonstrated that in the ventricles cardiac memory was abolished by 4-aminopyrid- 
ine, which blocks both the transient outward potassium current $\left(\mathrm{I}^{\mathrm{to}}\right)$ as well as $\mathrm{I}^{\mathrm{K}}$. In nerve cells the mechanism of memory has been shown to be caused by second messager activation of protein kinases which modify ion channel functions of the cell membrane. ${ }^{80}$ Although it is not yet known whether prolonged alteration of the atrial rate and activation sequence modulates protein synthesis and how this could change structure and/or function of potassium channels, the idea that the development of chronic atrial fibrillation may be based on changes in gene expression is an intriguing one and certainly merits more detailed studies using molecular biology techniques.

\section{Other Models of Sustained Atrial Fibrillation}

In 1985 Salmon $^{81}$ reported that atrial pacing $(60 \mathrm{~Hz})$ for more than 90 days resulted in the development of progressive left atrial enlargement and persistent AF in $4 / 6$ dogs. However, in this study no changes in atrial electrophysiological properties, like intra-atrial conduction velocity or refractory period, were studied.

Just recently, Morillo et al. ${ }^{82}$ published a canine study in which 6 weeks of continuous rapid atrial pacing $(400 / \mathrm{min})$, produced sustained atrial fibrillation (defined as AF lasting 15 minutes) in $82 \%$ of the animals. At pacing intervals of 400 and $300 \mathrm{~ms}$ the atrial refractory period had shortened from $150 \pm 8$ to $127 \pm 10 \mathrm{~ms}(-15 \%)$ and from $147 \pm 11$ to $123 \pm 12 \mathrm{~ms}(-16 \%)$ respectively. Together with a marked increase in atrial size this shortening of the atrial refractory period yielded a positive predictive value of $88 \%$ for the induction of sustained AF. In our study we found an even more marked shortening in atrial refractoriness measured at a wider range of pacing intervals. Already after 2-4 days of atrial fibrillation the refractory period during the maximal pacing rate still eliciting a $1: 1$ response $\left(\mathrm{F}_{\max }\right)$, had shortened from $123 \pm 13$ to $90 \pm 16 \mathrm{~ms}(-27 \%)$. During slow pacing (400 ms interval) the shortening of AERP was as much as $45 \%$, from $146 \pm 19$ to $81 \pm 22 \mathrm{~ms}$. Due to the more pronounced shortening of the AERP during slow heart rates, the normal rate adaptation of the refractory period was inverted and instead of getting longer. now the refractory period actually got shorter as a response to slowing of the heart rate.

Both clinical and experimental studies have shown that within the first week after open heart surgery there is a high incidence of atrial tachyarrhythmias due to the development of a sterile pericarditis. ${ }^{23,83,84}$ In 1986 Pagé et al. ${ }^{83}$ described a new model of atrial flutter in dogs, in which a sterile pericarditis was deliberately produced by dusting generous amounts of talcum powder on the atria and by leaving a gauze on the free wall of the atria. During the first week following this procedure, episodes of atrial flutter could be induced reproducibly by programmed electrical stimulation. More recently the same technique has been used by Ortiz et al to produce atrial fibrillation in dogs with sterile pericarditis. ${ }^{85}$. In our study the animals also underwent a thoracotomy and multiple electrodes were sutured to the atria probably causing a sterile pericarditis. To avoid electrophysiological changes due to pericarditis the goats were allowed to recover from surgery for 2 weeks. The experimental protocol was started after an additional control period of 1 week during which the electrophysi- 
ological measurements of conduction velocity and refractory period were stable and long-lasting episodes of atrial fibrillation could not be induced. Therefore we believe that despite the presence of chronically implanted electrodes pericarditis did not play a major role in our present model of AF. This is further supported by the observation that all changes associated with maintained $\mathrm{AF}$ were found to be completely reversible after conversion to sinus rhythm.

\section{Clinical Implications}

The concept that 'atrial fibrillation begets atrial fibrillation' might have some important clinical implications. First of all it emphasizes that most of our electrophysiologic knowledge stems from acute experiments and that we know relatively little about chronic electrophysiological adaptation processes. If it is true that the long-term shortening of atrial refractoriness during fibrillation is based on a fundamental change in composition of the ion channels responsible for repolarization of the atrial cells, the action of anti-arrhythmic drugs on fibrillating atria may be different than the effects as measured during sinus rhythm. The clinically observed diminished efficacy of chemical cardioversion after a prolonged period of atrial fibrillation ${ }^{9-12}$ might be explained by such a process of electrical remodeling. In fact it might be imperative to reevaluate the effects of existing anti-fibrillatory drugs in chronically fibrillating hearts. On the other hand it opens the possibility to develop new drugs specifically targeted at those ion channels that become expressed during atrial fibrillation. At this moment however, these implications are still speculative and more information is needed about the ionic mechanisms of the fibrillation-induced shortening of repolarization before any firm conclusions can be drawn.

The observed anomalous rate adaptation of the atrial refractory period may play an important role in the recurrences of AF which are so frequently seen clinically during the first week after electrical or chemical defibrillation. ${ }^{14,18}$ Directly after cardioversion the atrial interval suddenly prolongs from about $100-150 \mathrm{~ms}$ during atrial fibrillation to about $1000 \mathrm{~ms}$ during sinus rhythm. When the atrial refractory period fails to adapt to such a sudden slowing in heart rate by a prolongation of the refractory period, or even worse, when it becomes shorter due to an inversed rate adaptation, after conversion to sinus rhythm the atria will be left with a dangerously short refractory period. Without the natural protection of a long refractory period, the atrial wavelength will be very short and on first occasion an atrial premature beat may start fibrillation again. In the goat the shortening of the atrial refractory period and the maladaptation to heart rate was reversible within the first days of sinus rhythm. If this is also true in man, protection against the fibrillation-induced maladaptation of the refractory period during the first week after conversion might help to prevent early recurrences of AF.

The question remains whether electrical remodeling by AF also occurs in humans and if so, how this process of electrical remodeling would interfere with atrial fibrillation. As pointed out above the shortening of the atrial refractory might explain 
the diminished success rate of chemical and electrical cardioversion in patients with long-lasting atrial fibrillation. And indeed the finding that the shortening of atrial refractoriness needs a few days to revert completely could explain the early recurrences seen after cardioversion. However the complete reversion of the electrophysiological changes within 1 week after restoration of sinus rhythm implies that the role of electrical remodeling in patients with paroxysmal atrial fibrillation with an incidence of less than once a week seem limited. Due to the reversibility of electrical remodeling of $\mathrm{AF}$ each paroxysm of $\mathrm{AF}$ is independent of the previous one. In general however our study implicates that the best prevention of atrial fibrillation is to terminate the arrhythmia as soon as possible, thus interrupting the electrophysiological secuellae which will lead to chronic atrial fibrillation.

Limitations of the Study

One of the limitations of this study is that we could not follow the changes in atrial refractory period and conduction velocity for much longer than the first days of fibrillation. Due to the increased vulnerability of the atria, by that time programmed electrical stimulation induced periods of $\mathrm{AF}$ lasting for such a long time that it became impossible to complete the protocol. For the same reason it was impossible to measure the exact time course of reversibility of the shortening of the refractory period. Directly after cardioversion the atria are still so vulnerable that the administration of premature stimuli will re-induce long-lasting episodes of atrial fibrillation, which obviously interrupt the reversibility process. Therefore our reversibility measurements are limited and do not allow accurate quantitative conclusions. Nevertheless the data that could be collected leave little doubt that the shortening of refractoriness and the maladaptation to rate are both completely reversible. After one week of sinus rhythm the atrial refractory period and the duration of induced paroxysms of AF were normal again. Because of this, each animal served as its own control and it was not necessary to include a control group of sham operated animals. However, after conversion to sinus rhythm the intra-atrial conduction velocity did not return to control values. The lack of a control group of sham operated animals makes it hard to decide whether the observed slowing in atrial conduction velocity is caused by chronic atrial fibrillation or is a long-term effect of the presence of the implanted electrodes.

The observations reported in this paper raise many questions which can not be answered at the present time. Additional experiments will be needed to determine the possible role of neurohumoral changes, atrial dilatation, ischemia, ANF, and to determine the ionic channels responsible for the fibrillation-induced shortening of the action potential. It also remains to be determined whether on the long term, structural changes of the atrial wall and increased heterogeneity of excitability, refractoriness and conduction properties contribute to the development of chronic AF. Despite all these limitations, our study indicates that the concept of 'domestication of atrial fibrillation' may have a clear pathophysiologic basis which seems worthwhile to explore. More specifically, our study indicates that the AF-induced electrophysiologi- 
cal changes should also be studied in man, and that the reversibility of these changes after conversion to sinus rhythm should be monitored.

\section{References}

1 Godtfredsen I: Atrial fibrillation: etiology, course and prognosis. A follow-up study of 1212 cases. Copenhagen, Denmark: University of Copenhagen, 1975, (Thesis)

2 Kannel WB, Abbott RD, Savage DD, McNamara PM: Epidemiologic features of chronic atrial fibrillation: the Framingham study. $N$ Engl J Med 1982;306:1018-1022

3 Petersen P. Godtfredsen J: Atrial fibrillation: a review of course and prognosis. Acta Med Scand 1984;216:5-9

4 Alpert JS, Petersen P, Godtfredsen J: Atrial fibrillation: natural history, complications and management. Ann Rev Med 1988;39:41-52

5 Evans W, Swann P: Lone auricular fibrillation. Br Heart J 1954;16:189-194

6 Brand FN, Abbott RD, Kannel WB, Wolf PA: Characteristics and prognosis of lone atrial fibrillation. 30-Year follow-up in the Framingham study. JAMA 1985;254:3449-3453

7 Kopecky SL, Gersh BJ, McGoon MD, Whisnant JP. Holmes DR, IIstrup DM, Frye RL: The natural history of lone atrial fibrillation: a population based study over three decades. $N$ Engl $J$ Med 1987;317:669-674

8 Davidson E, Rotenberg Z, Weinberger I, Fuchs J, Agmon J: Diagnosis and characteristics of lone atrial fibrillation. Chest 1989;95:1048-1050

9 Crozier IG, Ikram H, Kenealy M, Levy L: Flecainide acetate for conversion of acute supraventricular tachycardia to sinus rhythm. Am J Cardiol 1987;59:607-609

10 Crijns HJGM, Wijk van LM, Gilst van WH, Kingma HJ, Van Gelder IC, Lie KI: Acute conversion of atrial fibrillation to sinus rhythm: clinical efficacy of flecainide acetate. Comparison of two regimes. Eur Heart J 1988;9:634-638

11 Suttorp MJ, Kingma JH, Lie-A-Huen L, Mast EG: Intravenous flecainide versus verapamil for acute conversion of paroxysmal atrial fibrillation or flutter to sinus rhythm. Am J Cardiol 1989;63:693-696

12 Suttorp MJ, Kingma HJ, Jessurun ER, Lie-A-Huen L, van Hemel NM, Lie KI: The value of class IC antiarrhythmic drugs for acute conversion of paroxysmal atrial fibrillation or flutter to sinus rhythm. J Am Coll Cardiol 1990:16:1722-1727

13 Gold RL, Haffajee CI, Charos G, Sloan K, Baker S, Alpert JS: Amiodarone for refractory atrial fibrillation. Am J Cardiol 1986;57:124-127

14 Bjerkelund C. Orning O: An evaluation of DC shock treatment of atrial arrhythmias. Acta Med Scand 1968;184:481-491

15 Waris E, Kreus K, Salokannel J: Factors influencing persistence of sinus rhythm after DC shock treatment of atrial fibrillation. Acta Med Scand 1971:189:161-166

16 Van Gelder IC. Crijns HJGM, Gilst van WH, Verwer R, Lie KI: Prediction of uneventful cardioversion and maintenance of sinus rhythm from direct-current electrical cardioversion of chronic atrial fibrillation and flutter. Am J Cardiol 1991:68:41-46

17 Morris JJ, Jr., Peter RH, McIntosh HD: Electrical conversion of atrial fibrillation. Immediate and long-term results and selection of patients. Ann Intern Med 1966;65:216-231

18 Resnekov L. McDonald L: Appraisal of electroconversion in treatment of cardiac dysrhythmias. $\mathrm{Br}$ Hear J 1968:30:786-811

19 Crijns HJGM, Van Gelder IC, Gilst van WH, Hillege H, Gosselink M, Lie KI: Serial antiarrhythmic drug treatment to maintain sinus rhythm after electrical cardioversion for chronic atrial fibrillation or atrial flutter. Am J Cardiol 1991:68:335-341

20 Allessie MA, Hoeks APG, Schmitz GML, Reneman RS: On-line mapping system for the visualization of the electrical activation of the heart. Int I Cardiac Imag 1986;2:59-63 
21 Kadish A, Toivonen L, Kushner J, Summit J, Schmaltz S, Morady F: Factors that influence the reproducibility of ventricular refractory period measured by the extrastimulus technique. J Am Coll Cardiol 1989;13:45A (abstract)

22 Konings KTS, Kirchhof CJHJ, Smeets JLRM, Wellens HJJ, Penn OC, Allessie MA: High-density mapping of electrically induced atrial fibrillation in humans. Circulation 1994:89:1665-1680

23 Wells JL, Karp RB, Kouchoukos NT, Maclean WAH, James TN, Waldo AL: Characterization of atrial fibrillation in man: Studies following open heart surgery. Pace 1978;1:426-438

24 Moe GK, Abildskov JA: Atrial fibrillation as a self-sustaining arrhythmia independent of focal discharge. Am Heart J 1959;58:59-70

25 Moe GK: On the multiple wavelet hypothesis of atrial fibrillation. Arch Int Pharmacodyn Ther 1962;140:183-188

26 Moe GK. Rheinboldt WC, Abildskov JA: A computer model of atrial fibrillation. Am Heart J 1964;67:200-220

27 Allessie MA, Lammers WJEP, Bonke FIM, Hollen SJ: Experimental evaluation of Moe's multiple wavelet hypothesis of atrial fibrillation. In: Zipes DP, Jalife J (eds): Cardiac Electrophysiology' and Arrhythmias. NY, Grune \& Stratton, 1985, pp 265-275

28 Hoffman BF, Rosen MR: Cellular mechanisms for cardiac arrhythmias. Circ Res 1981;49:1-15

29 Cox $\mathrm{L}$, Canavan TE, Schuessler RB, Cain ME, Lindsay BD, Stone CM. Smith PK, Corr PB, Boineau JP: The surgical treatment of atrial fibrillation. II. Intraoperative electrophysiologic mapping and description of the electrophysiologic basis of atrial flutter and atrial fibrillation. JThor Card Surg 1991;101:406-426

30 Smeets JLRM, Allessie MA, Lammers WJEP, Bonke FIM, Hollen SJ: The wavelenght of the cardiac impulse and reentrant arrhythmias in isolated rabbit atrium. The role of heart rate, autonomic transmitters, temperature, and potassium. Circ Res 1986:58:96-108

31 Rensma PL, Allessie MA, Lammers WJEP, Bonke FIM, Schalij MJ: Length of excitation wave and susceptibility to reentrant atrial arrhythmias in normal conscious dogs. Circ Res 1988;62:395-410

32 Moore EN, Spear JF: Natural occurrence and experimental initiation of atrial fibrillation in different animal species. In: Kulbertus HE, Olsson SB, Schlepper M (eds): Atrial fibrillation. Mölndal, Sweden, 1982, pp 33-41

33 Henry WL, Morganroth J, Pearlman AS, Clark CE, Redwood DR, Itscoitz SB, Epstein SE: Relation between echocardiographically determined left atrial size and atrial fibrillation. Circulation 1976;53:273-279

34 Allessie MA, Rensma PL, Brugada J, Smeets JLRM, Penn OC, Kirchhof CJHJ: Pathophysiology of atrial fibrillation. In: Zipes DP, Jalife J (eds): Cardiac electrophysiology. From cell to bedside. Philadelphia, Saunders, 1990, pp 548-559

35 Wang Z, Page PL, Nattel S: Mechanism of flecainide's antiarrhythmic action in experimental atrial fibrillation. Circ Res 1992;71:271-287

36 Wang J, Bourne GW, Wang Z. Villemaire C, Talajic M, Nattel S: Comparative mechanisms of antiarrhythmic drug action in experimental atrial fibrillation. Circulation 1993:88:1030-1044

37 Bayes de Luna A, Cladellas M, Oter R. Torner P, Guindo J, Marti V. Rivera I, Iturralde: P: Intcratrial conduction block and retrograde activation of the left atrium and paroxysnial supraventricular tachyarrhythmias. Eur Heart $J$ 1988;9:1112-1118

38 Simpson RJ, Jr., Foster JR, Gettes LS: Atrial excitability and conduction in patients with interatrial conduction defects. Am J Cardiol 1982:50:1331-1337

39 Cosio FG, Palacios J, Vidal JM, Cocina EG, Gomez-Sanchez A, Tamargo L: Electrophysiologic studies in atrial fibrillation. Slow conduction of premature impulses: A possible manifestation of the background for reentry. Am J Cardiol 1983:51:122-130

40 Ohe T. Matsuhisa M, Kamakura S, Yamada J, Sato I, Nakajima K, Shimomura K: Relation between the widening of the fragmented atrial activity zone and atrial fibrillation. Am J Cardiol 1983:52:1219-1222

41 Buxton AE, Waxman HL, Marchlinski FE, Josephson ME: Atrial conduction: effects of extrastimuli with and without atrial dysrhythmias. Am J Cardiol 1984;54:755-761 
42 Cosio FG, Arribas F: Role of conduction disturbances in atrial arrhythmias. In: Attuel P, Coumel P, Janse MJ (eds): The atrium in Healsh and Disease. Mount Kisco, NY, Futura Publishing Co, 1989, pp 133-157

43 Kumagai K, Akimitsu S, Kawahira K, Kawanami F, Yamanouchi Y, Hiroki T, Arakawa K: Electrophysiological properties in chronic lone atrial fibrillation. Circulation 1991;84:1662-1668

44 Cosio FG: Intra-atrial conduction and atrial fibrillation. In: Olsson SB, Allessie MA, Campbell RWF (eds): Atrial Fibrillation. Mechanisms and Therapeutic Strategies. Armonk, NY. Futura Publishing Co.. Inc. 1994, pp 51-65

45 Stafford PJ, Turner I, Vincent R: Quantitative analysis of signal-averaged P waves in idiopathic paroxysmal atrial fibrillation. Am J Cardiol 1991:68:751-755

46 Yamada T, Fukunami M, Ohmori M, Kumagai K, Sakai A, Minamino T. Hoki N: Characteristics of frequency content of atrial signal-averaged electrocardiograms during sinus rhythm in patients with paroxysmal atrial fibrillation. $J$ Am Coll Cardiol 1992;19:559-563

47 Spach MS, Dolber PC: Relating extracellular potentials and their derivatives to anisotropic propagation at a microscopic level in human cardiac muscle. Circ Res 1986;58:356-371

48 Spach MS, Kootsey JM, Sloan JD: Active modulation of electrical coupling between cardiac cells of the dog. A mechanism for transient and steady state variations in conduction velocity. Circ Res 1982:51:347-362

49 Ten Eick RE, Singer DH: Electrophysiologic properties of diseased human atrium. I.Low diastolic potential and altered cellular response to potassium. Circ Res 1979;44:545

50 Singer D. Ten Eick R: Aberrancy: Electrophysiologic aspects. Am J Cardiol 1971;28:381-401

51 Hordof AJ, Edie R, Malm JR, Hoffman BF, Rosen MR: Electrophysiologic properties and response to pharmacologic agents of fibers from diseased human atria. Circulation 1976;54:774-779

52 Allessie MA, Bonke FIM, Schopman FJG: Circus movement in rabbit atrial muscle as a mechanism of tachycardia. II. The role of nonuniform recovery of excitability in the occurrence of unidirectional block, as studied with multiple microelectrodes. Circ Res 1976;39:168-177

53 Ramdat Misier AR, Opthof T, Hemel van NM, Defauw JJAM, Bakker de JMT, Janse MJ, Capelle van FJL: Increased dispersion of 'refractoriness' in patients with idiopathic paroxysmal atrial fibrillation. J Am Coll Cardiol 1992:19:1531-1535

54 Le Heuzey J, Boutjdir M, Gagey S, Lavergne T, Guize L: Cellular aspects of atrial vulnerability, In: Attuel P, Olsson SB, Schlepper M (eds): The atrium in Health and Disease. Mount Kisco, Futura Publishing, 1989, pp 81-94

55 Boutjdir M, Le Heuzey J, Lavergne T. Chauvaud S, Guize L, Carpentier A. Peronneau P: Inhomogeneity of cellular refractoriness in human atrium: factor of arrhythmia? Pace 1986;9:1095-1100

56 Lammers WJEP, Allessie MA. Rensma PL: The use of fibrillation cycle length to determine spatial dispersion in electrophysiological properties and to characterize the underlying mechanism of fibrillation. New Trends Arrhythm 1986:2:109-112

57 Opthof T, Ramdat Misier AR, Coronel R. Vermeulen JT, Verberne HJ, Frank RGJ, Moulijn AC. Capelle van FJL. Janse MJ: Dispersion of refractoriness in canine ventricular myocardium: effects of sympathetic stimulation. Circ Res 1991;68:1204-1215

58 Allessie MA, Kirchhof CJHJ, Scheffer GJ, Chorro FJ, Brugada J: Regional control of atrial fibrillation by rapid pacing in conscious dogs. Circulation 1991:84:1689-1697

59 Kirchhof CJHJ, Chorro FJ, Scheffer GJ. Brugada J, Konings KTS, Zetelaki Z, Allessie MA: Regional entrainment of atrial fibrillation studied by high-resolution mapping in open-chest dogs. Circulation 1993:88:736-749

60 Davies MJ, Pomerance A: Pathology of atrial fibrillation in man. Br Hear J 1972:34:520-525

61 Attuel P. Childers RW, Cauchemez B, Poveda J, Mugica J, Coumel P: Failure in the rate adaptation of the atrial refractory period: its relationship to vulnerability. Int J Cardiol 1982;2:179-197

62 Attuel P, Childers RW, Haissaguerre M, Leclereq J, Mugica J, Coumel P: Failure in the rate adaptation of the atrial refractory periods: new parameter to assess atrial vulnerability. Pace $1984 ; 7: 1382$ 
63 Coumel P, Attuel P, Lavallee J, Flammang D, Leclercg JF, Slama R: Syndrome darythmie auriculaire d'origine vagale. Arch Mal Coeur 1978;71:645-656

64 Coumel P: Neurogenic and humoral influences of the autonomic nervous system in the detemination of paroxysmal atrial fibrillation. In: Attuel P, Olsson SB, Schlepper M (eds): The atritum in Health and Disease. Mount Kisco, NY. Futura Publishing Co, 1989, pp 213-232

65 Reiter MJ, Synhorst DP, Mann DE: Electrophysiological effects of acute ventricular dilatation in the isolated rabbit heart. Circ Res 1988:62:554-562

66 Calkins H, Maughan WL, Kass DA, Sagawa K, Levine JH: Electrophysiological effect of volume load in isolated canine hearts. Am J Physiol 1989;256:H-1697-H-1706

67 Benditt DG, Kriett JM, Tobler HG, Gornick CC, Detloff BLS, Anderson RW: Electrophysiological effects of transient aortic occlusion in intact canine heart. Am J Physiol 1985:249:-14-1017-11-1023

68 Taggard P, Sutton P, Lab MJ, Runnalls M, O'Brien W, Treasure T: Effect of abrupt changes in ventricular loading on repolarization induced by transient aortic occlusions in tumans. Am J Physiol 1992;263:H-816-H-823

69 Klein LS, Miles WM, Zipes DP: Effect of atrioventricular interval during pacing or reciprocating tachycardia on atrial size, pressure, and refractory period. Contraction-excitation feedback in human atrium. Circulation 1990;82:60-68

70 Calkins H, El-Atassi R, Leon A, Kalbfleisch SJ, Borganelli M, Langberg JJ, Morady F: Effect of the atrioventricular relationship on atrial refractoriness in humans. Pace 1992;15:771-778

71 White CW, Kerber RE, Weiss HR, Marcus ML: The effects of atrial fibrillation on atrial pressurevolume and flow relationships. Circ Res 1982;51:205-215

72 Clemo HF, Baumgarten CM, Stambler BS, Wood MA, Ellenbogen KA: Atrial natriuretic factor: Implications for cardiac pacing and electrophysiology. Pace 1994;17:70-91

73 Stambler BS. Turner DA, Guo C, Guo GB, Ellenbogen KA: Characterization of the in vivo cardiac electrophysiologic effects of atrial natriuretic factor (ANF). Circulation 1994;90(4):I-247 (abstract)

74 Rosenbaum MB, Blanco HH, Elizari MV, Lazzari JO, Davidenko JM: Electrotonic modulation of the T wave and cardiac memory. Am J Cardiol 1982;50:213-222

75 Katz AM: T Wave "memory": possible causal relationship to stress-induced changes in cardiac ion channels? J Cardiovasc Electrophysiol 1992;3:150-159

76 Agnew WS: A Rosetta stone for K channels. Nature 1988:331:114-115

77 Aldrich RW: Potassium channels. Mixing and Matching. Nature 1990;345:475-476

78 Del Balzo U, Rosen MR: T-wave changes persisting after ventricular pacing in canine heart are altered by 4-aminopyridine but not by lidocaine. Implications with respect to phenomenon of cardiac "memory". Circulation 1992:4:1464-1472

79 Geller JC, Rosen MR: Persistent $T$-wave changes after alteration of the ventricular activation sequence. New insights into cellular mechanisms of "cardiac memory". Circulation 1993;88:18111819

80 Schwartz TH, Greenberg SM: Molecular mechanisms for memory and second messenger induced modifications of protein kinases in nerve cells. Annu Rev Neurosci 1987:10:459-476

81 Salmon DR, McPerson DD, Augustine DE. Holida MD, White CW: A canine model of chronic atrial fibrillation: echocardiographic and electrocardiographic validation. Circulation 1985:72:111250(abstract)

82 Morillo CA, Klein GJ, Jones DL, Guiraudon CM: Chronic rapid atrial pacing: structural. functional and electrophysiologic characteristics of a new model of sustained atrial fibrillation. Circulation 1995;91:1588-1595

83 Pagé PL. Plumb VJ, Okumura K, Waldo AL: A new animal model of atrial flutter. $J$ Am Coll Cardiol $1986 ; 8: 872-879$

84 Waldo AL, MacLean WAH, Cooper TB, Kouchoukos NT, Karp RB: The use of temporarily placed epicardial atrial wire electrodes for the diagnosis and treatment of cardiac arrhythmias following open heart surgery. J Thorac Cardiovasc Surg 1978;76:500-505

85 Ortiz. J. Igarashi M, Gonzalez X, Johnson NJ, Waldo AL: A new reliable atrial fibrillation model with a clinical counterpart. J Am Coll Cardiol 1993;21:183A(abstract) 


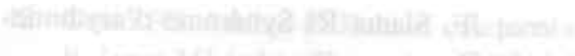

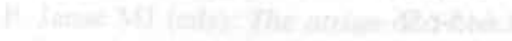

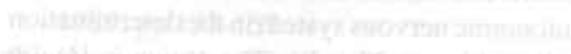

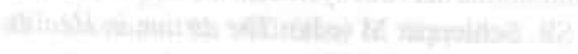

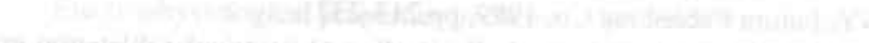

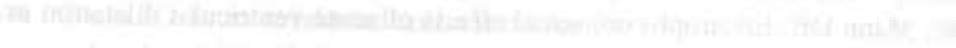

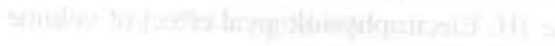

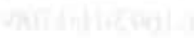

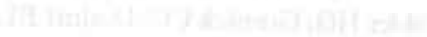

15. 


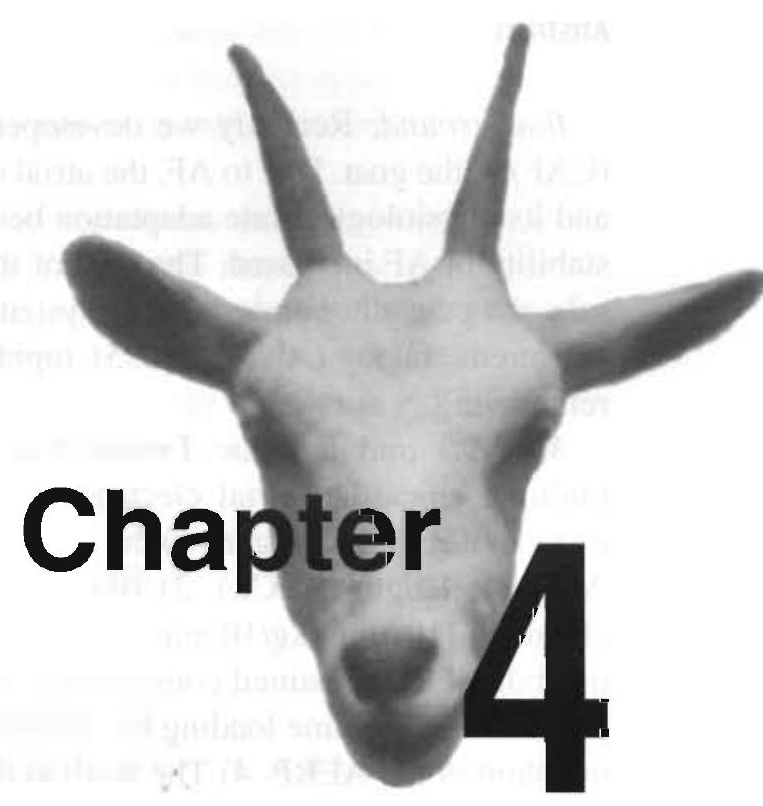

\section{Electrical Remodeling Due to Atrial Fibrillation in Chronically Instrumented Conscious Goats}

The Role of Neurohumoral Changes, Ischemia, Atrial Stretch, and High Rate of Electrical Activation

Maurits C.E.F. Wijffels

Charles J.H.J. Kirchhof

Rick Dorland

John Power

Maurits A. Allessie

Accepted for Publication in Circulation 


\section{Abstract}

Background: Recently we developed a new model of chronic atrial fibrillation (CAF) in the goat. Due to AF, the atrial effective refractory period (AERP) shortened and its physiological rate adaptation became inversed. At the same time the rate and stability of AF increased. The goal of the present study was to evaluate the possible role of 1) the autonomic nervous system (ANS), 2) ischemia, 3) stretch, 4) the atrial natriuretic factor (ANF), and 5) rapid atrial pacing in this process of electrical remodeling.

Methods and Results: Twenty-five goats were chronically instrumented with multiple epicardial atrial electrodes. 1) Infusion of atropine (1.0 mg/kg, $n=6)$ or propranolol $(0.6 \mathrm{mg} / \mathrm{kg}, \mathrm{n}=6)$ did not abolish the AF-induced shortening of AERP or AF cycle length (AFCL). 2) Blockade of ATP-regulated $\mathrm{K}+$-channels by glybenclamide $^{\circledR}(10 \mu \mathrm{mol} / \mathrm{kg} / 10 \mathrm{~min} ; \mathrm{n}=6)$ slightly increased the AFCL from $95 \pm 4$ to $101 \pm 5$ ms, but AFCL remained considerably shorter than during recent onset AF (145 ms, $p<0.001) .3)$ Volume loading by infusion of 0.5-1.0 liters of Haemaccel ${ }^{(1)}(n=12)$ did not shorten the AERP. 4) The median plasma level of ANF increased from 42 to 99 $\mathrm{pg} / \mathrm{ml}$ after $1-4$ weeks of AF ( $\mathrm{n}=6)$, but infusion of ANF $(0.1-3.1 \mu \mathrm{g} / \mathrm{min})(\mathrm{n}=4) \mathrm{did}$ not shorten AERP. 5) Prolonged rapid pacing (24-48h) $(\mathrm{n}=12)$ progressively shortened AERP from $134 \pm 10$ to $105 \pm 6 \mathrm{~ms}(-22 \%)$ and attenuated or inversed the normal physiological rate adaptation of the refractory period. These changes were completely reversible.

Conclusions: The shortening of AERP by AF is not mediated by changes in autonomic tone, atrial ischemia, acute stretch or ANF. Rather, the high rate of electrical activation itself seems to provide the stimulus for the AF induced electrical remodeling of the atria.

\section{Introduction}

Recently, we reported a study in chronically instrumented goats demonstrating that: "Atrial librillation begets atrial fibrillation'. 'Whereas initially, atrial fibrillation (AF) induced by burst pacing. terminated spontaneously within less than 5 seconds, the repetitive induction of $\mathrm{AF}$ led to a progressive prolongation of the duration of the induced paroxysms of atrial fibrillation. Within 1-3 weeks, this culminated in sustained atrial fibrillation lasting longer than 24 hours. Also the rate of atrial fibrillation changed during the first week of maintained AF, increasing from about 400 beats per minute during the first day, to more than $600 / \mathrm{min}$ after I week. Programmed electrical stimulation, which could be performed during the first days when AF still terminated spontaneously, revealed a significant shortening of the atrial effective refractory period (AERP). This shortening of the AERP was more pronounced at slower than at faster heart rates ( $45 \%$ versus $23 \%$ ) and the normal physiological rate adaptation of 
refractoriness became inversed. Instead of prolonging, now the AERP actually got shorter at slower heart rates. These observations suggest that the observed 'domestication of atrial fibrillation', was at least partly due to an AF-induced shortening and maladaptation of the atrial refractory period.

The goal of the present study was to elucidate the stimuli that were responsible for this process of $\mathrm{AF}$-induced electrical remodeling. In this respect we evaluated the possible role of the autonomic nervous system, atrial ischemia, acute dilatation, and the atrial natriuretic factor (ANF). We also performed experiments to test the hypothesis that the high rate of electrical activation per se was the trigger for the long-term shortening and inversed rate adaptation of the refractory period by atrial fibrillation.

\section{Methods}

The Goat Model of Chronic Atrial Fibrillation

Twenty five goats weighing between 43 and $82 \mathrm{~kg}$ (mean $57 \pm 9 \mathrm{~kg}$ ) were used for this study. Animal handling was performed according to the guiding principles of the American Society of Physiology and approved by the Animal Investigation Committee of the University of Limburg.

In Fig 1, the most important characteristics of the chronically instrumented goat model of atrial fibrillation are given as described in greater detail in Wijffels et al. ${ }^{1}$ In order to instrument the goats with multiple epicardial atrial electrodes, the animals were anaesthetized with $\mathrm{Nesdonal}{ }^{\circledR}$ (Thiopental, $15 \mathrm{mg} / \mathrm{kg}$ ) and ventilated by Halothane ${ }^{(1)}(1-2 \%)$ and a $1: 2$ mixture of $\mathrm{O}_{2}$ and $\mathrm{N}_{2} \mathrm{O}$. A left intercostal thoracotomy was made and the pericardium was opened to expose the heart. A teflon felt strip (Bard ${ }^{(2)}$ ) of $10 \times 1.2 \mathrm{~cm}$, containing 15 unipolar silver recording electrodes (diameter $2 \mathrm{~mm}$, inter-electrode distance $6-10 \mathrm{~mm}$ ) was guided through the anterior transverse sinus between the atria and the aortic root and sutured to the tips of both atrial appendages. Two smaller felt strips of $3 \times 1.2 \mathrm{~cm}$, each containing 6 electrodes, were sutured to the lateral walls of the right and left atria. Thus, a total of 27 unipolar electrodes were implanted on the atria (Fig 1, upper left panel). After approximation of the pericardium and closure of the thorax, the electrode leads were tunneled subcutaneously to the neck and exteriorized by a 30-pin connector (Lemosa ${ }^{\circledR}$, outer diameter $10 \mathrm{~mm}$ ). Three silver plates (diameter $25 \mathrm{~mm}$ ) were left subcutaneously to serve as grounding and indifferent electrodes and to record a precordial electrocardiogram. Post-operatively the animals received buprenorfine $\left(0.01 \mathrm{mg} / \mathrm{kg}\right.$, Temgesic ${ }^{\circledR}$ Reckitt \& Colman) for 1-3 days. Prophylactically, gentamicin ( $3 \mathrm{mg} / \mathrm{kg}$ ) and sodiumampicillin (Pentrexyl ${ }^{\circledR} 1000 \mathrm{mg}$, Bristol-Myers Squibb) were given intravenously directly before surgery. After surgery an additional single dose of sodium-ampicillin ( $1000 \mathrm{mg}$ ) was given intramuscularly.

After about 2-3 weeks. when the animals had completely recovered from surgery, the goats were connected to an external fibrillation pacemaker. This pacemaker was 
Chronically Instrumented goat

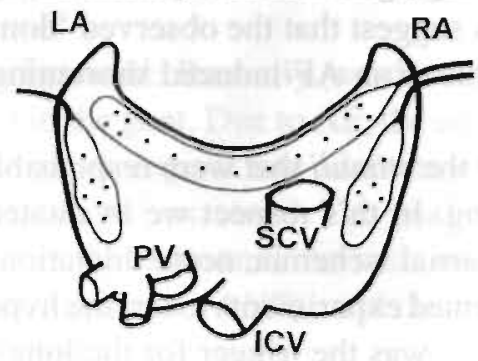

Development of Sustained AF

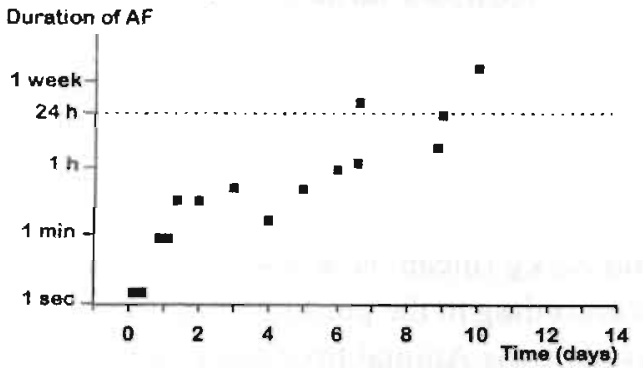

Fibrillation pacemaker

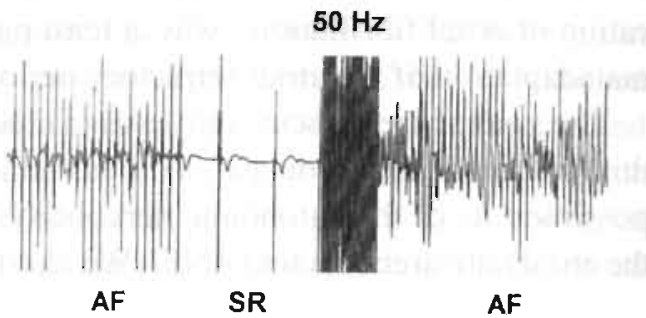

Electrical remodeling

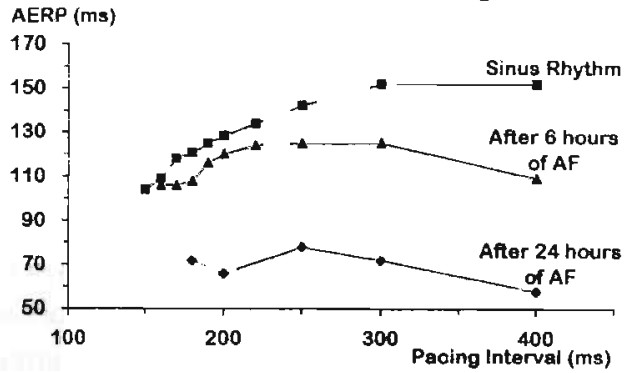

Figure 1. The goat model of sustained atrial fibrillation. Upper Left: Schematic drawing of the implanted epicardial electrodes. One long teflon felt strip $(10 \times 1.2 \mathrm{~cm}$ ), containing 15 unipolar silver electrodes (diameter 2 mim, inter-electrode distance $6-10 \mathrm{~mm}$ ) was guided through the anterior transverse sinus between the atria and the aortic root and sutured to the tips of both atrial appendages. Two smaller felt strips of $3 \times 1.2 \mathrm{~cm}$ containing 6 electrodes, were sutured to the lateral walls of the right and left atria. LA, left atrial appendage; RA, right atrial appendage: PV, pulmonary veins; SCV, superior caval vein: ICV, inferior caval vein. Upper Right: Three to four weeks after implantation, the goats were connected to an external fibrillation pacemaker. This device was able to automatically detect conversion of AF to sinus rhythm by measuring the length of the iso-electrical segment of a bipolar atrial electrogram. As soon as AF terminated spontaneously. it was immediately reinduced by delivering a 1 second burst of stimuli ( $50 \mathrm{~Hz}, 4$ times diastolic threshold). In this way atrial fibrillation was maintained 24 hours a day, 7 days a week. Lower Left: A representative example of the development of sustained atrial fibrillation. As the pacemaker was switched on (day 0), the induced episodes of AF lastecl only for a couple of seconds. However, the repetitive induction of $\mathrm{AF}$ resulted in a progressive increase in the duration of fibrillation. In this case $\mathrm{AF}$ became sustained ( 24 hours) after 1 week of electrically maintained AF. Lower Right: An example of the electrical remodeling by AF. During sinus rhythm the AERP at slow heart rates was $150 \mathrm{~ms}$ and showed a physiological adaptation to rapid rates (shortening to $100 \mathrm{~ms}$ at the maximal pacing rate). During the first 24 hours of atrial fibrillation the refractory period progressively shortened at all heart rates to less than $80 \mathrm{~ms}$. The physiological rate adaptation was lost and the AERP had approximately the same; value at all heart rates.

able to recognize the spontaneous termination of AF by monitoring the length of the iso-electrical segment in a bipolar atrial electrogram. As soon as resumption of sinus rhythm was detected, the pacemaker promptly reinduced atrial fibrillation by delivering a 1 second burst of electrical stimuli $(50 \mathrm{~Hz}, 4$ times diastolic threshold) (Fig 1 , right upper panel). In this way, the fibrillation pacemaker automatically maintained AF. 24 hours a day, 7 days a week. A full description of the automatic fibrillation pacemaker is given elsewhere. ${ }^{1}$ 
In the left lower panel of Fig 1, the effect of chronically maintained AF on the duration of the fibrillation episodes is shown. When the fibrillation pacemaker was switched on (day 0), the induced paroxysms of AF were short-lasting and AF terminated spontaneously within less than 5 seconds. However, the repetitive induction of AF by the automatic fibrillation pacemaker, led to a progressive increase in the stability of $\mathrm{AF}$. In this example, after 24 hours of $\mathrm{AF}$ the episodes of $\mathrm{AF}$ lasted for one minute, after 6 days for about one hour, and after 9 days for longer than 24 hours (sustained $\mathrm{AF}$ ). In this case, the last episode of AF induced at day 10 (last data point) continued for several weeks, after which AF was cardioverted.

In the right lower panel of Fig 1, the effects of the first 24 hours of AF on the atrial refractory period are shown. The upper curve shows the normal physiological rate adaptation of the refractory period. Before $\mathrm{AF}$ was induced (sinus rhythm), the atrial refractory period was $150 \mathrm{~ms}$ at pacing intervals of $300-400 \mathrm{~ms}$ and shortened progressively to about $100 \mathrm{~ms}$ at shorter pacing intervals. After 6 hours of AF (middle curve), the AERP during slow pacing had shortened from 150 to $110 \mathrm{~ms}$. During fast pacing, the shortening of the refractory period was less pronounced. However, as can be seen from the lower curve, after 24 hours of AF also the refractory period at the higher pacing rates had shortened. As a result, the physiological rate adaptation of the refractory period was lost or even slightly reversed, with in this case an AERP of 65-75 $\mathrm{ms}$ at high pacing rates and less than $60 \mathrm{~ms}$ during pacing at an interval of $400 \mathrm{~ms}$

\section{Electrophysiological Measurements}

Two weeks after implantation of the atrial electrodes and before connecting the goat to the fibrillation pacemaker, a control electrophysiological study was done. The AERP was measured at both the right and left atrial appendage during various $S_{1}-S_{1}$ pacing intervals between $600 \mathrm{~ms}$ and $120 \mathrm{~ms}$. A single premature stimulus $\left(\mathrm{S}_{2}\right)$ of 4 times diastolic threshold was interpolated after every fifth basic interval. The measurement of the local AERP was started with an $S_{1}-S_{2}$ coupling interval shorter than the atrial refractory period and incremented in steps of $1 \mathrm{~ms}$. The shortest $\mathrm{S}_{1}-\mathrm{S}_{2}$ coupling interval that resulted in a propagated premature atrial response was taken as the AERP.

The rate of atrial fibrillation was measured from a bipolar atrial electrogram by counting the number of individual atrial complexes during 15 seconds of AF. The ventricular response rate during AF was measured from a precordial electrocardiogram.

Infusion of Atropine, Propranolol and Glybenclamide

Atropine and propranolol were administered both before the induction of $\mathrm{AF}$ (goats in sinus rhythm), after 1-3 days of atrial fibrillation, and after AF had become sustained (duration $>24$ hours). Atropine-sulfate was infused intravenously in cumulative dosages of $0.1,0.3,0.6$ and $1.0 \mathrm{mg} / \mathrm{kg}$ in steps of 10 minutes. Propranolol-HCL 
(Inderal ${ }^{\circledR}$, Zeneca) was given in a similar way in cumulative dosages of $0.1,0.3$ and $0.6 \mathrm{mg} / \mathrm{kg}$. In 5 goats with sustained AF, glyburide (glybenclamide ${ }^{\circledR}$, Sigma Chemical) was administered intravenously as a 5 -minute bolus of $10 \mu \mathrm{mol} / \mathrm{kg}(4.94 \mathrm{mg} / \mathrm{kg}$ ). Before infusion glybenclamide was freshly dissolved in $\mathrm{NaOH}$ and distilled water (1 mmol glybenclamide; $17 \mathrm{ml} \mathrm{NaOH} 0.1 \mathrm{~N} ; 40 \mathrm{ml}$ distilled water). In 3 of 5 goats plasma levels of glybenclamide were determined by high pressure liquid chromatography analysis (H.P.L.C.) and fluorescence detection. ${ }^{2}$ Venous blood samples of $5 \mathrm{ml}$ were collected in heparinized tubes and centrifuged with $3000 \mathrm{rpm}$ at $4^{\circ} \mathrm{C}$. The plasma was immediately stored at $-20^{\circ} \mathrm{C}$.

Acute Atrial Dilatation

In 12 goats the effects of acute atrial dilatation were studied by rapid infusion of a blood expanding fluid (Haemaccel ${ }^{\circledR}$, Hoechst). The infusion regime was 0.5 liters in 5 minutes, followed after 10 minutes by another 0.5 liter in 8 goats. During the volume loading process with Haemaccel, a two-dimensional echocardiogram was made in 7 goats (Hewlett Packard, 77020-A system, 3.5 MHz transducer). For this purpose the animals were anaesthetized with an infusion of propofol (Diprivan ${ }^{\circledR}$, Zeneca) $(10-20$ $\mathrm{mg} / \mathrm{min}$ ). With the animals positioned on their left side, the left atrial diameter was measured by $\mathrm{M}$-mode echocardiography, using a parasternal long-axis view. In 4 goats the right atrial pressure was measured by a Swan-Ganz catheter (Baxter) inserted through an incision in the right jugular vein.

\section{The Atrial Natriuretic Factor (ANF)}

In 6 goats plasma levels of ANF were monitored during the development of chronic atrial fibrillation. Venous blood samples were taken from the saphenous vein in cooled disposable tubes containing EDTA ( $2 \mathrm{mg} / \mathrm{ml}$ blood), immediately centrifuged at $4^{\circ} \mathrm{C}$ (3000 r.p.m.) and stored at $-20^{\circ} \mathrm{C}$. The concentration of ANF was determined by a radio-immunoassay technique (Nichols Institute Diagnostics). ${ }^{3}$

In 4 control goats, ANF ( $\alpha$-human 1-28 ANF, Sigma Chemical) was infused intravenously. As shown by Olsson et al. ${ }^{4}$ administration of human ANF to conscious goats $(1.5-2 \mu \mathrm{g} / \mathrm{min})$ increased plasma ANF levels from $3 \pm 1$ to $525 \pm 90 \mathrm{pmol} / /$ and effectively increased natriuresis and attenuated water intake in dehydrated animals. ANF was administered intravenously in the left saphenous vein. Every 2 minutes the infusion rate was increased with $0.1 \mu \mathrm{g} / \mathrm{min}$ until after 60 minutes a cumulative dosage of about $100 \mu \mathrm{g}$ was given. The effective ANF plasma level was determined from venous blood samples taken from the contra-lateral saphenous vein at $0,15,30,45$ and 60 minutes after the start of the infusion. 
The effects of a long-term increase in the atrial pacing rate was studied in 9 goats. First the atria were paced during 1 to 3 days with a fixed pacing interval between 360 and $400 \mathrm{~ms}$. After the goats were hemodynamically adapted to the fixed slow pacing rate, the pacing rate was suddenly doubled (interval between 180 and $200 \mathrm{~ms}$ ). However, due to the development of $2: 1 \mathrm{AV}$-block, the ventricular rate remained the same. The long-term changes in atrial refractory period by prolonged rapid pacing were followed during 1 to 2 days, after which the pacing interval was switched back again to its original interval of 360 to $400 \mathrm{~ms}$. During the next 1 to 2 days the time course of the reversibility of the changes in AERP were studied.

Statistical Analysis

Data are presented as mean \pm standard deviation. Statistical analysis was performed by a paired Student's $t$-test. The p-values were corrected for multiple statistical comparisons by multiplying with the number of comparisons (Bonferroni's correction). A p-value of less than 0.05 was considered to be statistically significant.

\section{Results}

\section{Effects of Atropine and Propranolol}

To test the possibility that the AF-induced changes of the atrial refractory period were mediated by the autonomic nervous system (ANS), the parasympathetic and sympathetic limb of the ANS were blocked by continuous infusion of a stepwise increasing concentration of atropine or propranolol. In 6 goats, the effects on the atrial effective refractory period were measured, both during control (goat in sinus rhythm) and after a relatively short period (1-3 days) of maintained AF. The refractory period was measured at various pacing intervals between 600 and $140 \mathrm{~ms}$. In Fig 2 a representative example of the effects of atropine (left panel) and propranolol (right panel) are given. In both experiments (different goats), the AF induced shortening of the AERP after 24 hours can be clearly seen. The administration of atropine during sinus rhythm (total dosage $1.0 \mathrm{mg} / \mathrm{kg}$ ) slightly prolonged the atrial refractory period during slow pacing (400 ms interval) (left panel). Obviously, in the awake goat, the cardiac parasympathetic nerves are not very active, and the atrial refractory period is only slightly shortened by the low quantities of acetylcholine released from the vagal nerve endings. The important point to note here however, is that after 24 hours of AF, atropine still prolonged the AERP only slightly. The fact that the AF-induced shortening of atrial refractoriness was not abolished by atropine means that the shortening of the AERP by atrial fibrillation was not mediated by an increased vagal tone or a higher sensitivity of the atrial cells for acetylcholine. 

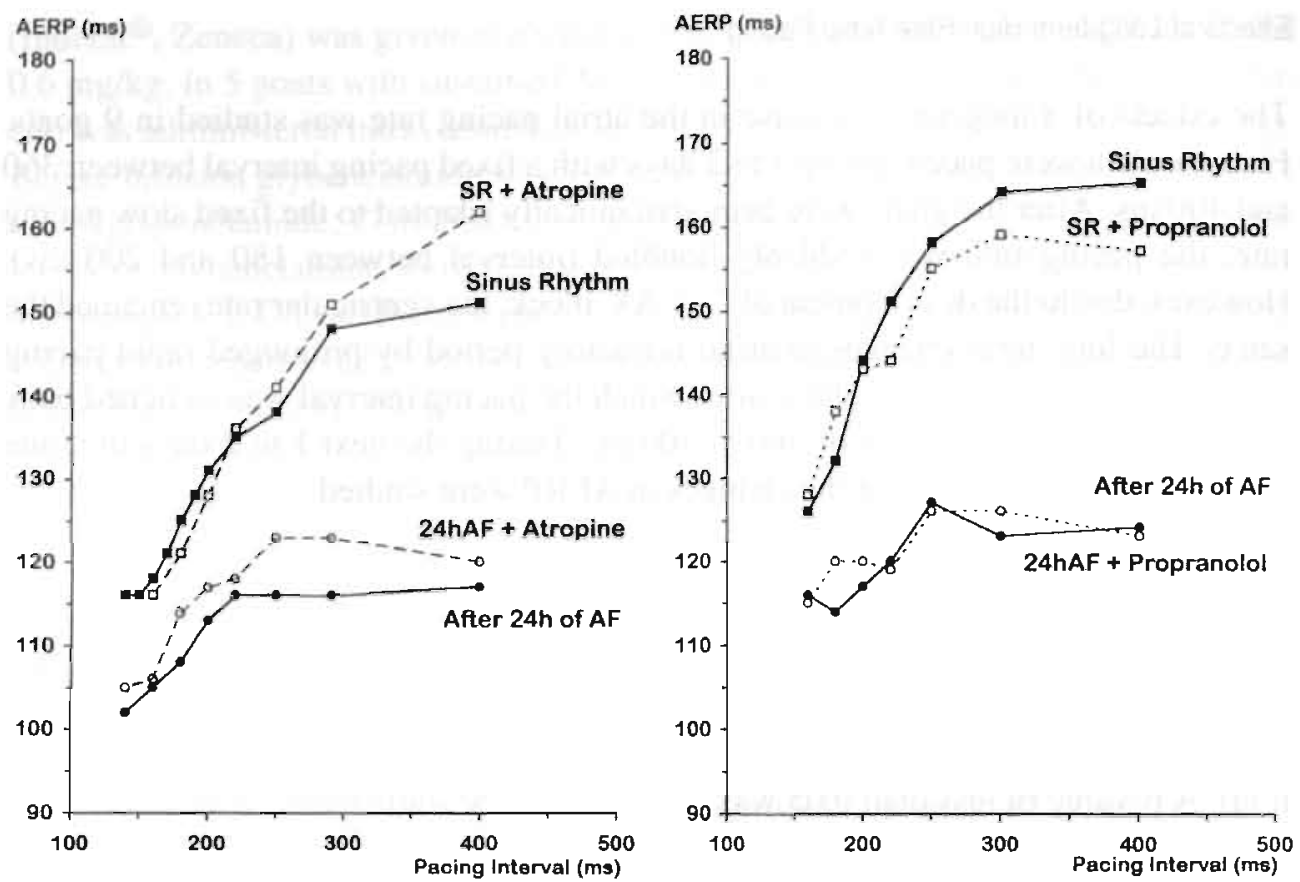

Figure 2. Representative examples of the effects of atropine and propranolol on the atrial effective refractory period (AERP) during sinus rhythm and after 24 hours of electrically maintained AF. Left: The rate dependent AERP during sinus rhythm before $\left(\_\right.$) and after administration of atropine ( ). After 24 hours of atrial fibrillation (I). the refractory period had shortened markedly at all heart rates and the rate adaptation was attenuated. Also after 24 hours of AF, atropine still prolonged the AERP only slightly ( ) and the shortening by AF was not counteracted. Right: Example of the effects of propranolol on AERP during sinus rhythm and after electrical remodeling by 24 hours of AF (different goat). Blockade of the B-adrenergic system had no significant effect on the shortening of the atrial refractory period induced by atrial fibrillation.

The right panel of Fig 2 shows that infusion of propranolol $(0.6 \mathrm{mg} / \mathrm{kg})$ during sinus rhythm slightly shortened the AERP at slow pacing rates. After 24 hours of atrial fibrillation, blockade of the $B$-adrenergic system did not exert a significant effect on the atrial refractory period.

To evaluate the role of the autonomic nervous system in sustained atrial fibrillation, the effects of atropine and propranolol on the mean AF-interval were measured. The ventricular response rate during $A F$ (mean $R R$-Interval) was monitored for the effects on AV-conduction. The infusion rate of atropine and propranolol was increased every 10 minutes, until a total dosage of $1.0 \mathrm{mg} / \mathrm{kg}$ of atropine and $0.6 \mathrm{mg} / \mathrm{kg}$ of propranolol was given. In Fig 3, the effects of atropine (left) and propranolol (right) on sustained atrial fibrillation are shown. Both drugs had a concentration dependent effect on AV-conduction, the mean RR-interval during AF becoming shorter by atropine and longer by propranolol. However neither drug had a clear effect on the mean atrial fibrillation interval. 


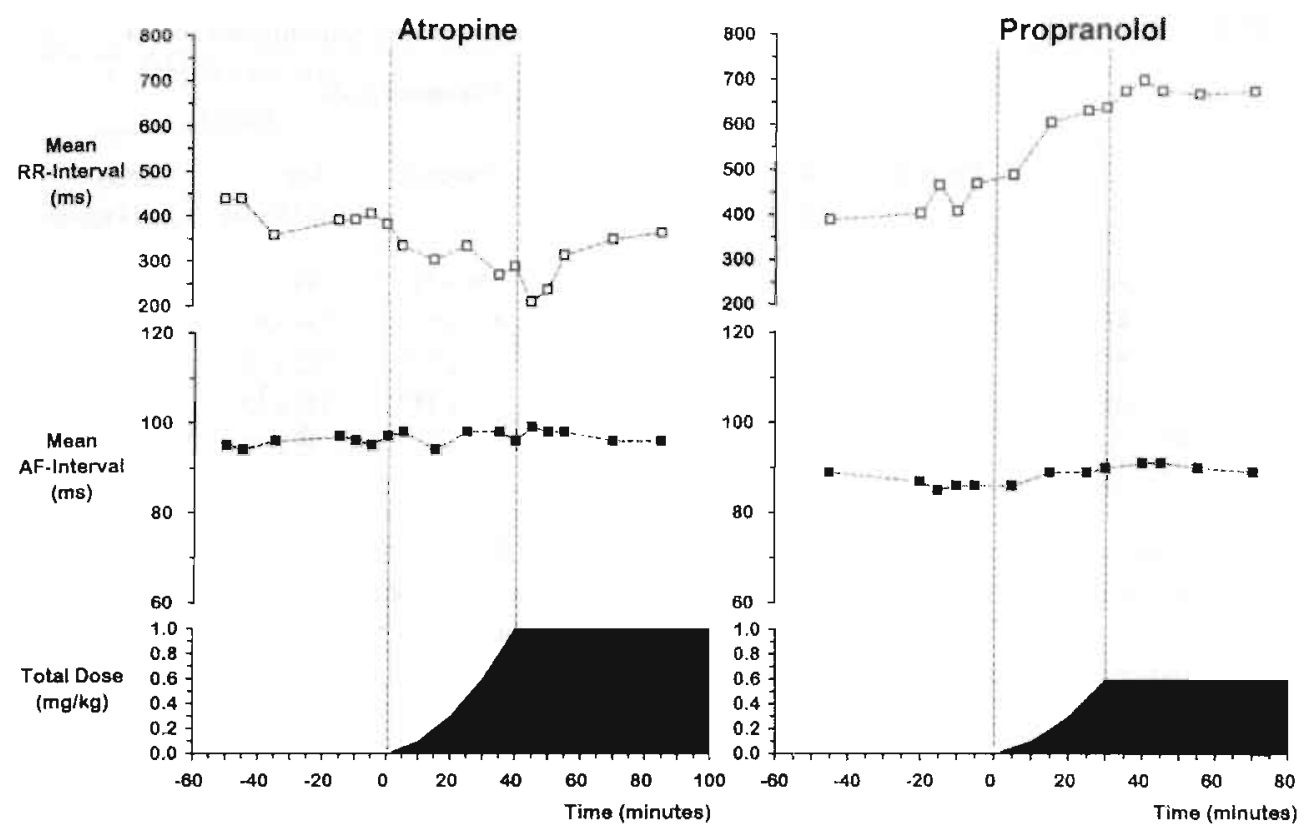

Figure 3. The effects of atropine and propranolol on sustained atrial fibrillation. Left pancl: Infusion of atropine shortencd the mean RR-interval from 400 to $240 \mathrm{~ms}$ (upper curve), whereas it had no effect on the mean AF-interval (middle curve). Right panel: Propranolol significantly lengthened the mean RR-interval from about 450 ms to more than $650 \mathrm{~ms}$ (upper curve). However, the mean atrial fibrillation interval of about $90 \mathrm{~ms}$ was not affected by the drug (lower curve).

Table 1 summarizes the effects of atropine and propranolol on the atrial refractory period and mean AF-interval, during sinus rhythm, after 1-3 days of AF, and during sustained AF (6 goats). During sinus rhythm, atropine slightly prolonged the AERP 400 from $148 \pm 11$ to $155 \pm 11 \mathrm{~ms}$ (n.s.). The AERP 200 was $134 \pm 7$ and $135 \pm 6$ respectively (n.s.). After 1-3 days of atrial fibrillation, the refractory periods had shortened to 116 $\pm 17(\mathrm{p}<0.01)$ and $117 \pm 12 \mathrm{~ms}(\mathrm{p}<0.05)$. After $1-3$ days of $A F$, atropine prolonged the AERP 400 slightly from $116 \pm 17$ to $127 \pm 14$ and the $\mathrm{AERP}_{200}$ from $117 \pm 12$ to and $124 \pm 7 \mathrm{~ms}$. However, both the $\mathrm{AERP}_{400}$ and the $\mathrm{AERP}_{200}$ remained shorter than before $A F$ was induced $(p<0.05$ and $p=0.07$ ). The mean $A F$-interval during sustained AF slightly lengthened by atropine from $93 \pm 8 \mathrm{~ms}$ to $99 \pm 5 \mathrm{~ms}(\mathrm{p}<0.05)$, whereas the mean RR-interval shortened from $462 \pm 71 \mathrm{~ms}$ to $351 \pm 137 \mathrm{~ms}(\mathrm{p}=0.09)$. In 1 of 6 experiments atrial fibrillation terminated 45 minutes after infusion of atropine. In this case the mean AF cycle length had prolonged from 84 to $101 \mathrm{~ms}$.

Propranolol slightly decreased the $\mathrm{AERP}_{400}$ during sinus rhythm from $159 \pm 18$ to $149 \pm 14 \mathrm{~ms}$ (n.s.); the $\mathrm{AERP}_{200}$ before and after propranolol was $134 \pm 6$ and $139 \pm$ 6 ms (n.s.). After 1-3 days of AF, propranolol had no effect on atrial refractoriness, the $\mathrm{AERP}_{400}$ and $\mathrm{AERP}_{200}$ before and after $B$-blockade being respectively $103 \pm 17$ and $102 \pm 15$ and $108 \pm 12$ and $109 \pm 12$ ms. The lengthening of the mean AF interval 
Table 1. Sensitivity of AERP and AF-Interval to Atropine and Propranolol During Sinus Rhythm and AF

\begin{tabular}{|c|c|c|c|c|c|c|c|}
\hline & & Atropine $\langle\mathrm{n}=$ & & & Propranolo & & \\
\hline & & Pre-drug & $\begin{array}{l}\text { After } \\
40 \text { Minutes }\end{array}$ & $\begin{array}{l}\text { Effect } \\
\text { of Atropine }\end{array}$ & Pre-drug & $\begin{array}{l}\text { After } \\
30 \text { Minutes }\end{array}$ & $\begin{array}{l}\text { Effect } \\
\text { of Propranolor }\end{array}$ \\
\hline Sinus & $\mathrm{AERP}_{400}$ & $148 \pm 11$ & $155 \pm 11^{\S}$ & $7 \pm 5$ & $159 \pm 18$ & $149 \pm 14$ & $-10 \pm 10$ \\
\hline Rhythm & $\mathrm{AERP}_{200}$ & $134 \pm 7$ & $135 \pm 6$ & $1 \pm 2$ & $134 \pm 6$ & $139 \pm 6$ & $4 \pm 5$ \\
\hline After $1-3$ & AERP $_{400}$ & $116 \pm 17^{* *}$ & $127 \pm 14^{\dagger}$ & $9 \pm 5$ & $103 \pm 17^{*}$ & $102 \pm 15^{\circ}$ & $-1 \pm 4$ \\
\hline days AF & $\mathrm{AERP}_{200}$ & $117 \pm 12^{*}$ & $124 \pm 7$ & $7 \pm 8$ & $108 \pm 12^{* *}$ & $109 \pm 12^{* *}$ & $1 \pm 4$ \\
\hline Sustained AF & AF-interval & $93 \pm 8$ & $99 \pm 5^{\dagger}$ & $6 \pm 5$ & $93 \pm 6$ & $98 \pm 10$ & $4 \pm 6$ \\
\hline & RR-interval & $462 \pm 71$ & $351 \pm 137$ & $-111 \pm 119$ & $454 \pm 68$ & $666 \pm 83^{\ddagger}$ & $212 \pm 88$ \\
\hline
\end{tabular}

Numbers indicate mean values and standard deviation of the mean; $\mathrm{AERP}_{400}$. Atrial effective refractory period during pacing with $400 \mathrm{~ms}$ cycle length; $A E R P_{200}$, Atrial effective refractory period during pacing with $200 \mathrm{~ms}$ cycle length; $\S$, in one goat the AERP at $400 \mathrm{~ms}$ could not be measured after atropine due to an increase in sinus rhythm; " $p<0.05$, , $p<0.01$, compared to sinus rhythm pre-drug (paired Student's f-test, corrected for multiple comparisons); $f p<0.05$, drug compared to pre-drug (paired Student's t-test).

by propranolol from $93 \pm 6 \mathrm{~ms}$ to $98 \pm 10 \mathrm{~ms}$ was not statistically significant. The mean RR-interval lengthened from $454 \pm 68$ to $666 \pm 83 \mathrm{~ms}$ ( $\mathrm{p}<0.01$ ).

Despite blockade of either the parasympathetic limb of the ANS by atropine or the sympathetic limb by propranolol, the mean cycle length of sustained atrial fibrillation remained significantly shorter than during recent onset AF $(99 \pm 5$ and $98 \pm 10 \mathrm{~ms}$ versus $148 \pm 13 \mathrm{~ms})(\mathrm{p}<0.001)$.

Atrial Ischemia and Administration of Glybenclamide

In anesthetized dogs induction of atrial fibrillation causes a sharp increase in oxygen consumption of the atrial myocardium from $3.9 \pm 0.6$ to $12.3 \pm 2.8 \mathrm{ml} \mathrm{O}_{2} / \mathrm{min}$ per 100 gram (3.2-fold increase) ${ }^{5}$ At the same time coronary perfusion of the atria increases 2- to 3 -fold. During atrial fibrillation, the reactive hyperemia response was found to be markedly attenuated and in some dogs nearly abolished. ${ }^{5}$ Thus, although in the anesthetized dog the coronary flow still seemed adequate to meet the increased oxygen demand during acutely induced AF, it might be possible that in conscious animals the reduced coronary flow reserve may no longer meet the increased oxygen demand of the chronically fibrillating atria. If, as a result, the atria would become ischemic, opening of ATP-regulated potassium channels might lead to a shortening of the action potential and atrial refractory period. To test this hypothesis, in 5 goats with sustained AF the ATP regulated potassium channels were blocked by a bolus injection of glybenclamide (10 $\mu \mathrm{mol} / \mathrm{kg}$ i.v.). In Fig 4 an example is given. After infusion of glybenclamide the mean RR-interval during atrial fibrillation increased from 500 to more than $600 \mathrm{~ms}$. In this case no effect on the mean AF-interval could be seen. 


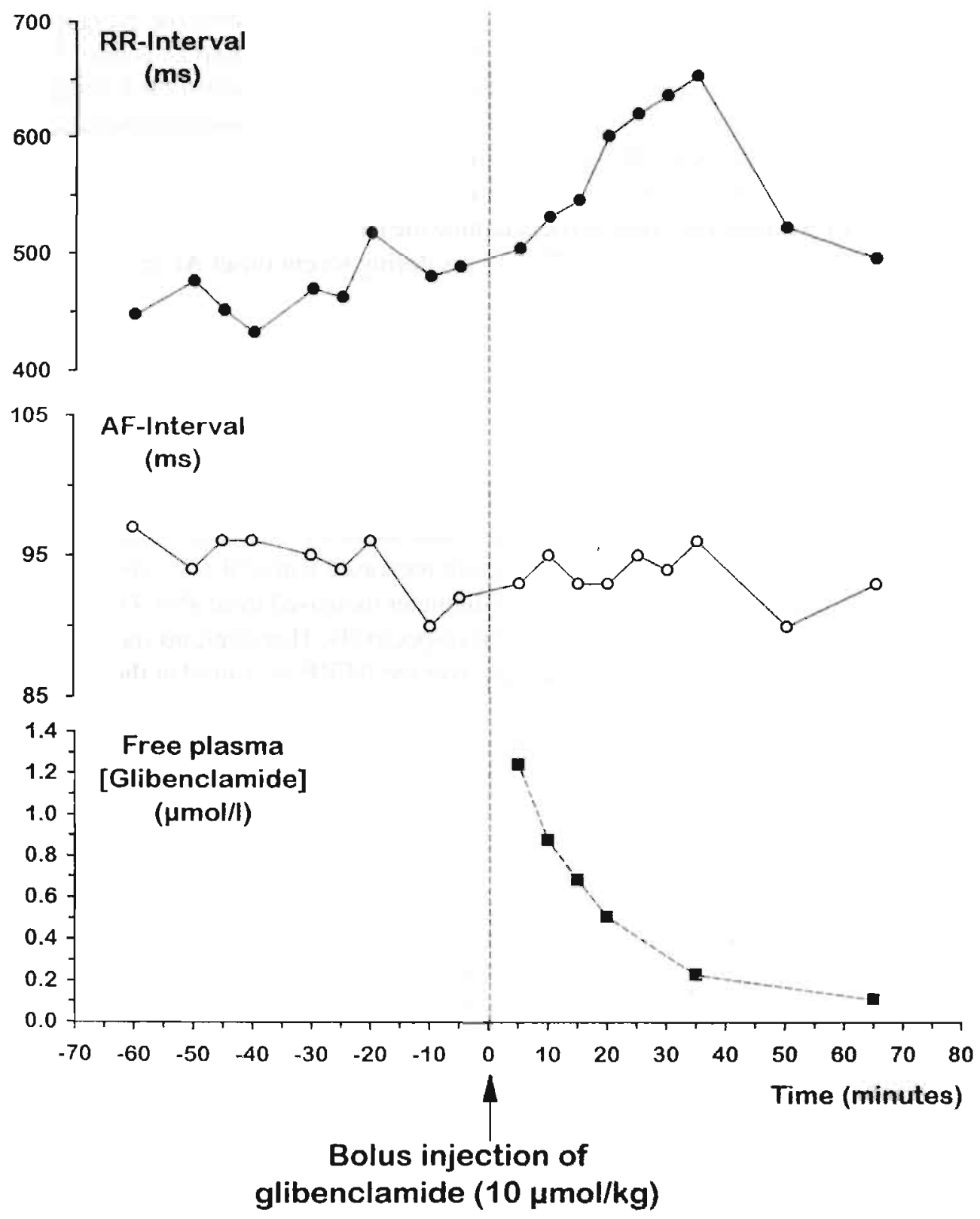

Figure 4. The effects of a bolus injection of glybenclamide $(10 \mu \mathrm{mol} / \mathrm{kg})$ on chronic atrial fibrillation (effective free plasma concentration of $1.24 \mu \mathrm{mol} /$, lower panel). The RR-interval slightly increased from about $500 \mathrm{~ms}$ to $600 \mathrm{~ms}$. However, the AF-interval was not affected by blockade of the ATP-regulated K-channels. 
Five, 10 and 15 minutes after the bolus injection of glybenclamide, the average free plasma concentration was $1.2 \pm 0.1,0.7 \pm 0.2$ and $0.6 \pm 0.2 \mu \mathrm{mol} / \mathrm{l}$ ( 3 goats). These plasma levels were well within the effective range of glybenclamide of $0.1-1.5 \mu \mathrm{M}$ ats reported by Escande et al. ${ }^{6}$ On the average, in 5 goats the injection of glybenclamide slightly prolonged the mean AF-interval from $95 \pm 4$ to $101 \pm 5 \mathrm{~ms}(\mathrm{p}<0.05)$. However blockade of the ATP regulated potassium channels did not abolish the AF-induced shortening of AF-interval. After glybenclamide the mean AF-interval of sustained $\mathrm{AF}$ was still $101 \pm 5 \mathrm{~ms}$ compared to $145 \pm 11 \mathrm{~ms}$ during recent onset $\mathrm{AF}$ ( $\mathrm{p}<0.001$ ).

\section{Acute Atrial Dilatation}

To determine whether atrial dilatation could be the cause of the observed AF-induced shortening of AERP, in 12 normal goats having been in sinus rhythm before, the vascular system was overfilled with 0.5-1.0 liters of a blood expanding fluid. In Table 2 the effects of acute volume loading are given. As expected, infusion of Haemaccel ${ }^{\circledR}$ resulted in a clear increase in atrial pressure and diameter. After infusion of 0.5 and 1.0 liter of Haemaccel the right atrial pressure increased with $2.0 \pm 0.7(\mathrm{p}<0.05)$ and $4.5 \pm 0.5 \mathrm{mmHg}(p<0.001)$. The left atrial diameter increased from $45 \pm 4 \mathrm{~mm}$ during control to $48 \pm 4(p<0.001)$ and $47 \pm 2 \mathrm{~mm}$ respectively. However, no shortening of the atrial refractory period was found. The average AERP measured at the right and left atria during pacing with $300-350 \mathrm{~ms}$ interval were $163 \pm 21$ and $164 \pm 21 \mathrm{~ms}$ during control, $171 \pm 21$ and $166 \pm 19 \mathrm{~ms}$ after infusion of 0.5 liter of Haemaccel ${ }^{(i)}$ and $168 \pm 23$ and $176 \pm 16$ ms respectively after 1.0 liter (n.s.).

\section{The Atrial Natriuretic Factor}

In 6 goats the level of atrial natriuretic factor was determined from peripheral venous blood samples collected during sinus rhythm and after 1-2 days and 1-4 weeks of continuous atrial fibrillation. During sinus rhythm the median ANF plasma level was $42 \mathrm{pg} / \mathrm{ml}$. After 1-2 days and 1-4 weeks of AF the ANF plasma levels were 61 (n.s.) and $99 \mathrm{pg} / \mathrm{ml}(\mathrm{p}<0.05)$ respectively.

To test the hypothesis that an increase in ANF plasma levels is responsible for the shortening of AERP by AF, in 4 goats $\alpha$-human 1-28 ANF wals infused during 60 minutes at increasing dosages between 0.1-3.1 $\mu \mathrm{g} / \mathrm{min}$. In Fig 5 an example is given. The ANF infusion resulted in a progressive increase in plasma ANF from $165 \mathrm{pg} / \mathrm{ml}$ to $550 \mathrm{pg} / \mathrm{ml}$ at the end of the infusion. Despite this more than 3-fold increase in ANF, no effects on the atrial effective refractory period was detected. The average ANF plasma level before and after infusion $(\mathrm{n}=3)$ was $127 \pm 27$ and $506 \pm 33 \mathrm{pg} / \mathrm{ml}$ $(\mathrm{p}<0.001)$. The atrial refractory period before and after infusion of ANF was $133 \pm$ 18 and $138 \pm 16 \mathrm{~ms}$ (n.s.). 
Table 2. The Effects of Acute Volume Loading on Right Atrial Pressure, Left Atrial Diameter and Atrial Refractory Period

\begin{tabular}{|c|c|c|c|c|}
\hline & Control & & & \\
\hline & Right & Left & Right" & Left \\
\hline Goal & Atrial ERP & Atrial ERP & Atrial & Atrial \\
\hline$\#$ & $\begin{array}{l}300-350 \\
(\mathrm{~ms})\end{array}$ & $\begin{array}{l}300-350 \\
\text { (ms) }\end{array}$ & $\begin{array}{l}\text { Pressure } \\
\text { (mmHg) }\end{array}$ & $\begin{array}{l}\text { Diameter } \\
\text { (mm) }\end{array}$ \\
\hline
\end{tabular}

\begin{tabular}{llll}
\multicolumn{3}{l}{ After Volume Loading With } & 0.5 Liters \\
\hline Right & Left & Change in & Left \\
Atrial ERP & Atrial ERP & Right Atrial & Atrial \\
$300-350$ & $300-350$ & Pressure & Diameter \\
(ms) & (ms) & (mmHg) & (mm)
\end{tabular}

After Volume Loading With 1.0 Liters

\begin{tabular}{|c|c|c|c|c|c|c|c|c|c|c|c|c|}
\hline 1 & 156 & 145 & - & 41 & 152 & 148 & - & 44 & - & - & - & - \\
\hline 2 & 149 & 174 & - & 49 & 148 & 173 & - & 51 & - & - & - & - \\
\hline 3 & 178 & 158 & - & 47 & 180 & 163 & - & 49 & - & - & - & - \\
\hline 4 & 172 & 133 & - & 52 & 175 & 134 & - & 56 & - & - & - & - \\
\hline 5 & 122 & 139 & 4 & - & 139 & 152 & +2 & & 139 & 154 & +5 & - \\
\hline 6 & 192 & 179 & 9 & 42 & 198 & 182 & +3 & 44 & 195 & 181 & +4 & 50 \\
\hline 7 & 176 & 181 & 3 & 42 & 180 & 182 & +2 & 44 & 179 & 181 & +5 & 45 \\
\hline 8 & 192 & 191 & 7 & 44 & 193 & 195 & +1 & 45 & 200 & 193 & +4 & 47 \\
\hline 9 & 165 & 149 & - & - & - & - & - & - & 159 & 158 & - & - \\
\hline 10 & 136 & 151 & - & - & - & - & - & - & 133 & 163 & - & - \\
\hline 11 & 171 & 198 & - & - & - & - & - & - & 175 & 199 & - & - \\
\hline 12 & 149 & - & - & - & - & - & - & - & 165 & - & - & - \\
\hline Mean & 163 & 164 & 5.8 & 45 & 171 & 166 & $+2.0^{\circ}$ & $48^{\circ}$ & 168 & 176 & $+4.55^{\circ \prime}$ & 47 \\
\hline Sd & 21 & 21 & 2.4 & 4 & 21 & 19 & 0.7 & 4 & 23 & 16 & 0.5 & 2 \\
\hline$n$ & 12 & 11 & 4 & 7 & 8 & 8 & 4 & 7 & 8 & 7 & 4 & 3 \\
\hline
\end{tabular}

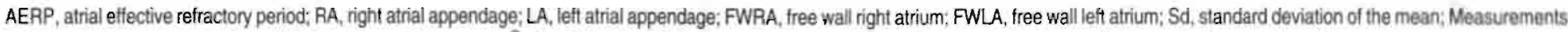
before and after volume loading with $0.5-1.0$ liters of Haemaccel ${ }^{3}$; $" p<0.05, " p<0.01$ compared with control (paired Student's t-test, corrected for multiple comparisons). 


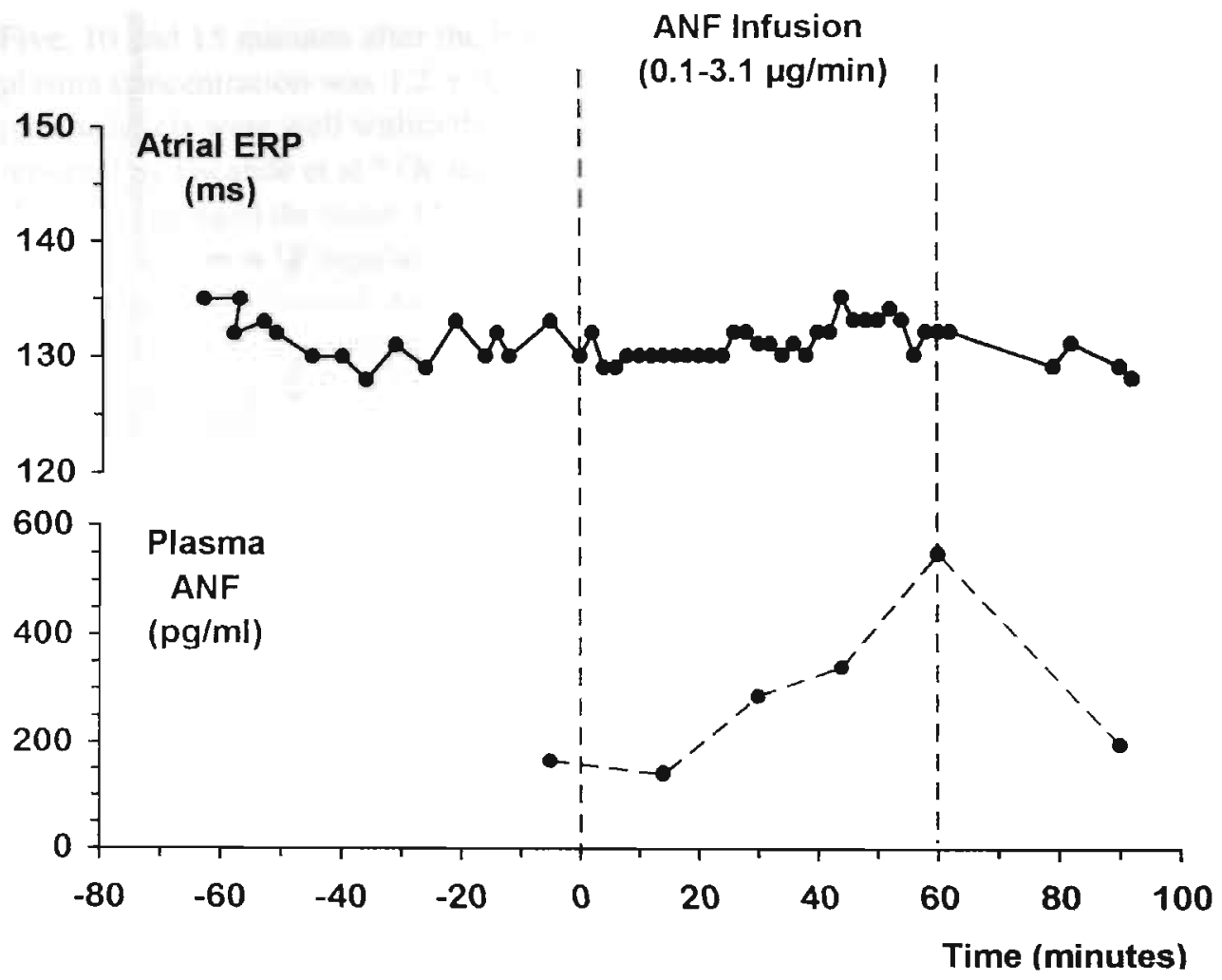

Figure 5. Demonstration of the lack of effect of infusion of $\alpha$-human 1-28 ANF on the atrial refractory period during pacing at an interval of $400 \mathrm{~ms}$. ANF was infused during 60 minutes in a continuously increasing dosage of 0.1 to 3.1 $\mu \mathrm{g} / \mathrm{min}$. The progressive increase in plasma levels of ANF to more than $500 \mathrm{pg} / \mathrm{ml}$ did not exert an effect on the refractory period of the atria.

\section{Long-term Effects of Rapid Atrial Pacing}

In 10 goats the effects of prolonged rapid pacing with a cycle length of $180-200 \mathrm{~ms}$ was studied. Fig 6 gives a representative example of the long-term effects of rapid pacing on the atrial effective refractory period. In this example the atria were paced with an interval of $180 \mathrm{~ms}$ associated with $2: 1 \mathrm{AV}$ block. At the start of rapid pacing the AERP was $120 \mathrm{~ms}$ (upper tracing). Already after 6 hours of maintained rapid pacing the atrial refractory period had shortened to $105 \mathrm{~ms}$ and the early premature beat was followed by 3 rapid repetitive responses (middle tracing, asterisks). After 24 hours of rapid pacing the refractory period was further shortened to $99 \mathrm{~ms}$ and the early premature stimulus now induced a short run of atrial fibrillation (lower tracing). In Fig 7 an example of the time course of this long-term shortening of atrial refractoriness is shown. First the heart was paced during about 2 days with a fixed interval of $360 \mathrm{~ms}$ with $1: 1 \mathrm{AV}$ conduction. During this time the goat was allowed to adapt hemodynamically to this fixed pacing rate. Continuous atrial pacing with an 

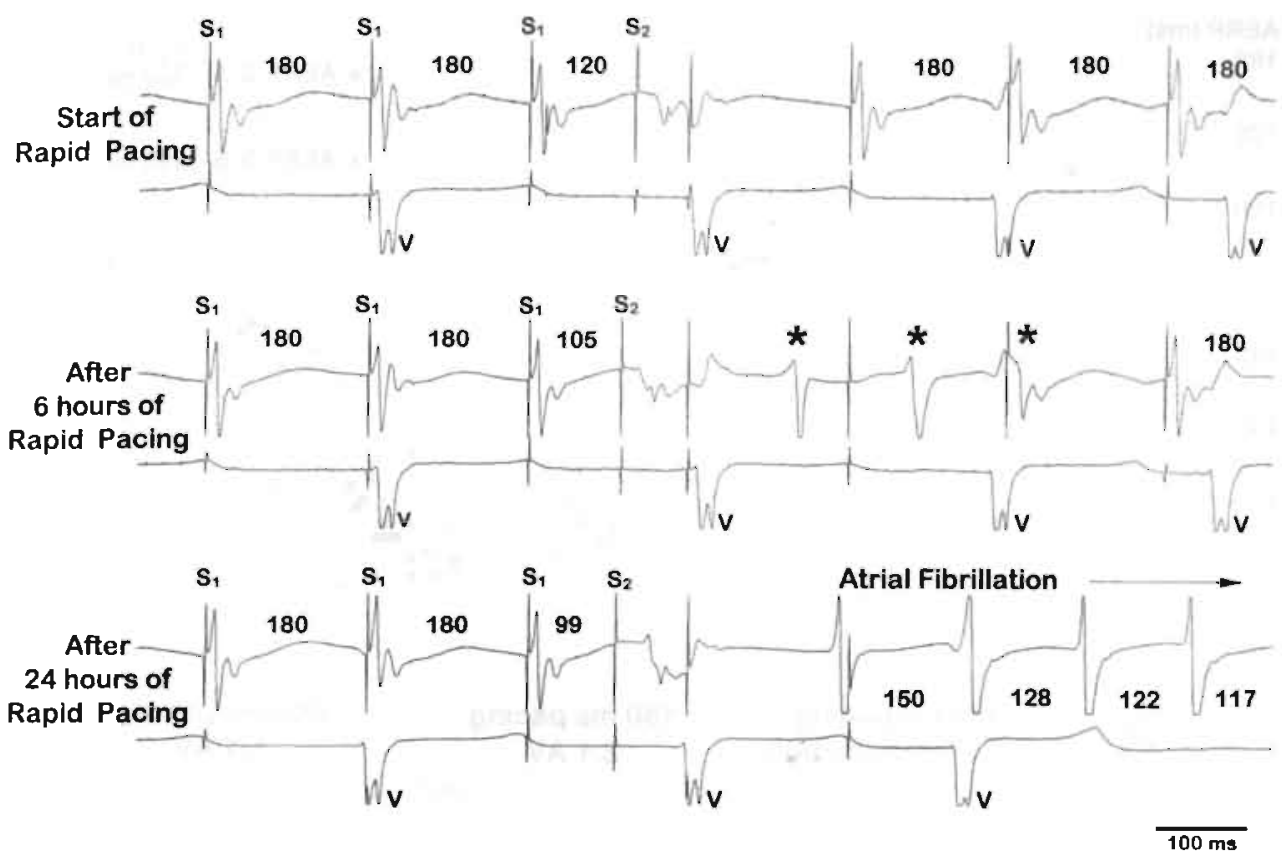

Figure 6. An example of the prolonged effects of rapid pacing on the atrial effective refractory period. The atria were paced with an $S_{1}-S_{1}$ interval of $180 \mathrm{~ms}$ with $2: 1$ AV block. Al the start of rapid pacing the shortest $S_{1}-S_{2}$ interval that captured the atria was $120 \mathrm{~ms}$ (upper traces). Already after 6 hours of rapid pacing the AERP had shortened to 105 ms (middle traces). After 24 hours (lower tracings) the shortest coupling interval that could evoke a premature response was $99 \mathrm{~ms}$. This long-term rate adaptation of the refractory period had a clear effect on the inducibility of atrial arrhythmias. Whereas in the beginning the earliest premature beat did not induce an arrhythmia, after 6 hours of rapid pacing a single early premature beat was followed by three spontaneous repetitive responses (asterisks). After 24 hours the early premature stimulus induced a short run of atrial fibrillation.

interval of $360 \mathrm{~ms}$ shortened the AERP from 165 to $155 \mathrm{~ms}$. When the atrial pacing rate was suddenly doubled $(\mathrm{t}=0)$, the atrial refractory period immediately shortened to $135 \mathrm{~ms}$ (physiological rate adaptation). However, when this high pacing rate was maintained, the AERP continued to shorten to 110-115 ms during the first 1-2 days. This long-term shortening of the AERP showed an exponential time course. During the first 24 hours the shortening was most pronounced, whereas during the second day the shortening was clearly less. During the period of rapid pacing the ventricular rate was unchanged due to the occurrence of $2: 1 \mathrm{AV}$ block. When after 2 days of rapid atrial pacing the paced rate was reduced again to an interval of $360 \mathrm{~ms}(1: 1 \mathrm{AV}$ conduction), the $\mathrm{AERP}_{360}$ was $115 \mathrm{~ms}$ compared to $155 \mathrm{~ms}$ before the two days of rapid pacing. This long-term shortening of the atrial refractory period of $40 \mathrm{~ms}$ was completely reversible and within 1-2 days of slow pacing the AERP gradually prolonged again to $155 \mathrm{~ms}$.

In Fig 8 the rate adaptation of the atrial effective refractory period is given both during slow pacing ( $360 \mathrm{~ms}$ ) and after 2 days of rapid pacing (interval $180 \mathrm{~ms}$ ) (same 


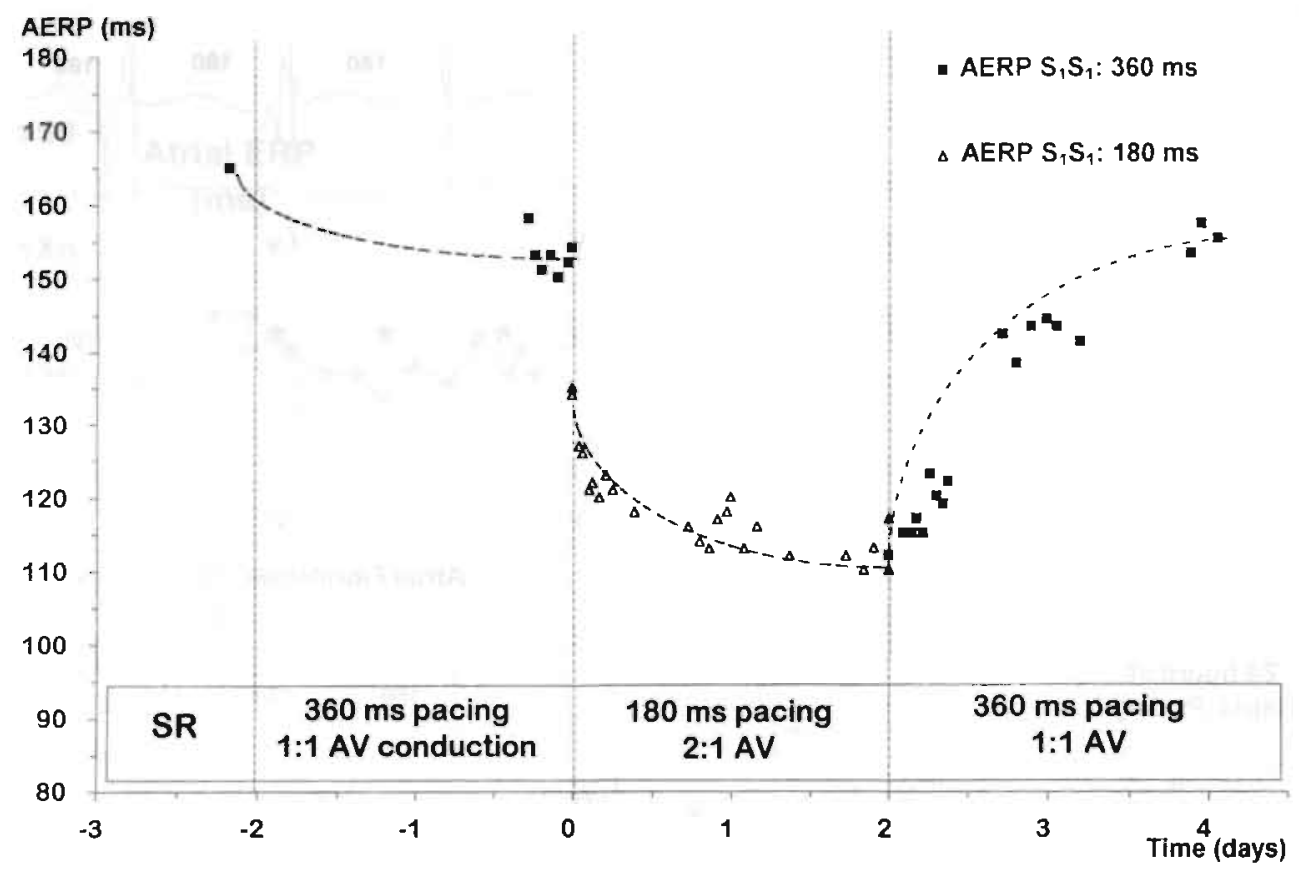

Figure 7. The cuorse of fong-term adistation of the refractory period to pacing rate. After 2 days of atrial pacing with a fixed interval of $360 \mathrm{~ms}$ ( $1: 1 \mathrm{AV}$-conduction), the atrial refractory period was $155 \mathrm{~ms}(\mathrm{~J}$. Shortening of the atrial pacing interval to $180 \mathrm{~ms}$ resulted in an immediate shortening of the AERP to $135 \mathrm{~ms}(\Delta)$ (short-term rate adaptation). When the high pacing rate was maintained during 2 days. the AERP further shortened to $110-115 \mathrm{~ms}$. This long-term adaptation to a higher pacing rate occurred while the ventricular rate remained unchanged due to the presence of $2: 1 \mathrm{AV}$-block. When after 2 days of rapid pacing the pacing rate was slowed again (interval $360 \mathrm{~ms}$ ) the AERP gradually prolonged again to its original value.

experiment as Fig 7). After 2 days of rapid pacing the AERP had shortened markedly at all pacing rates. Especially at the slower pacing rates, the physiological rate adaptation was inverted and instead of getting longer, now the AERP got shorter at longer pacing intervals. This resulted in a marked shortening of the refractory period during pacing with an $S_{1}-S_{1}$ interval of $400 \mathrm{~ms}$ from 153 to $110 \mathrm{~ms}$. Due to the maladaption of the refractory period to heart rates, after two days of rapid pacing, the AERP at high and low heart rates was about the same. The adaptation curve with the open symbols was measured 2 days after the atria had been paced again at a slow rate. As can be seen the long-term effects of rapid pacing on the atrial refractory period were reversible and within 2 days the AERP's had almost returned to control values. In Table 3 the effects of prolonged rapid atrial pacing on the refractory period are given for 10 goats. During sinus rhythm the atrial refractory period at a pacing interval of $400 \mathrm{~ms}$ was $156 \pm 15 \mathrm{~ms}$ shortening to $137 \pm 5$ at a pacing interval of $200 \mathrm{~ms}$. After 1-2 days of slow pacing the $\mathrm{AERP}_{400}$ and $\mathrm{AERP}_{200}$ were $134 \pm 10 \mathrm{~ms}$ and $130 \pm 9$ $\mathrm{ms}$ respectively. One day of prolonged rapid atrial pacing clearly shortened the $\mathrm{AERP}_{400}$ from $134 \pm 10$ to $105 \pm 8 \mathrm{~ms}(\mathrm{p}<0.001)$. The $\mathrm{AERP}_{200}$ had shortened from 


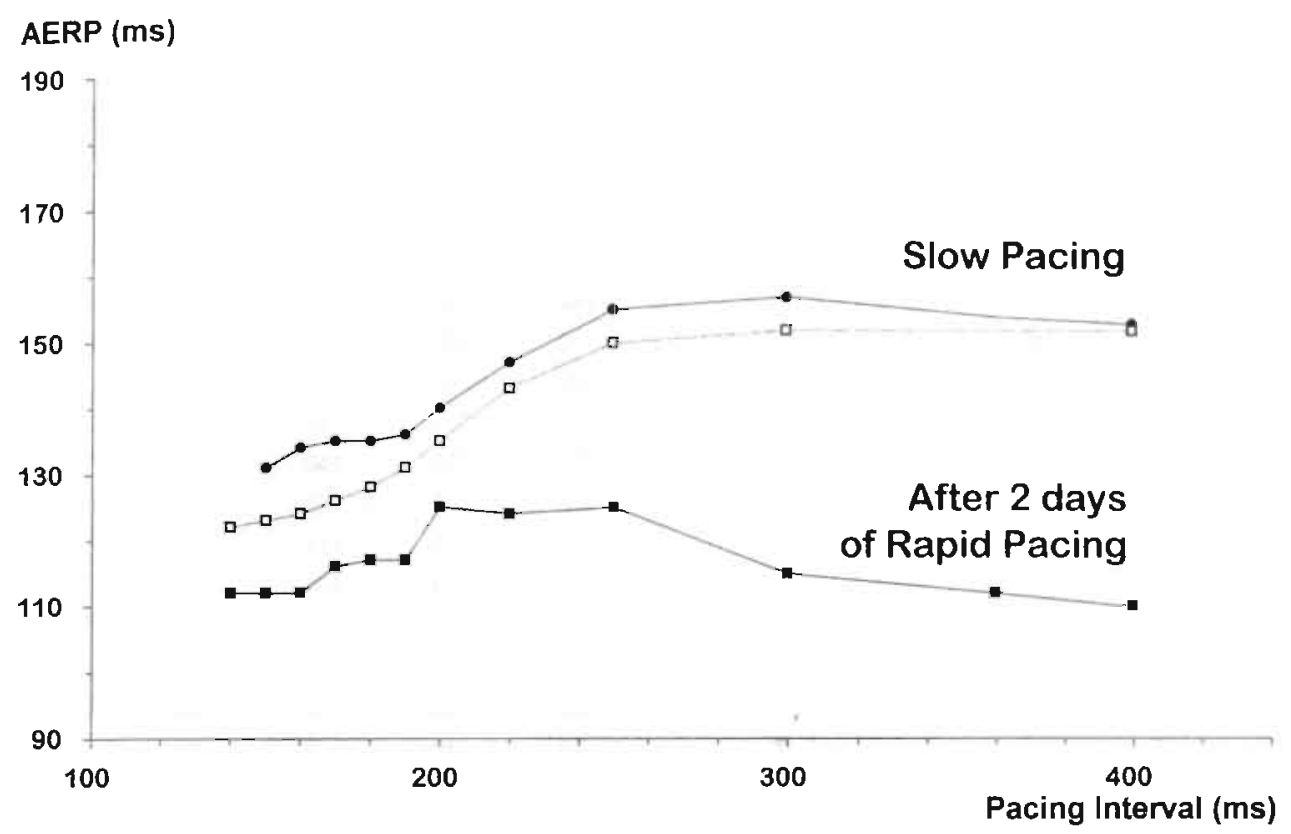

Figure 8. The short-term adaptation to different pacing rates before and after 2 days of continuous rapid atrial pacing. After 2 days of slow pacing the atrial refractory period shortened from 153 to $130 \mathrm{~ms}$ during pacing with progressively shorter $S_{1}-S_{1}$ intervals $(\bullet)$. After 2 days of rapid pacing $\left(S_{1}-S_{1}\right.$ interval $180 \mathrm{~ms}: 2: 1$ AV-block) the AERF was shortened at all heart rates (_). In addition the normal physiological rate adaptation was inverted and as a result during slow pacing the refractory period was now as short as during the maximal pacing rate. When after 2 days of rapid pacing the pacing interval was doubled again to $360 \mathrm{~ms}$. within 2 days the long-term changes of the AERP by rapid pacing had almost reversed to control completely (_.).

$130 \pm 9$ to $110 \pm 8 \mathrm{~ms}(\mathrm{p}<0.001)$. After 2 days of rapid pacing the refractory period did not show a further statistically significant shortening. The physiological prolongation of the refractory period in response to a slowing in heart rate was completely abolished after 1-2 days of continuous rapid pacing, the AERP at the maximal pacing rate now being slightly longer than during pacing with $400 \mathrm{~ms}$ interval ( $108 \pm 7$ versus $105 \pm 6 \mathrm{~ms}$ ). As can be seen from the last columns, all the long-term changes in AERP were completely reversible and after $1-2$ days of slow pacing no statistically significant changes in refractory periods could be measured anymore.

\section{Discussion}

Recently we reported, that in chronically instrumented goats the repetitive induction of atrial fibrillation resulted in a progressive shortening of atrial refractoriness and development of sustained atrial fibrillation. ${ }^{1}$ The present study was designed to evaluate whether the autonomic nervous system, atrial ischemia, acute atrial stretch, 
Table 3. Adaptation of the Atrial Effective Refractory Period to Prolonged Rapid Atrial Pacing

\begin{tabular}{|c|c|c|c|c|c|c|c|c|}
\hline \multirow{2}{*}{$\begin{array}{l}\text { Goat } \\
\#\end{array}$} & \multicolumn{4}{|c|}{$\begin{array}{l}\text { Sinus Rhythm } \\
\text { Pacing Intervals }\end{array}$} & \multicolumn{4}{|c|}{$\begin{array}{l}\text { After 1-3 Days of Slow Pacing } \\
\text { Pacing Intervals }\end{array}$} \\
\hline & 400 & 250 & 200 & Fmax & 400 & 250 & 200 & Fmax \\
\hline 1 & 154 & 170 & 141 & 133 & 131 & 151 & 143 & 129 \\
\hline 2 & 185 & 153 & 138 & 129 & 142 & 132 & 124 & 117 \\
\hline 3 & 148 & 149 & 135 & 117 & 130 & 132 & 121 & 106 \\
\hline 4 & 142 & 144 & 146 & 145 & 134 & 143 & 138 & 140 \\
\hline 5 & 140 & 142 & 132 & 115 & 124 & 131 & 121 & 102 \\
\hline 6 & 165 & 157 & 140 & 130 & 153 & 155 & 140 & 131 \\
\hline 7 & 178 & 155 & 143 & 140 & 146 & 141 & 138 & 128 \\
\hline 8 & 141 & 138 & 130 & 116 & 115 & 121 & 114 & 104 \\
\hline 9 & 161 & 150 & 139 & 128 & 137 & 138 & 134 & 122 \\
\hline 10 & 146 & 141 & 130 & 124 & 130 & 134 & 125 & 115 \\
\hline Mean & 156 & 150 & 137 & 128 & $134^{\S \S}$ & $138^{\S \S}$ & $130^{\S}$ & $119^{\S \S}$ \\
\hline $\mathrm{Sd}$ & 15 & 9 & 5 & 10 & 10 & 10 & 9 & 12 \\
\hline
\end{tabular}

Numbers indicate atrial effective refractory period in ms. Fmax, maximal pacing frequency; Sd, standard deviation; During slow pacing the atrium was paced with a fixed interval between 360 and $400 \mathrm{~ms}$ and 1:1 AV-conduction; During rapid pacing the atrium was paced with a fixed interval between 180 and 200 ms and $2: 1 \mathrm{AV}$-conduction; $\S p<0.01, \S \S p<0.0011$-2 days of slow pacing compared to sinus rhythm (paired Student's t-test); "'p<0.001 1 day of rapid pacing compared to control (paired Student's t-test); No stalistically signilicant differences were found between 2 days and 1 day of rapid pacing or between reversibility and 1-2 days of slow pacing; $¥$, in these guats changes in atrial refractoriness could not be followed anymore because long-lasting episodes of atrial fibrillation were induced. -- missing data because in these goats only 24 hours of rapid pacing was periormed.

the atrial natriuretic factor or a high rate of atrial activation itself play a role in this process of electrical remodeling.

The Autonomic Nervous System

Changes in the neurohumoral balance are important both for the induction and perpetuation of atrial fibrillation. In humans, Coumel et al. ${ }^{7}$ has distinguished two different types of atrial fibrillation based on the activity of the autonomic nervous system prior to the occurrence of AF. In one group of patients, AF occurred in the presence of a high vagal tone, whereas in the other group the sympathetic limb of the ANS was predominantly active. Experimental studies showed that administration of acetylcholine or a high vagal tone shorten the refractory period and the wavelength of the atrial impulse, thereby facilitating the induction of atrial arrhythmias. ${ }^{8-11}$ The effects of increased sympathetic activity are less clear. Sometimes a shortening of atrial refractoriness occurs, ${ }^{9,12-14}$ whereas in other cases refractoriness prolongs. ${ }^{10,13.14}$ This discrepancy might be explained by the fact that stimulation of $\beta$-adrenergic receptors enhances inward currents $\left(\mathrm{Na}^{+}\right.$or $\left.\mathrm{Ca}^{2+}\right),{ }^{15}$ as well as outward 
Table 3 (continued). Adaptation of the Atrial Effective Refractory Period to Prolonged Rapid Atrial Pacing

\begin{tabular}{|c|c|c|c|c|c|c|c|c|c|c|c|c|}
\hline \multirow{2}{*}{$\begin{array}{l}\text { Goat } \\
\#\end{array}$} & \multicolumn{4}{|c|}{$\begin{array}{l}\text { After } 1 \text { Day of Rapid Pacing } \\
\text { Pacing Intervals }\end{array}$} & \multicolumn{4}{|c|}{$\begin{array}{l}\text { After } 2 \text { Days of Rapid Pacing } \\
\text { Pacing Intervals }\end{array}$} & \multicolumn{4}{|c|}{$\begin{array}{l}\text { Reversibility After } 1 \cdot 2 \text { Days of Slow Pacing } \\
\text { Pacing Intervals }\end{array}$} \\
\hline & 400 & 250 & 200 & Fmax & 400 & 250 & 200 & Fmax & 400 & 250 & 200 & $F_{\max }$ \\
\hline 1 & 95 & 117 & 110 & 112 & - & - & - & - & 129 & 162 & 148 & 133 \\
\hline 2 & 108 & $\{15$ & 112 & 106 & - & - & - & - & 148 & 142 & 133 & 125 \\
\hline 3 & 100 & 105 & 102 & 95 & - & - & - & - & 143 & 142 & 129 & 110 \\
\hline 4 & 110 & 111 & 113 & 114 & 104 & 106 & 108 & 111 & 124 & 131 & 134 & 132 \\
\hline 5 & $\ddagger$ & $\ddagger$ & $\ddagger$ & $\ddagger$ & $\ddagger$ & $\ddagger$ & $\ddagger$ & $\neq$ & 133 & 147 & 131 & 97 \\
\hline 6 & 121 & 127 & 128 & 116 & 110 & 125 & 125 & 112 & 154 & 150 & 135 & 122 \\
\hline 7 & 108 & 107 & 106 & 106 & 115 & 115 & 120 & 118 & 156 & 163 & 134 & 123 \\
\hline 8 & 99 & 109 & 104 & 93 & 100 & 105 & 106 & 100 & 128 & 124 & 120 & 110 \\
\hline 9 & $\ddagger$ & $\ddagger$ & $\ddagger$ & $\ddagger$ & $\ddagger$ & $\ddagger$ & $\ddagger$ & $\ddagger$ & 136 & 145 & 135 & 118 \\
\hline 10 & 97 & 107 & 107 & 97 & 98 & 100 & 102 & 100 & 133 & 136 & 126 & 120 \\
\hline Mean & $105^{\circ}$ & $112^{*}-$ & $110^{*}$ & $105^{*}$ & 105 & 110 & 112 & 108 & 138 & 144 & 133 & 119 \\
\hline Sd & 8 & 7 & 8 & 8 & 6 & 9 & 9 & 7 & 11 & 12 & 7 & 10 \\
\hline
\end{tabular}

potassium currents. ${ }^{16}$ The effects of adrenergic stimulation on the action potential were studied by Quadbeck et al. ${ }^{14}$ and Kass et al. ${ }^{13}$ They showed that noradrenaline exerted a biphasic effect on the duration of the action potential. At low concentrations $\left(10^{-7} \mathrm{M}\right)$ the action potential prolonged, whereas at higher concentrations $\left(5 \times 10^{-5} \mathrm{M}\right)$ the duration of the action potential shortened again. Quadbeck et al. ${ }^{14}$ suggested that the lengthening of repolarization was caused by activation of an inward current (possibly $\mathrm{Na}^{+}$-ions), while at higher concentrations this effect was counteracted by enhancement of an outward potassium current. Kass and co-workers ${ }^{13}$ measured the dose-dependent effects of noradrenaline on the L-type $\mathrm{Ca}^{2+}$-current and the outward $\mathrm{K}^{+}$-currents. They explained the shortening of the action potential at a higher concentration of noradrenaline by a more pronounced effect on the $\mathrm{K}^{+}$-current (5-fold) than on the $\mathrm{Ca}^{2+}$-current (2.5-fold). Thus it will depend on the relative contribution of $\mathrm{Na}^{+}$, $\mathrm{Ca}^{2+}$ - and $\mathrm{K}^{+}$-channels and on the amount of sympathetic stimulation whether the action potential and hence the refractory period will shorten or lengthen.

In the present study we measured the effects of atropine and propranolol on atrial refractoriness before and after electrical remodeling by AF. Atropine and propranolol had only minor effects on the AERP, both during normal sinus rhythm and after AF 
had been maintained for 1-3 days. In all cases the shortening of the refractory period by AF was preserved after blockade of either limb of the autonomic nervous system (Table 1). When atropine or propranolol were given during chronic AF, the mean fibrillation interval remained significantly shorter than during recent onset fibrillation ( $99 \pm 5$ and $98 \pm 10$ versus $148 \pm 13 \mathrm{~ms}$ ). From these data it might be concluded that the AF-induced shortening of the atrial refractory period is not mediated by an increase in parasympathetic or sympathetic activity or by a higher sensitivity for neurotransmitters.

Atrial Ischemia and Blockade of the ATP-regulated Potassium Channels

In anesthetized dogs, White et al. ${ }^{5}$ studied the acute effects of electrically induced atrial fibrillation on the balance between blood supply and energy demand. They found that atrial fibrillation caused a 2-3 fold increase in atrial blood flow and oxygen consumption, the resulting reduction in the atrial flow reserve making it conceivable that a turther increase in metabolic demands during AF might lead to atrial ischemia. It has been shown that the shortening of the action potential by ischemia is caused by activation of an ATP-regulated potassium channel. ${ }^{17}$ To test the hypothesis that the AF-induced shortening of the refractory period was caused by atrial ischemia, we administered a specific blocker of the ATP-regulated channel (glybenclamide) during sustained AF. We used a high dosc of glybenclamide $(10 \mu \mathrm{mol} / \mathrm{kg})$ compared to other studies $(0.6-6.0 \mu \mathrm{mol} / \mathrm{kg}),{ }^{8} 8,19$ resulting in a free plasma concentration of $1.2 \pm 0.1$ $\mu \mathrm{M}$ (assuming $99 \%$ binding to plasmaproteins ${ }^{20}$ ). This concentration is well within the effective range of $0.1-1.5 \mu \mathrm{M}$ used in vitro by other investigators. ${ }^{6}$ Administration of glybenclamide during chronic AF prolonged the mean AF cycle length only slightly from $95 \pm 4$ to $101 \pm 5 \mathrm{~ms}(\mathrm{p}<0.05)$. This small increase in AF interval by glybenclamide can be explained by the observation of Smallwood et al. ${ }^{19}$ that also the $\mathrm{K}^{+} \mathrm{ATP}$ channels are slightly activated in the absence of ischemia. Because the mean AF remained significantly shorter than during recent onset $\mathrm{AF}(101 \pm 5 \mathrm{~ms}$ versus $145 \pm$ $11 \mathrm{~ms}, \mathrm{p}<0.001$ ), one can conclude that $\mathrm{K}^{+}$ATP channels were not responsible for the shortening of the atrial refractory period and the increase in rate of atrial fibrillation occurring during the first days of AF.

Atrial Dilatation and Effects of Acute Volume Loading

Several studies have shown a positive correlation between atrial enlargement and the incidence of AF. ${ }^{21-25}$ Petersen and co-workers compared the left atrial size determined by echocardiography, in patients in sinus rhythm, in patients with atrial fibrillation of 'short' duration ( $<3$ months) and in a group of patients being in AF for at least one year. ${ }^{21}$ The smallest atria were found during sinus rhythm $(38 \pm 6 \mathrm{~mm})$, an intermediate size in patients with AF of short duration $(43 \pm 5 \mathrm{~mm})$, whereas the largest atria were found in patients in which AF already existed for a long time ( $49 \pm$ $5 \mathrm{~mm}$ ). For many years it has been discussed whether atrial enlargement is either the 
cause or a consequence of atrial fibrillation. The high incidence of atrial fibrillation in the presence of mitral stenosis and/or mitral insufficiency strongly suggests that atrial dilatation is a cause of $\mathrm{AF}^{22,23}$ In the Framingham study the presence of rheumatic heart disease increased the risk ratio for the development of chronic $\mathrm{AF}$ to 8.3 in men and 15.3 in women. ${ }^{26}$ Other evidence that atrial stretch causes an increased propensity for atrial fibrillation was provided by animal studies in which atrial fibrillation was produced by mitral insufficiency or acute volume expansion. ${ }^{27-29}$ Several studies have shown that an inverse relationship exists between the size of the atria and the success rate of cardioversion and maintenance of sinus rhythm. ${ }^{24,30,31}$

While this body of evidence leaves little doubt that atrial enlargement is a cause of atrial fibrillation, other studies indicate that it may also be the result of it. Both in humans and animals it has been shown that the atrial pressure and/or capillary wedge pressure rises acutely during transition from sinus rhythm to atrial fibrillation. $5,32,33$ However, an acute rise in atrial pressure at the onset of AF was not associated with an immediate increase in atrial size. ${ }^{33}$ Other investigators ${ }^{24}$ measured the atrial diameter in patients in sinus rhythm and with paroxysmal or chronic AF and found no increase in atrial size after a paroxysm of AF. Other studies however showed that prolonged periods of atrial fibrillation did lead to atrial enlargement. ${ }^{25,34}$ Sanfillipo et al. followed a group of 15 patients with lone AF with normal atrial dimensions and no mitral valve or left ventricular pathology. ${ }^{34}$ During a follow-up period of 12-28 months (average 20.6 months), the diameter of the left and right atria increased with about $10-15 \%$ while right and left atrial volume increased with $35 \%$ and $42 \%$ respectively. Studies by Gosselink et al. ${ }^{35}$ and Van Gelder et al ${ }^{36}$ further supported the development of atrial enlargement as a result of AF by showing that after successful cardioversion the dimensions of the atria decreased with 5-10\%. From all these studies thus it appears that atrial dilatation can be both a cause and a consequence of atrial fibrillation.

There is a discrepancy in the literature about the effects of (acute) atrial dilatation on the refractory period of the atrial myocardium. In some studies a shortening of the AERP or the monophasic action potential was found, ${ }^{28,29}$ whereas other investigations reported no effect or a lengthening of the refractory period. ${ }^{37-39}$ In the present study we measured the effects of infusion of 0.5-1.0 liter of Haemaccel ${ }^{\circledR}$ on the AERP. The right atrial pressure rose with $4.5 \pm 0.5 \mathrm{mmHg}$ while the diameter of the left atrium increased with 4-7\%. The atrial refractory period of both right and left atria did not shorten but slightly prolonged, although this effect was not statistically significant (Table 2). The fact that in the goat, an acute increase in atrial pressure did not shorten the AERP suggests that the AF-induced shortening of the atrial refractory period was not mediated by an increase in atrial wall stress.

However, this does not exclude that prolonged atrial stretch, during days or weeks, will exert a different effect. Recently, Le Grand et al. studied the effects of chronic atrial dilatation on the duration of the human atrial action potential. ${ }^{40}$ In specimens taken from non-dilated atria (diameter $<40 \mathrm{~mm}$ ) and from dilated atria (diameter 55 
$\mathrm{mm})$, the duration of the refractory period and the action potential was determined. Although in the two groups no significant differences were found in the atrial refractory period, marked differences existed in the shape and duration of the action potential. Action potentials recorded from dilated atria showed a depressed or absent plateau phase, and at slow pacing intervals the duration of the action potential, measured at $50 \%$ and $90 \%$ repolarization, was as much as $31 \%$ and $13 \%$ shorter. Because in the dilated atria the rate adaptation of the duration of the action potential was attenuated, at higher pacing rates the action potential duration was similar in the two groups.

Both an increased outward potassium current or a decreased inward calcium can be responsible for this action potential shortening by chronic dilatation. Another possibility is activation of a chloride current by stretch which will accelerate the first part of the repolarization. ${ }^{41}$ Voltage clamp measurements have revealed that in dilated atria the total outward current, especially the calcium independent Iransient outward current $\left(\mathrm{I}_{\mathrm{tol}}\right)$, was diminished with more than $50 \% .{ }^{40}$ However, the L-type calcium current was even more reduced (75\%), thus explaining the depression of the action potential plateau and the shortening of the action potential. ${ }^{40}$ Because 20 of the 27 dilated atria were not fibrillating, these changes were considered to be caused by atrial dilatation rather than by AF. Therefore, although in our study acute volume loading did not result in a shortening of atrial refractoriness, it can not be excluded that prolonged atrial stretch is involved in the observed shortening of the atrial refractory period by sustained AF.

\section{The Atrial Natriuretic Factor}

It is well documented that the plasma level of ANF increases in response to atrial tachyarrhythmias. ${ }^{42}$ This was confirmed in our study in which the plasma level of ANF increased from 42 to $99 \mathrm{pg} / \mathrm{ml}$ after $1-4$ weeks of AF. The electrophysiological effects of ANF were recently reviewed by Clemo et al. ${ }^{43}$ ANF may exert an electrophysiological effect either by a direct effect on cardiac ionic channels or indirectly by modifying the autonomic nervous system. Le Grand et al. ${ }^{4+4}$ studied the effects of ANF on L-type Ca-currents $\left(\mathrm{I}_{\mathrm{Ca}}\right)$ and calcium-independent potassium currents $\left(\mathrm{I}_{\mathrm{tol}}\right)$ in isolated human atrial myocytes. They found that both currents decreased under the influence of ANF, the $\mathrm{I}_{\mathrm{Ca}}$ with about $38 \%$ and $\mathrm{I}_{\mathrm{tol}}$ with $22 \%$. Although the effects of ANF on the duration of the action potential were not determined, another study from the same group ${ }^{40}$ showed that in myocytes from dilated human atria a similar depression of $\mathrm{I}_{\mathrm{Ca}}$ and $\mathrm{I}_{\mathrm{tol}}$ was associated with a marked shortening of the action potential. The in vivo electrophysiological effects of ANF in dogs were studied by Stambler et al. ${ }^{45}$ Infusion of a low dosage of ANF $(0.015$ $\mu \mathrm{g} / \mathrm{kg} / \mathrm{min}$ ) shortened the atrial effective refractory period (AERP) and the duration of the monophasic action potential (MAPD 90$)$, but at higher dosages $(0.15$ and 0.60 $\mu \mathrm{g} / \mathrm{kg} / \mathrm{min}$ ) no shortening of atrial refractoriness was found. After vagal blockade (vagotomy + atropine), low dose ANF prolonged AERP and MAPD90, whereas after 
combined vagal and $\beta$-adrenergic blockade (vagotomy + atropine + propranolol) low dose ANF did not affect AERP and MAPD90 anymore. From this study it was concluded that the shortening of refractoriness by ANF was mediated by the autonomic nervous system.

In the present study we determined the changes in ANF during maintained atrial fibrillation and infused atrial natriuretic factor during sinus rhythm. Although after 1-4 weeks of AF the ANF plasma level was significantly higher than during sinus rhythm, after 1-2 days of AF, when the AERP had already markedly shortened, the ANF plasma level was not yet statistically significant increased. Infusion of a gradual increasing dosage of ANF during sinus rhythm also did not shorten the atrial refractory period. These observations do not support that ANF plays a major role in the AF-induced shortening of atrial refractoriness.

High Rate of Electrical Activation

Our present data suggest that the AF-induced shortening of the AERP is a direct eflect of the high rate of electrical activation of the atrial cells. Already after 24 hours of continuous rapid atrial pacing (interval $180-200 \mathrm{~ms}$ ) the atrial refractory period was shortened considerably at all heart rates, the physiological rate adaptation of the refractory period being attenuated or inversed. These effects of prolonged rapid atrial pacing are strikingly similar to the changes in atrial refractory period resulting of the repetitive induction of AF. ${ }^{\perp}$ In both cases, the shortening of atrial refractoriness was accompanied by an increase in inducibility and stability of AF. In the rapid pacing experiments, it is unlikely that hemodynamic changes are mediating the changes in AERP since the doubling of atrial pacing rate was associated with the development of 2: $1 \mathrm{AV}$ block and thus the ventricular rate remained the same. Recently, Morillo et al. ${ }^{46}$ studied the effects of 6 weeks of rapid atrial pacing ( 400 beats per minute) in dogs. After 6 weeks the AERP had shortened by about $15 \%$ and episodes of AF lasting for longer than 15 minutes could be induced in the majority of the animals. In this study the time course of these changes was not measured. In our study the most marked changes in AERP already occurred during the first 24 hours. During the first day of rapid pacing the refractory period shortened progressively with about 1-2 ms per hour.

\section{Short- and Long-Term Rate Adaptation of the Refractory Period}

It is already known for a long time that the refractory period adapts to acut' changes in cycle length. ${ }^{47,48}$ Although the duration of the refractory period is predominantly determined by the immediately preceding cycle, ${ }^{47}$ later studies have shown that after a sudden change in heart rate it may take several hundreds of beats before the duration of the refractory period has attained a new stable value. ${ }^{49,50}$ Our present study shows that the adaptation of the atrial refractory period after a change in heart rate actually may continue for several days. There are some indications that such a long-term adaptation of the refractory period also exists in the ventricles. In dogs Vos ct al. 51 
have shown that 6 weeks after the production of total AV-block, the duration of the ventricular monophasic action potential had increased by $4-24 \%$.

Which lonic Channels are Responsible for the AF-induced Shortening of the AERP?

Up to now we do not know which ionic channels are involved in the long-term shortening of atrial refractoriness. Theoretically the action potential can be shortened either by a decrease in inward current or an increase in outward current. A study of Le Grand et al. ${ }^{40}$ showed that in isolated cells from human dilated atria in which the action potential duration (APD) was shortened, the calcium influx was markedly depressed. Interestingly like in atrial fibrillation, also in these dilated atria the shortening of APD was less pronounced at higher than at lower heart rates, and the physiological rate adaptation of the action potential was attenuated. Down-regulation of L-type $\mathrm{Ca}^{2+}$ channels was recently demonstrated to occur in cells isolated from the border zone of a myocardial infarction. 52

Rosenbaum et al. ${ }^{53}$ noted that alterations in rate and sequence of ventricular activation may result in $\mathrm{T}$-wave changes which can persist for several weeks. It has been suggested that this cardiac "memory" was a result of tachycardia-induced changes in channel proteins in the plasma membrane. ${ }^{54}$ The finding that this memory could be abolished by administration of 4-aminopyridine strongly suggests that it is mediated through an up-regulation of the transient outward current $\left(\mathrm{I}_{\mathrm{to}}\right)$. $^{55}$

Recent work by Koning et al. ${ }^{18}$ showed that also $\mathrm{K}_{\mathrm{ATP}}{ }^{+}$-channels can be activated by short periods of rapid ventricular pacing. In anesthetized pigs, 30 minutes of rapid ventricular pacing ( 200 beats per minute) significantly reduced the infarct size resulting from occlusion of the LAD. Although rapid ventricular pacing itself did not cause ventricular ischemia, its protective effect could be abolished by pre-treatment with glybenclamide $(1.0 \mathrm{mg} / \mathrm{kg}$ ). This indicates that rapid ventricular pacing caused a non-ischemic activation of $\mathrm{K}_{\mathrm{ATP}}{ }^{+}$-channels.

Like the post-tachycardia $T$-wave changes and the pacing induced activation of $\mathrm{K}_{\mathrm{ATP}}{ }^{+}$-channels, also the long-term shortening of the atrial refractory period by atrial fibrillation or rapid pacing might be caused by a change in expression of potassium channels. Although, in the present study we did not determine the role of the transient outward current, failure of a high dose of glybenclamide $(10 \mu \mathrm{mol} / \mathrm{kg} \sim 4.94 \mathrm{mg} / \mathrm{kg}$ ) to abolish the AF-induced shortening of the atrial fibrillation interval argues against a role of $\mathrm{K}_{\mathrm{ATP}}{ }^{+}$-channels.

The inversed rate adaptation of the refractory period during electrical remodeling by AF or rapid pacing may give an important clue about the ionic channels involved in this process. The transient outward current $\left(\mathrm{I}_{\text {tol }}\right)$ is known to become partially inactivated at higher heart rates due to its slow recovery from inactivation. ${ }^{56}$ An increase in the density of these channels could therefore well explain the phenomenon of reversed rate adaptation. Giles and van Ginneken ${ }^{56}$ showed that in isolated rabbit atrial myocytes a decrease in pacing rate from 1 to $0.25 \mathrm{~Hz}$ shortened the duration of the action potential due to an increase of the 4-aminopyridine sensitive transient 
outward current. In isolated sheep Purkinje fibers, Boyett and Fedida ${ }^{57}$ determined the rate dependent changes in duration of the action potential. In this preparation, the Iongest action potentials were found at a rate of 60 beats per minute. Both decreasing and increasing the pacing rate resulted in a shortening of the action potential, by a combined decrease in inward $\mathrm{Ca}^{2+}$-current and increase in background outward currents.

In goats in sinus rhythm, propranolol slightly shortened the AERP during slow pacing from $159 \pm 18$ to $149 \pm 14 \mathrm{~ms}$ (n.s) whereas no changes were found during higher pacing rates. After 1-3 days of continuous AF this effect of propranolol had disappeared (Table 1). Since the shortening of atrial refractoriness at slow rates by propranolol might be due to a reduction of the inward $\mathrm{Ca}^{2+}$-current, the disappearance of this effect of propranolol by a couple of days of atrial fibrillation, may point to a depression of the inward $\mathrm{Ca}^{2+}$-current by $\mathrm{AF}$.

Activation of $\mathrm{K}_{\mathrm{ATP}}{ }^{+}$-channels also affects the action potential duration or the refractory period in a different way depending on the heart rate. In canine Purkinje fibers, Bril and Man, ${ }^{58}$ showed that activation of $\mathrm{K}_{\mathrm{ATP}}{ }^{+}$-channels by BRL 34915 (cromakalim, $100 \mu \mathrm{M}$ ) reduced the action potential duration (APD95) most markedly at lower heart rates (pacing cycle length $1000 \mathrm{~ms}$ ) from $298 \pm 13$ to $172 \pm 31 \mathrm{~ms}$ $(-42 \%)$. At higher rates (cycle length $300 \mathrm{~ms}$ ) the APD shortening was less pronounced from $205 \pm 7$ to $138 \pm 20(-33 \%)$, thereby attenuating the physiological rate adaptation of the APD. Athough these studies suggest that up-regulation of the transient outward or the ATP-regulated potassium currents, or down-regulation of calcium currents could be involved in the process of electrical remodeling by AF, at this moment it is still unclear which ionic currents are responsible for the electrical remodeling by $\mathrm{AF}$ and which are the stimuli involved in a possible up- or down-regulation of these channels.

\section{Clinical Implications}

Indirect evidence suggests that AF-induced electrical remodeling may also occur in humans. Not only that paroxysmal AF frequently deteriorates in chronic AF but also the success rate of electrical and pharmacological cardioversion diminishes when atrial fibrillation has persisted for a long time. ${ }^{30,59,60}$ Recently, more direct evidence for electrical remodeling by $\mathrm{AF}$ in humans was given by Attuel et al. ${ }^{61}$ and Daoud et al., ${ }^{62}$ who reported that short episodes of AF or rapid atrial pacing decreased the atrial refractory period and attenuated or even reversed its rate adaptation. Because the AF-induced shortening of the atrial refractory increases the propensity for atrial fibrillation, interventions directed against this process of electrical remodeling might have clinical implications for a more effective treatment of $\mathrm{AF}$.

In the present study the electrical remodeling by atrial fibrillation seemed not to be mediated by changes in autonomic tone, atrial ischemia, acute stretch or increased blood levels of ANF. Instead, the high rate of electrical activation itself seemed to be the stimulus for the electrical remodeling. At this moment, we do not know the cellular 
mechanisms which are responsible for this phenomenon. As shown recently by Tieleman et al. ${ }^{63}$ the process of electrical remodeling was delayed by verapamil, suggesting that the high calcium influx associated with the high activation rate ${ }^{64}$ serves as an intra-cellular stimulus.

If the AF-induced shortening of atrial refractoriness is indeed due to changes in the function of a specific ion-channel, drugs might be developed targeting these channels which may exert a specific anti-fibrillatory action by counteracting the AF-induced electrical remodeling. Similar to the effects of atrial fibrillation or prolonged rapid pacing, also atrial flutter might be expected to shorten atrial refractoriness, thus increasing the propensity for atrial fibrillation. 65

A limitation of the present study is that we did not study the stimuli for electrical remodeling during the development of shortening of atrial refractoriness. Theoretically, it is possible that the factors involved in the development of electrical remodeling are no longer operative after the remodeling process of the cell membrane has been completed. Another limitation is that we did not follow the changes in atrial diameter and pressure during the development of chronic atrial fibrillation. Only the effects of acute stretch of the atrial wall on the atrial refractory period were evaluated, which may differ from the effects of prolonged atrial stretch.

Our present study is far from complete and especially the role of specific ion-channels in the shortening of atrial refractoriness needs to be further explored. Unfortunately, many selective channel blockers are toxic and can not be used in vivo. Future experiments using isolated tissue samples and/or single cells from fibrillating myocardium will be needed to evaluate the involvement of the various ion-channels in the AF-induced changes in the repolarization phase of the action potential.

\section{Acknowledgments}

The authors would like to thank J.J. van der Heyden and co-workers from the department of Clinical Pharmacology and Toxicology Academic Hospital Maastricht for determining the plasma glybenclamide levels and Dr. R.G. Tieleman from the department of Cardiology Academic Hospital Groningen for the determination of the ANF plasma levels.

\section{References}

1 Wijffels MCEF, Kirchhof CJHJ, Dorland R, Allessie MA: Atrial fibrillation begets atrial fibrillation. A study in awake chronically instrumented conscious goats. Circulation 1995:92:1954-1968

2. Adams WJ. Skinner GS. Bombardt PA. Courney M. Brewer JE: Determination of glyburide in human serum by liquid chromatography with fluorescence detection. Anal Chem 1982;54:1287$129 !$

3. Tan ACITL, Rosmalen FMA, Hofman JA. Kloppenborg PWC, Benraad TJ: Evaluation of a direct assay for atrial natriuretic peptide. Clin Chim Acta 1989;179:1-12 
4 Olsson K, Dahlbom K, Nygren K, Karlberg BE, Andén N-E, Eriksson L: Fluid balance and arterial blood pressure during intracarotid infusions of atrial natriuretic peptide (ANP) in water-deprived goats. Acta Physiol Scand 1989;137:249-257

5 White CW, Kerber RE, Weiss HR, Marcus ML: The effects of atrial fibrillation on atrial pressurevolume and flow relationships. Circ Res 1982;51:205-215

6 Escande D: The pharmacology of ATP-sensitive $\mathrm{K}^{+}$channels in the heart. Pflügers Arch 1989;414 (Supp] 1):S93-S98

7 Coumel P, Attuel P, Lavallee J, Flammang D, Leclercq JF, Slama R: Syndrome d'arythmie auriculaire d'origine vagale. Arch Mal Coeur 1978:71:645-656

8 Hoffman BF, Siebens AA, McBrooks C: Effect of vagal stimulation on cardiac excitability. Am J Physiol 1952:169:377-383

9 Rensma PL, Allessie MA, Lammers WJEP, Bonke FIM, Schalij MJ: Length of excitation wave and susceptibility to reentrant atrial arrhythmias in normal conscious dogs. Circ Res 1988;62:395-410

10 Smeets JLRM, Allessie MA, Lammers WJEP, Bonke FIM, Hollen SJ: The wavelength of the cardiac impulse and reentrant arrhythmias in isolated rabbit atrium. The role of heart rate, autonomic transmitters, temperature, and potassium. Circ Res 1986;58:96-108

11 Wang Z, Page PL, Nattel S: Mechanism of flecainide's antiarrhythmic action in experimental atrial fibrillation. Circ Res 1992;71:271-287

12 Farges JP, Ollagnier M, Faucon G: Influence of acetylcholine, isoproterenol, quinidine and ouabain on effective refractory periods of atrial and ventricular myocardium in the dog. Arch Int Phamacodyn 1977;227:206-219

13 Kass RS, Wiegers SE: The ionic basis of concentration-related effects of noradrenaline on the action potential of calf cardiac Purkinje fibres. J Physiol 1982;322:541-558

14 Quadbeck J, Reiter M: Cardiac action potential and inotropic effects of noradrenaline and calcium. Naunyn-Schmiedeberg's Arch Pharmacol 1975;286:337-351

15 Pelzer D, Pelzer S, McDonald TF: Properties and regulation of calcium channels in muscle cells. Rev Physiol Biochem Pharmacol 1990;114:107-207

16 Yazawa K, Kameyama M: Mechanism of receptor-mediated modulation of the delayed outward potassium current in guinea-pig ventricular myocytes. J Physiol 1990;421:135-150

17 Noma A: ATP-regulated $\mathrm{K}^{+}$channels in cardiac muscle. Nature 1983:305:147-148

18 Koning MMG, Gho BCG, van Klaarwater E, Opstal RLJ, Duncker DJ, Verdouw PD: Rapid ventricular pacing produces myocardial protection by nonischemic activation of $\mathrm{K}_{\mathrm{ATP}}{ }^{*}$ channels. Circulation 1996:93:178-186

19 Smallwood JK, Ertel PJ, Steinberg MI: Modification by glibenclamide of the electrophysiological consequences of myocardial ischaemia in dogs and rabbits. Naunyn-Schmiedeberg's Arch Pharmacol 1990:342:214-220

20 Crooks MJ, Brown KF: The binding of sulphonylureas to serum albumin. J Pharm Pharmac 1974;26:304-311

21 Petersen P, Kastrup J, Brinch K, Godtfredsen J, Boysen G: Relation between left atrial dimension and duration of atrial fibrillation. Am J Cardiol 1987:60:382-384

22 Selzer A, Cohn KE: Natural history of mitral stenosis: a review. Circulation 1972;45:878-890

23 Selzer A, Katayama F: Mitral regurgitation: clinical patterns, pathophysiology and natural history. Medicine 1972:51:337-366

24 Henry WL. Morganroth J, Pearlman AS, Clark CE. Redwood DR, Itscoitz SB, Epstein SE: Relation between echocardiographically determined left atrial size and atrial fibrillation. Circulation 1976;53:273-279

25 Probst P, Goldschlager N, Selzer A: Left atrial size and atrial fibrillation in mitral stenosis: factors. influencing their relationship. Circulation 1973:48:1282-1287

26 Kannel WB, Abbott RD, Savage DD, McNamara PM: Epidemiologic features of chronic atrial fibrillation: the Framingham study. $N$ Engl J Med 1982;306:1018-1022

27 Cox JL, Canavan TE, Schuessler RB, Cain ME, Lindsay BD, Stone CM, Smith PK, Corr PB, Boineau JP: The surgical treatment of atrial fibrillation. II. Intraoperative electrophysiologic 
mapping and description of the electrophysiologic basis of atrial flutter and atrial fibrillation. $J$ Thor Card Surg 1991;101:406-426

28 Solti F. Vecsey T, Kekési V, Juhász-Nagy A: The effect of atrial dilatation on the genesis of atrial arrhythmias. Cardiovasc Res 1989;23:882-886

29 Ravelli F, Allessie MA: Atrial stretch decreases refractoriness and induces atrial fibrillation in the isolated rabbit heart. Circulation 1995:92:1-754(Abstract)

30 Resnekov L, McDonald L: Appraisal of electroconversion in treatment of cardiac dysrhythmias. $\mathrm{Br}$ Heart J 1968;30:786-81 I

31 Brodsky MA, Allen BJ: Factors determining maintenance of sinus rhythm after chronic atrial fibrillation with left atrial dilatation. Am J Cardiol 1989;63:1065-1068

32 Shapiro W, Klein G: Alterations in cardiac function immediately following electrical conversion of atrial fibrillation to normal sinus rhythm. Circulation 1968:38:1074-1084

33 Leistad E, Christensen G, Ilebekk A: Effects of atrial fibrillation on left and right atrial dimensions, pressures, and compliances. Am J Physiol 1993;264:H1093-H1097

34 Sanfilippo AJ, Abascal VM, Sheehan M, Oertel LB, Harrigan P, Hughes RA, Weyman AE: Atrial enlargement as a consequence of atrial fibrillation. Circulation 1990;82:792-797

35 Gosselink MAT, Crijns HJGM, Hamer HPM, Hillege H, Lie KI: Changes in left and right atrial size after cardioversion of atrial fibrillation: Role of mitral valve disease. $J$ Am Coll Cardiol $1995 ; 22: 1666-1672$

36 Van Gelder IC, Crijns HJGM, Gilst van WH, Hamer HPM, Lie KI: Decrease of right and left atrial sizes after direct-current electrical cardioversion in chronic atrial fibrillation. Am J Cardiol $1991 ; 67: 93-95$

37 Calkins H, El-Atassi R, Leon A, Kalbfleisch SJ, Borganelli M, Langberg JJ, Morady F: Effect of the atrioventricular relationship on atrial refractoriness in humans. Pace 1992;15:771-778

38 Kaseda S, Zipes DP: Contraction-excitation feedback in the atria: a cause of changes in refractoriness. J Am Coll Cardiol 1988;11:1327-1336

39 Klein LS, Miles WM. Zipes DP: Effect of atrioventricular interval during pacing or reciprocating tachycardia on atrial size, pressure, and refractory period. Contraction-excitation feedback in human atrium. Circulation 1990:82:60-68

40 Le Grand B. Hatem S. Deroubaix E, Couétil JP. Coraboeuf E: Depressed transient outward and calcium currents in dilated human atria. Cardiovasc Res 1994;28:548-556

41 Hume JR, Harvey RD: Chloride conductance pathways in heart. Am J Physiol 1991;261:C399-C412

42 Clemo HF, Baumgarten CM. Stambler BS, Wood MA, Ellenbogen KA: Atrial natriuretic factor: Implications for cardiac pacing and electrophysiology. Pace 1994;17:70-91

43 Clemo HF, Baumgarten CM, Ellenbogen KA, Stambler BS: Atrial natriuretic peptide and cardiac electrophysiology: Autonomic and direct effects. J Cardiovasc Electrophysiol 1996; 7:149-162

44 Le Grand B, Deroubaix E, Couétil JP, Coraboeuf E: Effects of atrionatriuretic factor on $\mathrm{Ca}^{2+}$ current and $\mathrm{Ca}_{\mathrm{i}}$-independent transient outward $\mathrm{K}^{+}$current in human atrial cells. Pflügers Arch 1992:421:486-49 I

45 Stambler BS. Turner DA, Guo C, Guo GB, Ellenbogen KA: Characterization of the in vivo cardiac electrophysiologic effects of atrial natriuretic factor (ANF). Circulation 1994:90(4):I-247(Abstract)

46 Morillo CA, Klein GJ, Jones DL, Guiraudon CM: Chronic rapid atrial pacing: structural, functional and electrophysiologic characteristics of a new model of sustained atrial fibrillation. Circulation 1995:91:1588-1595

47 Mendez C, Grunzit CC, Moe GK: Influence of cycle length upon refractory period of auricles, ventricles and AV node in the dog. Am J Physiol 1956:184:287

48 Denes P. Delon W, Dhingra R, Pietras RJ, Rosen KM: The effects of cycle length on cardiac refractory periods in man. Circulation 1974;49:32-41

49 Janse MJ, Van der Steen, van Dam RT, Durrer D: Refractory period of the dog's ventricular myocardium following sudden changes in frequency. Circ Res 1969:24:251-262

50 Olsson SB. Broman H. Hellström C, Talwar KK, Volkmann R: Adaptation of human atrial muscle repolarisation after high rate stimulation. Cardiovasc Res 1984:19:7-14 
51 Vos MA, De Groot SHM, Van der Zande I, Verduyn SC. Wellens HJJ: Electrophysiological changes observed after creation of AV-block in the dog. Pace 1995;18:1094(Abstract)

52 Aggarwal R, Boyden PA: Altered pharmacological responsiveness of reduced L-type calcium currents in myocytes surviving in the infarcted heart. J Cardiovasc Electrophysiol 1996;7:20-35

53 Rosenbaum MB, Blanco HH, Elizari MV, Lazzari JO, Davidenko JM: Electrotonic modulation of the T wave and cardiac memory. Am J Cardiol 1982;50:213-222

54 Katz AM: T Wave "memory": possible causal relationship to stress-induced changes in cardiac ion channels? J Cardiovasc Electrophysiol 1992;3:150-159

55 Del Balzo U, Rosen MR: $\mathrm{T}$-wave changes persisting after ventricular pacing in canine heart are altered by 4-aminopyridine but not by lidocaine. Implications with respect to phenomenon of cardiac "memory". Circulation 1992;4:1464-1472

56 Giles WR, van Ginneken ACG: A transient outward current in isolated cells from crista terminalis of rabbit heart. $J$ Physiol 1985;368:243-264

57 Boyett MR, Fedida D: The effect of heart rate on the membrane currents of isolated sheep Purkinje fibres. J Physiol 1988:399:467-491

58 Bril A, Man RY: Effects of the potassium channel activator, BRL 34915, on the action potential characteristics of canine cardiac Purkinje fibers. J Pharmacol Exp Ther 1990;253:1090-1096

59 Van Gelder IC, Crijns HJGM, Gilst van WH, Verwer R, Lie KI: Prediction of uneventful cardioversion and maintenance of sinus rhythm from direct-current electrical cardioversion of chronic atrial fibrillation and flutter. Am J Cardiol 1991;68:41-46

60 Suttorp MJ, Kingma HJ, Jessurun ER, Lie-A-Huen L, van Hemel NM, Lie KI: The value of class IC antiarrhythmic drugs for acute conversion of paroxysmal atrial fibrillation or flutter to sinus rhythm. J Am Coll Cardiol 1990;16:1722-1727

61 Attuel P, Leclercq JF, Coumel P: Atrial electrophysiological substrate remodelling after tachycardia in patients with and without atrial fibrillation. Pace 1995;18:804(Abstract)

62 Daoud EG, Niebauer M, Bogun F, Castellani M, Chan KK, Goyal R, Harvey M, Man CK, Strickberger SA, Morady F: Atrial fibrillation induced shortening of atrial refractoriness in humans. Circulation 1995:92:I-404(Abstract)

63 Tieleman RG, de Langen CDJ, van der Woude HJ, Grandjean JG, Bel KJ, Wijffels MCEF, Allessie MA, Crijns HJGM: Reduction of electrical remodeling of the atrium by verapamil. Circulation 1995:92:I-754(Abstract)

64 Langer $\mathrm{GA}$ : Calcium exchange in dog ventricular muscle: relation to frequency of contraction and maintenance of contractility. Circ Res 1965;17:78-89

65 Peters RW, Weiss DN, Carliner NH, Feliciano Z, Shorofsky SR, Gold MR: Overdrive pacing for atrial flutter. Ain J Cardiol 1994;74:1021-1.023 



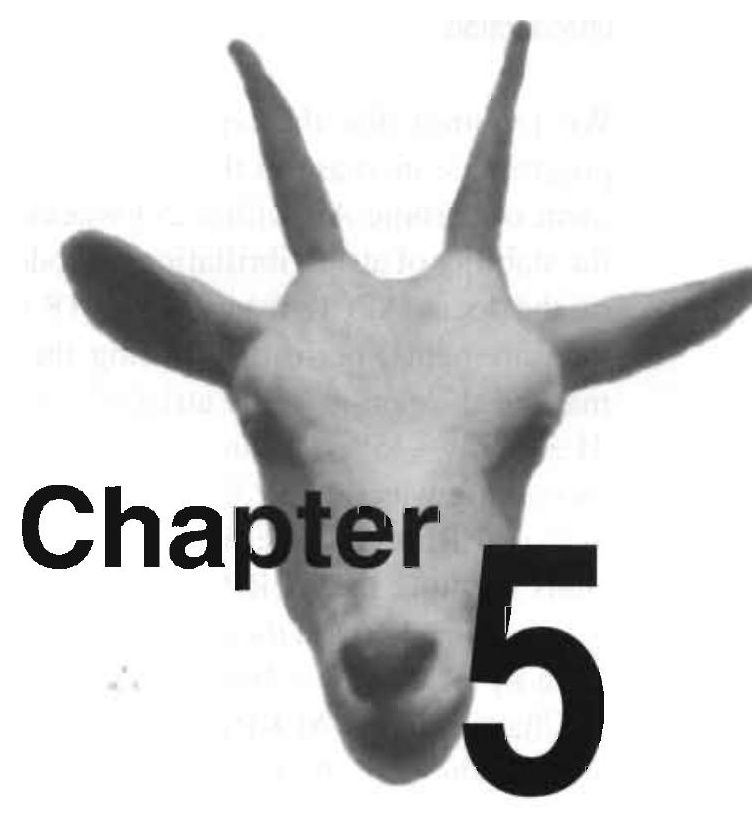

\title{
Atrial Fibrillation Shortens The Duration and Inverses the Physiological Rate-Adaptation of the Monophasic Action Potential Duration in the Goat
}

\author{
Maurits C.E.F. Wijffels
}

Lucie van der Zee

Rick Dorland

Marc A. Vos

Maurits A. Allessie

This study was presented in part at the 69th Annual Scientific sessions of the American Heart Association. November 10-13, New Orleans, Louisiana (Circulation 1996;94(8):I-556) 


\section{Introduction}

We reported that the repetitive induction of atrial fibrillation (AF) resulted in a progressive increase in the duration of AF-episodes, finally leading to the development of chronic AF within 2-4 weeks (see Chapter 3 ). ${ }^{1}$ The progressive increase in the stability of atrial fibrillation episodes was accompanied by a significant shortening of the local AFCL from $145 \pm 18$ to $100 \pm 5 \mathrm{~ms}(-31 \%)$. Electrophysiological measurements, performed during the first 2-4 days of maintained $\mathrm{AF}$, revealed a marked shortening of the atrial effective refractory period (AERP) from $146 \pm 19$ to $81 \pm 22 \mathrm{~ms}(-45 \%)$ (pacing interval $400 \mathrm{~ms}$ ). At the maximal pacing rate however, the shortening was less $(-23 \%)$, which resulted in an inversion of the normal adaptation of the AERP to changes in heart rate (maladaptation). While during control (goats in sinus rhythm), the AERP shortened from $146 \pm 19 \mathrm{~ms}$ at slow heart rates $\left(S_{1}-S_{1} 400\right.$ $\mathrm{ms})$ to $117 \pm 12 \mathrm{~ms}$ at the maximal heart rate, after 2-4 days of AF the AERP prolonged from $81 \pm 22$ to $90 \pm 16 \mathrm{~ms}$ when heart rate was increased (Chapter 3 ). ${ }^{1}$

Changes in the AERP are most probably due to changes in the duration of the atrial action potential. It was the aim of the present study to investigate whether the AF-induced shortening of the AERP and its inversed rate adaptation were indeed associated with similar changes in the duration of the atrial action potential. For this reason, we recorded monophasic action potentials (MAP's) from the epicardial surface of the right atrium in goats which had been in sinus rhythm all the time and in goats in which chronic AF had developed.

\section{Methods}

The Goat Model of Chronic Atrial Fibrillation.

Eleven goats weighing between 46 and $82 \mathrm{~kg}$ (mean $58 \pm 10 \mathrm{~kg}$ ) were used for this study. Animal handling was performed according to the guiding principles of the American society of Physiology and approved by the Animal Investigation Committee of the University of Limburg. In order to perform long-term electrophysiological studies and to induce chronic AF, the goats were instrumented with multiple epicardial electrodes as described previously in more detail by Wijffels et al. (Chapter 3 and 4). ${ }^{1,2}$ About $2-3$ weeks after surgery the goats were connected to an external automatic atrial fibrillator. This device maintained AF continuously which resulted in the development of chronic AF (duration more than 24 hours) within a few weeks of artificially maintained AF (Chapter 3 ). ${ }^{\text {. }}$

Recordings of the Monophasic Action Potential

Epicardial monophasic action potential recordings of the lateral free wall of the right atrium were made just prior to the implantation of the epicardial electrodes $(n=9)$ 
and after $135 \pm 13$ days of maintained AF (range $97-190$ days) $(n=7)$. During both conditions, anesthesia was induced with Nesdonal ${ }^{\circledR}$ (Thiopental, $15 \mathrm{mg} / \mathrm{kg}$ IV) and maintained by Halothane ${ }^{\circledR}(1-2 \%)$ and a $1: 2$ mixture of $\mathrm{O}_{2}$ and $\mathrm{N}_{2} \mathrm{O}$. To record monophasic action potentials, a contact electrode (Franz catheter, EPT No. 1650) was positioned at the epicardial surface of the right atrial free wall. The MAP signals were amplified by a custom made DC-coupled differential amplifier (gain 10-500) provided with a $20 \mathrm{mV}$ calibration pulse. ${ }^{3}$ The signals were sampled at $1 \mathrm{kHz}$ and stored on magnetic tape. ${ }^{4}$ During the experiment, special attention was paid to record signals with a stable and smooth morphology, a stable diastolic baseline and a minimal amplitude, defined as the difference between phase 2 and phase 4 of the atrial MAP, of $3 \mathrm{mV} .5,6$ If these criteria were not fulfilled, the contact electrode was moved to another site.

\section{Experimental Protocol and Data Analysis}

MAP signals were recorded during: 1) normal sinus rhythm, 2) incremental regular atrial pacing with $S_{1}-S_{1}$ intervals ranging between 400 and $180 \mathrm{~ms}$, and 3) acute or chronic atrial fibrillation. Atrial pacing was performed from a pair of pacing electrodes at the right atrial appendage ( $2 \mathrm{~ms}$ biphasic stimuli, $4 \times$ threshold). Pacing was started with an interval just below the sinus rhythm interval and decreased in steps of 10-50 ms until 1:1 atrial conduction was lost $\left(\mathrm{F}_{\max }\right)$. In sinus rhythm goats, AF was induced by rapid atrial pacing or by a 1 second burst of atrial stimuli $(50 \mathrm{~Hz}, 4 \times$ threshold). In chronically fibrillating goats. after registration of MAP's during AF, fibrillation was cardioverted by an epicardially applied biphasic DC-shock $(3: 3 \mathrm{~ms}, 150-350$ V) synchronized to the ventricular activity recorded on the surface electrocardiogram. Shocks were applied through two epicurdial electrodes positioned on the right and left atrial appendages. MAP signals were recorded from a site remote from the site where the DC-shock had been delivered. The duration of the MAPD was measured at a repolarization of $20 \%$ and $80 \%$ of the total amplitude. Because the tail of the repolarization is asymptotic we considered the $\mathrm{MAPD}_{80}$ a more reliable measurement than the MAPD90.

\section{The Measurements of the Atrial Effective Refractory Period}

About 2 weeks after implantation of the atrial electrodes but before connecting the goats to the automatic atrial fibrillator, a short control electrophysiological study was performed. The atrial effective refractory period (AERP) was measured at either the right or the left atrial appendage during various pacing intervals $\left(S_{1}-S_{1}\right)$ between 500 and $130 \mathrm{~ms}$ (biphasic stimuli, width $2 \mathrm{~ms}, 4 \mathrm{x}$ diastolic threshold). A single premature stimulus $\left(S_{2}, 4 \times\right.$ diastolic threshold) was interpolated after every fifth basic interval and, starting from well within the refractory period, the $S_{1}-S_{2}$ interval was incremented in steps of 1-2 ms. The shortest $S_{1}-S_{2}$ coupling interval that resulted in a propagated premature atrial response was taken as the AERP. In all goats, these 


\section{$400 \mathrm{~ms}$}

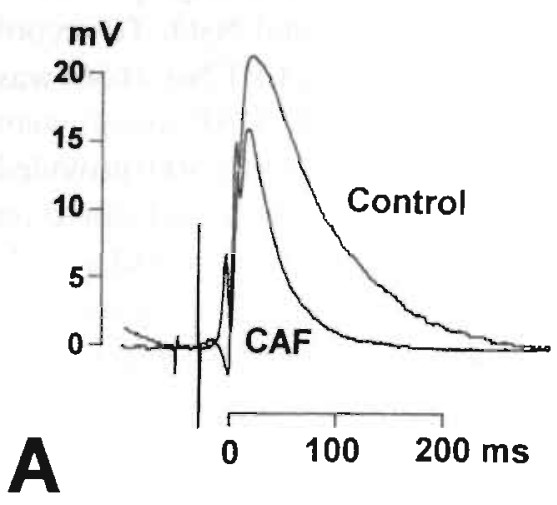

$200 \mathrm{~ms}$

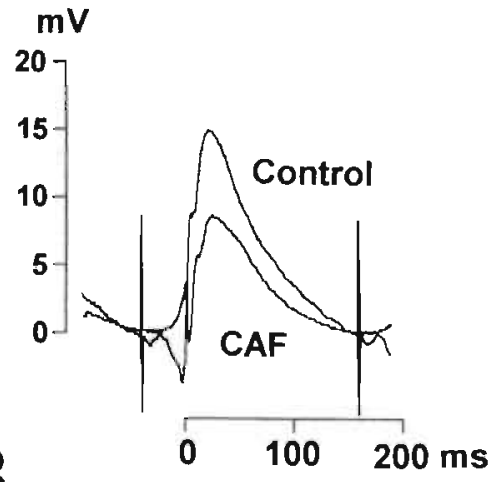

Figure 1. Representative examples of the AF-induced changes in monophasic action potentials during slow and fast pacing rates. $U_{i} p e r$ panel: During slow pacing $\left(S_{1}-S_{1}\right.$ : $400 \mathrm{~ms}) \mathrm{AF}$ shortened the MAP dramatically from more than $200 \mathrm{~ms}$ to about $100 \mathrm{~ms}$. Lower panel: At fast pacing rates $\left(S_{1}-S_{1}: 200 \mathrm{~ms}\right)$ the $A F$-induced shortening of the MAP duration was less pronounced. $400 \mathrm{~ms}$ ). Whereas during control (sinus rhythm) the MAPD was longer than $200 \mathrm{~ms}$, after cardioversion of chronic AF the MAPD had shortened to about $100 \mathrm{~ms}$. Panel B shows that the AF-induced shortening of the MAPD was much less pronounced at faster pacing rates (S1S1: $200 \mathrm{~ms}$ ). Although in these examples, the amplitude of the MAP from the chronically fibrillating atrium was somewhat smaller than the one recorded during control, in all goats no significant differences in MAP amplitudes 


\section{Control}

\section{Chronic AF}
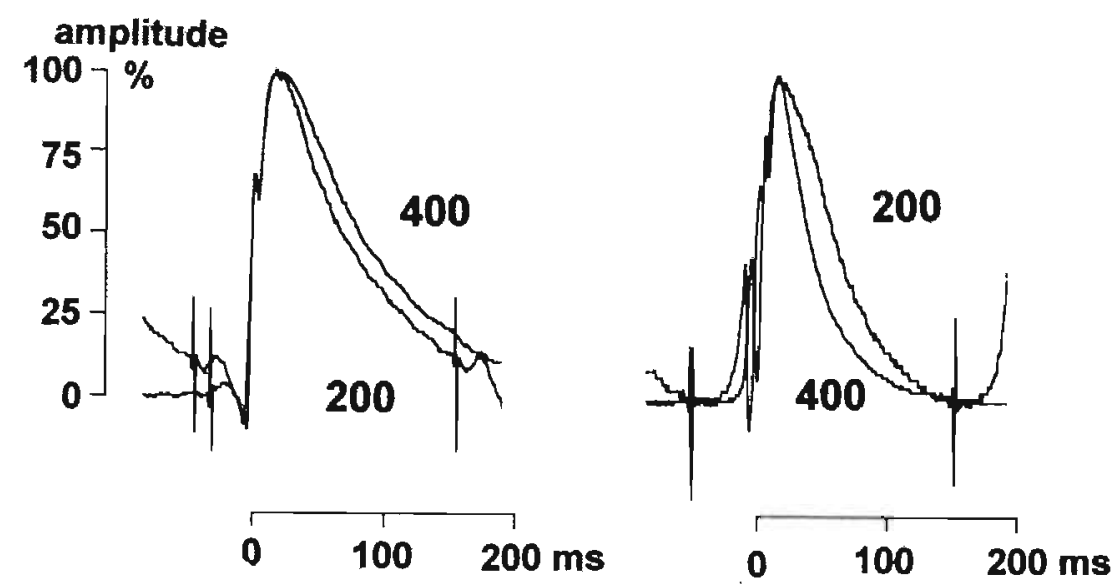

Figure 2. Illustration of the AF-induced inversion of the physiological rate adaptation of the action potential duration. Whereas during control (left panel) the action potential shortened in response to a shortening of the pacing interval from 400 to $200 \mathrm{~ms}$, after cadioversion of CAF (right panel) the duration of the MAP prolonged at higher pacing rates.

between the two groups were found (control $15.3 \pm 4 \mathrm{mV}$ versus $12.6 \pm 4 \mathrm{mV}$ for chronic AF)

In Fig 2 the AF-induced changes in the rate dependence of the MAP duration are illustrated. For the same goat, the (normalized) MAP recorded during control (left panel) and after cardioversion of chronic $\mathrm{AF}$ (right panel) are superimposed for pacing intervals of 400 and $200 \mathrm{~ms}$. Whereas during control the monophasic action potential duration shortened when the pacing interval was decreased from 400 to $200 \mathrm{~ms}$ (physiological rate adaptation), after cardioversion of chronic AF the duration of the MAP prolonged in response to a faster pacing rate (inversed rate adaptation).

In Table 1 the values of the MAPD at $20 \%$ and $80 \%$ of total repolarization $\left(\mathrm{MAPD}_{20}\right.$ and $\left.\mathrm{MAPD}_{80}\right)$ are given for different pacing intervals for goats in sinus rhythm and for goats that had been in chronic AF. On the average, after cardioversion of chronic AF, during pacing with $400 \mathrm{~ms}$, both the MAPD 20 and the MAPD 80 had shortened markedly from $32 \pm 4$ to $19 \pm 3 \mathrm{~ms}(-41 \%, \mathrm{p}<0.05)$ and from $132 \pm 4 \mathrm{~ms}$ to $67 \pm 5 \mathrm{~ms}(-49 \%, \mathrm{p}<0.001)$. At a pacing interval of $200 \mathrm{~ms}$, the shortening of the MAPD $_{80}$ was much smaller from $97 \pm 7$ to $89 \pm 11 \mathrm{~ms}(-8 \%, \mathrm{n} . \mathrm{s}$.) while the average $\mathrm{MAPD}_{20}$ had increased in the fibrillating goats from $23 \pm 4 \mathrm{~ms}$ to $30 \pm 4 \mathrm{~ms}(+30 \%$, n.s.). Due to the inversion of the rate adaptation of the MAPD in chronically fibrillating goats, both the MAPD 20 and $\mathrm{MAPD}_{80}$ at slow pacing rates had become shorter than at fast pacing rates ( $20 \pm 3$ versus $30 \pm 4 \mathrm{~ms}$ and $67 \pm 5$ versus $89 \pm 11 \mathrm{~ms}$ ). 
Table 1. Effects of Atrial Fibrillation on Monophasic Action Potential Duration.

Goats in Sinus Rhythm (Control)

\begin{tabular}{|c|c|c|c|c|c|c|c|c|c|c|c|c|c|}
\hline \multirow{2}{*}{$\begin{array}{l}\text { Goat } \\
\#\end{array}$} & \multirow{2}{*}{$\begin{array}{l}\text { Sinus } \\
\text { Rinythm } \\
\text { (ms) }\end{array}$} & \multicolumn{6}{|c|}{$\begin{array}{l}\text { MAPD } 20 \\
\text { Pacing Intervals }\end{array}$} & \multicolumn{6}{|c|}{$\begin{array}{l}\text { MAPD } \\
\text { Pacing Intervals }\end{array}$} \\
\hline & & SR & 400 & 300 & 250 & 200 & 180 & SR & 400 & 300 & 250 & 200 & 180 \\
\hline 1 & 440 & 33 & 37 & 38 & 36 & 30 & - & 130 & 139 & 132 & 122 & 121 & - \\
\hline 2 & 480 & 45 & 41 & 38 & 36 & 36 & - & 137 & 137 & 135 & 125 & 124 & - \\
\hline 3 & 560 & 14 & 34 & 29 & 29 & 26 & - & 122 & 118 & 109 & 102 & 95 & - \\
\hline 4 & 490 & 32 & 25 & 20 & 22 & 18 & - & 125 & 152 & 109 & 100 & 85 & - \\
\hline 5 & 540 & 4 & 9 & 7 & 5 & 9 & 7 & 86 & 117 & $\Uparrow 16$ & 98 & 82 & 75 \\
\hline 6 & 475 & 31 & 30 & 32 & 26 & 20 & 21 & 109 & 126 & 137 & 136 & 93 & 96 \\
\hline 7 & 580 & 21 & 29 & 28 & 22 & 19 & - & 100 & 122 & 164 & 145 & 79 & - \\
\hline 8 & 480 & 38 & 35 & 39 & 34 & - & - & 139 & 143 & 136 & 130 & - & - \\
\hline 9 & 450 & 49 & 45 & 54 & - & - & $\rightarrow$ & 150 & 148 & 154 & - & - & - \\
\hline Mean & 499 & 30 & 32 & 32 & 25 & 23 & 14 & 122 & 132 & 134 & 120 & 97 & 86 \\
\hline SE & 17 & 5 & 4 & 5 & 4 & 4 & 10 & 7 & 4 & 6 & 6 & 7 & 6 \\
\hline
\end{tabular}

After Cardioversion of CAF ( $125 \pm 16$ Days of AF)

\begin{tabular}{|c|c|c|c|c|c|c|c|c|c|c|c|c|c|}
\hline \multirow{3}{*}{$\begin{array}{l}\text { Goat } \\
\#\end{array}$} & \multirow{3}{*}{$\begin{array}{l}\text { Sinus } \\
\text { Rhythm } \\
\text { (ms) }\end{array}$} & \multirow{2}{*}{\multicolumn{6}{|c|}{$\begin{array}{l}\text { MAPD }_{20} \\
\text { Pacing Intervals }\end{array}$}} & \multirow{2}{*}{\multicolumn{6}{|c|}{$\begin{array}{l}\text { MAPD }_{80} \\
\text { Pacing Intervals }\end{array}$}} \\
\hline & & & & & & & & & & & & & \\
\hline & & SA & 400 & 300 & 250 & 200 & 180 & SR & 400 & 300 & 250 & 200 & 180 \\
\hline 1 & 566 & 11 & 15 & 19 & 21 & 30 & 32 & 63 & 61 & 78 & 88 & 89 & 87 \\
\hline 2 & 410 & 15 & 14 & 16 & 18 & 24 & 30 & 54 & 49 & 57 & 64 & 70 & 95 \\
\hline 3 & 455 & 19 & 17 & 20 & 23 & 30 & - & 83 & 89 & 104 & 106 & 105 & - \\
\hline 4 & 480 & 22 & 27 & 35 & 38 & 42 & - & 86 & 73 & 113 & 121 & 129 & - \\
\hline 8 & 480 & 31 & 30 & 35 & 39 & 44 & 47 & 85 & 81 & 87 & 91 & 103 & 105 \\
\hline 10 & 580 & 10 & 15 & 17 & 17 & 23 & 22 & 60 & 60 & 70 & 79 & 80 & 76 \\
\hline 11 & 510 & 22 & 21 & 20 & 18 & 15 & - & 55 & 58 & 62 & 55 & 45 & - \\
\hline Mean & 497 & 19 & $20^{*}$ & 23 & 25 & 30 & 33 & $69^{* * *}$ & $67^{* * *}$ & $82^{* * *}$ & $86^{* *}$ & 89 & 91 \\
\hline SE & 25 & 3 & 3 & 3 & 4 & 4 & 6 & 6 & 5 & 8 & 9 & 11 & 6 \\
\hline
\end{tabular}

Numbers indicate duration of monophasic action potential in $\mathrm{ms} \mathrm{MAPD}_{20}$, monophasic action potential duration at $20 \%$ of complete repolarization; MAPDso, monophasic action potential duration at $80 \%$ of complete repolarization; SR, sinus inythm; SE, slandard error of the mean; " $p<0.05, "$ " $p<0.01, \cdots p<0.001$ compared to control (unpaired Student's -test). 
Table 2. Effects of Atrial Fibrillation on Atrial Effective Refractory Period.

\begin{tabular}{|c|c|c|c|c|c|c|c|c|c|c|}
\hline \multirow{2}{*}{$\begin{array}{l}\text { Goat } \\
\#\end{array}$} & \multicolumn{5}{|c|}{$\begin{array}{l}\text { Goats in Sinus Rhythm } \\
\text { Pacing Intervais }\end{array}$} & \multicolumn{5}{|c|}{$\begin{array}{l}\text { After } 11 \pm 3 \text { Days of Maintained AF } \\
\text { Pacing Intervals }\end{array}$} \\
\hline & 400 & 300 & 250 & 200 & 180 & 400 & 300 & 250 & 200 & 180 \\
\hline 1 & 123 & 121 & 126 & 121 & 111 & 54 & 57 & 60 & 61 & 62 \\
\hline 2 & 166 & 158 & 146 & 133 & 126 & 64 & 68 & 69 & 74 & 75 \\
\hline 3 & 141 & 138 & 134 & 122 & 119 & 60 & 61 & 63 & 69 & 72 \\
\hline 4 & 137 & 138 & 134 & 123 & 120 & 102 & 101 & 100 & 97 & 97 \\
\hline 5 & 167 & 165 & 158 & 140 & 133 & - & - & - & - & - \\
\hline 6 & 162 & 165 & 159 & 140 & 137 & 70 & 75 & 80 & 80 & 83 \\
\hline 7 & 177 & 166 & 155 & 148 & 142 & 102 & 111 & 114 & 119 & 110 \\
\hline 8 & 129 & 130 & 127 & 116 & 112 & 90 & 100 & 99 & 108 & 104 \\
\hline 9 & 165 & 163 & 151 & 134 & 122 & 105 & 107 & 108 & 109 & 106 \\
\hline 10 & 149 & 156 & 159 & 139 & 134 & 70 & 77 & 85 & 89 & 91 \\
\hline 11 & 162 & 151 & 150 & 141 & 135 & 86 & 93 & 98 & 92 & 95 \\
\hline Mean & 153 & 150 & 145 & 132 & 127 & $80^{\star * *}$ & $85^{* \ldots *}$ & $88^{* * *}$ & $90^{* * *}$ & $90^{* * *}$ \\
\hline SE & 5 & 5 & 4 & 3 & 3 & 6 & 6 & 6 & 6 & 5 \\
\hline
\end{tabular}

Numbers indicate the atrial effective refractory period in $\mathrm{ms}$; SE, standard error of the mean; "** $p<0.001$ compared to cuntrol (unpaired Student's t-test).

Effects of Atrial Fibrillation on the Duration and Rate-Adaptation of the Atrial Effective Refractory Period

Before the goats were connected to the automatic atrial fibrillator and after $11 \pm 3$ days (range 1-21 days) of maintained AF, the atrial effective refractory period (AERP) was measured during a wide range of pacing intervals. In Table 2 , the average values of the AERP at different pacing rates are given for all experiments. Atrial fibrillation markedly shortened the AERP during slow pacing with an interval of $400 \mathrm{~ms}$, from $153 \pm 5 \mathrm{~ms}$ to $80 \pm 6 \mathrm{~ms}(-48 \%, \mathrm{p}<0.001)$. At a pacing interval of $200 \mathrm{~ms}$, the effects of AF on atrial refractoriness was less, the AERP shortening from $132 \pm 3 \mathrm{~ms}$ to 90 $\pm 18 \mathrm{~ms}(-32 \%, \mathrm{p}<0.001)$ and as a result, the rate adaptation of the AERP became inversed. While during sinus rhythm, the AERP shortened when heart rate was increased, after $11 \pm 3$ days of maintained AF the refractory prolonged at faster pacing rates ( $80 \pm 6$ versus $90 \pm 6 \mathrm{~ms}$ ).

So, similarly to previous reports ${ }^{1,2}$ (see Chapter 3 and 4) maintenance of AF resulted in a marked shortening and inversion of the rate adaptation of the AERP. The present data show that these dramatic changes in atrial refractoriness are indeed associated with similar changes in the duration of the MAP. 


\section{Pacing Interval $200 \mathrm{~ms}$}

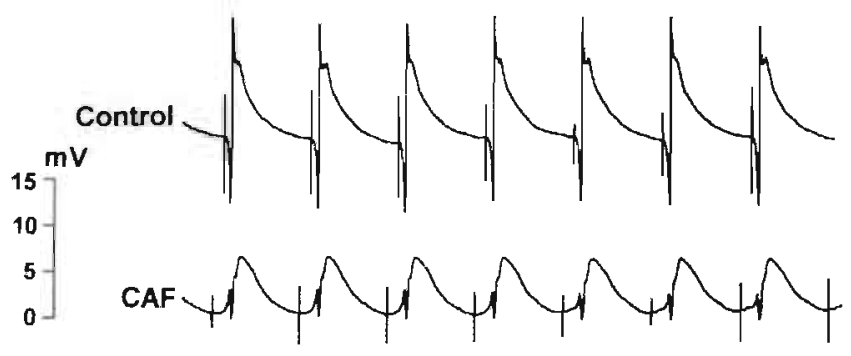

Atrial Fibrillation

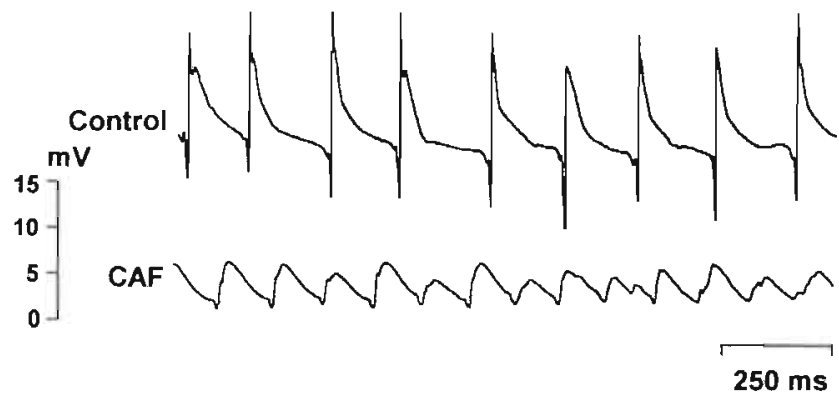

Figure 3. Illusirations of MAP's recorded in control and chronic AF goats during fast pacing with an interval of $200 \mathrm{~ms}$ (upper panel) and AF (lower panel). MAP's recorded during fast pacing and AF were much broader (increased $M A \mathrm{PD}_{20}$ ) in the chronically fibrillating goats cornpared to the sinus rhythm goats. Although during acute AF a clear beat to beat variation in AF cycle length was observed only small variations were seen in beat to beat morphology. The shape of MAP's remained rather similar to those obtained during fast pacing, showing a fast upstroke and a smooth and fast repolarization. Clear iso-electric segments were still present during acute AF. During chronic AF, the AF-cycle length had significantly shortened form 150 to $100 \mathrm{~ms}$ while clear beat to beat changes in the morphology, upstroke and amplitude were seen. Iso-electric segment were no longer present.

\section{Temporal Variation of the Monophasic Action Potential During AF}

In Fig 3, representative examples of monophasic action potentials recorded during pacing with an interval of $200 \mathrm{~ms}$ (upper panel) and during AF (lower panel) are given for control and chronic AF. As previously shown (Table 1) MAP's recorded during 200 ms pacing interval were much broader (increased $\mathrm{MAPD}_{20}$ ) in chronically fibrilating goats compared to sinus rhythm goats whereas their duration (MAPD 80 ) was not significantly different. MAP's recorded during atrial fibrillation showed a similar morphology as during rapid pacing (lower panel). Although during acute AF a clear beat to beat variation in AF cycle length was found, only small beat to beat changes in the MAP morphology were present while between consecutive beats clear iso-electric segments were present. The bottom tracing shows MAP's obtained in the 


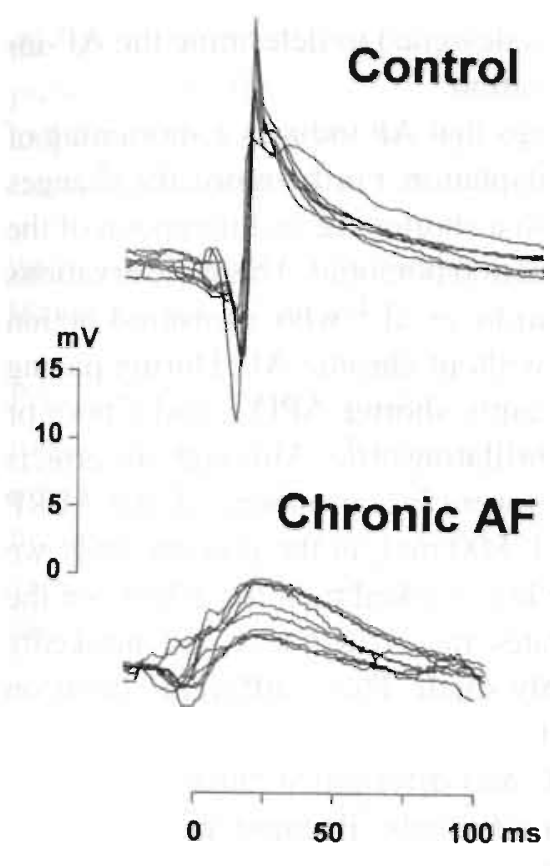

Figure 4. A number of the MAP's recorded during acute AF (control, upper panel) and chronic AF (lower panell) are superimposed. During acute AF, all MAP's had a similar morphology: a fast upstroke, a relatively high amplitude and more or less the same duration. In contrast, during chronic AF the amplitude of recorded signals was much smaller and the upstrokes was slower. Furthermore, marked beal to beat changes in MAP morphology and duration were found.

same goat after $\mathrm{AF}$ had been maintained for about 20 weeks. The median AF cycle length had shortened significantly from about 150 to $100 \mathrm{~ms}$. MAP's recorded during chronic AF showed a considerable irregularity in beat to beat morphology, upstroke and amplitude while between the consecutive activations no clear iso-electric segments were observed.

In Fig 4, the beat to beat variations in MAP morphology are illustrated in more detail by superimposition of a number of the MAP's recorded during AF. During acute AF (upper panel), all MAP's had a similar morphology; showing a fast upstroke and a similar amplitude and duration. In contrast, during chronic AF (lower panel) marked variations in MAP morphology and duration were present. While some MAP's still showed a relatively fast upstroke and a large amplitude, other action potential were depressed showing a slow upstrokc and a considerably smaller amplitude.

\section{Discussion}

\section{AF-induced Changes in Atrial Monophasic Action Potentials}

We previously reported that in chronically instrumented goats, the repetitive induction of $\mathrm{AF}$ resulted in a dramatic shortening of the atrial effective refractory period. Because the shortening of the AERP was most pronounced at slow pacing rates, the physiological rate adaptation of the AERP in the fibrillating heart was lost or even became inversed. ${ }^{1}$ Since changes in the AERP are most likely a result of changes in 
the duration of the action potential, this study was designed to determine the AF-induced changes in monophasic action potential duration.

The present study confirms our previous findings that AF induces a shortening of the AERP and inversion of its physiological rate adaptation. Furthermore, the changes in atrial refractoriness were indeed associated with a shortening and inversion of the rate adaptation of the duration of the monophasic action potential. These observations are in agreement with results obtained by Boutjdir et al. ${ }^{7}$ who measured action potentials in atrial tissue from patients with and without chronic AF. During pacing at intervals between 400 and $1600 \mathrm{~ms}$, a significantly shorter $\mathrm{APD}_{90}$ and a poor or absent rate adaptation of the APD was found in fibrillating atria. Although the effects on atrial refractoriness in human fibrillating atria were less pronounced, the AERP was only shortened at slow pacing rates (interval $800 \mathrm{~ms}$ ), in the present study we found that the effects of AF on the MAPD were less marked than the effects on the AERP (Tables 1 and 2). While at fast heart rates the AERP was still markedly shortened by AF, the changes in MAPD were only small. These different effects on MAPD and AERP might be explained by the fact that both parameters were not measured simultaneously. In addition, the MAPD was determined during anesthesia whereas the AERP was determined in conscious animals. Because in chronically fibrillating goats each measurement of the AERP would have induced long-lasting episodes of AF, a number of electrical cardioversions would have been necessary to complete the protocol.

Although previous studies had reported that diseased atrial tissue often shows a less negative membrane potential, resulting in "slow" rising action potentials and a decreased intra-atrial conduction velocity, ${ }^{8-10}$ these findings were not confirmed by our present study and the work of Boutjdir et al. ${ }^{7}$ However, we only accepted MAP recordings which showed a stable baseline, a smooth morphology and an amplitude of more than $3 \mathrm{mV}$ which might have induced a selection bias in our data. Although MAP recordings do not reproduce true membrane voltages and therefore can not be used as absolute measurements of the amplitude and or upstroke of the intracellular action potential, the rapid upstroke of the MAP makes it unlikely that resting membrane potentials were markedly depressed in tibrillating atria. In addition, we previously reported that no gross abnormalities in conduction velocity were observed after conversion of chronic AF in this goat model. ${ }^{1}$

Marked differences in MAP morphology during acute and chronic AF were found. During acute AF. MAP's showed a last upstroke, minor beat to beat changes in morphology and duration and clear iso-electrical segments between different activations. In contrast, during chronic AF MAP's showed a slower upstroke, a smaller amplitude and more pronounced beat to beat changes in morphology, while iso-electrical segments were no longer present. These observations suggest that during acute $\mathrm{AF}$ the right atrium was still activated by rapidly conducting broad macro-reentrant waves in the presence of a clear excitable gap (type I $\mathrm{AF}^{11}$ ). In contrast, during chronic $\mathrm{AF}$ the right atrial activation seemed more complex, atrial rate was not only faster but 
the conduction velocity seemed depressed while only a small excitable gap was present (Type II-III $\mathrm{AF}^{11}$ ). The beat to beat changes in action potential morphology and duration during chronic AF suggest that also an increased temporal dispersion in 'atrial refractoriness' was present during chronic AF.

Which lonic Currents can be Involved in the Shortening and Reversed Rate Adaptation of the Monophasic Action Potential?

Previously we have suggested that AF-induced changes in the atrial refractory period might be caused by changes in the structure and/or function of plasma-membrane ion-channels (Chapter 3 and 4). ${ }^{12}$ Although in the present study we did not evaluate the role of specific ion-currents in the process of electrical remodeling, these observations make it very likely that $\mathrm{AF}$-induced changes in the ionic currents are indeed involved.

The action potential can be shortened by a reduction of inwardly directed currents and/or by an increase in repolarizing outwardly directed currents. Atrial inwardly directed currents are mainly carried through $\mathrm{Na}^{+}$channels, $\mathrm{Ca}^{2+}$ channels and the $\mathrm{Na}^{+} / \mathrm{Ca}^{2+}$ exchange current while outward currents are carried by several different $\mathrm{K}^{+}$channels, a $\mathrm{Cl}^{-}$channel and the $\mathrm{Na}^{+} / \mathrm{K}^{+}$pump ATP-ase. The AF-induced changes in MAPD were dramatic, the MAP becoming as short as $50-85 \mathrm{~ms}$ (Table 1). This makes it likely that currents particularly activated during the initial phase of the repolarization play an important role in this process of electrical remodeling. Although the importance of other currents can not be excluded, below we will consider the possible role of the $\mathrm{Ca}^{2+}$-current and the transient outward current $\left(\mathrm{I}_{\mathrm{tol}}\right)$.

Is electrical remodeling related to a diminished inwardly directed $\mathrm{Ca}^{2+}{ }^{2+}$ current ?

The voltage dependent slow inward L-type $\mathrm{Ca}^{2+}$ current plays an important role in determining the duration of the action potential. Whereas activation of this channel is rapid, may last long and is voltage dependent, inactivation is reported to be slow and voltage as well as $\mathrm{Ca}^{2+}$ dependent. Reduction of $\mathrm{Ca}^{2+}$-current has been reported to occur under different pathological conditions such as heart failure, myocardial ischemia, ${ }^{12}$ and atrial dilatation. ${ }^{13}$ In myocytes isolated from dilated human atrium, it was shown that a depressed $\mathrm{Ca}^{2+}$-current was responsible for the observed shortening in action potential duration. ${ }^{13}$ Recently, Leistad et al. ${ }^{14}$ demonstrated that postfibrillation atrial contractile dysfunction could be reduced by the pretreatment with the calcium agonist verapamil. These data suggest that an increased transsarcolemmal $\mathrm{Ca}^{2+}$-influx during AF contributes to this atrial dysfunction. In the rat heart, Chatelain et al. ${ }^{15}$ reported a down-regulation of $\mathrm{Ca}^{2+}$-channels after isoproterenol induced $\mathrm{Ca}^{2+}$-overload, which could be prevented after blocking the $\mathrm{Ca}^{2+}$-channels with SR 33557. Similarly, Tieleman et al. ${ }^{16}$ recently showed that rapid atrial pacing induced electrical remodeling in the goat could be delayed by administration of the $\mathrm{Ca}^{2+}$-channel blocker verapamil. These studies suggest that $\mathrm{AF}$ induced enhanced $\mathrm{Ca}^{2+}$-entry 
and subsequent $\mathrm{Ca}^{2+}$-overload resulting in down-regulation of $\mathrm{Ca}^{2+}$ channels may account for the AF induced shortening of the action potential.

Increasing the frequency usually has a biphasic effect on the inward $\mathrm{Ca}^{2+}$-current. ${ }^{17,18}$ Boyett and Fedida ${ }^{18}$ reported that in sheep Purkinje fibers, on going from 6 to $60 \mathrm{stimuli} / \mathrm{min}$, an increase in slow inward current was found while at higher pacing rates a decrease in $\mathrm{Ca}^{2+}$ current was reported. The role of this current in the frequency dependence of the action potential duration is supported by the findings of Ruiz-Petrich et al. ${ }^{19}$, who observed in rabbit ventricular cells that the $\mathrm{Ca}^{2+}$ channel blocker $\mathrm{Co}^{++}$strongly reduced the rate dependent shortening of the action potential. So if AF induces an intra-cellular $\mathrm{Ca}^{2+}$-overload which depresses the inward $\mathrm{Ca}^{2+}$-currents, this may account for the observed maladaptation of the MAPD. However, it does not easily explain the AF-induced inversed rate adaptation of the MAPD at fast pacing rates for which another rate dependent current seemed to be involved.

Is electrical remodeling related to an increased transient outward current?

The transient outward $\mathrm{K}^{+}$current $\left(\mathrm{I}_{\mathrm{tol}}\right)$ is known to play an important role during the initial repolarization and shows rapid voltage dependent activation followed by a period of voltage dependent inactivation. Due to a slow recovery from activation this channel becomes inactivated at higher heart rates. An increase in the density of these channels could therefore well explain the phenomenon of reversed rate adaptation. Giles and van Ginneken ${ }^{20}$ showed that in isolated rabbit atrial myocytes a decrease in the pacing frequency from 1 to $0.25 \mathrm{~Hz}$ shortened the duration of the action potential due to an increase in the 4-aminopyridine sensitive transient outward current.

Acknowledgments

Jet Leunissen and Marieke De Groot are greatly aknowledged for their support and assistance during the experiments, Clifford Garratt for his most helpful comments on preparing the manuscript.

\section{References}

l Wijffels MCEF, Kirchhof CJHJ, Dorland R, Allessie MA: Atrial fibrillation begets atrial fibrillation. A study in awake chronically instrumented conscious goats. Circulation 1995;92:1954-1968

2 Wijffels MCEF, Kirchhof CJHJ, Dorland R, Power J, Allessie MA: Electrical remodeling due to atrial fibrillation in chronically instrumented conscious goats. The role of neurohumoral changes, ischemia, atrial stretch and high rate of electrical activation. Circulation (submitted) 1996;

3 De Groot SHM, Vos MA, Gorgels APM, Leunissen JDM, Van de Steld BJ, Wellens HJJ: Combining monophasic action potential recordings with pacing to demonstrate delayed afterdepolarizations and triggered arrhythmias in the intact heart. Value of diastolic slope. Circulation 1995;92:2697-2704

4 Allessie MA, Hoeks APG, Schmitz GML, Reneman RS: On-line mapping system for the visualization of the electrical activation of the heart. Int J Cardiac Imag 1986;2:59-63 
5 Yuan S, Blomstrom-Lundqvist C, Olsson SB: Monophasic Action Potentials: concepts to practica\} applications. I Cardiovasc Electrophysiol 1994:5:287-308

6 Olsson SB: Estimation of ventricular repolarization in man by monophasic action potential recording technique. Eur Heart $J$ 1985;6:71-79

7 Boutjdir M, Le Heuzey J, Lavergne T, Chauvaud S, Guize L, Carpentier A, Peronneau P: Inhomogeneity of cellular refractoriness in human atrium: factor of armythmia? Pace 1986;9:1095-1100

8 Hordof AJ, Edie R, Malm JR, Hoffman BF, Rosen MR: Electrophysiologic properties and response to pharmacologic agents of fibers from diseased human atria. Circulation 1976;54:774-779

9 Ten Eick RE. Singer DH: Electrophysiologic properties of diseased human atrium. 1.Low diastolic potential and altered cellular response to potassium. Circ Res 1979;44:545

10 Mary-Rabine L, Albert A, Pham TD, Hordof AJ, Fenoglio JJ, Jr., Malm JR, Rosen MR: The relationship of human atrial cellular electrophysiology to clinical function and ultrastructure. Circ Res 1983;52:188-199

11 Konings KTS, Kirchhof CJHJ, Smeets JLRM, Wellens HJJ, Penn OC, Allessie MA: High-density mapping of electrically induced atrial fibrillation in humans. Circulation 1994:89:1665-1680

12 Aggarwal R. Boyden PA: Altered pharmacological responsiveness of reduced L-type calcium currents in myocytes surviving in the infarcted heart. $J$ Cardiovasc Electrophysiol 1996;7:20-35

13 Le Grand B, Hatem S, Deroubaix E, Couétil JP, Coraboeuf E: Depressed transient outward and calcium currents in dilated human atria. Cardiovasc Res 1994;28:548-556

14 Leistad E, Aksnes G, Verburg E, Christensen G: Atrial contractile dysfunction after short-term atrial fibrillation is reduced by verapamil but increased by BAY K8644. Circulation 1996; 93:1747-1754.

15 Chatelain P, Laruel A, Beaufort P, Meysmans L, Clinet M: Prevention of calcium overload and down-regulation of calcium channels in rat heart by SR 33557, a novel calcium entry blocker. Cardioscience 1992;3:117-123

16 Tieleman RG, de Langen CDJ, van der Woude HJ, Grandjean JG, Bel KJ. Wijffels MCEF, Allessie MA, Crijns HJGM. Reduction of electrical remodeling of the atrium by verapamil. Circulation 1995;92:I-754 (abstract)

17 Payet MD, Schanne OF, Ruiz-Ceretti E: Frequency dependence of the ionic currents determining the action potential repolarization in rat ventricular muscle. J Moll Cell Cardiol 1981:13:207-215

18 Boyett MR, Fedida D: The effect of heart rate on the membrane currents of isolated sheep Purkinje fibres. J Physiol 1988;399:467-491

19 Ruiz-Petrich $\mathrm{E}$, Leblanc $\mathrm{N}$ : The mechanism of the rate-dependent changes of the conducted action potential in rabbit ventricle. Can J Physiol Pharmacol 1989;67:780-787

20 Giles WR, van Ginneken ACG: A transient outward curtent in isolated cells from crista terminalss of rabbit heart. J Physiol 1985;368:243-264 



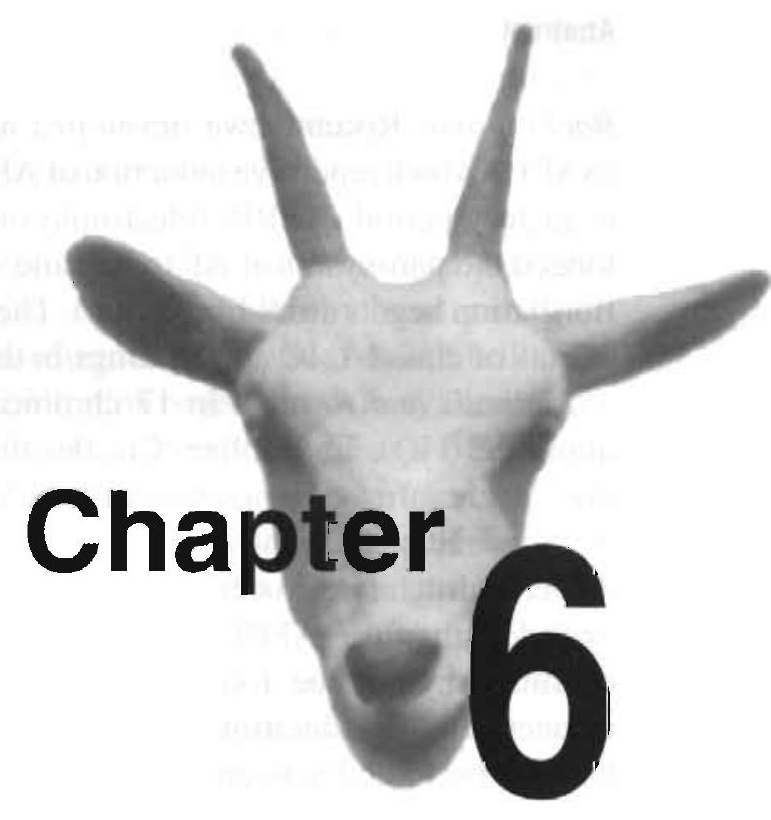

Pharmacological Conversion of Chronic Atrial Fibrillation by Class IA, IC and III Drugs in the Goat A Comparison Between Hydroquinidine, Cibenzoline, Flecainide and d-Sotalol

Maurits C.E.F. Wijffels

Rick Dorland

Maurits A. Allessie

This study was presented in part at the 69th Annual Scientific Sessions of the American Heart Association, November 10-13, New Orleans, Louisiana (Circulation 1996;94(8): I-351) 


\section{Abstract}

Background: Recently we developed a goat model of sustained atria] fibrillation (SAF) in which repetitive induction of AF by burst pacing shortened the atrial effective refractory period (AERP) (electrophysiological remodeling) and progressively prolonged the paroxysms of AF to become sustained ( 24 hours) within 1-3 weeks (atrial fibrillation begets atrial fibrillation). The aim of the present study was to compare the effects of class IA, IC and III drugs in this animal model of chronic AF.

Methods and Results: In 17 chronically fibrillating goats, the effects of hydroquinidine (HQ), cibenzoline (Ci), flecainide (Fl) and $d$-sotalol (dS) were studied. All drugs were infused intravenously until SAF was cardioverted or adverse drug effects occurred. $\mathrm{HQ}, \mathrm{Ci}, \mathrm{Fl}$ and $d \mathrm{~S}$ restored sinus rhythm in $86,86,67$ and $92 \%$ of the cases. Adverse drug effects occurred in $14,43,56$ and $8 \%$ respectively. The average atrial cycle length of $\mathrm{AF}$ (AFCL) was prolonged to a different degree. Just before restoration of sinus rhythm the four drugs had increased AFCL by $72,102,50$ and $20 \%$ respectively. The duration of the QRS-complex was prolonged $17 \%$ by $\mathrm{HQ}, 60 \%$ by $\mathrm{Ci} 50 \%$ by $\mathrm{Fl}$ and was unchanged by $d \mathrm{~S}$. The RR-interval was not affected by $\mathrm{HQ}$, slightly prolonged by $\mathrm{Ci}$ and $\mathrm{Fl}$, and markedly prolonged by $d \mathrm{~S}(48 \%)$. The QT-time was lengthened by $\mathrm{HQ}, \mathrm{Ci}, \mathrm{Fl}$ and $d \mathrm{~S}$ by $10,21,25$ and $34 \%$. Directly after restoration of sinus rhythm the AERP during pacing with an interval of $400 \mathrm{~ms}$ was $92 \pm 29$ (HQ), $123 \pm 30(\mathrm{Ci}), 66 \pm 10(\mathrm{Fl})$ and $73 \pm 18 \mathrm{~ms}(\mathrm{dS})$ (control value: $149 \pm 19 \mathrm{~ms}$ ). Intra-atrial conduction velocity was $83 \pm 7,74 \pm 13,86 \pm 12$ and $110 \pm 11 \mathrm{~cm} / \mathrm{s}$ (control value: $116 \pm 10$ $\mathrm{cm} / \mathrm{s}$ ). Although all four drugs were effective in terminating AF, after cardioversion the atrial vulnerability was still very high and a single premature stimulus reinduced $\mathrm{AF}$ in $100 \%$ of the animals (HQ, Fl or $\mathrm{dS})(67 \%$ for $\mathrm{Ci}$ ). As a result of the short AERP by the $\mathrm{AF}$-induced remodeling and the depressed intra-atrial conduction by the class I drugs, directly after cardioversion the atrial wavelength was abnormally short (between 5.7 and $8.8 \mathrm{~cm}$ ). This can explain the still high atrial vulnerability to AF directly after cardioversion by class I or class III drugs.

Conclusions: In a goat model of chronic atrial fibrillation infusion of class IA, IC, and class III drugs restored sinus rhythm in $67-92 \%$ of the cases. However, due to the short AERP and the depressed intra-atrial conduction directly after cardioversion, the atrial vulnerability was still very high and a premature beat easily reinduced AF.

\section{Introduction}

Atrial fibrillation (AF) can be converted to sinus rhythm (SR) either by pharmacological or electrical cardioversion. ${ }^{1-5}$ Pharmacological cardioversion of AF can be done successfully by different agents like class IA drugs (quinidine, procainamide), ${ }^{6-10}$ class IC drugs (propafenone, flecainide, cibenzoline), $3-5.9,11-13$ or class III drugs (d..l)-sotalol, amiodarone). ${ }^{14-17} \mathrm{~A}$ consistent clinical finding is that the success rate 
of pharmacological cardioversion is closely related to the length of time that AF had persisted before cardioversion is attempted. For instance. Crijns et al. ${ }^{3}$ and Suttorp et al. $^{4.5}$ found that the efficacy of intravenous flecainide in restoring sinus rhythm diminished from $86 \%$ in patients with recent onset fibrillation ( $<24$ hours) to $39 \%$ in patients with AF of longer duration.

Recently we developed a new model of atrial fibrillation in chronically instrumented goats. ${ }^{18}$ In these animals the repetitive induction of AF by burst pacing ( 1 second, $50 \mathrm{~Hz}$ ) during 1-3 weeks, gradually transformed paroxysmal atrial fibrillation into chronic AF. This observation that 'atrial fibrillation begets atrial fibrillation', may give an explanation for the clinical experience that the efficacy of anti-fibrillatory drugs diminishes when $\mathrm{AF}$ had persisted for a longer period of time. ${ }^{3-5}$ Electrophysiological measurements performed during the first days of electrically maintained $\mathrm{AF}$, revealed a marked shortening of the atrial effective refractory period and the AF cycle length by more than $30 \%$. This process of electrical remodeling might affect the antifibrillatory action of class I and class III drugs. Since most electrophysiological studies on the effects of antifibrillatory drugs have been done during acutely induced atrial fibrillation, ${ }^{19-23}$ the effects of these drugs on remodeled atrial myocardium are yet unknown. The present study was undertaken to evaluate the antifibrillatory efficacy of hydroquinidine (class IA), flecainide (class IC), cibenzoline (class IC with additional class III and IV effects) and $d$-sotalol (class III) in the goat model of chronic atrial fibrillation. To determine the effects of these drugs on remodeled myocardium, directly after pharmacological cardioversion the atrial refractory period, the intraatrial conduction velocity, the wavelength and the atrial vulnerability for AF were measured.

\section{Methods}

The Goat model of Chronic Atrial Fibrillation

Seventeen goats weighing between 41 and $82 \mathrm{~kg}(57.6 \pm 9.7 \mathrm{~kg})$ were used for this study. Animal handling was performed according to the guiding principles of the American Society of Physiology and approved by the Animal Investigation Committee of the University of Limburg. The goats were instrumented with multiple epicardial electrodes as has been previously described. ${ }^{18}$ Briefly, during general anesthesia a left intercostal thoracotomy was made and the pericardium was opened. In all goats a teflon felt strip $\left(\right.$ Bard $\left.^{\circledR}\right)(10 \times 1.2 \mathrm{~cm})$ containing 15 unipolar silver electrodes (diameter $2 \mathrm{~mm}$, inter-electrode distance 6-10 $\mathrm{mm}$ ) was sutured to the surface of Bachmann's bundle. In 5 goats two smaller felt strips $(3 \times 1.2 \mathrm{~cm})$ each containing 6 electrodes, were sutured to the lateral walls of the right and left atria. In 12 goats an array of 30 electrodes (interelectrode distance $4-4.5 \mathrm{~mm}$ ) was implanted on the free wall of the right and left atrium. A small strip $(1.2 \times 1.2 \mathrm{~cm})$ containing 4 electrodes was sutured to the surface of the left ventricle. After closure of the thorax, 
the electrode leads were tunneled subcutaneously to the neck and externalized by three 30-pin Lemosa ${ }^{\circledR}$ connectors. Three silver plates (diameter $25 \mathrm{~mm}$ ) were left subcutaneously to serve as grounding electrodes and to record a precordial electrocardiogram. Post-operatively the animals received buprenorfine (Temgesic ${ }^{\circledR}, 0.01 \mathrm{mg} / \mathrm{kg}$, Reckitt \& Colman) during 1-3 days. Gentamicin ( $3 \mathrm{mg} / \mathrm{kg}$ ) and sodium-ampicillin (Pentrexyl ${ }^{\circledR} 1000 \mathrm{mg}$, Bristol-Myers Squibb) was given intravenously directly before surgery. After surgery an additional dose of sodium-ampicillin (1000 mg) was given intramuscularly.

About 2-4 weeks after surgery, the goats were connected to an external atrial fibrillator. This device, which has been described in detail elsewhere, ${ }^{18}$ continuously analyses the length of the iso-electrical segment in a bipolar atrial electrogram and by this parameter is able to distinguish sinus rhythm from atrial fibrillation. As soon as spontaneous conversion to sinus rhythm is detected, the fibrillator promptly reinduces atrial fibrillation by delivering a 1 second burst of electrical stimuli $(50 \mathrm{~Hz}, 4$ times diastolic threshold). In this way, $\mathrm{AF}$ is maintained automatically 24 hours a day, seven days a week. Within the first days the initially short episodes of $\mathrm{AF}$ ( $<10$ seconds) progressively prolonged and after 1-3 weeks of maintaining AF, atrial fibrillation became sustained (lasting 24 hours). ${ }^{18}$ In Table 1, the characteristics of the 17 goats included in this study are given. In this series atrial fibrillation became sustained (24 hours) after an average of $12 \pm 10$ days (range 1-34 days). Pharmacological cardioversion was carried out after a total average duration of $\mathrm{AF}$ of $32 \pm 22$ days (range 2 to 116 days) and $19 \pm 20$ days after AF had become sustained (range 1-87 days). For each goat the median atrial fibrillation cycle length (AFCL), the total duration of $A F$ and the duration of sustained AF (from the moment the episodes of AF lasted 24 hours) prior to pharmacological cardioversion by each of the 4 drugs are given, together with the rate and duration of infusion, the total amount of the drugs administered and whether cardioversion was successful. Compared to the median AF cycle length of $145 \mathrm{~ms}$ of acutely induced $A F .^{18}$ the median cycle length during chronic AF was markedly shortened to an average of $93 \pm 7 \mathrm{~ms}$. It is important to note that the degree of electrical remodeling (shortening of AFCL) and the total duration of maintained and chronic AF did not differ in the four groups (one-way ANOVA).

\section{The Electrophysiological Study}

About 2-3 weeks after implantation, before the animals were connected to the automatic fibrillator, an electrophysiological study was performed. The atrial effective refractory period (AERP) was measured during pacing with a fixed $S_{1}-S_{1}$ cycle length of $400 \mathrm{~ms}$ at either the right or left atrial appendage. A single premature stimulus $\left(S_{2}\right)$ of 4 times diastolic threshold was interpolated after every fifth basic stimulus. The measurement of AERP was started with an $S_{1}-S_{2}$ coupling interval shorter than the atrial refractory period and was incremented in steps of 1 or $2 \mathrm{~ms}$. The shortest $\mathrm{S}_{1}-\mathrm{S}_{2}$ interval that resulted in a propagated premature atrial response was taken as the AERP. Intra-atrial conduction velocity was measured during regular pacing with an 
Table 1. Characteristics of AF and Drug Infusion

\begin{tabular}{|c|c|c|c|c|c|c|c|c|c|c|c|c|c|c|}
\hline & Hydroc & inidine ( $n=7$ & & & & & & Cibenz & line $(n=14)$ & & & & & \\
\hline $\begin{array}{l}\text { Goat } \\
\#\end{array}$ & $\begin{array}{l}\mathrm{AFCL} \\
(\mathrm{ms})\end{array}$ & $\begin{array}{l}\text { Duration } \\
\text { of AF } \\
\text { (Days) }\end{array}$ & $\begin{array}{l}\text { Duration } \\
\text { of SAF } \\
\text { (Days) }\end{array}$ & $\begin{array}{l}\text { Infusion } \\
\text { Rate } \\
\text { (mg/kg/min) }\end{array}$ & $\begin{array}{l}\text { Infusion } \\
\text { time } \\
\text { (Min) }\end{array}$ & $\begin{array}{l}\text { Drug } \\
\text { Dosage } \\
\text { (mg/kg) }\end{array}$ & $\begin{array}{l}\text { Cardjo- } \\
\text { version }\end{array}$ & $\begin{array}{l}\text { AFCL } \\
(m s)\end{array}$ & $\begin{array}{l}\text { Duration } \\
\text { of AF } \\
\text { (Days) }\end{array}$ & $\begin{array}{l}\text { Duration } \\
\text { of SAF } \\
\text { (Days) }\end{array}$ & $\begin{array}{l}\text { Infusion } \\
\text { Rate } \\
\text { (mg/kg/min) }\end{array}$ & $\begin{array}{l}\text { Infusion } \\
\text { Time } \\
\text { (Min) }\end{array}$ & $\begin{array}{l}\text { Drug } \\
\text { Dosage } \\
\text { (mg/kg) }\end{array}$ & $\begin{array}{l}\text { Cardio- } \\
\text { version }\end{array}$ \\
\hline 1 & 87 & 26 & 2 & 0.25 & 25 & 6.25 & yes & 89 & 40 & 16 & $0.1+0.2$ & 83 & 10.6 & no \\
\hline 2 & 99 & 51 & 17 & 0.25 & 26 & 6.5 & yes & 104 & 42 & 8 & 0.1 & 57 & 5.7 & yes \\
\hline 3 & 100 & 2 & 1 & 0.25 & 52 & 13 & yes & 93 & 9 & 8 & 0.1 & 39 & 3.9 & yes \\
\hline 4 & - & - & - & - & - & - & - & 97 & 16 & 15 & 0.1 & 51 & 5.1 & yes \\
\hline 5 & 99 & 35 & 23 & 0.25 & 21 & 5.25 & yes & 94 & 51 & 39 & $0.1+0.2$ & 90 & 12.0 & yes \\
\hline 6 & - & - & - & - & - & - & - & 92 & 63 & 56 & 0.2 & 52 & 10.4 & yes \\
\hline 7 & - & - & - & - & - & - & - & 97 & 15 & 9 & 0.2 & 22 & 4.4 & yes \\
\hline 8 & - & - & - & - & - & - & - & 86 & 14 & 6 & 0.2 & 75 & 15.0 & yes \\
\hline 9 & - & - & - & - & - & - & - & 89 & 42 & 24 & 0.2 & 36.5 & 7.3 & yes \\
\hline 10 & - & - & - & - & - & - & - & 98 & 34 & 5 & 0.2 & 9 & 1.8 & yes \\
\hline 11 & - & - & - & - & - & - & - & 89 & 9 & 1 & 0.2 & 55 & 11.0 & yes \\
\hline 12 & - & - & - & - & - & - & - & 100 & 10 & 3 & 0.1 & 44 & 4.4 & yes \\
\hline 13 & - & - & - & - & - & - & - & 77 & 116 & 87 & 0.18 & 85 & 15.3 & no \\
\hline 14 & - & - & - & $\cdots$ & - & - & - & 89 & 11 & 1 & 0.1 & 80 & 8.0 & yes \\
\hline 15 & 79 & 81 & 70 & 025 & 140 & 35 & no & - & $\rightarrow$ & - & - & - & - & - \\
\hline 16 & 89 & 60 & 55 & 0.25 & 80 & 20 & yes & - & - & - & - & - & - & - \\
\hline 17 & 84 & 28 & 27 & 0.25 & 54 & 13.5 & yes & - & - & - & - & - & - & - \\
\hline Mean & 91 & 40 & 28 & & 57 & 14.2 & $6 / 7$ & 92 & 34 & 20 & & 56 & 8.2 & $12 / 14$ \\
\hline$S d$ & 8 & 24 & 24 & & 39 & 9.8 & $86 \%$ & 7 & 29 & 24 & & 24 & 4.1 & $86 \%$ \\
\hline
\end{tabular}


$\vec{\sim}$ Table 1 (continued). Characteristics of AF and Drug Infusion

\section{Flecainide ( $n=9)$}

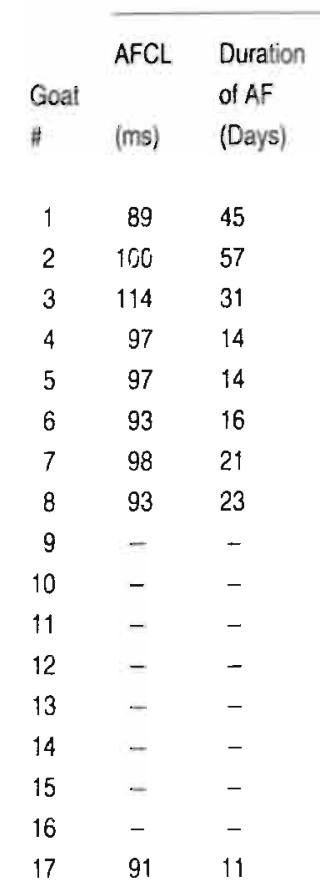

Mean $\quad 97 \quad 26 \quad 15$

Sd $7 \quad 15$
Duration Intusion

of SAF Rate

(Days) (mg/kg/min)

$21 \quad 0.1+0.2$

$23 \quad 0.1$

30

13

2

9

15

15

$-$

$-$

$-$

$-$

$-$

$-$

$-$

$0.1+0.2$
$0.1+0.2$

$0.1+0.2$

0.1

$0.1+0.2$

0.1

$0.1+0.2$

$-$

$-$

$-$

$-$

$-$

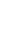

$d-S o t a l o l(n=12)$

\begin{tabular}{lllllll}
\hline AFCL & Duration & Duration & Infusion & Infusion & Drug & Cardio- \\
& of AF & of SAF & Rate & Time & Dosage & version \\
(ms) & (Days) & (Days) & $(\mathrm{mg} / \mathrm{kg} / \mathrm{min})$ & $(\mathrm{Min})$ & $(\mathrm{mg} / \mathrm{kg})$ &
\end{tabular}

(Mime Dosage version

(ms)

$\begin{array}{llll}88 & 35 & 11 & 0.2\end{array}$

$98 \quad 38$

$-\quad-$

$99 \quad 7$

$\begin{array}{cc}11 & 0.2 \\ 4 & 0.2 \\ - & - \\ 6 & 0.2\end{array}$

52 10.4 yes

$-\quad-$

$\begin{array}{ll}92 & 63 \\ 96 & 18\end{array}$

$81 \quad 18$

$95 \quad 32$

$101 \quad 36$

$92 \quad 15$

$110 \quad 44$

$\begin{array}{ll}- & - \\ 88 & 18\end{array}$

$\begin{array}{ll}88 & 18 \\ - & -\end{array}$

$-\quad-$

$-$

$95 \quad 11.0 \quad$ yes

$\begin{array}{lll}71 & 8.1 & 6 / 9 \\ 12 & 20 & 67 \%\end{array}$

$\begin{array}{lll}93 & 30 & 17\end{array}$

$\begin{array}{lllll}2.0 & 67 \% & 8 & 15 & 15\end{array}$ 
interval of $400 \mathrm{~ms}$ at either the left or the right atrial appendage. The conduction velocity was calculated from the activation times along the row of electrodes along Bachmann's bundle. The total distance between the electrodes used for measurement of the conduction velocity varied in different experiments between 5.0 and $7.8 \mathrm{~cm}$ (average $7.0 \pm 0.7 \mathrm{~cm}$ ). After the goats had been maintained in atrial fibrillation cluring an average of $12 \pm 14$ days (range 1 - 51 days) the electrophysiological study was repeated.

\section{Pharmacological Cardioversion of AF}

During the infusion of the anti-fibrillatory drugs. the goats were connected to a multichannel recording unit (gain 200-400: bandwidth 1-500 Hz) ${ }^{24}$ and the median atrial fibrillation cycle length (AFCL), RR interval, the width of the QRS-complex and the QT-time were measured every 5-10 minutes. The AFCL was measured from a bipolar electrogram recorded from the left or right atrial appendage and fibrillation interval histograms were collected during a period of 15-30 seconds of AF (150-300 cycles). The ventricular response rate was measured by counting the number of ventricular activations in a ventricular electrogram during 1 minute of $\mathrm{AF}$. The duration of the QRS-complex and the QT-time were measured either from one of the precordially implanted subcutaneous silver plates or from a precordial surface ECG. The average value of 3-6 successive QRS complexes and QT intervals was taken. First, control measurements were made during 40-80 minutes to ascertain that all parameters were stable. Then the infusion of one of the 4 drugs was started until one of the following conditions occurred: 1) cardioversion of AF to sinus rhythm, 2) prolongation of the duration of the QRS-complex by more than 70\%,3) occurrence of multiple wide QRS-complexes or ventricular tachycardia (VT), 4) general clinical symptoms (cold nose, pale mucosae, shortness of breath, gasping, tremors, etc.). Hydroquinidine-chlorhydrate (Serecor ${ }^{\circledR}$, Roussel UCLAF) was dissolved freshly in distilled water $(10-15 \mathrm{mg} / \mathrm{ml})$ and administered at a rate of $0.25 \mathrm{mg} / \mathrm{kg} / \mathrm{min} /(7$ goats $)$. Cibenzoline (Cipralan ${ }^{\circledR}, 10 \mathrm{mg} / \mathrm{ml}$, Searle) was infused either at $0.1 \mathrm{mg} / \mathrm{kg} / \mathrm{min}$ (7 goats) or at $0.2 \mathrm{mg} / \mathrm{kg} / \mathrm{min}$ ( 7 goats). In 2 goats after 60 minutes the infusion rate of $0.1 \mathrm{mg} / \mathrm{kg} / \mathrm{min}$ was increased to $0.2 \mathrm{mg} / \mathrm{kg} / \mathrm{min}$. Infusion of flecainide (Tambocor ${ }^{\mathrm{TM}}$, $10 \mathrm{mg} / \mathrm{ml}$, Riker 3M Pharma) was started at a dose of $0.1 \mathrm{mg} / \mathrm{kg} / \mathrm{min}$ and in 6 of 9 goats, after $60-75$ minutes increased to $0.2 \mathrm{mg} / \mathrm{kg} / \mathrm{min}$. The class III drug $d$-sotalol (Bristol-Myers Squibb, $10 \mathrm{mg} / \mathrm{ml}$ ) was infused either at $0.2 \mathrm{mg} / \mathrm{kg} / \mathrm{min}(\mathrm{n}=6)$ or at 0.4 $\mathrm{mg} / \mathrm{kg} / \mathrm{min}(\mathrm{n}=6)$. In one goat initially treated with the low dose, the infusion was increased to a rate of $0.4 \mathrm{mg} / \mathrm{kg} / \mathrm{min}$ after 90 minutes.

\section{Statistical Analysis}

Data are presented as mean \pm standard deviation. Statistical analysis was performed by either a (paired) Student's $t$-test or by a one-way ANOVA (differences between groups). If data were not normally distributed a Mann-Whitney rank sum test was 
used. In case of multiple comparisons, the p-value was corrected by multiplying it with the number of comparisons (Bonferroni's correction). A p-value of less than 0.05 was considered to be statistically significant.

\section{Results}

Effects of Hydroquinidine on AF Cycle Length, RR Interval and QRS Duration

In 7 goats hydroquinidine (class IA) was given as a continuous infusion of 0.25 $\mathrm{mg} / \mathrm{kg} / \mathrm{min}$. In Fig 1 the drug effects on AF-cycle length, RR-interval and QRS-width are given together with the cumulative rate of successful cardioversion and adverse drug effects. Average values are plotted together with the standard deviation and the number of goats in which the drug was still being infused. Hydroquinidine markedly prolonged the AF-cycle length from $91 \pm 8 \mathrm{~ms}$ during control to $162 \pm 25 \mathrm{~ms}$ after 60 minutes of infusion $(p<0.001)$. At this time, sinus rhythm was restored in 5 of 7 animals without any adverse drug effects being observed. In one goat sinus rhythm was restored after 80 minutes, whereas in another goat cardioversion was unsuccessful, and after 140 minutes the infusion of hydroquinidine was stopped because the QRS-width had prolonged by more than $70 \%$ (adverse effect). The total success rate of cardioversion by hydroquinidine thus was $86 \%$ ( 6 of 7 goats), whereas adverse drug effects occurred in $14 \%$ ( 1 of 7 cases). Hydroquinidine did not affect the ventricular rate during AF significantly. After 60 minutes of infusion the RR interval was $399 \pm$ 33 compared to $384 \pm 63 \mathrm{~ms}$ during control (n.s.). The changes in duration of the QRS-complex, are plotted in the lower panel. At the moment of cardioversion, the QRS-width had increased by $17 \pm 7 \%$ compared to $74 \%$ in the goat that did not cardiovert.

\section{Effects of Cibenzoline on AF Cycle Length, RR Interval and QRS Duration}

In 14 goats cibenzoline (class IC with additional class III and IV properties) was given either at a low dosage of $0.1 \mathrm{mg} / \mathrm{kg} / \mathrm{min}$ ( 7 goats) or at a high dosage of $0.2 \mathrm{mg} / \mathrm{kg} / \mathrm{min}$ (7 goats) (Table 1). In Fig 2 the effects of infusion of the high dosage of cibenzoline are shown. During the first 60 minutes the median AFCL prolonged from $89 \pm 6$ to $187 \pm 31 \mathrm{~ms}(\mathrm{p}<0.001)$. At this time, sinus rhythm had been restored in five goats. In one goat infusion was stopped after 53 minutes because of a wide QRS-complex and AF terminated 5 minutes later. The sixth goat cardioverted after 75 minutes of cibenzoline infusion whereas in one goat cardioversion did not occur and after 85 minutes infusion of cibenzoline was stopped because of a wide QRS-complex. Thus, the success rate of cardioversion of AF by cibenzoline at a rate of $0.2 \mathrm{mg} / \mathrm{kg} / \mathrm{min}$ was $86 \%$ ( 6 out of 7). Adverse effects of this high dose of cibenzoline were observed in $29 \%$ of the cases ( 2 out of 7 QRS-width prolongation of more than $70 \%$ ). As can be seen from the middle and lower panels of Fig 2, cibenzoline moderately prolonged 


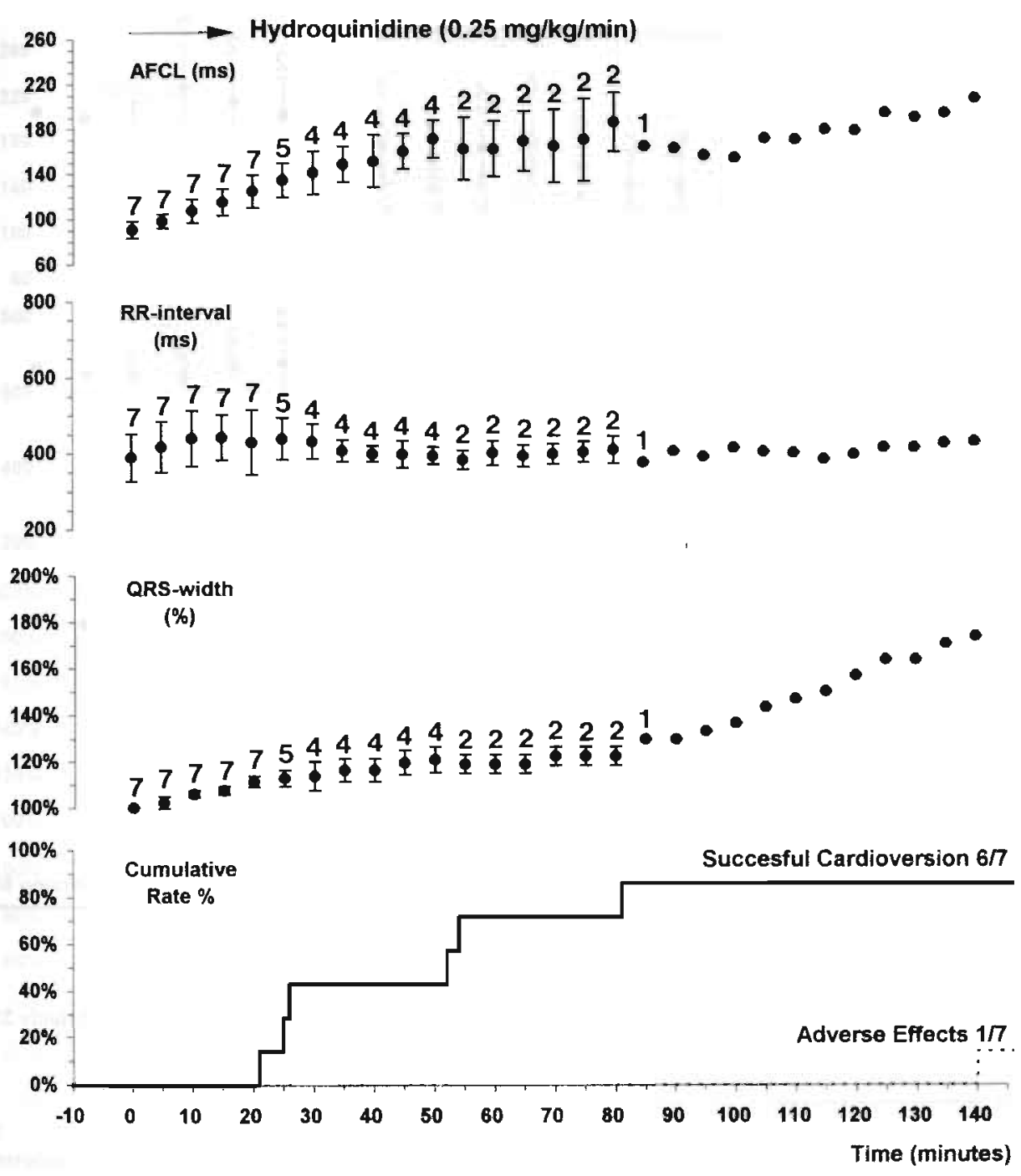

Figure 1. The effects of infusion of hydroquinidine $(0.25 \mathrm{mg} / \mathrm{kg} / \mathrm{min})$ on AF cycle length, RR interval, ORS width and the rate of cardioversion and adverse drug effects. In the upper three panels the mean values and heir standard deviations are ploted. The numbers on top of the standard deviation bars indicate the number of goats in which hydroquinidine was still infused. See text for further discussion. AFCL: atrial fibrillation cyele length.

the RR- interval from $437 \pm 94$ during control to $662 \pm 62 \mathrm{~ms}$ after 60 minutes ( $p<$ 0.05 ). The duration of the QRS-complex showed a dose dependent increase. At the moment of cardioversion, the QRS-width had increased with $60 \pm 28 \%$ compared to $118 \pm 39 \%$ in the 2 goats in which restoration of sinus rhythm failed. In the 7 goats initially treated with the low dose of cibenzoline, sinus rhythm was restored in 6 animals (86\%) while adverse effects (QRS-width prolongation of more than $70 \%$ ) were seen in 4 animals $(57 \%)$. 


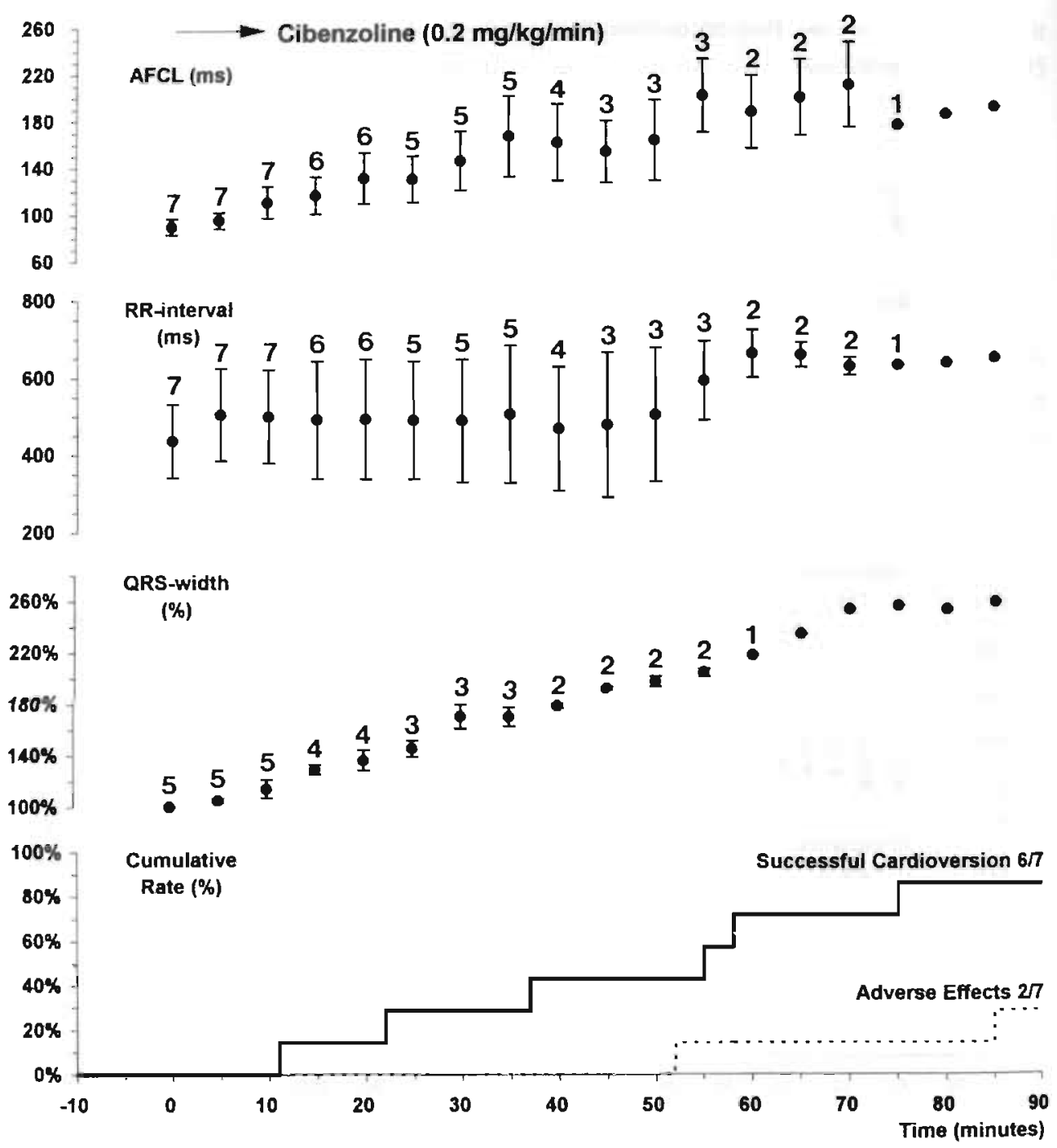

Figure 2. The effects of infusion of cibencoline $(0.2 \mathrm{mg} / \mathrm{kg} / \mathrm{min})$ on AF cycle length, RR interval, QRS width and the rate of cardioversion and adverse drug effects. In the upper three panels the mean values and their standard deviations are plotted. The numbers on top of the standard deviation bars indicate the number of goats in which cibenzoline was still infused. See text for further discussion. AFCL: atrial fibrillation cycle length.

Effects of Flecainide on AF Cycle Length, RR Interval and QRS Duration

In Fig 3 the effects of infusion of flecainide (class IC) are plotted (9 goats). During the first 60 minutes flecainide was infused at a rate of $0.1 \mathrm{mg} / \mathrm{kg} / \mathrm{min}$. In case sinus rhythm was not yet restored followed by a 30 minutes period at a rate of $0.2 \mathrm{mg} / \mathrm{kg} / \mathrm{min}$. Flecainide increased the atrial fibrillation cycle length from $97 \pm 7 \mathrm{~ms}(\mathrm{n}=9)$ to $128 \pm$ $26 \mathrm{~ms}(\mathrm{n}=6)$ after 60 minutes of infusion $(\mathrm{p}<0.01)$. At that time AF was converted 


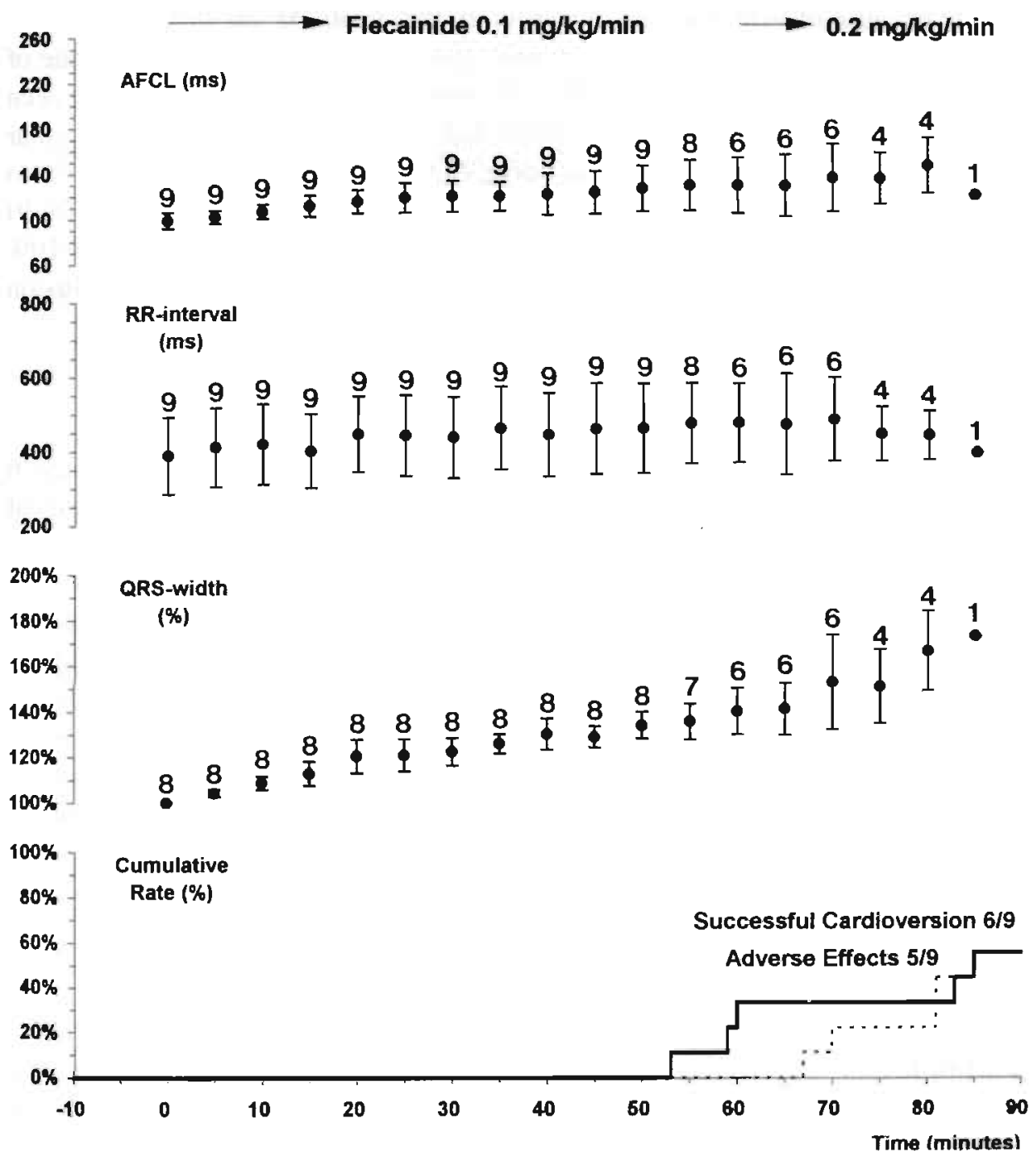

Figure 3. The effects of 60 minutes of infusion of flecainide at a rate of $0.1 \mathrm{mg} / \mathrm{kg} / \mathrm{min}$ followed by infusion at a rate of $0.2 \mathrm{mg} / \mathrm{kg} / \mathrm{min}$ on AF cycle length. RR interval, QRS width and the rate of cardioversion and adverse drug effects. In the upper three panels the mean values and their standard deviations are plotted. The numbers on top of the standard deviation bars indicate the number of goats in which flecainide was stili infused. See text for further discussion. AFCL: atrial fibrillation cycle length.

in three goats. When the infusion rate of flecainide was increased to $0.2 \mathrm{mg} / \mathrm{kg} / \mathrm{min}$ (in four goats after 60 minutes and in one goat after 75 minutes) the AFCL further prolonged to $147 \pm 24 \mathrm{~ms}$ after 80 minutes of infusion $(n=4)(p=0.32$ versus $60 \mathrm{~min})$. In 5 of the 6 goats that had not cardioverted after 60 minutes, adverse drug effects were observed. In 2 goats flecainide infusion was stopped because of a long QRS complex, in two because of occurrence of multiple beats with a wide QRS-complex 
and in one because of ventricular tachycardia. In two goats AF cardioverted respectively 2 and 25 minutes after the infusion was stopped. Thus the total success rate of cardioversion by flecainide was $67 \%$ (6 of 9 goats) while adverse effects were seen in $56 \%$ of the cases ( 5 of 9 goats). Flecainide had no clear effects on the ventricular rate during $A F$, the average $R R$ interval being $468 \pm 113$ ms after 60 minutes $(n=6)$ and $445 \pm 66 \mathrm{~ms}$ after 80 minutes of infusion $(n=4)$ compared to $404 \pm 104 \mathrm{~ms}(n=9)$ during control (n.s.). The width of the QRS complex gradually increased to $140 \pm 10 \%$ after 60 minutes $(p<0.001)$ and to $167 \pm 18 \%$ after 80 minutes of flecainide infusion ( $\mathrm{p}<0.05$ versus $60 \mathrm{~min}$ ).

Effects of $\alpha$-Sotalol on AF-Cycle Length, RR Interval and QRS Duration

$D$-sotalol was given as a continuous infusion of either $0.2 \mathrm{mg} / \mathrm{kg} / \mathrm{min}$ (low dosage, 6 goats) or $0.4 \mathrm{mg} / \mathrm{kg} / \mathrm{min}$. (high dosage, 6 goats). In Fig 4 the effects of 60 minutes of the low rate of infusion of $d$-sotalol are given. Although $d$-sotalol only slightly prolonged the AFCL, the drug was very effective in converting chronic AF to sinus rhythm ( 6 of 6 goats). No adverse drug effects were seen. Although $d$-sotalol has less $\beta$-blocking effects than its isomer $l$-sotalol, the drug still considerably slowed the ventricular rate during $A F$, the $R R$ interval being prolonged from $374 \pm 109 \mathrm{~ms}$ during control to $518 \pm 6 \mathrm{~ms}$ after 60 minutes of infusion (n.s.). As can be seen from the lower panel, $d$-sotalol had no effect on the duration of the QRS-complex. In 5 of the 6 goats treated with the high dosage of $d$-sotalol sustained AF was restored successfully ( $83 \%)$ whereas in one an adverse drug effect occurred. This goat developed a shock after 27 minutes (10.8 $\mathrm{mg} / \mathrm{kg}$ ) of infusion (see below).

\section{Relative Drug Effects on AF Cycle Length and QRS Width}

A prolongation of the AF cycle length is generally considered as a 'positive' effect of an anti-fibrillatory drug. On the other hand, a slowing of intraventricular conduction (widening of the QRS-complex) is considered as a 'negative' effect because it increases the propensity for ventricular arrhythmias. For these reasons, the relative effect of a drug on atrial fibrillation and intraventricular conduction might be useful to express its efficacy/safety ratio. In Fig 5 the relative changes in AF cycle length and QRS width ( $\triangle$-AFCL/ $\triangle$-QRS-ratio) are plotted for each of the four drugs being studied. Hydroquinidine ( $\mathrm{n}=7$ ) had a significantly stronger effect on $\mathrm{AF}$ cycle length than on the duration of the QRS-complex (upper left panel). In the goats that converted to sinus rhythm the AF cycle length prolonged with about $130 \%$ whereas the QRS width increased with only $30 \%$. In the goat that did not convert to sinus rhythm, at the higher concentration of hydroquinidine the effect on the QRS width was larger (up to $75 \%$ ). For the whole group the $\Delta-A F C L / \Delta-Q R S$ ratio was 2.8 . Both cibenzoline ( $n=11)$ and flecainide $(\mathrm{n}=8)$ prolonged the QRS-duration relatively more than hydroquinidine. The effects on AF cycle length were comparable for cibenzoline and considerably smaller for flecainide. Consequently, the $\Delta$-AFCL/ $\Delta-\mathrm{QRS}$ ratio of 


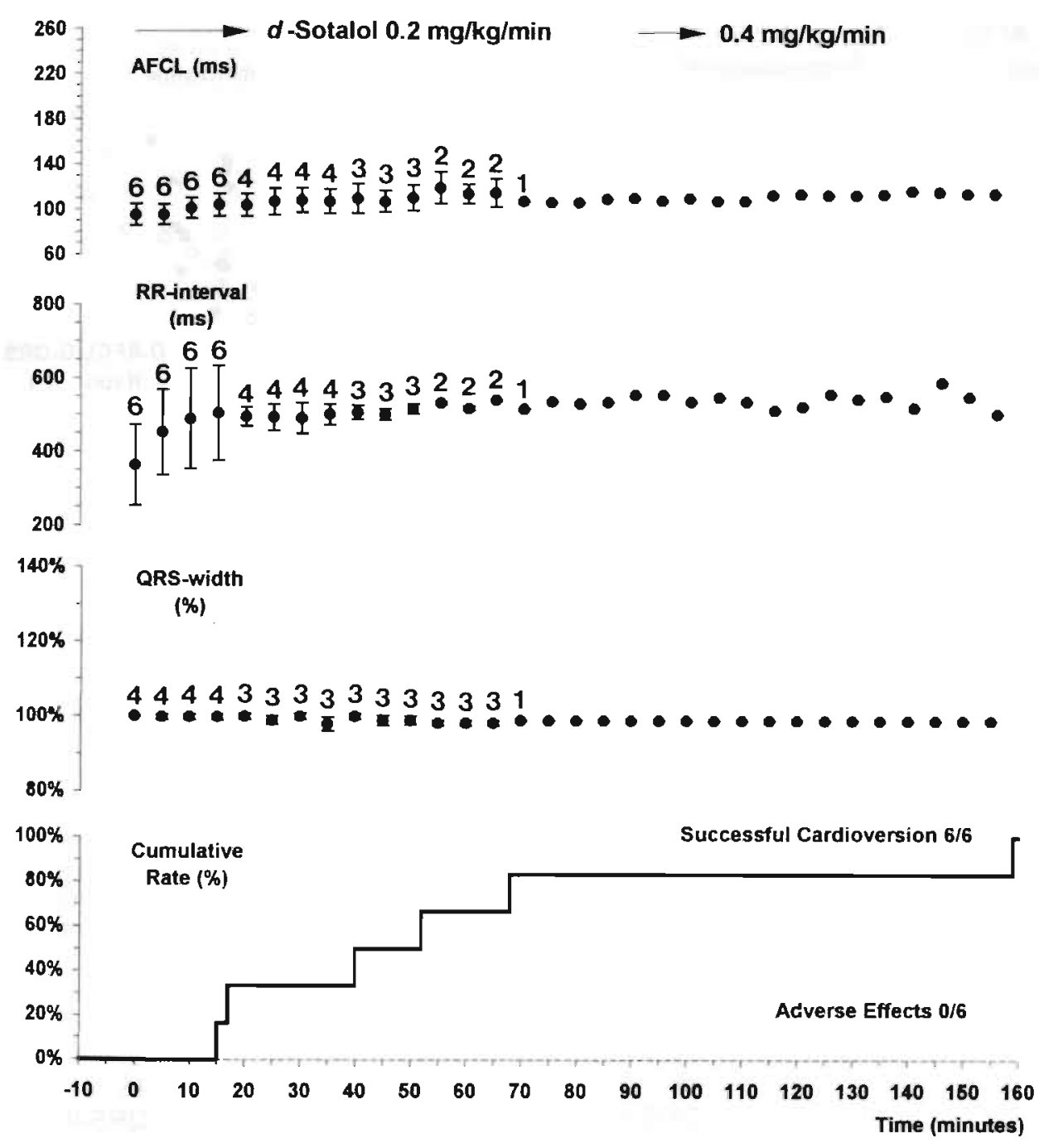

Figure 4. The effects of infusion of $d$-sotalol $(0.2 \mathrm{mg} / \mathrm{kg} / \mathrm{min}$ followed by $0.4 \mathrm{mg} / \mathrm{kg} / \mathrm{min})$ on AF cycle length. RR interval, QRS width and the rate of cardioversion and adverse drug effects. In the upper three panels the mean values and their standard deviations are plotted. The numbers on top of the standard deviation bars indicate the number of goats in which $d$-sotalol was still infused. See text for further discussion. AFCL: atrial fibrillation cycle length.

cibenzoline and flecainide were lower than for hydroquinidine (1.1 for cibenzoline and 0.8 for flecainide). Administration of $d$-sotalol $(n=4)$ increased the AF cycle length with a maximum of $40-5() \%$. Because the QRS-duration was not altered the $\triangle$-AFCL/ $\Delta$-QRS ratio wals infinite. 

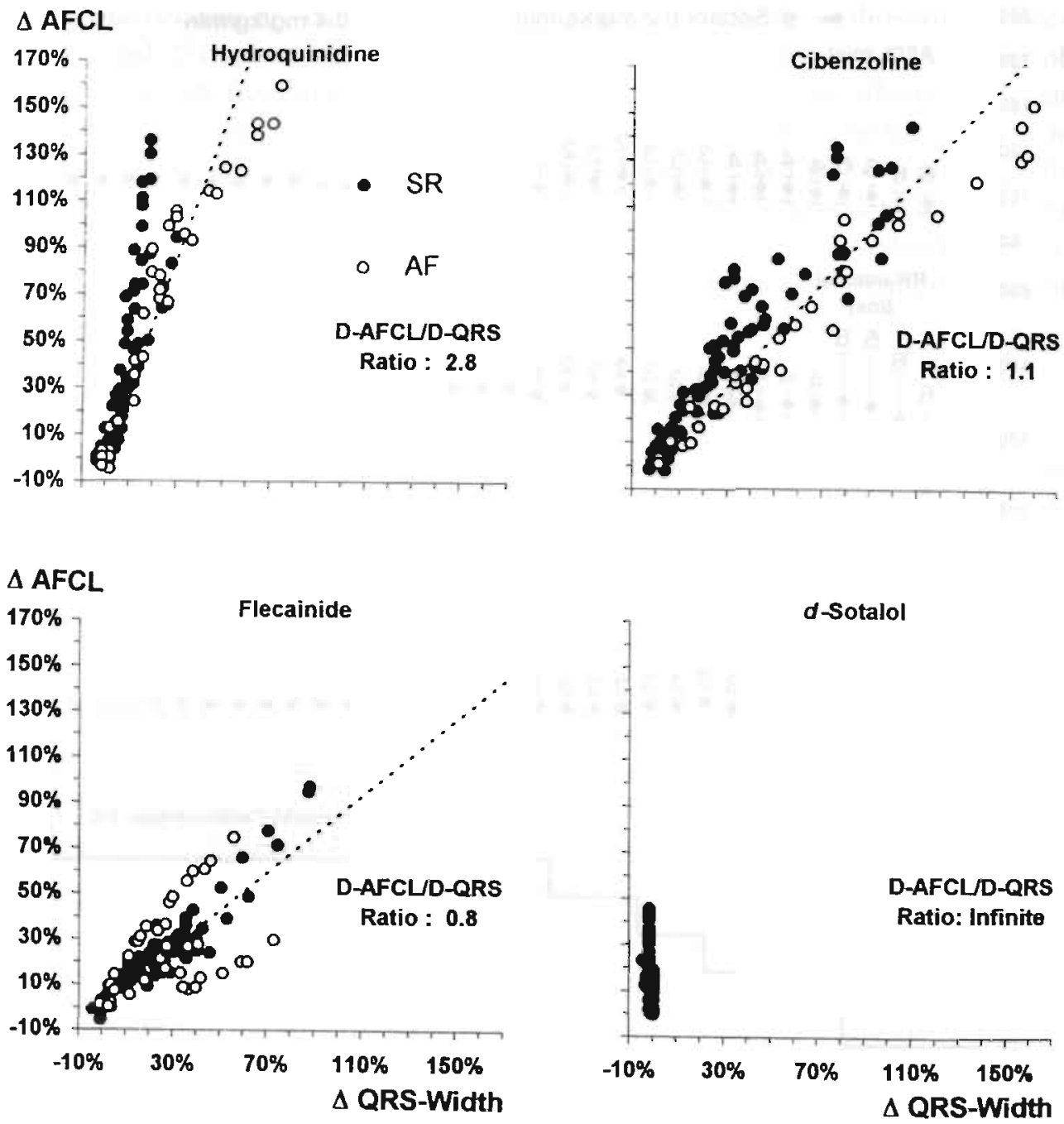

Figure 5. Four panels showing the relation between the percentage effects on the AFCL (vertical axis) and the percentage effects on the width of the QRS-complex (horizontal axis) for hydroquinidine ( $n=7$. upper left panel), cibenzoline $(n=11$, upper right), flecainide $(n=8$, lower left) and $d$-sotalol $(n=4$, lower right). In each panel the data points represent the individual measurements done during the experiments (at intervals of 5 - 10 minutes) and are given separately for goats in which AF was cardioverted (1) and for goats in which AF did not cardiovert $\left({ }^{\circ}\right)$. The relation between both parameters is given by the linear regression line through all data point and expressed as the $\Delta-\mathrm{AFCL} / \Delta$ QRS ratio.

Success Rate of Cardioversion and Effects on AFCL and QRS-Width

In Fig 6 the cumulative success rates of cardioversion by hydroquinidine, cibenzoline, flecainide and $d$-sotalol are plotted in relation to the effects on AF cycle length and QRS duration. For all drugs the success rate of cardioversion was associated with an increase in AFCL. Hydroquinidine and flecainide showed a similar quantitative 

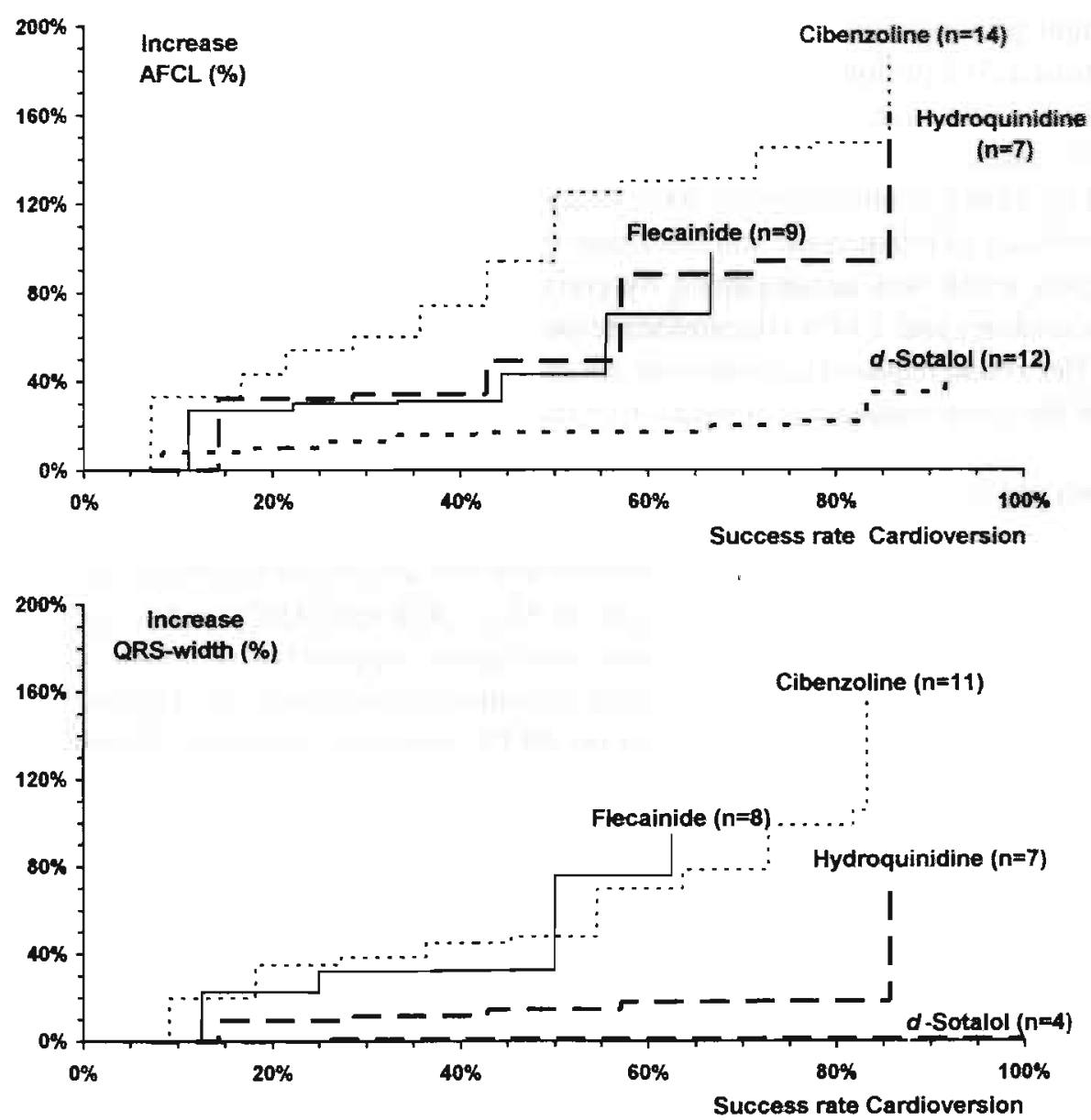

Figure 6. Upper panel: The relation between the amount of increase in AF cycle length (vertical axis) and the cumulative success rate of cardioversion (horizontal axis) for hydroquinidine. cibenzoline, Ilecainide and $d$-sotalol. Lower panel: The relation between the amount of increase in QRS-width (vertical axis) and the cumulative success rate of cardioversion (horizontal axis) for hydroquinidine, cibenzoline. flecainide and $d$-sotalol.

relationship between the prolongation of AFCL and the success rate of cardioversion. When the AFCL was prolonged by $50 \%$ about half of the animals had converted to sinus rhythm. The lower success rate of cardioversion by flecainide (67\%) compared to hydroquinidine $(86 \%$ ) was due to the fact that flecainide widened the QRS complex more than hydroquinidine and infusion had to be interrupted before cardioversion had occurred (see lower panel). Although cibenzoline had a slightly lower cardioversion rate relative to its slowing of the AF rate, the total success of cardioversion by cibenzoline $(86 \%)$ was higher than for flecainide since infusion could be continued until it prolonged the AFCL by as much as $190 \%$. D-sotalol showed a completely different profile than the three class I drugs. Not only that the class III drug excrted almost no effect on the duration of the QRS complex, but it cardioverted AF with only 
a slight prolongation of the average AF cycle length of not more than $10-20 \%$. In contrast a $20 \%$ prolongation of the AFCL by any of the class I drugs did not cardiovert $\mathrm{AF}$ in a single case.

The success rate of cardioversion of AF by hydroquinidine of $86 \%$ was accompanied by a QRS-prolongation of $30 \%$. At this degree of widening of the QRS complex the efficacy of cibenzoline and flecainide to convert AF was poor and a $30 \%$ increase in QRS width was accompanied by conversion to sinus rhythm of 1 of 11 goats (cibenzoline) and 1 of 8 (flecainide) respectively. The concentration of cibenzoline and flecainide required to cardiovert AF in respectively $82 \%$ (9 of 11) and $63 \%$ (5 of 8 ) of the cases caused a prolongation of the QRS width with 106 and $88 \%$.

\section{Efficacy and Safety Profiles}

In Table 2 the rate of successful cardioversion and adverse drug effects are summarized for all drugs. The average effects on AF cycle length, QRS-width. $\triangle$-AFCL/ $\Delta$ QRS ratio, RR-interval and QT-time are given separately for goats that were cardioverted successfully and for those remaining in sustained AF. Hydroquinidine and cibenzoline had a marked effect on AFCL while the effects of flecainide and $d$-sotalol on AFCL were less pronounced.

As can be seen, in goats the QRS-duration is relatively short compared to humans (40-45 $\mathrm{ms}$ versus $80-120 \mathrm{~ms})^{25}$ As expected all three class I drugs slowed the conduction velocity of the cardiac activation wave in the ventricle, though to a different degree. A few minutes before AF was cardioverted, hydroquinidine, cibenzoline and flecainide had prolonged the QRS width with respectively 17,60 and 50\%. $d$-sotalol did not prolong the QRS complex. Due to the higher concentration of the drugs, in the animals in which AF did not cardiovert the maximal increase in QRS-width was higher. The ratio between the increase in AFCL and QRS-width at the moment of cardioversion was 4.2 for hydroquinidine, 1.7 for cibenzoline, 1.0 for flecainide and infinite for $d$-sotalol. In goats that did not cardiovert, the $\Delta$-AFCL/ $\Delta$ QRS ratio at the highest concentration of the drugs was lower $(2.2,1.2$, and 0.4 respectively). Although the numbers of goats that did not cardiovert are small, this suggests that the $\triangle$-AFCL/ $\triangle$-QRS ratio might be used as an index for the efficacy/safety of a class I drug during pharmacological cardioversion of AF. It reflects either a lower sensitivity of atrial fibrillation to respond to class I drugs, or a higher sensitivity of the intra-ventricular conduction.

Hydroquinidine did not affect the ventricular response rate during $\mathrm{AF}$, whereas cibenzoline and flecainide slightly prolonged the RR-interval. $d$-sotalol caused a considerable slowing of the ventricular rate during $A F$, the average RR-interval increasing with about $48 \%$. As expected the QT-time was markedly prolonged by $d$-sotalol $(34 \%)$. Hydroquinidine, cibenzoline and flecainide moderately prolonged the QT time by $10-25 \%$. Part of the prolongation of the QT-time was clearly related to the effects that drugs had on the ventricular rate during AF. Hydroquinidine did not affect the ventricular rate and had only small effects on QT-interval, while $d$-sotalol 
Table 2. Effects of Hydroquinidine, Cibenzoline, Flecainide and $d$ Sotalol

\begin{tabular}{|c|c|c|c|c|c|c|c|c|c|c|c|c|c|c|c|}
\hline \multicolumn{3}{|l|}{ Cardioversion } & \multicolumn{3}{|c|}{$\mathrm{AFCL}(\mathrm{ms})$} & \multicolumn{3}{|c|}{ QRS Width (ms) } & \multirow{2}{*}{$\begin{array}{l}\triangle-A F C L \\
\triangle \text {-QRS } \\
\text { ratio }\end{array}$} & \multicolumn{3}{|c|}{ RR Interval(ms) } & \multicolumn{2}{|c|}{ QT Time (ms) } & \multirow{2}{*}{$\begin{array}{l}\text { A-QT } \\
\text { (paired) }\end{array}$} \\
\hline $\begin{array}{l}\text { Success' } \\
\text { Failure }\end{array}$ & $\%$ & $\begin{array}{l}\text { Adverse } \\
\text { Effects }\end{array}$ & Control & Drug & $\begin{array}{l}\triangle-A F C L \\
\text { (paired) }\end{array}$ & Control & Drug & $\begin{array}{r}\Delta \text {-QRS } \\
\text { (paired) }\end{array}$ & & Control & Drug & $\begin{array}{l}\Delta \cdot R R \\
\text { (paired) }\end{array}$ & Control & Drug & \\
\hline \multicolumn{16}{|l|}{ Hydro-Qulnidine } \\
\hline Success 67 & $86 \%$ & 0 & $\begin{array}{l}93 \pm 6 \\
(6)\end{array}$ & $160 \pm 33^{\circ \cdot}$ & $\begin{array}{l}67 \pm 33 \\
72 \%\end{array}$ & $\begin{array}{l}46 \pm 13 \\
(6)\end{array}$ & $54 \pm 14^{\circ}$ & $\begin{array}{l}8 \pm 4 \\
17 \%\end{array}$ & $4.2 \pm 1.6$ & $\begin{array}{l}385 \pm 68 \\
(6)\end{array}$ & $404 \pm 34$ & $\begin{array}{l}19 \pm 41 \\
7 \%\end{array}$ & $\begin{array}{l}235 \pm 23 \\
(6)\end{array}$ & $258 \pm 17^{*}$ & $\begin{array}{l}23 \pm 14 \\
10 \%\end{array}$ \\
\hline Failure $1 / 7$ & $14 \%$ & 1 ORS $\uparrow$ & $\begin{array}{l}79 \\
\text { (1) }\end{array}$ & 207 & $\begin{array}{l}128 \\
161 \%\end{array}$ & $\begin{array}{l}29 \\
\text { (1) }\end{array}$ & 51 & $\begin{array}{l}22 \\
74 \%\end{array}$ & 2.2 & $\begin{array}{l}379 \\
\text { (1) }\end{array}$ & 430 & $\begin{array}{l}51 \\
13 \%\end{array}$ & $\begin{array}{l}218 \\
\text { (1) }\end{array}$ & 260 & $\begin{array}{l}42 \\
19 \%\end{array}$ \\
\hline \multicolumn{16}{|l|}{ Cibenzoline } \\
\hline Success $12 / 14$ & $86 \%$ & 4 QRS $\uparrow$ & $\begin{array}{l}94 \pm 5 \\
(12)\end{array}$ & $188 \pm 38^{* \cdots}$ & $\begin{array}{l}94 \approx 40 \\
102 \%\end{array}$ & $\begin{array}{l}41 \pm 8 \\
(9)\end{array}$ & $66 \pm 18 \cdots$ & $\begin{array}{l}25 \mp 13 \\
60 \%\end{array}$ & $1.7 \pm 0.4$ & $\begin{array}{l}401 \pm 84 \\
(12)\end{array}$ & $474 \pm 143^{\circ}$ & $\begin{array}{l}74 \pm 101 \\
18 \%\end{array}$ & $\begin{array}{l}215 \pm 13 \\
\text { (4) }\end{array}$ & $260 \pm 19^{\circ}$ & $\begin{array}{l}44 \pm 15 \\
21 \%\end{array}$ \\
\hline Failure 2/14 & $14 \%$ & 2 ORS $\uparrow$ & $\begin{array}{l}83 \pm 6 \\
(2)\end{array}$ & $187=5$ & $\begin{array}{l}104 \pm 11 \\
101 \%\end{array}$ & $\begin{array}{l}48 \pm 11 \\
(2)\end{array}$ & $101 \pm 6$ & $\begin{array}{l}52 \pm 6 \\
118 \%\end{array}$ & $1.2 \pm 0.2$ & $\begin{array}{l}528 \pm 102 \\
(2)\end{array}$ & $540 \pm 113$ & $\begin{array}{l}12 \pm 11 \\
2 \%\end{array}$ & $\begin{array}{l}239 \\
\text { (1) }\end{array}$ & 270 & $\begin{array}{l}31 \\
13 \%\end{array}$ \\
\hline \multicolumn{16}{|l|}{ Flecainide } \\
\hline Success $6 / 9$ & $67 \%$ & $\begin{array}{l}1 \text { WQRS, } \\
\text { IVT }\end{array}$ & $\begin{array}{l}95 \pm 4 \\
(6)\end{array}$ & $141 \pm 23^{\prime \prime}$ & $\begin{array}{l}47 \pm 23 \\
50 \%\end{array}$ & $\begin{array}{l}45 \pm 11 \\
(5)\end{array}$ & $65 \pm 6^{\circ}$ & $\begin{array}{l}20 \pm 6 \\
50 \%\end{array}$ & $1.0 \pm 0.1$ & $\begin{array}{l}390 \pm 101 \\
(6)\end{array}$ & $452 \pm 77$ & $\begin{array}{l}62 \pm 57 \\
20 \%\end{array}$ & $\begin{array}{l}201 \pm 13 \\
\text { (3) }\end{array}$ & $251 \pm 16$ & $\begin{array}{l}50 \pm 25 \\
25 \%\end{array}$ \\
\hline Failure $3 / 9$ & $33 \%$ & $\begin{array}{l}1 \text { WQRS, } \\
2 \text { QRS } \uparrow\end{array}$ & $\begin{array}{l}101 \pm 9 \\
(3)\end{array}$ & $149 \pm 36$ & $\begin{array}{l}47 \pm 27 \\
45 \%\end{array}$ & $\begin{array}{l}40 \pm 3 \\
(3)\end{array}$ & $70 \pm 10^{\circ}$ & $\begin{array}{l}30 \pm 8 \\
74 \%\end{array}$ & $0.4 \pm 0.0$ & $\begin{array}{l}433 \pm 104 \\
\text { (3) }\end{array}$ & $488 \pm 111$ & $\begin{array}{l}55 \pm 44 \\
21 \%\end{array}$ & $\begin{array}{l}226 \\
\text { (1) }\end{array}$ & 275 & $\begin{array}{l}49 \\
27 \%\end{array}$ \\
\hline \multicolumn{16}{|l|}{ d-Sotalol } \\
\hline Success 11/12 & $92 \%$ & 0 & $\begin{array}{l}93 \neq 8 \\
\text { (11) }\end{array}$ & $111 \pm 9^{\cdots}$ & $\begin{array}{l}18 \neq 8 \\
20 \%\end{array}$ & $\begin{array}{l}46 \neq 13 \\
\text { (4) }\end{array}$ & $45 \pm 13$ & $\begin{array}{l}0.3=0.4 \\
-1 \%\end{array}$ & $\infty$ & $\begin{array}{l}394 \pm 90 \\
(11)\end{array}$ & $572 \pm 106^{* \cdots}$ & $\begin{array}{l}178=59 \\
48 \%\end{array}$ & $\begin{array}{l}217 \pm 13 \\
\text { (4) }\end{array}$ & $291 \pm 24^{*}$ & $\begin{array}{l}74 \pm 23 \\
34 \%\end{array}$ \\
\hline Failure $1 / 12$ & $8 \%$ & 1 Shock & $\begin{array}{l}92 \\
\text { (1) }\end{array}$ & 108 & $\begin{array}{l}16 \\
20 \%\end{array}$ & - & - & - & - & $\begin{array}{l}287 \\
\text { (1) }\end{array}$ & 395 & $\begin{array}{l}108 \\
38 \%\end{array}$ & - & - & - \\
\hline
\end{tabular}

Number of observation is given between parenthesis. $\infty$, infinite; QRS $\uparrow$, prolongation of the duration of the QRS-complex by more than 70\%; WQRS, multiple beats with a wide QRS-complex; VT; ventricular tachycardia; " $p<0.05, " p<0.01, \cdots p<0.001$ versus control (paired Students Ftest). 
clearly prolonged the RR-interval which was related to a marked effect on the QT-interval.

As mentioned previously, the infusion of drugs was continued until AF was cardioverted or adverse drug effects occurred. In 1 of 7 goats which were cardioverted with hydroquinidine, the infusion was stopped before cardioversion could be accomplished because the QRS-complex had widened with more than $70 \%$. Infusion of cibenzoline (low and high dosage) restored sinus rhythm in 8 of the 14 experiments while in 6 cases infusion was stopped because the QRS-complex had widened with more than $70 \%$. However, because in 4 of these 6 cases, AF terminated 5, 8, 24 and 29 minutes after termination of the infusion, the success rate of cardioversion was still as high as $86 \%$. During Flecainide infusion ( 9 goats) termination of AF occurred only in 4 goats before one of the other end-points was reached. In 2 cases QRS-duration increased by more than $70 \%$ while in respectively 1 and 2 cases ventricular tachycardia and multiple wide $\mathrm{QRS}$ beats occurred. In 2 goats AF still terminated 2 and 25 minutes after cessation of infusion and the final success rate of flecainide was therefore $67 \%$ (6/9 cases). During $d$-sotalol AF terminated more frequently (success rate $11 / 12,92 \%$ ) while in 1 goat the infusion was stopped because of deterioration of the clinical situation of the goat. This goat (\#11, Table 1) developed a cardiogenic shock after $10.4 \mathrm{mg} / \mathrm{kg} d$-sotalol which was most probably caused by the negative inotropic effects of the drug (no primary rhythm disturbances). In none of the experiments Torsade de Pointes arrhythmias occurred, either during infusion of the drugs or after restoration of sinus rhythm.

Effects of Hydroquinidine, Cibenzoline, Flecainide and $\alpha$-Sotalol on Atrial Refractory Period, Conduction Velocity, Wavelength and Inducibility of AF.

To study the effects of anti-fibrillatory drugs on the atrial electrophysiological properties directly after cardioversion, immediately after restoration of sinus rhythm the atrial effective refractory period (AERP) and intra-atrial conduction velocity (CV) were measured. From these parameters the wavelength (WL) of the atrial impulse was calculated $(\mathrm{WL}=\mathrm{AERP} \times \mathrm{CV})$. In Fig 7 an example is given in which the refractory period, conduction velocity and wavelength is determined after cardioversion of chronic AF by $d$-sotalol. In this case the goat had been kept in atrial fibrillation for a total of 35 days, while during the last 11 days the goat had been in sustained AF. After 52 minutes of infusion of $d$-sotalol $(0.2 \mathrm{mg} / \mathrm{kg} / \mathrm{min}$, total dosage $10.4 \mathrm{mg})$, SAF converted into sinus rhythm. Immediately thereafter the atria were paced at the right atrial appendage with an interval of $400 \mathrm{~ms}$. The two unipolar electrograms shown in Fig 7 were recorded along Bachmann's bundle at respectively 6 and $72 \mathrm{~mm}$ from the pacing site, the difference in activation time between the two electrodes thus representing the conduction time along Bachmann's bundle from the right to the left atrium. The AERP at the right atrial appendage was determined by interpolated single stimuli $\left(\mathrm{S}_{2}\right)$ of 4 times diastolic threshold, starting well within the refractory period and incrementing the coupling interval in steps of 1-2 ms. In this case, the conduction time 


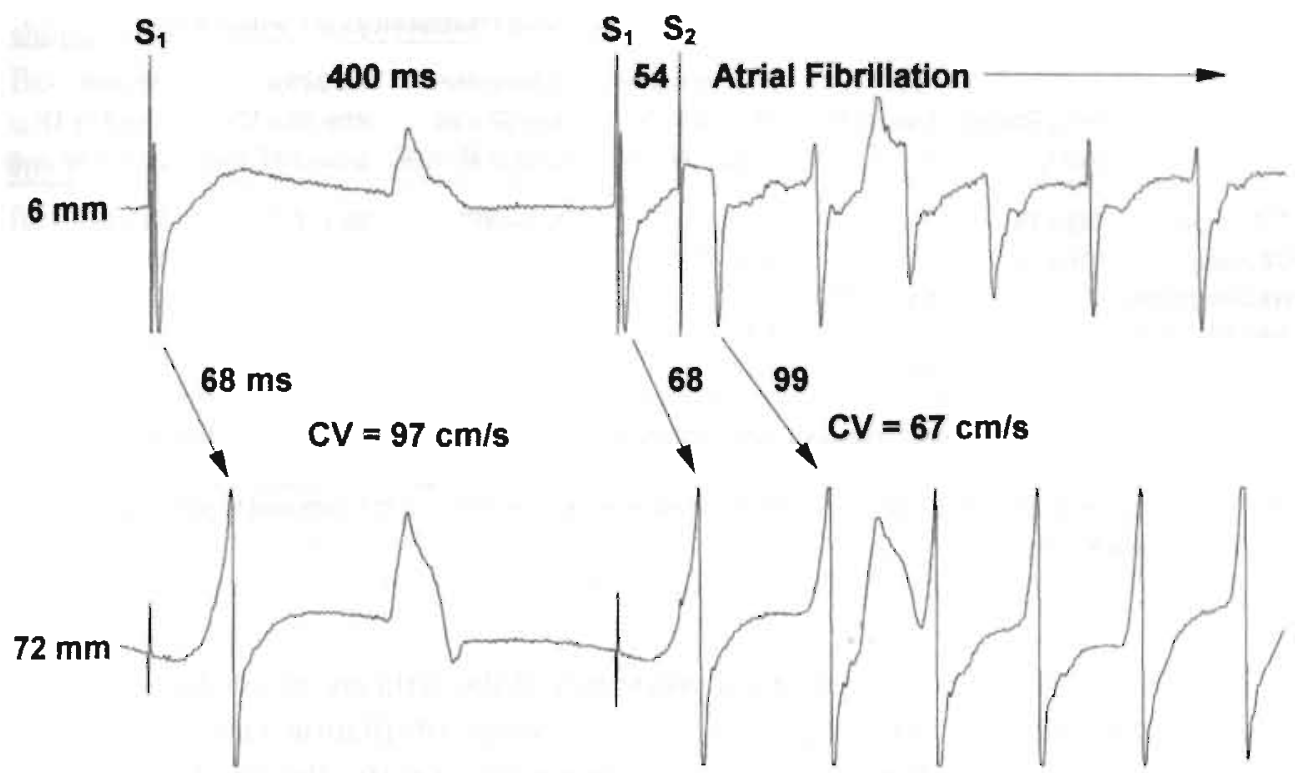

$W L=5.2 \mathrm{~cm} \mathrm{WL}=3.6 \mathrm{~cm}$

$100 \mathrm{~ms}$

Figure 7. Illustration of the failure of antifibrillatory drugs to prolong the atrial wavelength after successful termination of AF. In this experiment sustained AF terminated after 52 minutes of $d$-sotalol infusion at a rate of $0.2 \mathrm{mg} / \mathrm{kg} / \mathrm{min}$ $(10.4 \mathrm{mg} / \mathrm{kg}$ ). The atrial wavelength was measured during regular pacing at the right atrial appendage with an interval of $400 \mathrm{~ms}$. The atrial conduction velocity was determined by measuring the difference in activation times between two electrodes on Bachmann's bundle, which were $6 \mathrm{~mm}$ (upper tracing) and $72 \mathrm{~mm}$ from the stimulus site (lower tracing). The conduction velocity of the regular pulse was $97 \mathrm{~cm} / \mathrm{s}$. A premature stimulus introduced after $54 \mathrm{~ms}$ already evoked an atrial response (AERP) which conducted with a velocity of only $67 \mathrm{~cm} / \mathrm{s}$. The atrial wavelength of the regular pulse after termination of AF by $d$-sotalol was only $5.2 \mathrm{~cm}$ and as short as $103.6 \mathrm{~cm}$ for the premature activation. As a result, atrial fibrillation was easily induced by one single extra-stimulus.

during regular pacing was $68 \mathrm{~ms}$, corresponding with a conduction velocity of $97 \mathrm{~cm} / \mathrm{s}$ (interelectrode distance $66 \mathrm{~mm}$ ). Surprisingly, despite the presence of a high concentration of $d$-sotalol and the slow rate of pacing, the AERP was still very short and a premature stimulus with a coupling interval of only 54 ms already elicited a propagated response. The conduction time of the early premature impulse was $99 \mathrm{~ms}$ corresponding to a conduction velocity of $67 \mathrm{~cm} / \mathrm{s}$. Thus, directly after cardioversion the wavelength of the atrial impulse was as short as $5.2 \mathrm{~cm}(54 \mathrm{~ms} \times 97 \mathrm{~cm} / \mathrm{s})$. Assuming that the AERP of the premature beat was at least as short as during regular pacing, the slowing of conduction must have shortened the wavelength of the premature beat to less than $4 \mathrm{~cm}$. This makes it understandable that the premature beat promptly reinduced atrial fibrillation. Thus, although $d$-sotalol was very effective in terminating long-standing atrial fibrillation, it was quite ineffective in preventing its reinduction. This paradoxical action of $d$-sotalol was also found for the other drugs (see below). 
Table 3. Electrophysiological Properties of the Atria Before and After Pharmacological Cardicversion

\begin{tabular}{|c|c|c|c|c|c|c|}
\hline & $\begin{array}{l}\text { Sinus Rhythm } \\
(n=11)\end{array}$ & $\begin{array}{l}\text { After } 12 \pm 14 \\
\text { Days of AF } \\
(n=11)\end{array}$ & $\begin{array}{l}\text { Hydroquinidine } \\
\text { After } 34 \pm 19 \\
\text { Days of AF ( } n=6)\end{array}$ & $\begin{array}{l}\text { Cibenzoline } \\
\text { After } 27 \pm 20 \\
\text { Days of AF ( } n=9)\end{array}$ & $\begin{array}{l}\text { Flecainide } \\
\text { After } 29 \pm 17 \\
\text { Days of AF }(n=5)\end{array}$ & $\begin{array}{l}\text { d-Sotalol } \\
\text { After } 31 \pm 17 \\
\text { Days of } A F(n=8\end{array}$ \\
\hline AERP (ms) & $149 \pm 19$ & $77 \pm 23^{4 * *}$ & $92 \pm 2.9$ & $123 \pm 30^{55}$ & $66 \pm 10$ & $73 \pm 18$ \\
\hline $\mathrm{CV}(\mathrm{cm} / \mathrm{s})$ & $116 \pm 10$ & $116 \pm 10$ & $83 \pm 7^{565}$ & $74 \pm 13^{\S \S \S}$ & $86 \pm 12^{\S \S 5}$ & $110 \pm 11$ \\
\hline Wavelength $(\mathrm{cm})$ & $17.4 \pm 3.2$ & $8.9 \pm 2.9^{* * *}$ & $7.5 \pm 2.0$ & $8.8 \pm 2.4$ & $5.7 \pm 1.3$ & $7.9 \pm 1.9$ \\
\hline \multirow[t]{2}{*}{ Inducibility of AF } & $0 / 11$ & $9 / 11^{t+t}$ & $6 / 6$ & $6 / 9$ & $5 / 5$ & $8 / 8$ \\
\hline & $0 \%$ & $82 \%$ & $100 \%$ & $67 \%$ & $100 \%$ & $100 \%$ \\
\hline
\end{tabular}

AERP, atrial effective refractory period measured during pacing with $400 \mathrm{~ms}$ interval; $\mathrm{CV}$, intra-atrial conduction velocity along Bachmann's bundle; "**, $p<0.001$ compared to goats in sinus rhythm (Student's t-test); $\$ \S, p<0.01 ; \S \S \S, p<0.001$ compared to goats atter $12 \pm 14$ days in AF (Student's t-test, corrected for multiple comparisons); $t+t, p<0.001$ compared to goats in sinus rhythm (Mann-Whitney rank sum test).

In Table 3 the electrophysiological properties of the atria are given during normal sinus rhythm $(n=11)$, after $12 \pm 14$ days of atrial fibrillation $(n=11)$ and after cardioversion by hydroquinidine $(n=6)$, cibenzoline $(n=9)$, flecainide $(n=5)$ and $d$-sotalol $(n=8)$. The atrial refractory period in normal goats in sinus rhythm measured at the right or left atrial appendage was $149 \pm 19 \mathrm{~ms}$ and the conduction velocity along Bachmann's bundle was $116 \pm 10 \mathrm{~cm} / \mathrm{s}$, thus giving a normal value for the atrial wavelength of $17.4 \pm 3.2 \mathrm{~cm}$. Although we previously reported that in normal goats $\mathrm{AF}$ can be induced by one single extra-stimulus in about $27 \%$ of the animals, ${ }^{18}$ in the present series the inducibility of AF during control was as low as $0 \%$. After $12 \pm 14$ days of maintained AF (range 1-21 days) the AERP had shortened markedly to $77 \pm$ $23 \mathrm{~ms}(\mathrm{p}<0.001)$ whereas the conduction velocity was not changed $(116 \pm 10 \mathrm{~cm} / \mathrm{s})$. As a result, within 12 days of $\mathrm{AF}$ the atrial wavelength had shortened from $17.4 \pm 3.2$ to $8.9 \pm 2.9 \mathrm{~cm}(\mathrm{p}<0.001)$ and now in 9 of 11 animals $(82 \% . \mathrm{p}<0.001)$ a single premature stimuli induced an episode of AF. Directly after cardioversion of chronic $\mathrm{AF}$ ( $34 \pm 19$ days) by hydroquinidine, the AERP and $\mathrm{CV}$ during pacing with an interval of $400 \mathrm{~ms}$, were $92 \pm 29 \mathrm{~ms}$ (n.s. versus $12 \pm 14$ days of $A F)$ and $83 \pm 7 \mathrm{~cm} / \mathrm{s}(\mathrm{p}<0.001)$ respectively. The calculated wavelength thus was as short as $7.5 \pm 2.0 \mathrm{~cm}$ and $\mathrm{AF}$ was reinduced by single premature stimuli in all goats $(100 \%)$. After cardioversion by cibenzoline, the AERP amounted $123 \pm 30 \mathrm{~ms}(\mathrm{p}<0.01)$ and the conduction velocity was depressed to $74 \pm 13 \mathrm{~cm} / \mathrm{s}(p<0.001)$. Due to the prolongation of the refractory period by cibenzoline, the wavelength after cardioversion was somewhat longer than for the other drugs $(8.8 \pm 2.4 \mathrm{~cm})$ and $A F$ was induced in $67 \%$ of the cases. After conversion by flecainide, the atrial wavelength was as short as $5.7 \pm 1.3 \mathrm{~cm}$, caused by both a short refractory period $(66 \pm 10 \mathrm{~ms})$ and depressed atrial conduction $(86 \pm$ $12 \mathrm{~cm} / \mathrm{s}$ ). AF could be readily reinduced in $100 \%$ of the animals. Surprisingly also after cardioversion by the class III drug $d$-sotalol, atrial refractoriness was still very short $(73 \pm 18 \mathrm{~ms}$ ). Although intra-atrial conduction velocity was not depressed (110 $\pm 11 \mathrm{~cm} / \mathrm{s}$ ), the shortening of the AERP to less than half the value during sinus rhythm 
shortened the atrial wavelength by more than $50 \%$ from $17.4 \pm 3.2$ to $7.9 \pm 1.9 \mathrm{~cm}$. Because $d$-sotalol apparently failed to exert its class III action on atrial myocardium which has been remodeled by one month of $\mathrm{AF}$, fibrillation could be reinduced by a single premature stimulus in all goats $(100 \%)$. Thus, although SAF could be successfully terminated by administration of all four drugs, the atrial vulnerability after cardioversion was still very high. Cardioversion of $\mathrm{AF}$ by hydroquinidine, flecainide or $d$-sotalol did not protect against reinduction of AF ( $100 \%$ inducibility). Only cibenzoline had some protective effect against recurrences of AF and in $33 \%$ of the goats a single premature stimulus did not induce atrial fibrillation (inducibility $67 \%$ ). Thus, although all four drugs markedly decreased the stability of SAF and were effective in restoring sinus rhythm, none of the drugs effectively lowered the vulnerability of the atria for $\mathrm{AF}$. The fact that after pharmacological cardioversion the atrial substrate was still prone to AF can be explained by the abnormally short wavelength of the atrial impulse (between 5.7 and $8.8 \mathrm{~cm}$ ).

\section{Discussion}

In this study we evaluated the anti-fibrillatory effects of drugs with class IA, IC and III properties in a recently developed model of sustained AF in goats. ${ }^{18}$ For each drug the efficacy in restorating sinus rhythm, the occurrence of adverse drug effects and the changes in AFCL, RR-interval, duration of the QRS-complex and QT-time were measured. In addition, the atrial refractory period and intra-atrial conduction velocity were measured directly after successful restoration of sinus rhythm and the effects of these drugs on atrial wavelength and vulnerability for AF were determined.

Mechanism of Perpetuation of Atrial Fibrillation

Around 1960, Moe and co-workers 26,27 introduced the multiple wavelet hypothesis for atrial fibrillation postulating that during AF the atrium is activated by several independent wavelets. The persistence of AF was thought to be dependent on the average number of wavelets that were present. If the number of wavelets is low, the chances that all wavelets will simultaneously die out is relatively high and AF will be short-lasting. On the other hand, with a high number of wavelets AF would be more stable because the probability that all wavelets extinguish at the same moment has become very small. In 1985, the multiple wavelet hypothesis was experimentally confirmed by Allessie et al. ${ }^{28}$ by reconstructing the activation pattern during $\mathrm{AF}$ in isolated canine hearts. In this study the critical number of wavelets necessary to maintain AF was estimated to be between four and six. Because the number of wavelets that can be simultaneously present is determined by the atrial size and the atrial wavelength, these factors are important for the perpetuation of AF. Evidence that the size of the atria is indeed essential for AF is the observation that fibrillation can be more easily induced in larger animals ${ }^{29}$ and that also in humans the presence 
of a dilated atrium is associated with a high incidence of $\mathrm{AF}{ }^{30}$ On the other hand, fibrillation ceases if the tissue is cut into small pieces ${ }^{31}$ and left atrial isolation, ${ }^{32}$ compartmentalization of the atria ${ }^{33}$ and the maze operation ${ }^{34}$ are effective treatments for AF. Another way of modifying the propensity for the atria to fibrillate is to change the length of the atrial excitation wave. Vagal stimulation, administration of acetylcholine, atrial stretch, prolonged atrial pacing and repetitive induction of AF are all stimuli which shorten atrial refractoriness and atrial wavelength and increase the inducibility and stability of AF. ${ }^{19,23,35-42}$ Since the atrial wavelength is the product of the atrial refractory period and intra-atrial conduction velocity ( $\mathrm{RP} \times \mathrm{CV}$ ), also a depression of conduction properties increases the propensity for atrial fibrillation. ${ }^{43-}$ 45

Efficacy and Safety of Cibenzoline, Hydroquinidine, Flecainide and $d$-Sotalol

In the present study, we showed that all four drugs were effective in converting chronic atrial fibrillation to sinus rhythm. However, the success rate of cardioversion varied considerably from only $67 \%$ during administration of flecainide to 86,86 and $92 \%$ during hydroquinidine, cibenzoline and $d$-sotalol infusion. In patients, it has been shown that the success rate of cardioversion is strongly dependent on the duration of the arrhythmia. ${ }^{3-5,14,16,46,47}$ and to some degree by the underlying heart disease and the degree of atrial dilatation. 46,47 Although the efficacy of antifibrillatory drugs in patients with chronic AF is usually very low, ${ }^{3-5,14,47,48}$ in our goat model of sustained AF the conversion rates were relatively high which may be caused by the higher drug concentration used. Although clinical studies usually show a superiority of class IA and IC drugs to class III drugs, in our present study flecainide was clearly less effective than the other three drugs. Although at present we can not explain the lower efficacy of flecainide, this seemed at least not to be caused by a longer duration of AF in these animals (Table 1) or, given the marked increase in QRS-width (Table 2), by a too low dosage of the drug. The relatively high efticacy of $d$-sotalol might well be explained by the high concentration which we administered $(3.2-27.5 \mathrm{mg} / \mathrm{kg}$, Table 1$)$. As recently shown by Wang and Nattel et al. 21,22 increasing the dosage of $d$-sotalol from 2 to $8 \mathrm{mg} / \mathrm{kg}$ markedly increased the efficacy of this class III drug to cardiovert AF $(13-25 \%$ versus $88-100 \%)$.

Although all drugs were effective in cardioversion of sustained $\mathrm{AF}$ at these high dosages adverse drug effects occurred more frequently (Table 2). In 13 of the 42 experiments $(31 \%)$ adverse effects were seen, varying between a prolongation of the QRS-complex with more than $70 \%$, the occurrence of multiple beats with a wide QRS-complex, ventricular tachycardia or clinical symptoms of hypotension. A prolongation of the QRS-width with more than $70 \%$ was most often seen with class IC drugs and was the reason for termination of infusion in 2 of the 9 (22\%) flecainide and in 6 of the $14(43 \%)$ cibenzoline attempts to pharmacologically cardiovert AF. In only 1 of the 7 (14\%) hydroquinidine and in none of the $12 d$-sotalol treated animals the QRS-complex became more than $70 \%$ prolonged. Multiple beats with a wide 
QRS-complex were seen in 2 flecainide experiments while paroxysmal ventricular tachycardia ( 5 beats) occurred in one. During one $d$-sotalol experiment, the infusion had to be stopped because of severe hypotension probably due to the negative inotropic effects of the drug. In none of the experiments Torsade de Pointes arrhythmias were observed.

In our present study we calculated the ratio between the percentage changes in $\mathrm{AFCL}$ and widening of the QRS-complex. This $\triangle$-AFCL/ $\triangle$-QRS-ratio showed a very good relation with the efficacy in cardioverting $A F$ and the tolerance of the different drugs. In goats with sustained AF the $\Delta$-AFCL/ $\Delta$-QRS-ratio was infinite for $d$-sotalol, 2.8 for hydroquinidine, 1.1 for cibenzoline and 0.8 for flecainide. The efficacy in cardioverting AF showed a similar decrease from $92 \%$ for $d$-sotalol, $86 \%$ for hydroquinidine and cibenzoline and $67 \%$ for flecainide. On the other hand the occurrence of adverse drug effects was inversely related to the $\Delta$-AFCL/ $\Delta$-QRS-ratio. Adverse effects were seen in only $8 \%$ of $d$-sotalol and $14 \%$ of hydroquinidine experiments, whereas this was the case in as much as $43 \%$ of cibenzoline and $56 \%$ of flecainide treated animals.

\section{Drug Effects on Atrial Fibrillation Cycle Length}

In the present study we found that all four drugs progressively prolonged the atrial fibrillation cycle length. Cibenzoline and hydroquinidine were the most effective drugs in this regard, prolonging the AFCL by about 80 and $100 \%$ whilst the effects of flecainide $(50 \%)$ and especially $d$-sotalol (20\%) were less marked (Table 2 ). These findings are in agreement with those of Wang et al. who showed that the prolongation of $\mathrm{AF}$ cycle length by procainamide, propafenone and flecainide was more pronounced than high dosages of $d, l$-sotalol. ${ }^{21-23}$

There was no good correlation between effects on AFCL and the success rate of cardioversion (table 2). For instance $d$-sotalol increased the AFCL by only $20 \%$ but it terminated AF in $92 \%$ of the cases. In contrast, flecainide prolonged the AFCL with about $50 \%$ while its efficacy in restoring sinus rhythm was less $(67 \%)$. This discrepancy might be explained by the different effects that these drugs have on intra-atrial conduction velocity. If we assume that $d$-sotalol had no significant effect on the atrial conduction velocity during sustained atrial fibrillation this would suggest that also the circuit size (product of AFCL and CV) during atrial fibrillation increased with about $20 \%$. In contrast, the depressive effects of class IC and to a lesser degree IA drugs on atrial conduction velocity are likely to diminish the actual prolongation of the circuit size during AF. As a result, the average size of intra-atrial reentrant circuits might be smaller than expected on the degree of prolongation of AFCL. 
Drug Effects on Atrial Effective Refractory Period, intra-atrial Conduction Velocity, Atrial Wavelength and Inducibility of AF

In order to evaluate the electrophysiological effects of the anti-fibrillatory drugs, we measured the intra-atrial conduction velocity and atrial effective refractory period after successful pharmacological cardioversion of sustained AF. Compared to the values obtained after $12 \pm 14$ days of fibrillation, the refractory period was increased by cibenzoline (from $77 \pm 23$ to $123 \pm 30 \mathrm{~ms}$ ). Hydroquinidine, flecainide and $d$-sotalol did not affect the AERP which remained as short as $66-92 \mathrm{~ms}$ (Table 3, n.s.). Very surprisingly, even the class III agent $d$-sotalol failed to prolong the atrial refractory period at slow heart rates and the AERP was still as short as $73 \pm 18 \mathrm{~ms}$. In all cases the AERP remained significantly shorter than $149 \pm 19 \mathrm{~ms}$ as measured before AF was started. The conduction velocity was not affected by $12 \pm 14$ days of AF (116 \pm $10 \mathrm{~cm} / \mathrm{s}$ ). After cardioversion by $d$-sotalol the intra-atrial conduction velocity was still as fast as $110 \pm 11 \mathrm{~cm} / \mathrm{s}$. As expected all class I drugs depressed the atrial conduction velocity to a value between 74 and $86 \mathrm{~cm} / \mathrm{s}$. As a result, after successful restoration of sinus rhythm by hydroquinidine, cibenzoline, flecainide, and $d$-sotalol the atrial wavelength was still as short as 5.7 to $8.8 \mathrm{~cm}$ compared to $17.4 \mathrm{~cm}$ during sinus rhythm and $8.9 \mathrm{~cm}$ after $12 \pm 14$ days of maintained $\mathrm{AF}$.

The relationship between the atrial wavelength and the susceptibility to reentrant atrial arrhythmia's was extensively studied by Rensma et al. ${ }^{19}$ In chronically instrumented conscious dogs three critical wavelength zones for the induction of different atrial reentrant arrhythmias were found. When the wavelength was longer than $12 \mathrm{~cm}$ the atrium was effectively protected against induction of reentrant arrhythmias while at a wavelength between 10 and $12 \mathrm{~cm}$ atrial repetitive responses were evoked. The critical wavelengths for the induction of atrial flutter and atrial fibrillation were 10 and $8 \mathrm{~cm}$ respectively. Our present findings are in agreement with the observations by Rensma et al. ${ }^{19}$ During control (goats in sinus rhythm) the average atrial wavelength was as long as $17 \mathrm{~cm}$ and $\mathrm{AF}$ was induced in none of the goats by one single premature stimulus. After maintenance of AF for $12 \pm 14$ days the wavelength shortened to $8.9 \mathrm{~cm}$ and simultaneously the inducibility increased to $82 \%$. After cardioversion by cibenzoline the wavelength remained as short as $8.8 \mathrm{~cm}$ and AF was reinduced in $66 \%$ of the cases. In goats treated with hydroquinidine, flecainide and $d$-sotalol the wavelength was even shorter $(5.7-7.9 \mathrm{~cm})$, which indeed corresponded with an inducibility of AF in $100 \%$ of the goats.

\section{Limitations of the Study}

In this study we evaluated the sffects of drugs in a model of chronically instrumented conscious goats. As previously reported, sustained AF developed within a few weeks of artificially maintenance of $\mathrm{AF}$ which seems to be related to a dramatic shortening of atrial refractoriness by AF. ${ }^{18}$ Although in humans the presence of a short atrial refractory period may be involved in the process of AF other factors are likely to play 
a role as well. (Locally) depressed atrial conduction properties, ${ }^{43-45,49}$ atrial ischemia and/or a high vagal or adrenergic tone ${ }^{36,37}$ may all modify the properties of antifibrillatory drugs and these factors are not taken into account in our present model of sustained AF. 18,41

Despite their high efficacy in cardioverting sustained AF, all four drugs failed to protect the atrium effectively against the reinduction of fibrillation. After cardioversion we measured the atrial wavelength at slow pacing rates and showed that the high reinducibility of AF could very well be explained by a failure of the drugs to prolong the atrial wavelength. However, due to this high atrial vulnerability we were not able to relate the efficacy of drugs in cardioversion of AF to their effects on atrial refractoriness and conduction velocity at high atrial pacing rates.

\section{Acknowledgments}

The authors would like to thank Dr. N. Kormoss from Continental Pharma/Searle Belgium for supplying the ampuls of Cipralan ${ }^{(c i b e n z o l i n e)}$ and Dr. C. Mouton Dorey from Laboratoires Houdé for supplying Serecor ${ }^{(i)}$ (hydroquinidine).

\section{References}

1 Resnekov L, McDonald L: Appraisal of electroconversion in treatment of cardiac dysrhythmias. $\mathrm{Br}$ Heart J 1968:30:786-811

2 Bjerkelund C, Orning O: An evaluation of DC shock treatment of atrial arrhythmias. Acta Med Scand 1968;184:481-491

3 Crijns HJGM, Wijk van LM, Gilst van WH, Kingma HJ, Van Gelder IC, Lie KI: Acute conversion of atrial fibrillation to sinus rhythm: clinical efficacy of flecainide acetate. Comparison of two regimes. Eur Heart J 1988;9:634-638

4 Suttorp MJ, Kingma HJ, Jessurun ER, Lie-A-Huen L, van Hemel NM, Lie KI: The value of class IC antiarrhythmic drugs for acute conversion of paroxysmal atrial fibrillation or flutter to sinus rhythm. J Am Coll Cardiol 1990;16:1722-1727

5 Suttorp MJ, Kingma JH. Lie-A-Huen L, Mast EG: Intravenous flecainide versus verapamil for acute conversion of paroxysmal atrial fibrillation or flutter to sinus rhythm. Am J Cardiol 1989:63:693-696

6 Halinen MO. Huttunen M, Paakkinen S, Tarssanen L: Comparison of Sotalol with DigoxinQuinidine for conversion of acute atrial fibrillation to sinus rhythm (the Sotalol-Digoxin-Quinidinetrial). Am J Cardiol 1995; 76:495-498

7 Coplen SE, Antman EM, Berlin JA, Hewitt P, Chalmers TC: Efficacy and safety of quinidine therapy for maintenance of sinus rhythm after cardioversion. A meta-analysis of randomized control trials. Circulation 1990;82:1106-1116

8 Nooijer de C. Sparling M: Quinidine treatment of chronic lone atrial fibrillation. Clin Cardiol 1990:13:711-714

9 Madrid AH, Moro C, Marín-Huerta E, Mestre JL. Novo L, Costa A: Comparison of flecainide and procainamide in cardioversion of atrial fibrillation. Eur Heart $J$ 1993;14:1127-1131

10 Fenster PE, Comess KA, Marsh R, Katzenberg C. Hager D: Conversion of atrial fibrillation to sinus rhythm by acute intravenous procainamide infusion. Am Heart $J$ 1983; 106:501-504

11 Vita JA. Friedman PL, Cantillon C. Antman EM: Efficacy of intravenous Propafenone for the acute management of atrial fibrillation. Am J Cardiol 1989:63:1275-1278 
12 Brugada J, Gursoy S, Brugada P, Atie J, Guiraudon GM, Andries E: Cibenzoline transforms random re-entry into ordered re-entry in the atria. Eur Heart J 1993;14:267-272

13 Kühlkamp V, Meerhof J, Schmidt F, Mayer F, Ickrath O, Haasis R, Seipel L: Electrophysiologic effects and efficacy of cibenzoline on stimulation-induced atrial fibrillation and flutter and implications for treatment of paroxysmal atrial fibrillation. Am J Cardiol 1990;65:628-632

14 Teo KK, Harte M, Horgan JH: Sotalol infusion in the treatment of supraventricular tachyarrhythmias. Chest 1985;87:113-118

15 Singh S, Saini RK, DiMarco J, Kluger J, Gold R, Chen Y: Efficacy and safety of Sotalol in digitalized patients with chronic atrial fibrillation. Am J Cardiol 1991:68:1227-1230

16 Gold RL. Haffajee CI, Charos G, Sloan K, Baker S, Alpert JS: Amiodarone for refractory atrial fibrillation. Am J Cardiol 1986;57:124-127

17 Gosselink MAT, Crijns HJGM, Van Gelder IC, Hillige H, Wiesfeld ACP, Lie KI: Low-dose amiodarone for maintenance of sinus rhythm after cardioversion of atrial fibrillation or flutter. JAMA 1992;267:3289-3293

18 Wijffels MCEF, Kirchhof CJHJ, Dorland R, Allessie MA: Atrial fibrillation begets atrial fibrillation A study in awake chronically instrumented conscious goats. Circulation 1995;92:1954-1968

19 Rensma PL, Allessie MA, Lammers WJEP, Bonke FIM, Schalij MJ: Length of excitation wave and susceptibility to reentrant atrial arrhythmias in normal conscious dogs. Circ Res 1988:62:395-410

20 Kirchhof CJHJ, Wijffels M, Brugada J, Planellas J, Allessie MA: Mode of action of a new class IC drug (ORG 7797) against atrial fibrillation in conscious dogs. J Cardiovasc Pharmacol 1991;17:116-124

21 Wang J, Feng J, Nattel S: Class III antiarrhythmic drug action in experimental atrial fibrillation. Differences in reverse use dependence and effectiveness between d-Sotalol and the new antiarrhythmic drug Ambasilide. Circulation 1994;90:2032-2040

22. Wang J, Bourne GW, Wang Z, Villemaire C, Talajic M, Nattel S: Comparative mechanisms of antiarrhythmic drug action in experimental atrial fibrillation. Circulation 1993;88:1030-1044

23 Wang Z, Page PL, Nattel S: Mechanism of flecainide's antiarrhythmic action in experimental atrial fibrillation. Circ Res 1992;71:271-287

24. Allessie MA, Hoeks APG, Schmitz GML, Reneman RS: On-line mapping system for the visualization of the electrical activation of the heart. Int J Cardiac Imag 1986;2:59-63

25 Schultz RA, Pretorius PJ, Terblanche M: An electrocardiographic study of normal sheep using a modified technique. Onderstepoon J.Vet.Res. 1972;39:97-106

26 Moe GK, Abildskov JA: Atrial fibrillation as a self-sustaining arrhythmias independent of focal discharge. Am Heart J 1959;58:59-70

27 Moe GK: On the multiple wavelet hypothesis of atrial fibrillation. Arch Int Pharmacodyn Ther $1962 ; 140: 183-188$

28 Allessie MA. Lammers WJEP, Bonke FIM, Hollen SJ: Experimental evaluation of Moe's multiple wavelet hypothesis of atrial fibrillation. in Zipes DP, Jalife J (eds): Cardiac Electrophysiology and Arrhythmias. NY, Grune \& Stratton, 1985, pp 265-275

29 Moore EN, Spear JF: Natural occurrence and experimental initiation of atrial fibrillation in different animal species, in Kulbertus HE. Olsson SB, Schlepper M (eds): Atrial fibrillation. Mölndal. Sweden, 1982, pp 33-41

30 Henry WL, Morganroth J, Pearlman AS, Clark CE, Redwood DR, Itscoitz SB, Epstein SE: Relation between echocardiographically determined left atrial size and atrial fibrillation. Circulation 1976:53:273-279

31 Garrey WE: The nature of fibrillation contraction of the heart; its relation to tissue mass and form. Am J Physiol 1914:33:397-414

32 Graffigna A, Pagani F, Minzioni G, Salemo J, Viganò M: Left atrial isolation associated with mitral valve operations. Ann Thorac Surg 1992:54:1093-1098

33 Shyu K, Cheng J, Chen J, Lin J, Lin F. Tseng Y, Kuan P, Lien W: Recovery of atrial function after atrial compartment operation for chronic atrial fibrillation in mitral valve disease. $J$ Am Coll Cardiol $1994: 24: 392-398$ 
34 Cox JL, Boineau JP, Schuessler RB, Ferguson TB, Lindsay BD, Cain ME, Corr PB, Kater KM, Lappas DG: A review of surgery for atrial fibrillation. J Cardiovasc Electrophysiol 1991;2:541-561

35 Smeets JLRM, Allessie MA, Lammers WJEP, Bonke FIM, Hollen SJ: The wavelength of the cardiac impulse and reentrant arrhythmias in isolated rabbit atrium. The role of heart rate, autonomic transmitters, temperature, and potassium. Circ Res 1986:58:96-108

36 Coumel P: Neurogenic and humoral influences of the autonomic nervous system in the determination of paroxysmal atrial fibrillation, in Attuel P, Olsson SB, Schlepper M (eds): The atrium in Health and Disease. Mount Kisco, NY, Futura Publishing Co, 1989, pp 213-232

37 Farges JP, Ollagnier M, Faucon G: Influence of acetylcholine, isoproterenol, quinidine and ouabain on effective refractory periods of atrial and ventricular myocardium in the dog. Arch Int Pharmacodyn 1977;227:206-219

38 Solti F, Vecsey T, Kekési V, Juhász-Nagy A: The effect of atrial dilatation on the genesis of atrial arrhythmias. Cardiovasc Res 1989;23:882-886

39 Ravelli F, Allessie MA: Atrial stretch decreases refractoriness and induces atrial fibrillation in the isolated rabbit heart. Circulation 1995:92:I-754(Abstract)

40 Morillo CA, Klein GJ, Jones DL, Guiraudon CM: Chronic rapid atrial pacing: structural, functional and electrophysiologic characteristics of a new model of sustained atrial fibrillation. Circulation 1995;91:1588-1595

41 Wijffels MCEF, Kirchhof CJHJ, Dorland R, Power J, Allessie MA: Electrical remodeling due to atrial fibrillation in chronically instrumented conscious goats. The role of neurohumoral changes, ischemia, atrial stretch and high rate of electrical activation. Circulation (accepted) 1996; (Chapter 4)

42 Daoud EG, Niebauer M, Bogun F. Castellani M, Chan KK, Goyal R, Harvey M, Man CK, Strickberger SA. Morady F: Atrial fibrillation induced shortening of atrial refiactoriness in humans. Circulation 1995:92:I-404(Abstract)

43 Cosio FG, Palacios J, Vidal JM, Cocina EG, Gomez-Sanchez A, Tamargo L: Electrophysiologic studies in atrial fibrillation. Slow conduction of premature impulses: A possible manifestation of the background for reentry. Am J Cardiol 1983;51:122-130

44 Ohe T, Matsuhisa M, Kamakura S, Yamada J, Sato I, Nakajima K, Shimomura K: Relation between the widening of the fragmented atrial activity zone and atrial fibrillation. Am J Cardiol 1983;52:1219-1222

45 Kumagai K, Akimitsu S, Kawahira K, Kawanami F, Yamanouchi Y, Hiroki T, Arakawa K: Electrophysiological properties in chronic lone atrial fibrillation. Circulation 1991;84:1662-1668

46 Bianconi L, Boccadamo R, Pappalardo A, Gentili C, Pistolese M: Effectiveness of intravenous propafenone for conversion of atrial fibrillation and flutter of recent onset. Am $J$ Cardiol 1989:64:335-338

47 Horowitz LN, Spielman SR, Greenspan AM, Mintz GS, Morganroth J, Brown R. Brady PM, Kay HR: Use of amiodarone in the treatment of persistent and paroxysmal atrial fibrillation resistant to quinidine therapy. J Am Coll Cardiol 1985;6:1402-1407

48 Gold RL. Haffajee CI, Charos G, Sloan K, Baker S, Alpert JS: Amiodarone for refractory atrial fibrillation. Am J Cardiol 1986;57:124-127

49 Hordof AJ, Edie R, Malm JR, Hoffman BF, Rosen MR: Electrophysiologic properties and response to pharmacologic agents of fibers from diseased human atria. Circulation 1976:54:774-779 


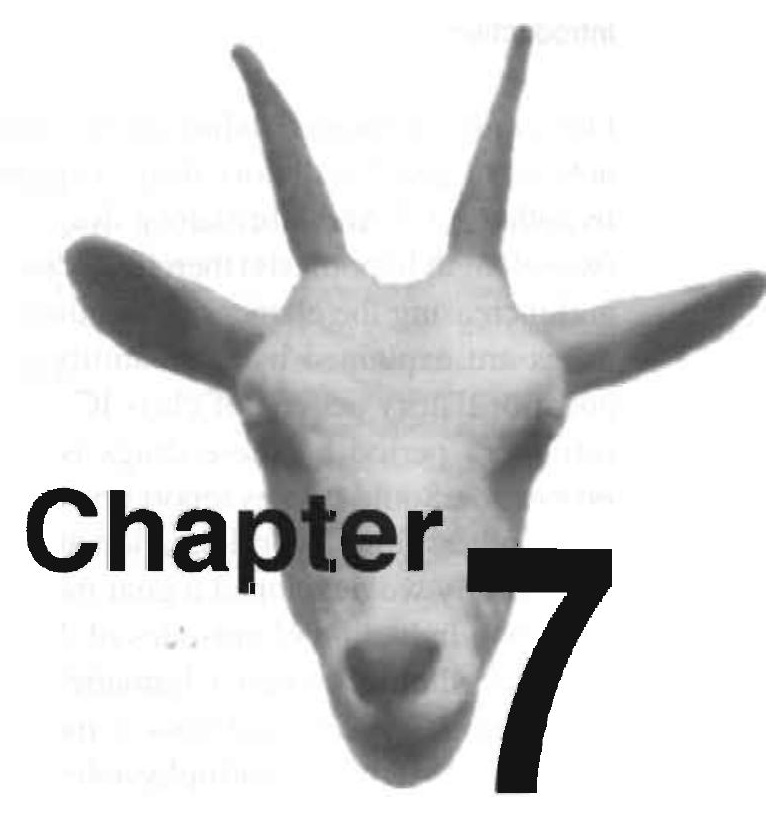

Effects of Hydroquinidine, Cibenzoline, Flecainide and $d$-Sotalol on Atrial Wavelength, Circuit Size and Excitable Gap During Chronic Atrial Fibrillation in the Goat

Maurits C.E.F. Wijffels

Rick Dorland

Matthijs J.P. Killian

Frans Mast

Maurits A. Allessie 


\section{Introduction}

Our common understanding of the mechanisms of atrial fibrillation (AF) and the actions of anti-fibrillatory drugs is primarily based upon Moe's "multiple wavelet" hypothesis. ${ }^{1-3}$ Anti-fibrillatory drugs are thought to prolong the atrial wavelength (wavelength hypothesis) thereby decreasing the number of wavelets fitting in the atria and increasing the chances of termination of $\mathrm{AF}^{4-9}$ The efficacy of class IA and III drugs are explained by their ability to prolong the wavelength. ${ }^{5,8.9}$ However, the anti-fibrillatory actions of class IC drugs are less clear because the prolongation in refractory period by these drugs is counteracted by the depression in conduction properties. Some studies report no effects of class IC drugs on the atrial wavelength, ${ }^{5}$ while others found a prolongation at very high pacing rates. ${ }^{6-8}$

Recently we developed a goat model of chronic AF in which we showed that the repetitive induction of episodes of AF resulted in the development of chronic AF. ${ }^{10}$ Atrial fibrillation caused a dramatic shortening of atrial refractoriness, no changes in conduction velocity and thus a marked shortening of the atrial wavelength. We suggested that these electrophysiological changes brought about by AF were likely to change the actions of anti-fibrillatory drugs and stressed the importance of testing anti-fibrillatory drugs in a model of chronic AF. In a previous study (chapter 6), we tested drugs with class IA, IC and III properties in goats with chronic AF and showed that they were all successful in terminating chronic AF (conversion rates 67-92\%). However, surprisingly these drugs failed to prolong the atrial wavelength after cardioversion at slow pacing rates and the reinducibility of $\mathrm{AF}$ by a single premature stimulus remained as high as $100 \%$ for hydroquinidine, flecainide and $d$-sotalol and $66 \%$ for cibenzoline. This discrepancy between a clear anti-fibrillatory effect and the absence of effects on atrial wavelength and inducibility of AF, stressed the importance of measuring the wavelength during atrial fibrillation itself.

In the present study we developed a method to mealsure the refractory period of the atrial myocardium during sustained AF. Using this novel technique we determined the effects of anti-arrhythmic drugs on atrial refractory period and conduction velocity during atrial fibrillation in our goat model of chronic atrial fibrillation. ${ }^{10}$ Subsequently the effects of hydroquinidine (class IA), cibenzoline (class IC with additional class III and IV properties), flecainide (class IC) and $d$-sotalol (class III) were studied. Much to our surprise we found that the anti-fibrillatory effects were not based on a prolongation of the atrial wavelength during $\mathrm{AF}$ as suggested in previous studies. Instead we observed that all drugs progressively widened the excitable gap during AF.

\section{Methods}

Six goats weighing between 46 and $65 \mathrm{~kg}(55 \pm 7 \mathrm{~kg}$ ) were used for this study. Animal handling was performed according to the guiding principles of the American Society 


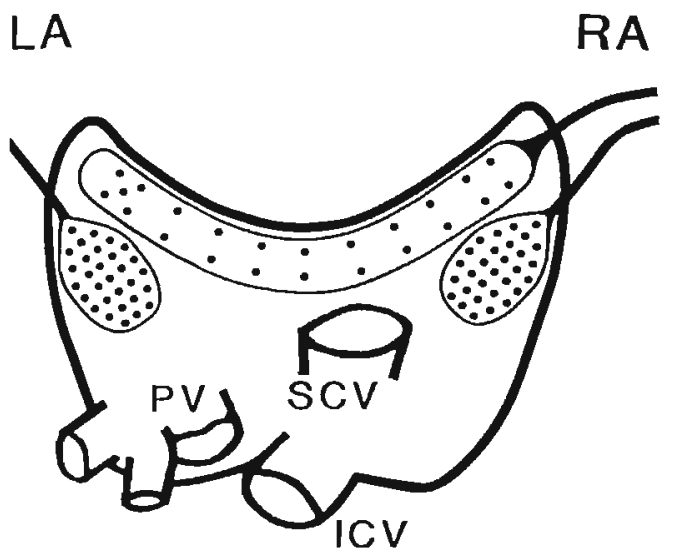

Figure 1. Diagram showing the position of the chronically implanted epicardial electrodes on the atria. One strip with 23 electrodes (inter-electrode distance $4-10 \mathrm{~mm}$ ) was led through the transverse sinus between the aorta and the atria and fixed to both atrial appendages. Two other electrode-plaques each containing 30 electrodes were sutured to the free, wall of the right and left atria. The inter-electrode distance of these electrodes was $4 \mathrm{~mm}$. RA, right atrium; LA, left atrium; PV, pulmonary veins; SCV, superior caval vein; ICV, inferior caval vein.

of Physiology and approved by the Animal Investigation Committee of the University of Limburg. During general anesthesia and sterile surgery, the goats were instrumented with multiple epicardial electrodes as described in more detail in chapters 3 , 4 and $6 .^{10,11}$ In Fig 1, a schematic drawing of the multiple epicardial electrodes is given. In addition to the long teflon felt strip (Bard ${ }^{\circledR}$ PTFE Felt, C.R. Bard Inc.) sutured to the surface of Bachmann's bundle, a teflon felt electrode-plaque of $3.5 \times 2.5 \mathrm{~cm}$, containing 30 electrodes, was sutured to the lateral walls of the right and left atria. These electrode-plaques were used for the measurements of the atrial refractory period and the intra-atrial conduction velocity during AF as will be described below. About 3-4 weeks after surgery the goats were connected to the external automatic atrial fibrillator which maintained AF continuously. ${ }^{10}$ As a result, AF usually became chronic within a few weeks of pacing.

\section{Electrophysiological Measurements During Chronic AF}

After AF had become chronic the goats were disconnected from the fibrillation pacemaker, placed in a mobile box (size $1.5 \times 0.7$ meter) with free access to food and water and brought to the electrophysiological laboratory. Three cables (each 30 wires) were plugged into the connectors in the neck of the animals and connected to a 256-channel recording unit (gain 200-400; bandwidth 1-500 Hz, sampling rate 1 $\mathrm{kHz}){ }^{12}$ For the electrophysiological measurements, a stimulator-amplifier (Medtronic SP3111) was used. This device was able to record a bipolar electrogram at the site of pacing. Atrial bipolar stimulation (biphasic stimulus, width $2 \mathrm{~ms}$ ) was performed with a strength of 4 times threshold as determined during entrainment of AF. 13,14

During the experiment the $A F$ cycle length (AFCL), refractory period during $A F$ $\left(R P_{A F}\right)$ and the conduction velocity during entrainment of $A F\left(C V_{A F}\right)$ were determined every 5-10 minutes. The local AFCL was measured from the bipolar signal recorded at the pacing site. A detection algorithm was used to automatically detect 
the moments of atrial activation (negative or positive peak) and 300 consecutive intervals were collected in a histogram. Of each of these histograms the median $\left(\mathrm{P}_{50}\right)$ and $\mathrm{P}_{5}$ and $\mathrm{P}_{95}$ values were calculated.

\section{Measurement of the Refractory Period During AF}

To measure the atrial effective refractory period during $\mathrm{AF}\left(\mathrm{RP}_{\mathrm{AF}}\right)$, the stimulatoramplifier (Medtronic SP3111) was connected to a pair of electrodes at the center of the electrode-plaque. The electrogram recorded at the site of stimulation was used to synchronize the stimulator. A single stimulus was introduced with a coupling interval which was well within the refractory period and incremented in steps of 1-2 ms. The post-stimulus response was visualized at an electrode $4 \mathrm{~mm}$ from the pacing site and in case of capture was characterized by a typical morphology (no R-wave) and a short latency. The occurrence of a long post-stimulus interval (compensatory pause) or acceleration of AF were used as additional criteria. In addition to these single electrogram criteria, activation maps were reconstructed to evaluate the effects of the single premature stimuli. Capture by the premature stimulus during AF was characterized by a radial spread of activation from the pacing site at the center of the plaque electrode. In Fig 2, a typical example of a non-capturing stimulus (upper two tracings) and a capturing stimulus (lower two tracings) during $\mathrm{AF}$ are given. In the upper tracings, a stimulus was introduced $63 \mathrm{~ms}$ after detection of a spontaneous AF-complex (AF-S). The electrogram recorded $4 \mathrm{~mm}$ from the pacing site showed no signs of capture. The post-stimulus response showed a normal AF morphology and a long latency of $53 \mathrm{~ms}$ (S-AF). The activation map given on the right shows that the area under the mapping electrode was activated by a wavefront propagating upwards. A typical example of capture of AF by a single stimulus is given in the lower tracings. In this case, a stimulus introduced with a coupling interval of $65 \mathrm{~ms}$, resulted in a typical morphology (absence of R-top) and a short latency of the post-stimulus response. In addition, after a short capture interval of $90 \mathrm{~ms}$ a relatively long interval of $117 \mathrm{~ms}$ occurred. The activation map at the right shows that the capture response was indeed associated with a radial spread of activation from the central site of pacing. For five goats and for several coupling intervals (average range between longest and shortest coupling interval: $41 \pm 15 \mathrm{~ms}$ ), the 'on line' evaluation of the post-stimulus response of a single electrogram morphology, was compared with the 'off-line' reconstruction of the whole activation map and the electrogram morphology off all electrodes surrounding the pacing site. In Table 1, the sensitivity, specificity, positive predictive value and the negative predictive value of the single electrogram criteria are given using the maps as a 'golden standard'. Despite this high correlation of more than $90 \%$, during the experiment the atrial activation pattern was reconstructed various times to confirm a positive capture response. The atrial refractory period during AF was defined as the shortest interval that evoked a capture response in at least 2 out of 10 attempts. 

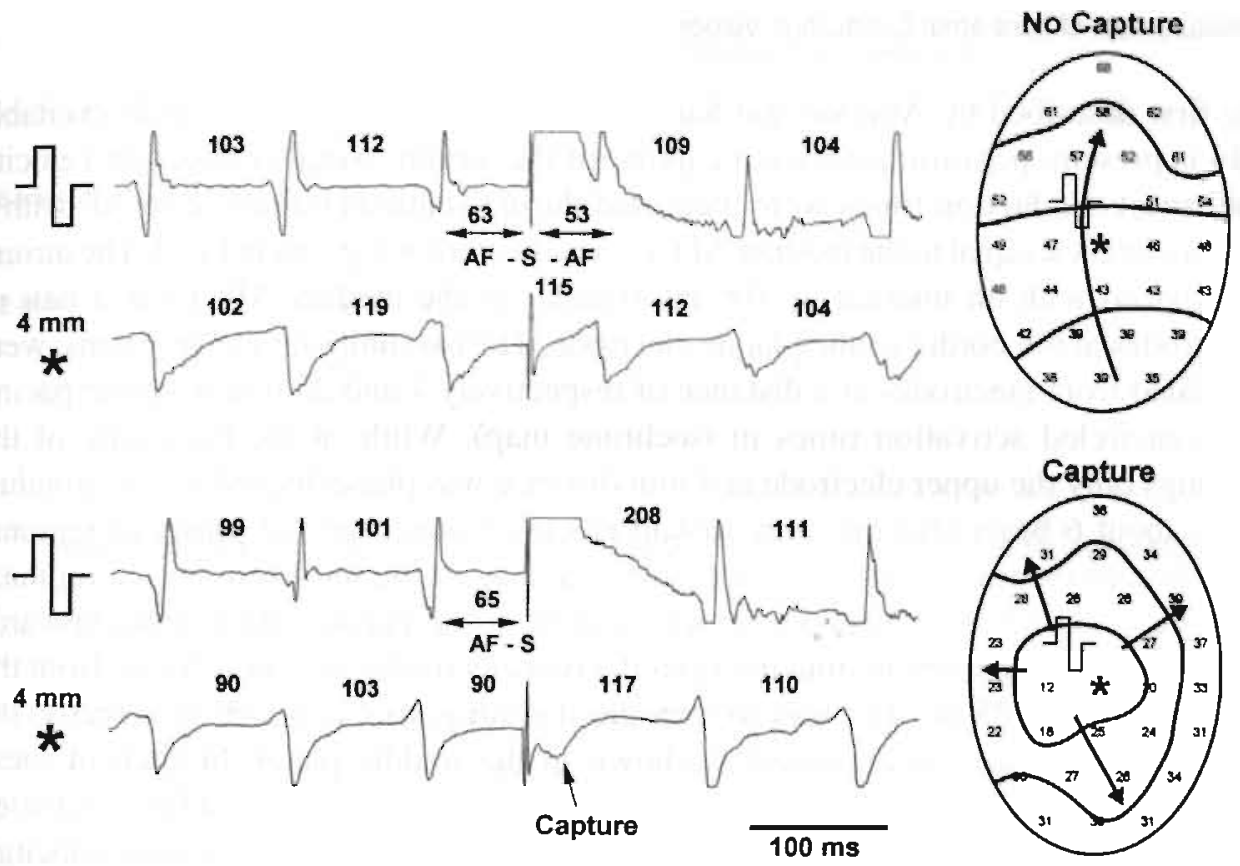

Figure 2. A typical example of a non-capturing stimulus (upper two tracings) and a capturing stimulus (lower two tracings) during AF (same experiment). A stimulus, introduced $63 \mathrm{~ms}$ after detection of a spontaneous AF-complex did not capture the atrium. On the electrogram recorded $4 \mathrm{~mm}$ from the pacing site (asterisk) no signs of capture were seen. The activation map at the right shows that $35 \mathrm{~ms}$ after the stimulus had been given the atrium was activated by a plane wavefront entering the mapping area from below. In contrast, as shown in the lower panel a stimulus with a coupling interval of $65 \mathrm{~ms}$ did capture the atrium during AF. The electrogram at $4 \mathrm{~mm}$ from the pacing site showed a typical capture morphology and a short latency. The activation map at the right shows a radial spread of activation from the pacing site to the borders of the electrode.

Table 1. Correlation Between the On-line Electrogram Criteria and Capture during AF Determined by Mapping.

\begin{tabular}{lcccc} 
Goat ${ }^{2}$ & Sensitivity & Specificity & Positive Predictive Value & Negative Predictive Value \\
\hline 1 & $94 \%$ & $97 \%$ & $95 \%$ & $92 \%$ \\
2 & $96 \%$ & $93 \%$ & $89 \%$ & $96 \%$ \\
3 & $84 \%$ & $96 \%$ & $95 \%$ & $98 \%$ \\
4 & $98 \%$ & $97 \%$ & $94 \%$ & $86 \%$ \\
5 & $83 \%$ & $98 \%$ & $95 \%$ & $99 \%$ \\
Mean & $91 \%$ & $96 \%$ & $94 \%$ & $94 \%$ \\
SD & $6 \%$ & $2 \%$ & $3 \%$ & $5 \%$ \\
\hline
\end{tabular}

For the on-line detection of a positive or negative capture response, the electrogram-morphology of a single electrode was used (see text for discussion). For the finally accepted off-line score, the absence or presence of a radial spread of activation and the electrogram-morphology of all electrodes surrounding the site of stimulation was used. For each stimulus, the on-line measurement was compared to the off-line score. Data are from 5 goats. In each goat, several coupling intervals were used (average range between the shortest and longest interval $41 \pm 15 \mathrm{~ms}$ ). For each coupling interval the on-line and of-line score of $10-20$ stimuli was determined. 
As first described by Allessie and Kirchhof et al., 13,14 during AF a small excitable gap is present, permitting regional capture of the atrium. Atrial conduction velocity and atrial conduction times were measured during stable entrainment of $\mathrm{AF}$ with a pacing interval equal to the median AFCL. An illustration is given in Fig 3. The atrium was paced with an interval of $106 \mathrm{~ms}$ (similar to the median AFCL) at a pair of electrodes at the border of the plaque electrode. The two unipolar electrograms, were recorded from electrodes at a distance of respectively 4 and $25 \mathrm{~mm}$ from the pacing site (encircled activation times in isochrone map). While at the beginning of the tracings only the upper electrode at $4 \mathrm{~mm}$ distance was phase-locked to the stimulus, after about 6 beats also the more distant electrode was captured (onset of regional capture). In the lower left panel, the isochrone map of the third beat during regional capture is shown. The atrium was activated from the pacing site in right upwards direction. The conduction time between the two electrodes at 4 and $25 \mathrm{~mm}$ from the pacing site was $25 \mathrm{~ms}$. In order to measure the intra-atrial conduction velocity, the electrode array was triangulated as shown in the middle panel. In each of these triangles the direction and velocity of the propagating wavefront could be calculated from the activation times at the corners of the triangle. The local conduction velocities arc plotted in the right lower panel and in addition were collected in a histogram and the median conduction velucity was determined. The conduction times and conduction velocities were determined off-line and the average and standard deviation of five activation maps was taken.

\section{Determination of the Window of Entrainment During AF}

During control and at the end of infusion of the drugs, rapid atrial pacing was used to determine the window of entrainment during AF. The atrium was stimulated with a fixed interval ( $4 x$ threshold) from a pair of electrodes selected at the center of the plaque electrode. Rapid pacing was started with an interval a few milliseconds shorter than the median AF cycle length. After stable capture was achieved, the pacing interval was gradually shortened and lengthened in steps of 1-2 ms until stable capture was lost (stable capture window). In addition, the range of pacing intervals at which at least 5 consecutive stimuli could capture the atrium was determined (total capture window).

\section{Administration of Anti-Fibrillatory Drugs}

After 60-90 minutes of baseline measurements (at least 7 control measurements) infusion of hydroquinidine (Serecor ${ }^{\circledR}$, Roussel UCLAF, France), cibenzoline (Cipralan ${ }^{(6)}$, Continental Pharma/Searle, Belgium), flecainide (Tambocor ${ }^{\mathrm{TM}}$, Riker 3 M Pharma) or $d$-sotalol (Bristol-Myers Squibb) was started and AFCL, RPAF and $\mathrm{CV}_{\mathrm{AF}}$ were measured every 5-10 minutes. Drugs were infused continuously at a speed 

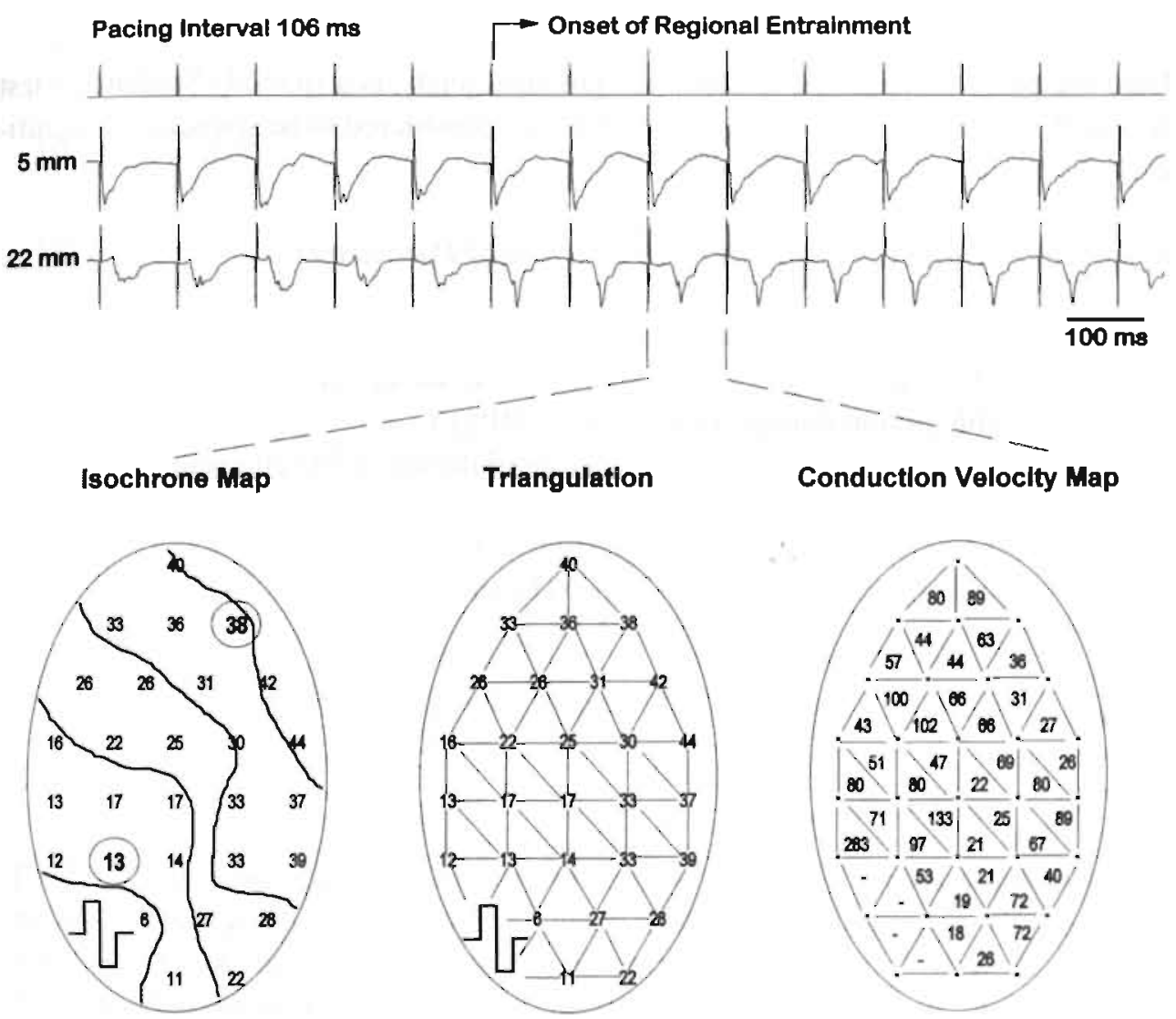

Figure 3. Method to measure the intra-atrial conduction velocity and the atrial conduction times during stable entrainment of AF. In this example the atrium was paced with an interval of 106 mins from a pair of electrodes at the border of the plaque-electrode. The two unipolar electrograms were recorded from electrodes at a distance of 5 and $22 \mathrm{~mm}$ from the pacing site (encircled activation times an isochrone map). After about 6 beats stable regional capture was obtained. The activation map (left lower panel) shows that the atrium was activated from the pacing site at the left lower border towards the right upper border. The conduction time between two selected electrodes was $25 \mathrm{~ms}$. After triangulation of the electrode array (middle panel) the local conduction velocities were calculated from the activation times at the comers of the triangles. The conduction velocities were plotted in a velocity map (right panel) and collected in a histogram. The median conduction velocity was taken to represent the conduction velocity.

of $0.1 \mathrm{mg} / \mathrm{kg} / \mathrm{min}$ (flecainide and cibenzoline) or $0.2 \mathrm{mg} / \mathrm{kg} / \mathrm{min}$ (hydroquinidine and $d$-sotalol). The end-points of infusion were restoration of sinus thythm or the occurrence of adverse drug effects (e.g. QRS - prolongation with more than 70\%, ventricular extra-systoles or ventricular tachycardia). At regular intervals during the infusion period (15-20 minutes), the capture thresholds at both pacing sites (site of $\mathrm{RP}_{\mathrm{AF}}$ and site of $\mathrm{CV}_{\mathrm{AF}}$ measurement) were redetermined and if necessary the strength of stimulation was adjusted. 


\section{Statistical Analysis}

Data are presented as mean $\pm S D$. For statistical analysis a (paired) Student's $t$-test was performed. A p-value of less than 0.05 was considered to be statistically significant.

\section{List of Abbreviations and Definitions of Measured Parameters}

AFCL: Atrial fibrillation cycle length

RPAF: Atrial Effective refractory period measured during AF

$\mathrm{EP}_{\mathrm{AF}}$ : Excitable period during AF (= AFCL - RPAF)

$\mathrm{CV}_{\mathrm{AF}}$ : Intra-atrial conduction velocity measured during stable entrainment of $\mathrm{AF}$

$\mathrm{CS}_{\mathrm{AF}}$ : Circuit size during $\mathrm{AF}$ ( $=\mathrm{AFCL} \times \mathrm{CV}_{\mathrm{AF}}$ )

WL $\mathrm{L}_{\mathrm{AF}}$ : Wavelength during $\mathrm{AF}\left(=\mathrm{RP}_{\mathrm{AF}} \times \mathrm{CV}_{\mathrm{AF}}\right)$

$\mathrm{EG}_{\mathrm{AF}}$ : Excitable Gap during $\mathrm{AF}\left(=\mathrm{CS}_{\mathrm{AF}}-\mathrm{WL}_{\mathrm{AF}}\right)$

\section{Results}

\section{The Effects of Hydroquinidine}

In Fig 4 a representative example is given of the effects of hydroquinidine on AFCL, $\mathrm{RP}_{\mathrm{AF}}$ (upper panel), $\mathrm{CV}_{\mathrm{AF}}$ (middle panel) and calculated circuit size (CS) and wavelength (WL) (lower panel). Before drug infusion the median AFCL was $68 \mathrm{~ms}$ ( $\mathrm{P}_{5} 49, \mathrm{P}_{95} 95 \mathrm{~ms}$ ) while the $\mathrm{RP}_{\mathrm{AF}}$ varied between 46 and $55 \mathrm{~ms}$ (about the $5^{\text {th }}$ percentile of the AFCL histogram). At $t=0$ the infusion of hydroquinidine $(0.2$ $\mathrm{mg} / \mathrm{kg} / \mathrm{min}$ ) was started and the AFCL progressively increased to $119 \mathrm{~ms}$ after 50 minutes of infusion. A few minutes later, AF converted to sinus rhythm and the infusion rate was adjusted to a maintenance dose of $0.1 \mathrm{mg} / \mathrm{kg} / \mathrm{min}$. Interestingly, despite a clear prolongation of the AFCL by hydroquinidine the RP $\mathrm{AF}_{\mathrm{AF}}$ did not change and remained as short as $50 \mathrm{~ms}$ (control value $50 \pm 3$ ). As a result, the excitable period $\left(\mathrm{EP}_{\mathrm{AF}}\right)$ increased considerably from $18 \mathrm{~ms}$ during control to $69 \mathrm{~ms}$ just prior to termination of $\mathrm{AF}(+278 \%)$. In this example the average conduction velocity during capture of AF was slightly increased by hydroquinidine from $37 \pm 4 \mathrm{~cm} / \mathrm{s}$ during control (range $32-45 \mathrm{~cm} / \mathrm{s}$ ) to about $44 \mathrm{~cm} / \mathrm{s}$ after 50 -minutes of infusion. Apparently, the depression of conduction velocity by the class IA drug was outweighed by the prolongation of the entrainment interval during $\mathrm{AF}$ (equal to the $\mathrm{AFCL}$ ) and the widening of the $\mathrm{EP}_{\mathrm{AF}}$. In the lower panel the effects of hydroquinidine on the atrial wavelength and circuit size during $A F$ are given. Due to the small increase in $\mathrm{CV}_{\mathrm{AF}}$, the wavelength slightly prolonged from $1.8 \pm 0.2 \mathrm{~cm}$ during control (range 1.5 and $2.3 \mathrm{~cm}$ ) to $2.2 \mathrm{~cm}$ after 50 minutes of hydroquinidine infusion. However, because the drug markedly prolonged the AFCL, the atrial circuit size increased considerably from $2.5 \pm 0.3 \mathrm{~cm}$ during control (range 2.2 and $3.1 \mathrm{~cm}$ ) to $5.3 \mathrm{~cm} \mathrm{(+109 \% )} \mathrm{after} 50$ minutes 


\section{Hydroquinidine $0.2 \mathrm{mg} / \mathrm{kg} / \mathrm{min}$}

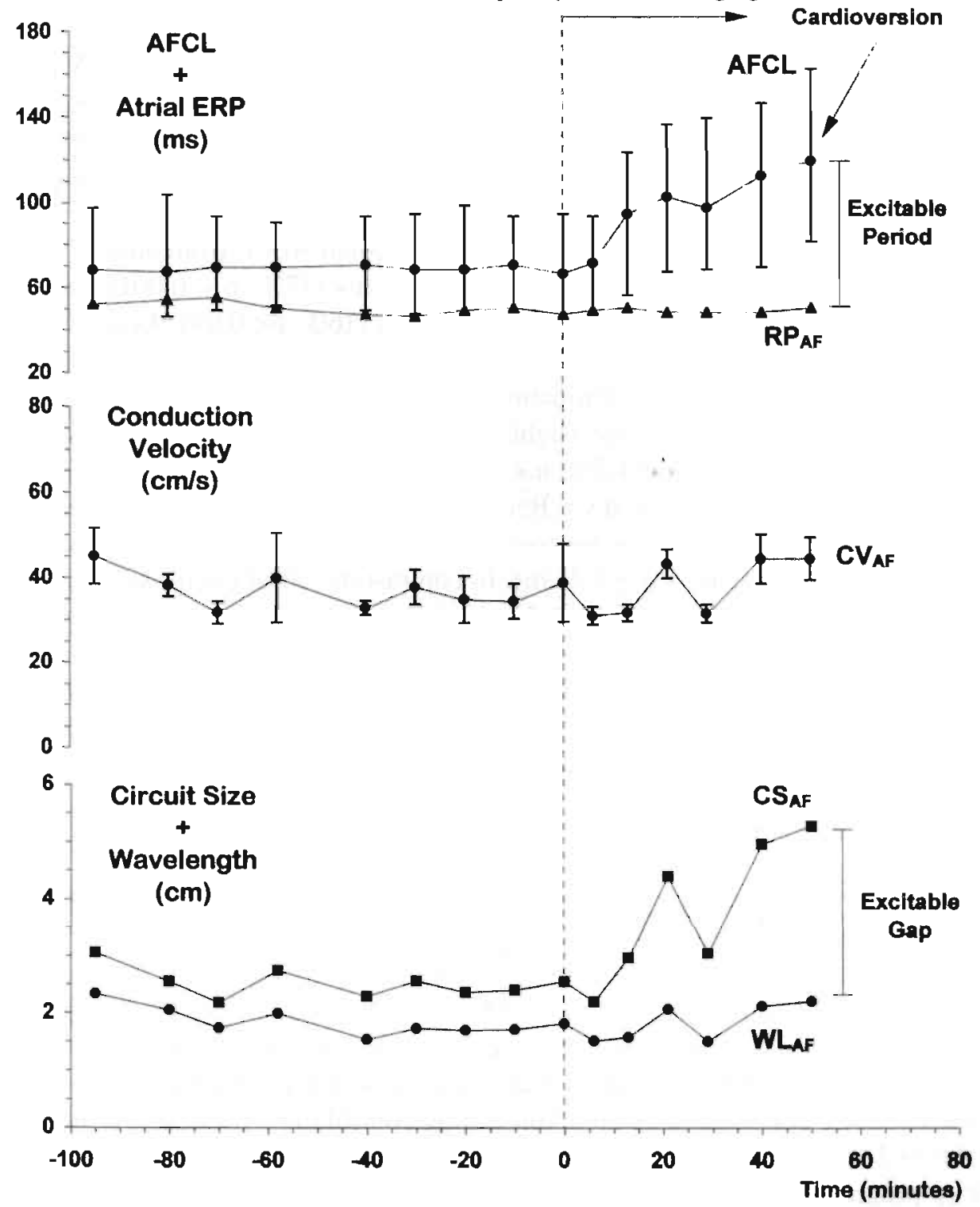

Figure 4. Upper panel: A representative example of the effects of hydroquinidine on the median AF cycle length (AFCL) and atrial refractory period during AF (RPAF). The bars represent the $\mathrm{P}_{5}$ and $\mathrm{P}_{95}$ of the AFCL histogram. Middle panel: The effects of hydroquinidine on the average intra-atrial conduction velocity (CV) during entrainment of AF. The bars represent the standard deviation of 5 consecutive measurements. Lower panel: The effects of hydroquinidine on the calculated wavelength (WL) and circuit size (CS) during AF. See text for description. 
of drug infusion. As a result, similar to the excitable period (ms) also the excitable $g a p(\mathrm{~cm})$ increased, in this case from $0.7 \pm 0.1 \mathrm{~cm}$ to $3.1 \mathrm{~cm}(+358 \%)$.

In Table 2, for 5 goats, the effects of hydroquinidine on AFCL. $\mathrm{RP}_{\mathrm{AF}}, \mathrm{CV}_{\mathrm{AF}}$ and conduction time, atrial WL, atrial CS, EP and EG are given together with the capture window and the range of entrainment intervals. For all parameters, the average value during control is given together with the values determined at an AFCL prolongation of about $10 \%, 25 \%$ and $50 \%$ as well as during the maximal prolongation of the AFCL. Although hydroquinidine prolonged the average median AFCL from $96 \pm 17$ during control to an average maximal value of $148 \pm 11 \mathrm{~ms}(57 \%, \mathrm{p}<0.001)$ the $\mathrm{RP}_{\mathrm{AF}}$ increased only slightly from $67 \pm 15$ to $79 \pm 15 \mathrm{~ms}(16 \%, \mathrm{p}<0.05)$. As a result, the average excitable period during AF widened dramatically from $29 \pm 10 \mathrm{~ms}$ during control to $69 \pm 16$ ms prior to termination $(+157 \%, p<0.01)$. taking up almost half of the AFCL. Hydroquinidine only slightly depressed intra-atrial conduction velocity from $69 \pm 21$ to $61 \pm 15 \mathrm{~cm} / \mathrm{s}(-7 \%$, n.s.) while the conduction time increased with about the same degree $(+13 \%$, n.s.). Because hydroquinidine slightly increased the $\mathrm{RP}_{\mathrm{AF}}$ and decreased the $\mathrm{CV}_{\mathrm{AF}}$ (opposing effects), the atrial wavelength was not affected $(4.8 \pm 1.8$ versus $4.9 \pm 1.7 \mathrm{~cm})$. In contrast the atrial circuit size increased considerably from $6.8 \pm 2.3$ to $9.1 \pm 2.5 \mathrm{~cm}(+50 \%, \mathrm{p}<0.05)$. As a result, like the EP also the EG increased dramatically from $2.0 \pm 0.8$ to $4.2 \pm 1.3 \mathrm{~cm}(158 \%, p<0.05)$. Thus prior to cardioversion about half of the circuit size consisted of an excitable gap. The last two columns in Table 2 show that also the capture window during AF was more than doubled by hydroquinidine.

\section{The Effects of Cibenzoline}

In Fig 5 a representative example of the effects of cibenzoline on $A F C L, \mathrm{RP}_{\mathrm{AF}}, \mathrm{CV} A \mathrm{~A}$, $\mathrm{CS}_{\mathrm{AF}}$ and $\mathrm{WL}_{\mathrm{AF}}$ is given. Cibenzoline was given as a continuous infusion of 0.1 $\mathrm{mg} / \mathrm{kg} / \mathrm{min}$ until after 60 minutes AF was cardioverted. Cibenzoline progressively increased the AFCL from $101 \pm 2 \mathrm{~ms}$ to $175 \mathrm{~ms}$ and the $\mathrm{RP}_{\mathrm{AF}}$ from $78 \pm 1 \mathrm{~ms}$ to about $108 \mathrm{~ms}$. However, similar to the effects of hydroquinidine (Fig 4), the prolongation in AFCL was much more pronounced than the increase in RP, which led to a widening of the excitable period from about $23 \mathrm{~ms}$ during control to $67 \mathrm{~ms}$ before termination of AF (+189\%). The middle panel shows that, despite the widening of the EG, the $\mathrm{CV}_{\mathrm{AF}}$ progressively decreased during the first 20 minutes of cibenzoline infusion from $81 \pm 3$ to $58 \mathrm{~cm} / \mathrm{s}$. After the initial 20 minutes of infusion. the conduction velocity remained unchanged. As a result, during the first 20 minutes of infusion, cibenzoline slightly shortened the $\mathrm{WL}_{\mathrm{AF}}$ and $C S_{\mathrm{AF}}$ to respectively $5.5 \mathrm{~cm}$ and $7.3 \mathrm{~cm}$. After 20 minutes, due to a continuing increase in AFCL, the CS prolonged to $10.3 \mathrm{~cm}$ prior to restoration of sinus rhythm. The excitable gap during atrial fibrillation gradually prolonged from $1.9 \pm 0.2$ during control to $3.9 \mathrm{~cm}$ prior to cardioversion $(+110 \%)$.

In Table 3 the effects of cibenzoline on AF parameters are summarized for 5 goats. As in Table 2, the parameters are given during control, and at an AFCL prolongation of about 10,25 and $50 \%$ and at the maximal increase in AFCL. Cibenzoline progres- 
Table 2. Effects of Hydroyuinidine on Atrial Fibriliation Parameters.

\begin{tabular}{|c|c|c|c|c|c|c|c|c|c|c|c|}
\hline & $\begin{array}{l}\text { Number } \\
\text { of Goats }\end{array}$ & $\begin{array}{l}\text { AF Cycle } \\
\text { Length } \\
\text { (ms) }\end{array}$ & $\begin{array}{l}\text { RP During } \\
\text { AF } \\
\text { (ms) }\end{array}$ & $\begin{array}{l}\text { Excitable } \\
\text { Period } \\
\text { (ms) }\end{array}$ & $\begin{array}{l}\text { CV During } \\
\text { Capture } \\
(\mathrm{cm} / \mathrm{s})\end{array}$ & $\begin{array}{l}\text { Cond Time } \\
\text { During Capture } \\
\text { (ms) }\end{array}$ & $\begin{array}{l}\text { Atrial } \\
\text { Wave-Length } \\
\text { (cm) }\end{array}$ & $\begin{array}{l}\text { Atrial Circuit } \\
\text { Size } \\
(\mathrm{cm})\end{array}$ & $\begin{array}{l}\text { Excitable } \\
\text { Gap } \\
(\mathrm{cm})\end{array}$ & $\begin{array}{l}\text { Total Capture } \\
\text { Windows } \\
\text { (ms) }\end{array}$ & $\begin{array}{l}\text { Stable Capture } \\
\text { Window } \\
\text { (ms) }\end{array}$ \\
\hline Control & 5 & $96 \pm 17$ & $67 \pm 15$ & $29 \pm 10$ & $69 \pm 21$ & $23 \pm 11$ & $4.8 \pm 1.8$ & $6.8 \pm 2.3$ & $2.0 \pm 0.8$ & $\begin{array}{l}32 \pm 7 \\
(78-110)\end{array}$ & $\begin{array}{l}12 \pm 11^{\S} \\
(91-111)\end{array}$ \\
\hline $\begin{array}{l}\text { After AFCL Increase } \\
\text { of About } 10 \%\end{array}$ & 5 & $\begin{array}{l}106 \pm 20 \\
(+9 \%)\end{array}$ & $\begin{array}{l}71 \pm 20 \\
(+3 \%)\end{array}$ & $\begin{array}{l}35 \pm 13 \\
(+20 \%)\end{array}$ & $\begin{array}{l}62 \pm 18 \\
(-10 \%)\end{array}$ & $\begin{array}{l}25 \pm 13 \\
(+9 \%)\end{array}$ & $\begin{array}{l}4.5 \pm 1.9 \\
(-7 \%)\end{array}$ & $\begin{array}{l}6.7 \pm 2.4 \\
(-2 \%)\end{array}$ & $\begin{array}{l}2.2 \pm 1.0 \\
(+8 \%)\end{array}$ & - & - \\
\hline $\begin{array}{l}\text { After AFCL Increase } \\
\text { of Aboul } 25 \%\end{array}$ & 5 & $\begin{array}{l}125 \pm 18 \\
(+31 \%)\end{array}$ & $\begin{array}{l}74 \pm 20 \\
(+9 \%)\end{array}$ & $\begin{array}{l}51 \pm 11 \\
(+85 \%)\end{array}$ & $\begin{array}{l}59 \pm 19 \\
(-15 \%)\end{array}$ & $\begin{array}{l}27 \pm 14 \\
(+18 \%)\end{array}$ & $\begin{array}{c}4.5 \pm 19 \\
(-8 \%)\end{array}$ & $\begin{array}{l}7.5 \pm 2.6 \\
(+11 \%)\end{array}$ & $\begin{array}{l}3.0 \pm 1.1 \\
(+57 \%)\end{array}$ & - & - \\
\hline $\begin{array}{l}\text { After AFCL Increase } \\
\text { of About } 50 \%\end{array}$ & 4 & $\begin{array}{l}141 \pm 17 \\
(+56 \%)\end{array}$ & $\begin{array}{l}69 \pm 14 \\
(+12 \%)\end{array}$ & $\begin{array}{l}72 \pm 11 \\
(+156 \%)\end{array}$ & $\begin{array}{l}62 \pm 18 \\
(-8 \%)\end{array}$ & $\begin{array}{l}28 \pm 15 \\
(+14 \%)\end{array}$ & $\begin{array}{l}4.4 \pm 1.9 \\
(+2 \%)\end{array}$ & $\begin{array}{r}8.8 \pm 3.0 \\
(+44 \%)\end{array}$ & $\begin{array}{l}4.4 \pm 1.2 \\
(+146 \%)\end{array}$ & - & - \\
\hline $\begin{array}{l}\text { At Maximum Increase } \\
\text { of } \mathrm{AFCL}\end{array}$ & 5 & $\begin{array}{l}148 \pm 11 \\
(+57 \%) \\
\ldots\end{array}$ & $\begin{array}{l}79 \pm 19 \\
(+16 \%)\end{array}$ & $\begin{array}{l}69 \pm 16 \\
(+157 \%)\end{array}$ & $\begin{array}{l}61 \pm 15 \\
(-7 \%) \\
\text { n.s. }\end{array}$ & $\begin{array}{l}26 \pm 13 \\
(+13 \%) \\
\text { n.s. }\end{array}$ & $\begin{array}{l}4.9 \pm 1.7 \\
(+7 \%) \\
\text { n.s. }\end{array}$ & $\begin{array}{l}9.1 \pm 2.5 \\
(+50 \%)\end{array}$ & $\begin{array}{l}4.2 \pm 1.3 \\
(+158 \%)\end{array}$ & $\begin{array}{l}70 \pm 12 \\
(97-167)\end{array}$ & $\begin{array}{l}34 \pm 15 \\
(111-145)\end{array}$ \\
\hline \multicolumn{12}{|c|}{$\begin{array}{l}\text { Numbers represent mean } \pm \mathrm{SD} \text {. Numbers between parentheses indicate the average percentage change of the given parameter; All measurements were pertormed during stable AF. In only } 4 \text { of } 5 \\
\text { goats an increase of } 50 \% \text { of the AF-interval was reached before termination of AF occurred; Excitable Peniod, difference between AF cycle length and RP during AF. Excitable Gap, difference between } \\
\text { circuit size and wavelength during AF; Total capture window, window between longest and shortest pacing interval at which at least } 5 \text { consecutive beats were captured; The average range of capture } \\
\text { intervals is given between parentheses; } \S \text { In } 2 \text { goats during control no stable caplure range was found (window defined as } 0 \text { ms); ", p<0.05; " , p<0.01; ***, p<0.001; n.S., not significant control versus } \\
\text { values at maximum AFCL increase (paired Student's } t \text {-test). }\end{array}$} \\
\hline
\end{tabular}




\section{Cibenzoline $0.1 \mathrm{mg} / \mathrm{kg} / \mathrm{min}$}

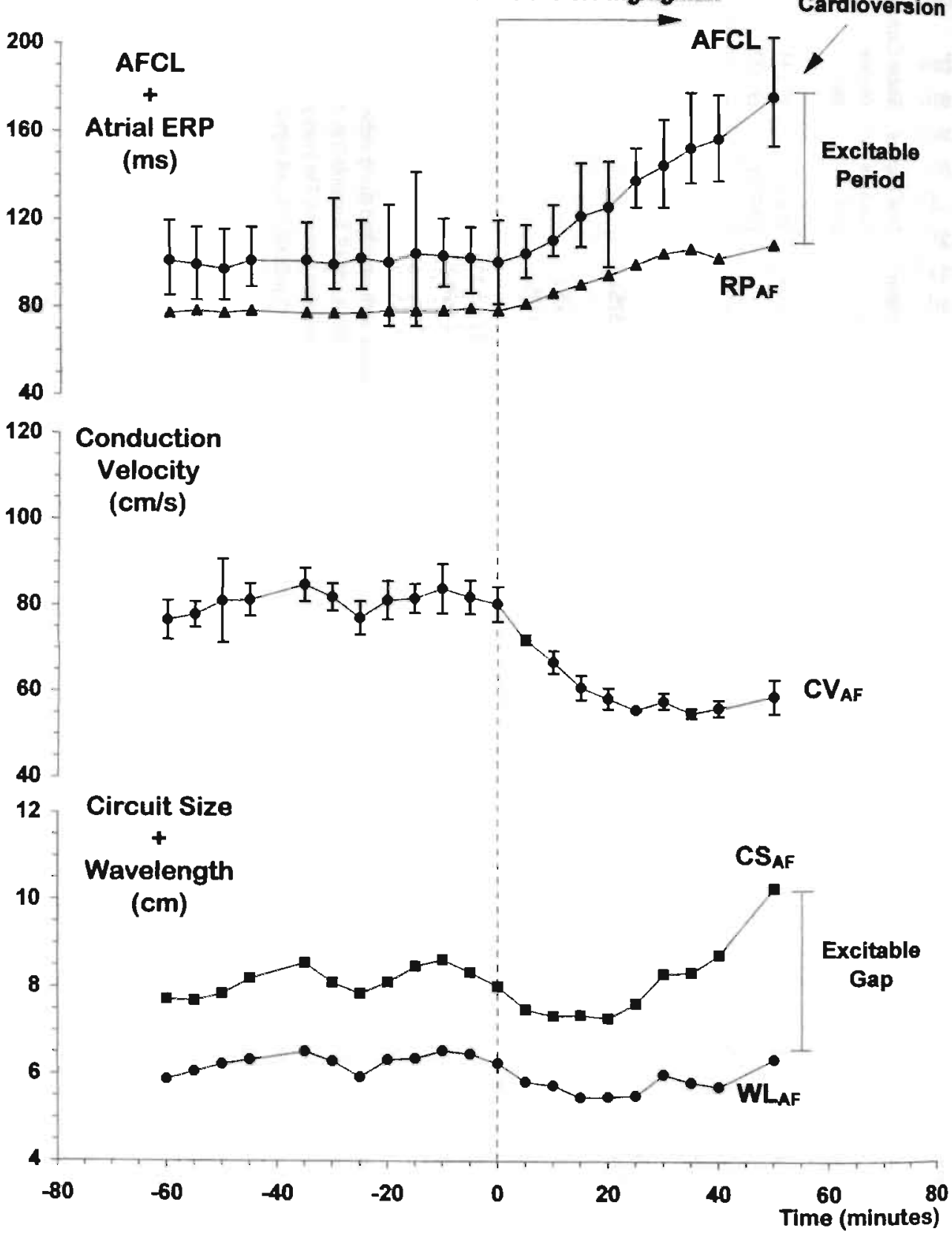

Figure 5. A representative example of the effects of cibenzoline on AF cycle length, refractory period (upper panel). conduction velocity (middle panel), circuit size and wavelength during AF (lower panel). See text for description. 
Table 3. Effects of Cibenzoline on Atrial Fibrillation Parameters.

\begin{tabular}{|c|c|c|c|c|c|c|c|c|c|c|c|}
\hline & $\begin{array}{l}\text { Number } \\
\text { of Goats }\end{array}$ & $\begin{array}{l}\text { AF Cycle } \\
\text { Length } \\
\text { (ms) }\end{array}$ & $\begin{array}{l}\text { RP During } \\
\text { AF } \\
\text { (ms) }\end{array}$ & $\begin{array}{l}\text { Excitable } \\
\text { Period } \\
\text { (ms) }\end{array}$ & $\begin{array}{l}\text { CV During } \\
\text { Capture } \\
(\mathrm{cm} / \mathrm{s})\end{array}$ & $\begin{array}{l}\text { Cond Time } \\
\text { During Capture } \\
\text { (ms) }\end{array}$ & $\begin{array}{l}\text { Atrial } \\
\text { Wave-Length } \\
\text { (cm) }\end{array}$ & $\begin{array}{l}\text { Atrial Circuit } \\
\text { Size } \\
(\mathrm{cm})\end{array}$ & $\begin{array}{l}\text { Excitable } \\
\text { Gap } \\
\text { (cm) }\end{array}$ & $\begin{array}{l}\text { Total Capture } \\
\text { Windows } \\
\text { (ms) }\end{array}$ & $\begin{array}{l}\text { Stable Capture } \\
\text { Window } \\
\text { (ms) }\end{array}$ \\
\hline Control & 5 & $96 \pm 4$ & $69 \pm 8$ & $27 \pm 5$ & $71 \pm 17$ & $23 \pm 11$ & $4.9 \pm 1.2$ & $6.8 \pm 1.5$ & $1.9 \pm 0.5$ & $\begin{array}{l}31 \pm 5 \\
(75-106)\end{array}$ & $\begin{array}{l}12 \pm 4 \\
(83-95)\end{array}$ \\
\hline $\begin{array}{l}\text { After AFCL Increase } \\
\text { of About } 10 \%\end{array}$ & 5 & $\begin{array}{l}107 \pm 6 \\
(+12 \%)\end{array}$ & $\begin{array}{l}75 \pm 11 \\
(+8 \%)\end{array}$ & $\begin{array}{l}32 \pm 8 \\
(+22 \%)\end{array}$ & $\begin{array}{l}54 \pm 16 \\
(-24 \%)\end{array}$ & $\begin{array}{l}29 \pm 13 \\
(+28 \%)\end{array}$ & $\begin{array}{l}4.1 \pm 1.3 \\
(-18 \%)\end{array}$ & $\begin{array}{l}5.8 \pm 1.5 \\
(-15 \%)\end{array}$ & $\begin{array}{l}1.7 \pm 0.4 \\
(-8 \%)\end{array}$ & - & - \\
\hline $\begin{array}{l}\text { After AFCL Increase } \\
\text { of About } 25 \%\end{array}$ & 4 & $\begin{array}{l}123 \pm 6 \\
(+28 \%)\end{array}$ & $\begin{array}{l}80 \pm 12 \\
(+17 \%)\end{array}$ & $\begin{array}{l}43 \pm 8 \\
(+56 \%)\end{array}$ & $\begin{array}{l}47 \pm 12 \\
(-36 \%)\end{array}$ & $\begin{array}{l}31 \pm 18 \\
(+39 \%)\end{array}$ & $\begin{array}{l}3.8 \pm 1.4 \\
(-25 \%)\end{array}$ & $\begin{array}{l}5.8 \pm 1.6 \\
(-18 \%)\end{array}$ & $\begin{array}{l}1.9 \pm 0.5 \\
(-0.3 \%)\end{array}$ & - & - \\
\hline $\begin{array}{l}\text { After AFCL Increase } \\
\text { of About } 50 \%\end{array}$ & 5 & $\begin{array}{l}146 \pm 8 \\
(+52 \%)\end{array}$ & $\begin{array}{l}89 \pm 14 \\
(+28 \%)\end{array}$ & $\begin{array}{l}56 \pm 10 \\
(+114 \%)\end{array}$ & $\begin{array}{l}45 \pm 10 \\
(-37 \%)\end{array}$ & $\begin{array}{l}35 \pm 19 \\
(+51 \%)\end{array}$ & $\begin{array}{l}4.1 \pm 1.3 \\
(-18 \%)\end{array}$ & $\begin{array}{l}6.5 \pm 1.5 \\
(-4 \%)\end{array}$ & $\begin{array}{l}2.4 \pm 0.3 \\
(+37 \%)\end{array}$ & - & - \\
\hline $\begin{array}{l}\text { At Maximum Increase } \\
\text { of } \mathrm{AFCL}\end{array}$ & 5 & $\begin{array}{l}171 \pm 8 \\
(+79 \%)\end{array}$ & $\begin{array}{l}95 \pm 15 \\
(+37 \%)\end{array}$ & $\begin{array}{l}76 \pm 10 \\
(+191 \%)\end{array}$ & $\begin{array}{l}42 \pm 15 \\
(-42 \%) \\
\end{array}$ & $\begin{array}{l}36 \pm 18 \\
(+58 \%) \\
+\end{array}$ & $\begin{array}{l}4.1 \pm 1.7 \\
(-20 \%) \\
\text { n.s. }\end{array}$ & $\begin{array}{l}7.2 \pm 2.7 \\
(+5 \%) \\
\text { n.s. }\end{array}$ & $\begin{array}{l}3.2 \pm 1.2 \\
(+69 \%)\end{array}$ & $\begin{array}{l}63 \pm 4 \\
(131-194)\end{array}$ & $\begin{array}{l}37 \pm 6 \\
(146-183)\end{array}$ \\
\hline
\end{tabular}

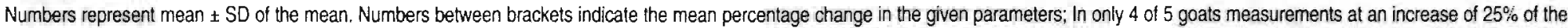
AF-interval were available; ${ }^{\prime}, p<0.05 ;{ }^{*}, p<0.01 ;{ }^{* * *}, p<0.001 ;$ n.S., not significant: control versus values al maximum AFCL increase (paired Student's $1-$ test); For abbreviations see legends Table 2. 
sively increased the AFCL from $96 \pm 4$ to $171 \pm 8 \mathrm{~ms}(\mathrm{p}<0.001)$ and the $\mathrm{RP}_{\mathrm{AF}}$ from $69 \pm 8$ to $95 \pm 15 \mathrm{~ms}(\mathrm{p}<0.01)$. Because the AFCL was lengthened more than that the $\mathrm{RP}$ AF prolonged (with 79 and $37 \%$ respectively), the excitable period widened from $27 \pm 5$ to $76 \pm 10 \mathrm{~ms}(191 \%, \mathrm{p}<0.001)$. On the average, the conduction velocity during capture was decreased significantly by cibenzoline ( $42 \%$ ) while the conduction time increased with at least a similar degree $(58 \%)$. Like the example shown in Fig 5 , the depression of conduction was most pronounced during the initial period of infusion. As a result, both the WL and CS shortened from $4.9 \pm 1.2$ and $6.8 \pm 1.5 \mathrm{~cm}$ to $3.8 \pm 1.4$ and $5.8 \pm 1.6 \mathrm{~cm}$ at a prolongation of the AFCL of $25 \%$. Thereafter the atrial WL slightly prolonged again to $4.1 \pm 1.7 \mathrm{~cm}$ but remained shorter than during control. The atrial CS gradually prolonged to $7.2 \pm 2.7 \mathrm{~cm}$ prior to conversion of AF. The excitable gap widened from $1.9 \pm 0.5$ during control to $3.2 \pm 1.2 \mathrm{~cm}$ before cardioversion $(p<0.05)$. Cibenzoline exerted a clear effect on the window of entrainment during AF. The total window of entrainment increased from $31 \pm 5 \mathrm{~ms}$ to $63 \pm 4 \mathrm{~ms}$, while the window of stable entrainment increased from $12 \pm 4 \mathrm{~ms}$ to 37 $\pm 6 \mathrm{~ms}$ (both $\mathrm{p}<0.001$ ).

\section{The Effects of Flecainide}

In Fig 6 an example of the effects of flecainide is given. At $t=0$ flecainide infusion was started at a rate of $0.1 \mathrm{mg} / \mathrm{kg} / \mathrm{min}$ resulting in a progressive increase in AFCL from $87 \pm 1$ to $131 \mathrm{~ms}(+50 \%)$. However, AF did not terminate. The effect of flecainide on atrial refractoriness was less pronounced, the $\mathrm{RP}_{\mathrm{AF}}$ prolonging from $69 \pm 1$ during control to $88 \mathrm{~ms}$ after 135 minutes of infusion. As a result, the EP increased from 18 $\pm 2 \mathrm{~ms}$ to $43 \mathrm{~ms}(+143 \%)$. Flecainide markedly depressed the conduction velocity during entrainment of AF from $55 \pm 4$ during control to less than $30 \mathrm{~cm} / \mathrm{s}$. The lower panel illustrates the consequences for the $\mathrm{CS}_{\mathrm{AF}}$ and $\mathrm{WL}_{\mathrm{AF}}$. Since the depression of $\mathrm{CV}_{\mathrm{AF}}$ by flecainide was more pronounced than the prolongation of AFCL and $\mathrm{RP}_{\mathrm{AF}}$ both the atrial $\mathrm{CS}_{\mathrm{AF}}$ and the $\mathrm{WL}_{\mathrm{AF}}$ became progressively shorter. While during control atrial CS and WL measured $4.8 \pm 0.4$ and $3.8 \pm 0.3 \mathrm{~cm}$. after 135 minutes of flecainide infusion they shortened to 3.7 and $2.5 \mathrm{~cm}$. Despite a clear widening of the EP (ms) (upper panel), due to the marked depression of $\mathrm{CV}_{\mathrm{AF}}$ by flecainide the excitable gap $(\mathrm{cm})$ increased only slightly from $1.0 \pm 0.1 \mathrm{~cm}$ during control to $1.2 \mathrm{~cm}$ at the maximal drug concentration.

In table 4 the effects of flecainide are summarized for 5 goats. Despite a maximal prolongation of $\mathrm{AFCL}$ of $48 \%$, the average $\mathrm{RP}_{\mathrm{AF}}$ did not increase significantly ( $71 \pm$ 12 versus a control value of $68 \pm 7 \mathrm{~ms}$ ). As a result the $E P$ widened from $23 \pm 5 \mathrm{~ms}$ to $63 \pm 9 \mathrm{~ms}(+189 \%, \mathrm{p}<0.01)$. The conduction velocity during capture of $\mathrm{AF}$ significantly decreased with $44 \%$ while the conduction time progressively increased with $62 \%$ (both $\mathrm{p}<0.05$ ). Administration of flecainide resulted in a marked shortening of the atrial wavelength during AF with $41 \%(\mathrm{p}<0.05)$. the estimated circuit size shortened by $18 \%$ (n.s.). Consequently the $E G$ widened from an average of $1.3 \pm 0.2$ during control to $2.0 \pm 0.7 \mathrm{~cm}(+55 \%)$. Again the widening of the EP and the EG was 
Flecainide $0.1 \mathrm{mg} / \mathrm{kg} / \mathrm{min}$

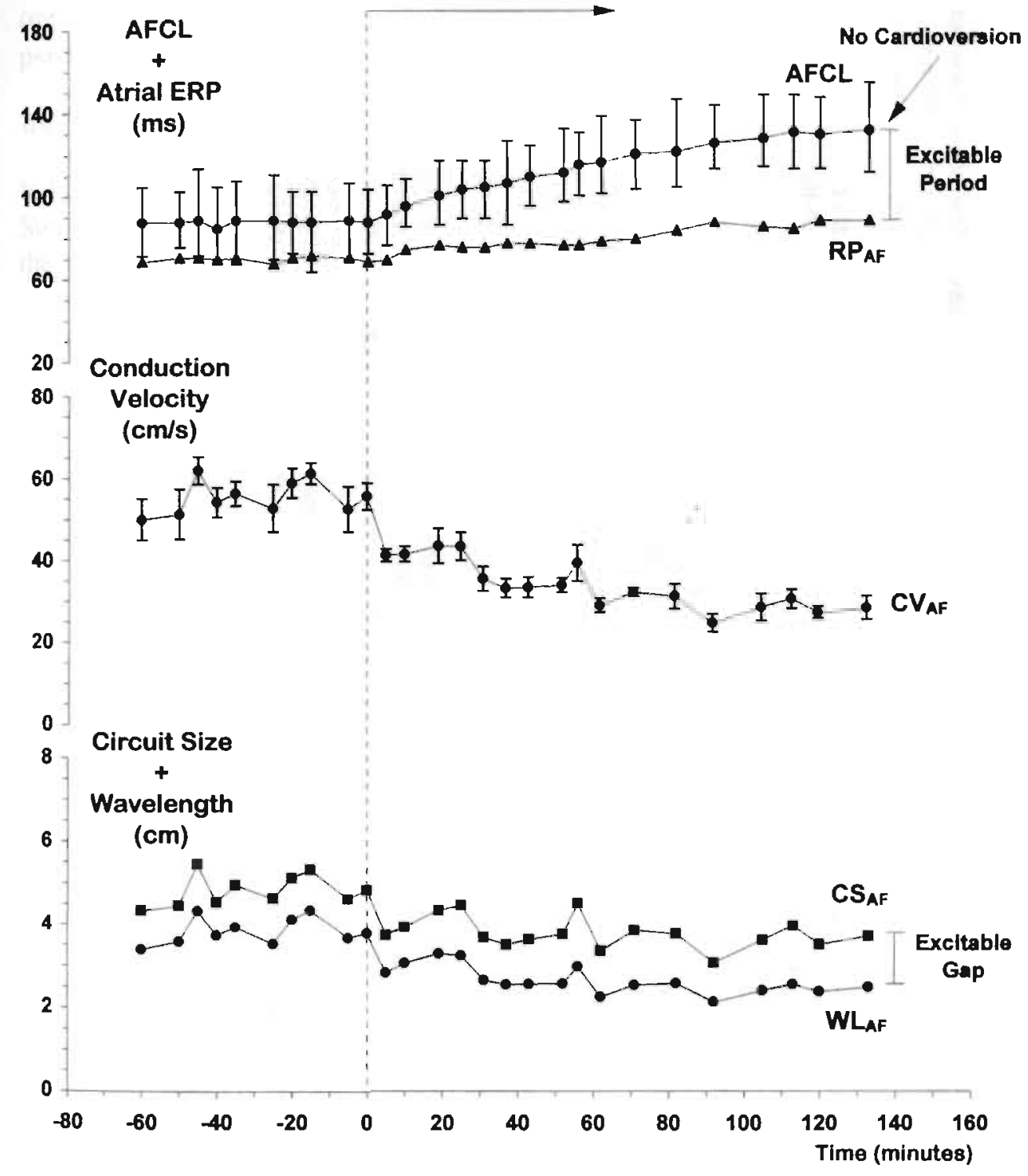

Figure 6. A representative example of the effects of flecainide on AF cycle length, refractory period (upper panel), conduction velocity (middle panel), circuit size and wavelength during AF (lower panel). See text for description. 
Table 4. Effects of Flecainide on Atrial Fibrillation Parameters.

\begin{tabular}{|c|c|c|c|c|c|c|c|c|c|c|c|}
\hline & $\begin{array}{l}\text { Number } \\
\text { of Goats }\end{array}$ & $\begin{array}{l}\text { AF Cycle } \\
\text { Length } \\
\text { (ms) }\end{array}$ & $\begin{array}{l}\text { AP During } \\
\text { AF } \\
\text { (ms) }\end{array}$ & $\begin{array}{l}\text { Excitable } \\
\text { Period } \\
\text { (ms) }\end{array}$ & $\begin{array}{l}\text { CV During } \\
\text { Capture } \\
(\mathrm{cm} / \mathrm{s})\end{array}$ & $\begin{array}{l}\text { Cond Time } \\
\text { During Capture } \\
\text { (ms) }\end{array}$ & $\begin{array}{l}\text { Atrial } \\
\text { Wave-Length } \\
\text { (cm) }\end{array}$ & $\begin{array}{l}\text { Atrial Circuit } \\
\text { Size } \\
\text { (cm) }\end{array}$ & $\begin{array}{l}\text { Excitable } \\
\text { Gap } \\
\text { (cm) }\end{array}$ & $\begin{array}{l}\text { Total Capture } \\
\text { Windows } \\
\text { (ms) }\end{array}$ & $\begin{array}{l}\text { Stable Capture } \\
\text { Window } \\
\text { (ms) }\end{array}$ \\
\hline Control & 5 & $91 \pm 8$ & $68 \pm 7$ & $23 \pm 5$ & $58 \pm 9$ & $24 \pm 7$ & $4.0 \pm 0.8$ & $5.3 \pm 0.9$ & $1.3 \pm 0.2$ & $\begin{array}{l}27 \pm 8 \\
(75-102)\end{array}$ & $\begin{array}{c}9 \pm 5^{8} \\
(85-96)\end{array}$ \\
\hline $\begin{array}{l}\text { After AFCL Increase } \\
\text { of about } 10 \%\end{array}$ & 5 & $\begin{array}{l}102 \pm 9 \\
(+11 \%)\end{array}$ & $\begin{array}{l}73 \pm 7 \\
(+7 \%)\end{array}$ & $\begin{array}{l}28 \pm 5 \\
(+25 \%)\end{array}$ & $\begin{array}{l}49 \pm 11 \\
(-17 \%)\end{array}$ & $\begin{array}{l}28 \pm 9 \\
(+18 \%)\end{array}$ & $\begin{array}{l}3.5 \pm 0.8 \\
(-11 \%)\end{array}$ & $\begin{array}{l}4.9 \pm 1.0 \\
(-7 \%)\end{array}$ & $\begin{array}{l}1.4 \pm 0.3 \\
(+5 \%)\end{array}$ & - & - \\
\hline $\begin{array}{l}\text { After AFCL Increase } \\
\text { of aboul } 20 \%\end{array}$ & 5 & $\begin{array}{l}110 \pm 9 \\
(+21 \%)\end{array}$ & $\begin{array}{l}72 \pm 10 \\
(+5 \%)\end{array}$ & $\begin{array}{l}38 \pm 7 \\
(+66 \%)\end{array}$ & $\begin{array}{l}45 \pm 11 \\
(-22 \%)\end{array}$ & $\begin{array}{l}29 \pm 10 \\
(+20 \%)\end{array}$ & $\begin{array}{c}3.3 \pm 0.9 \\
(-18 \%)\end{array}$ & $\begin{array}{l}5.0 \pm 1.3 \\
(-6 \%)\end{array}$ & $\begin{array}{l}1.7 \pm 0.5 \\
(+21 \%)\end{array}$ & - & - \\
\hline $\begin{array}{l}\text { After AFCL Increase } \\
\text { of about } 30 \%\end{array}$ & 5 & $\begin{array}{l}118 \pm 8 \\
(+30 \%)\end{array}$ & $\begin{array}{l}71 \pm 8 \\
(+4 \%)\end{array}$ & $\begin{array}{l}47 \pm 6 \\
(+111 \%)\end{array}$ & $\begin{array}{l}47 \pm 12 \\
(-19 \%)\end{array}$ & $\begin{array}{l}32 \pm 8 \\
(+38 \%)\end{array}$ & $\begin{array}{l}3.4 \pm 0.9 \\
(-17 \%)\end{array}$ & $\begin{array}{l}5.6 \pm 1.5 \\
(+5 \%)\end{array}$ & $\begin{array}{l}2.3 \pm 0.8 \\
(+72 \%)\end{array}$ & & - \\
\hline $\begin{array}{l}\text { At Maximum increase } \\
\text { of } \mathrm{AFCL}\end{array}$ & 5 & $\begin{array}{l}134 \pm 8 \\
(+48 \%) \\
*\end{array}$ & $\begin{array}{l}71 \pm 12 \\
(+4 \%) \\
\text { n.s. }\end{array}$ & $\begin{array}{l}63 \pm 9 \\
(+189 \%) \\
\end{array}$ & $\begin{array}{l}33 \pm 13 \\
(-44 \%)\end{array}$ & $\begin{array}{l}39 \pm 15 \\
(+62 \%) \\
\end{array}$ & $\begin{array}{l}2.4 \pm 1.1 \\
(-41 \%)\end{array}$ & $\begin{array}{l}4.3 \pm 1.7 \\
(-18 \%) \\
\text { n.s }\end{array}$ & $\begin{array}{l}2.0 \pm 0.7 \\
(+55 \%) \\
\text { n.s. }\end{array}$ & $\begin{array}{l}55 \pm 13 \\
(100-155)\end{array}$ & $\begin{array}{l}30 \pm 13 \\
(111-141)\end{array}$ \\
\hline
\end{tabular}

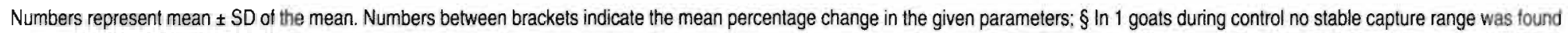

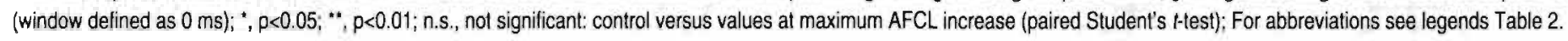


associated with a widening of the window of entrainment from $27 \pm 8$ to $55 \pm 13 \mathrm{~ms}$ (total capture window) and from $9 \pm 5$ to $30 \pm 13 \mathrm{~ms}$ (stable capture window) (both $\mathrm{p}<0.05)$.

The Effects of $d$-Sotalol

In Fig 7 a representative example of the effects of $d$-sotalol $(0.2 \mathrm{mg} / \mathrm{kg} / \mathrm{min})$ is given. Similar to hydroquinidine, cibenzoline and flecainide, $d$-sotalol gradually prolonged the AFCL from $71 \pm 1 \mathrm{~ms}$ during control to about $94 \mathrm{~ms}$ after $40-50$ minutes of infusion. At this time chronic AF terminated and sinus rhythm was restored. Interestingly, and quite unexpected the class III drug caused a shortening of the RPAF. Before administration of d-sotalol the atrial refractoriness during AF was $43 \pm 1 \mathrm{~ms}$. Just before restoration of sinus rhythm the $\mathrm{RP}_{\mathrm{AF}}$ had become as short as $33 \mathrm{~ms}$. As a result, the EP had widened markedly from $28 \pm 2$ to $59 \mathrm{~ms}(+113 \%)$. The middle panel shows that the $\mathrm{CV}_{\mathrm{AF}}$ increased from $40 \pm 4$ to $55 \mathrm{~cm} / \mathrm{s}$ which probably is due to an increase in the pacing interval and the widening of the EP. Due to the opposite effects on RP and $\mathrm{CV}$ the atrial wavelength during AF remained constant during $d$-sotalol infusion $(1.7 \pm 0.2$ versus $1.8 \mathrm{~cm})$. However, the atrial circuit size increased from $2.9 \pm 0.4$ to $5.1 \mathrm{~cm}(+76 \%)$ and the EG widened from $1.1 \pm 0.2$ to $3.2 \mathrm{~cm}(+190 \%)$.

Table 5 summarizes the effects of $d$-sotalol administration in 5 goats. Despite a clear prolongation of AFCL from $94 \pm 17$ to $116 \pm 19 \mathrm{~ms}(+24 \%, \mathrm{p}<0.001)$ the RPAF did not change significantly. As a result, the EP widened from $23 \pm 3$ to $47 \pm 11 \mathrm{~ms}$ $(+102 \%, \mathrm{p}<0.01)$. The atrial conduction properties during AF were not affected by $d$-sotalol, and also the slight increase in atrial wavelength from $4.5 \pm 1.9$ to $4.8 \pm 1.9$ $\mathrm{cm}(+7 \%)$ was not statistically significant. The estimated average circuit size prolonged from $5.9 \pm 2.3$ to $7.9 \pm 2.5 \mathrm{~cm}(+39 \%, \mathrm{p}<0.01)$, with a widening of the excitable gap from $1.4 \pm 0.5$ to $3.1 \pm 0.9 \mathrm{~cm}(+126 \%)$. As could be expected from the progressive widening of the EP and EG during AF, it became much easier to entrain the atria during AF during drug administration. The total and stable window of entrainment increased from $27 \pm 9 \mathrm{~ms}$ to $54 \pm 6 \mathrm{~ms}(\mathrm{p}<0.01)$ and from $7 \pm 10$ to 20 $\pm 14 \mathrm{~ms}(\mathrm{p}<0.05)$ respectively. Compared to hydroquinidine, cibenzoline and flecainide, $d$-sotalol exerted a relatively small effect on the average shortest pacing interval that could still entrain the atria during AF. This shortest pacing interval increased from $78 \mathrm{~ms}$ during control to $83 \mathrm{~ms}(6 \%)$ after $d$-sotalol versus an increase of $24 \%$ by hydroquinidine (from 78 to $97 \mathrm{~ms}$ ), $75 \%$ by cibenzoline (from 75 to 131 $\mathrm{ms}$ ) and $33 \%$ by flecainide (from 75 to $100 \mathrm{~ms}$ ).

\section{The Drug Effects Just Prior to Termination of Chronic AF}

In Table 6 the average effects of all four drugs are given on the various AF parameters for those goats that successfully cardioverted to sinus rhythm. Values are compared during chronic AF before drug administration and shortly before pharmacological restoration of sinus rhythm. Hydroquinidine and $d$-sotalol were successful in restoring 


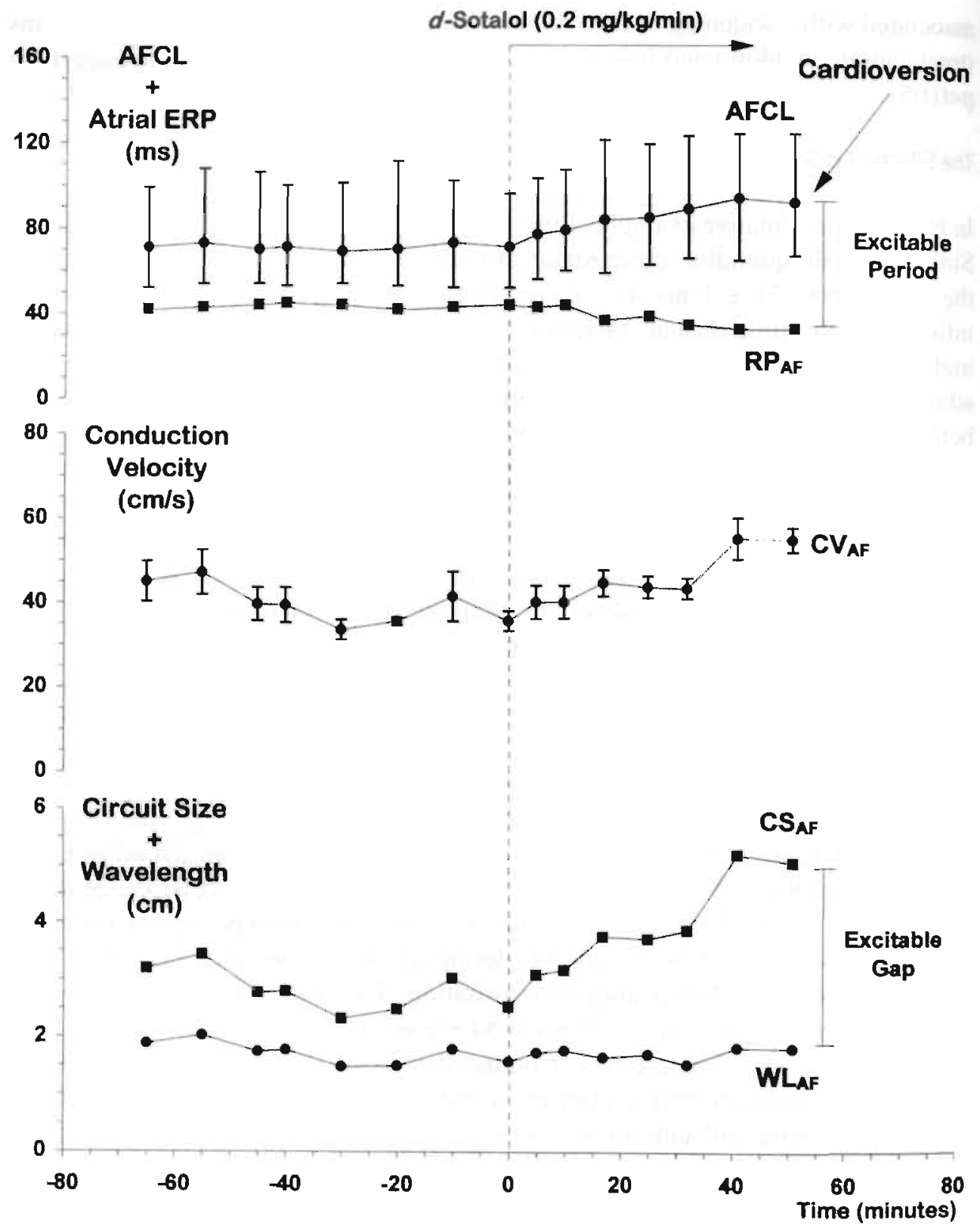

Figure 7. A, representative example of the effects of $d$-sotalol on AF cycle length, refractory period (upper panel) conduction velocity (middle panel), circuit size and wavelength during AF (lower panel). See text for description. 
Table 5. Effects of $d$-Sotalol on Atrial Fibrillation Parameters.

\begin{tabular}{|c|c|c|c|c|c|c|c|c|c|c|c|}
\hline & $\begin{array}{l}\text { Number } \\
\text { of Goats }\end{array}$ & $\begin{array}{l}\text { AF Cycle } \\
\text { Length } \\
\text { (ms) }\end{array}$ & $\begin{array}{l}\text { RP During } \\
\text { AF } \\
\text { (ms) }\end{array}$ & $\begin{array}{l}\text { Excitable } \\
\text { Period } \\
\text { (ms) }\end{array}$ & $\begin{array}{l}\text { CV During } \\
\text { Capture } \\
(\mathrm{cm} / \mathrm{s})\end{array}$ & $\begin{array}{l}\text { Cond Time } \\
\text { During Capture } \\
\text { (ms) }\end{array}$ & $\begin{array}{l}\text { Atrial } \\
\text { Wave-Length } \\
(\mathrm{cm})\end{array}$ & $\begin{array}{l}\text { Atrial Circuit } \\
\text { Size } \\
\text { (cm) }\end{array}$ & $\begin{array}{l}\text { Excitable } \\
\text { Gap } \\
\text { (cm) }\end{array}$ & $\begin{array}{l}\text { Total Capture } \\
\text { Windows } \\
\text { (ms) }\end{array}$ & $\begin{array}{l}\text { Stable Capture } \\
\text { Window } \\
\text { (ms) }\end{array}$ \\
\hline Control & 5 & $94 \pm 17$ & $71 \pm 18$ & $23 \pm 3$ & $63 \pm 24$ & $20 \pm 8$ & $4.5 \pm 1.9$ & $5.9 \pm 2.3$ & $1.4 \pm 0.5$ & $\begin{array}{l}27 \pm 9 \\
(78-105)\end{array}$ & $\begin{array}{l}7 \pm 10^{\S} \\
(99-116)\end{array}$ \\
\hline $\begin{array}{l}\text { After AFCL Increase } \\
\text { of About } 10 \%\end{array}$ & 5 & $\begin{array}{l}105 \pm 20 \\
(+12 \%)\end{array}$ & $\begin{array}{l}71 \pm 17 \\
(+1 \%)\end{array}$ & $\begin{array}{l}34 \pm 5 \\
(+47 \%)\end{array}$ & $\begin{array}{l}68 \pm 23 \\
(+11 \%)\end{array}$ & $\begin{array}{l}18 \pm 6 \\
(-7 \%)\end{array}$ & $\begin{array}{l}5.0 \pm 1.9 \\
(+12 \%)\end{array}$ & $\begin{array}{l}7.3 \pm 2.6 \\
(+23 \%)\end{array}$ & $\begin{array}{l}2.3 \pm 0.8 \\
(+64 \%)\end{array}$ & - & - \\
\hline $\begin{array}{l}\text { After AFCL Increase } \\
\text { of About } 20 \%\end{array}$ & 5 & $\begin{array}{l}112 \pm 20 \\
(+19 \%)\end{array}$ & $\begin{array}{l}71 \pm 18 \\
(-1 \%)\end{array}$ & $\begin{array}{l}44 \pm 7 \\
(+91 \%)\end{array}$ & $\begin{array}{l}65 \pm 24 \\
(+5 \%)\end{array}$ & $\begin{array}{l}20 \pm 8 \\
(-3 \%)\end{array}$ & $\begin{array}{l}4.7 \pm 2.0 \\
(+4 \%)\end{array}$ & $\begin{array}{l}7.3 \pm 2.6 \\
(+24 \%)\end{array}$ & $\begin{array}{l}2.6 \pm 0.8 \\
(+86 \%)\end{array}$ & - & - \\
\hline $\begin{array}{l}\text { After AFCL Increase } \\
\text { of About 30\% }\end{array}$ & 4 & $\begin{array}{l}119 \pm 21 \\
(+27 \%)\end{array}$ & $\begin{array}{l}68 \pm 22 \\
(-5 \%)\end{array}$ & $\begin{array}{l}51 \pm 10 \\
(+114 \%)\end{array}$ & $\begin{array}{l}74 \pm 19 \\
(+12 \%)\end{array}$ & $\begin{array}{l}17 \pm 6 \\
(+1 \%)\end{array}$ & $\begin{array}{l}5.2 \pm 2.0 \\
(+5 \%)\end{array}$ & $\begin{array}{l}8.7 \pm 2.1 \\
(+42 \%)\end{array}$ & $\begin{array}{l}3.6 \pm 0.2 \\
(+140 \%)\end{array}$ & - & - \\
\hline $\begin{array}{l}\text { At Maximum increase } \\
\text { of } \mathrm{AFCL}\end{array}$ & 5 & $\begin{array}{l}116 \pm 19 \\
(+24 \%) \\
* *\end{array}$ & $\begin{array}{l}70 \pm 20 \\
(-3 \%) \\
\text { n.s. }\end{array}$ & $\begin{array}{l}47 \pm 11 \\
(+102 \%) \\
\therefore\end{array}$ & $\begin{array}{l}68 \pm 21 \\
(+12 \%) \\
\text { n.s. }\end{array}$ & $\begin{array}{l}20 \pm 8 \\
(+1 \%) \\
\text { n.s. }\end{array}$ & $\begin{array}{l}4.8 \pm 1.9 \\
(+7 \%) \\
\text { n.s. }\end{array}$ & $\begin{array}{l}7.9 \pm 2.5 \\
(+39 \%)\end{array}$ & $\begin{array}{l}3.1 \pm 0.9 \\
(+126 \%)\end{array}$ & $\begin{array}{l}54 \pm 6 \\
(83-137)\end{array}$ & $\begin{array}{l}20 \pm 14^{\S} \\
(95-120)\end{array}$ \\
\hline
\end{tabular}

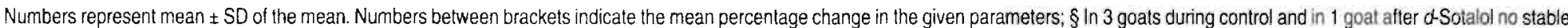

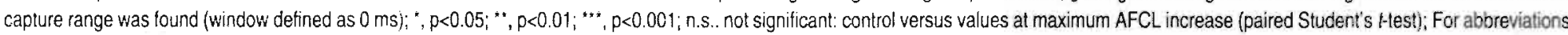
see legends Table 2. 
क् Table 6. Effects of Drugs on the Pre-cardioversion Values of AF Cycle Length, Refractory Period, Excitable Period, Conduction. Velocity, Wavelength, Circuit Size and Excitable Gap During AF.

\begin{tabular}{|c|c|c|c|c|c|c|}
\hline \multirow{2}{*}{$\begin{array}{l}\text { Restoration } \\
\text { of Sinus }\end{array}$} & \multicolumn{2}{|c|}{$\operatorname{AFCL}(\mathrm{ms})$} & \multicolumn{2}{|c|}{$\mathrm{RP}_{\mathrm{A} \mid}=(\mathrm{ms})$} & \multicolumn{2}{|c|}{ Excitable Period (ms) } \\
\hline & Chronic & Prior to & Chronic & Prior to & Chronic & Prior to \\
\hline Fhythm & $\mathrm{AF}$ & $\begin{array}{l}\text { Sinus } \\
\text { Ahythm }\end{array}$ & $\mathrm{AF}$ & Sinus & $\mathrm{AF}$ & Sinus \\
\hline
\end{tabular}

$C V_{A A}(\mathrm{~cm} / \mathrm{s})$

Wave Length $(\mathrm{cm})$

Circuit Size $(\mathrm{cm})$

Excitable Gap (cm)

Chronic Prior to

AF Sinus AF

Chronic

Prior to

Chronic Prior to Chronic Prior to

Ahythm Rhythm

Rhythm

Sinus

AF

Sinus

Rhythm

Sinus

Hydroqulnidine

$100 \%$

$(5 / 5)$

$96 \pm 1$

$130 \pm 17$

$67 \pm 15 \quad 74 \pm 19$

$29 \pm 10$

$56 \pm 15$

$68 \pm 21 \quad 63 \pm 18$

$4.8 \pm 1.8$

$4.9 \pm 2.1$
$+2 \%$

$6.8 \pm 2.3$

$8.1 \pm 2.42 .0 \pm 0.8$

$+30 \%$

Rhythm

\section{Cibenzoline}

$\begin{array}{lllllll}80 \% & 96 \pm 2 & 165 \pm 18 & 72 \pm 7 & 97 \pm 17 & 26 \pm 6 & 68 \pm 3 \\ (4 / 5) & & +69 \% & & +34 \% & & +176 \%\end{array}$

$65 \pm 13 \quad 39 \pm 13$

$4.7 \pm 1.3$

$3.9 \pm 1.7$

$6.3 \pm 1.4$

$6.6 \pm 2.6 \quad 1.6 \pm 0.2 \quad 2.7 \pm 0.9$

$-39 \%$

$-18 \%$

$+3 \%$

$67 \%$

Flecainide

$40 \%$

(2/5)

$96 \pm 8 \quad 125 \pm 2$

$+30 \%$

$68 \pm 10 \quad 71 \pm 17$

$+3 \%$

$28 \pm 2 \quad 54 \pm 16$

$+86^{\circ} \%$

$23 \pm 3 \quad 43 \pm 10$

$+88 \%$

(5/5)

$+20 \%$

$-2 \%$

$78 \pm 11$

$+31 \%$

n.s. $114 \%$

.
$50 \pm 6 \quad 31 \pm 11$

$3.4 \pm 0.9$

$2.4 \pm 1.3$

$-36 \%$

$4.8 \pm 0.9$

$3.9 \pm 1.4 \quad 1.4 \pm 0$.

$-22 \%$

$15 \pm 0$.

$63 \pm 24 \quad 66 \pm 23$

$+7 \%$

$4.5 \pm 1.9$

$4.8 \pm 2$

$+2 \%$

$7.7 \pm 3.0 \quad 1.4 \pm 0.5 \quad 2.9 \pm 1.0$

$+30 \%$

+110 :

$27 \pm 2 \quad 55 \pm 9114 \%$
$4.4 \pm 0.6$

$4.0 \pm 10$ $-12 \%$

n.s. n.s.

$6.6 \pm 1.6 \quad 1.6 \pm 0.2 \quad 2.6 \pm 07$ $+10 \%$ $+70 \%$

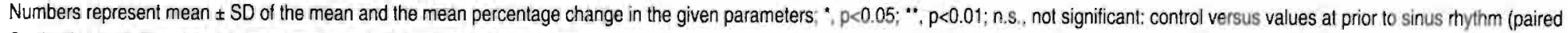
Student's t-test); For abbreviations see legends Table 2. 
sinus rhythm in 5 out of 5 goats, whereas cibenzoline and flecainide were effective in 4 and 2 out of 5 goats. Remarkably, the efficacy of the drugs to cardiovert AF was not related to the effects on AFCL, $\mathrm{RP}_{\mathrm{AF}}, \mathrm{CV}_{\mathrm{AF}}$ and $\mathrm{WL}_{\mathrm{AF}}$. The high successrate of cardioversion by hydroquinidine and $d$-sotalol seemed to be associated with a marked prolongation of atrial circuit size during AF of about $30 \%$. On the other hand, 4 of the 5 cibenzoline treated animals and 2 of the 5 goats treated with flecainide successfully cardioverted despite the fact that atrial $\mathrm{CS}_{\mathrm{AF}}$ did not prolong and even shortened in the case of flecainide. The only parameter that for all drugs was associated with cardioversion of $\mathrm{AF}$ was a prolongation of the excitable period. Due to a marked slowing of the $\mathrm{CV}_{\mathrm{AF}}$, flecainide had no clear effects on the EG despite a marked widening of the EP during AF.

Relation Between Changes in AFCL and Refractory Period During AF

If the electrophysiological mechanism of AF is based on (multiple) functional reentrant circuits with only a small excitable period, one would expect that changes in AFCL would be related to changes in atrial refractoriness. A lengthening of the $\mathrm{RP}_{\mathrm{AF}}$ would cause a prolongation of the AFCL whereas a shortening of the $\mathrm{RP}_{\mathrm{AF}}$ would leald to a shortening of the AFCL. To evaluate whether the drug-induced changes in AFCL were caused by changes in $\mathrm{RP}_{\mathrm{AF}}$, we examined the relationship between these two parameters. In Fig 8 , for all goats, the relative changes in atrial effective refractory period during AF are plotted against the changes in AFCL. With all drugs the relative increase in $\mathrm{RP}_{\mathrm{AF}}$ was clearly less than the prolongation of the AFCL. While during cibenzoline infusion still a clear relation between the changes in AFCL and RP ${ }_{A F}$ was seen, such a relationship was less clear for the other drugs.

\section{Relation Between Changes in AFCL and Conduction Velocity During AF}

On the other hand, if $\mathrm{AF}$ is based on reentrant circuits with a large excitable gap (e.g. anatomical reentry), changes of AFCL should be related to changes in the atrial conduction velocity during AF. In Fig 9, for all drugs, the relative changes in conduction velocity during entrainment of $\mathrm{AF}$ are plotted against the changes in AFCL. During flecainide administration, the changes in AFCL seemed clearly related to a slowing of the $\mathrm{CV}_{\mathrm{AF}}$ and all data points were lying around the line of identity. $\mathrm{A}$ similar pattern was seen during the initial phase of cibenzoline infusion (from $0-30 \%$ $\mathrm{AFCL}$ prolongation) whereas thereafter the AFCL continued to increase independent of a slowing of $\mathrm{CV}_{\mathrm{AF}}$. No clear relationship between changes in $\mathrm{AFCL}$ and $\mathrm{CV}_{\mathrm{AF}}$ were found during administration of hydroquinidine or $d$-sotalol.

Relation between Changes in AFCL and Excitable Period and Excitable Gap

In Fig 10 and 11 the relation between the prolongation in AFCL, and respectively the excitable period and the excitable gap are plotted. In each panel, the linear regression line is plotted together with its slope. As can be clearly seen, all four anti-fibrillatory drugs progressively increased both the excitable period and the 

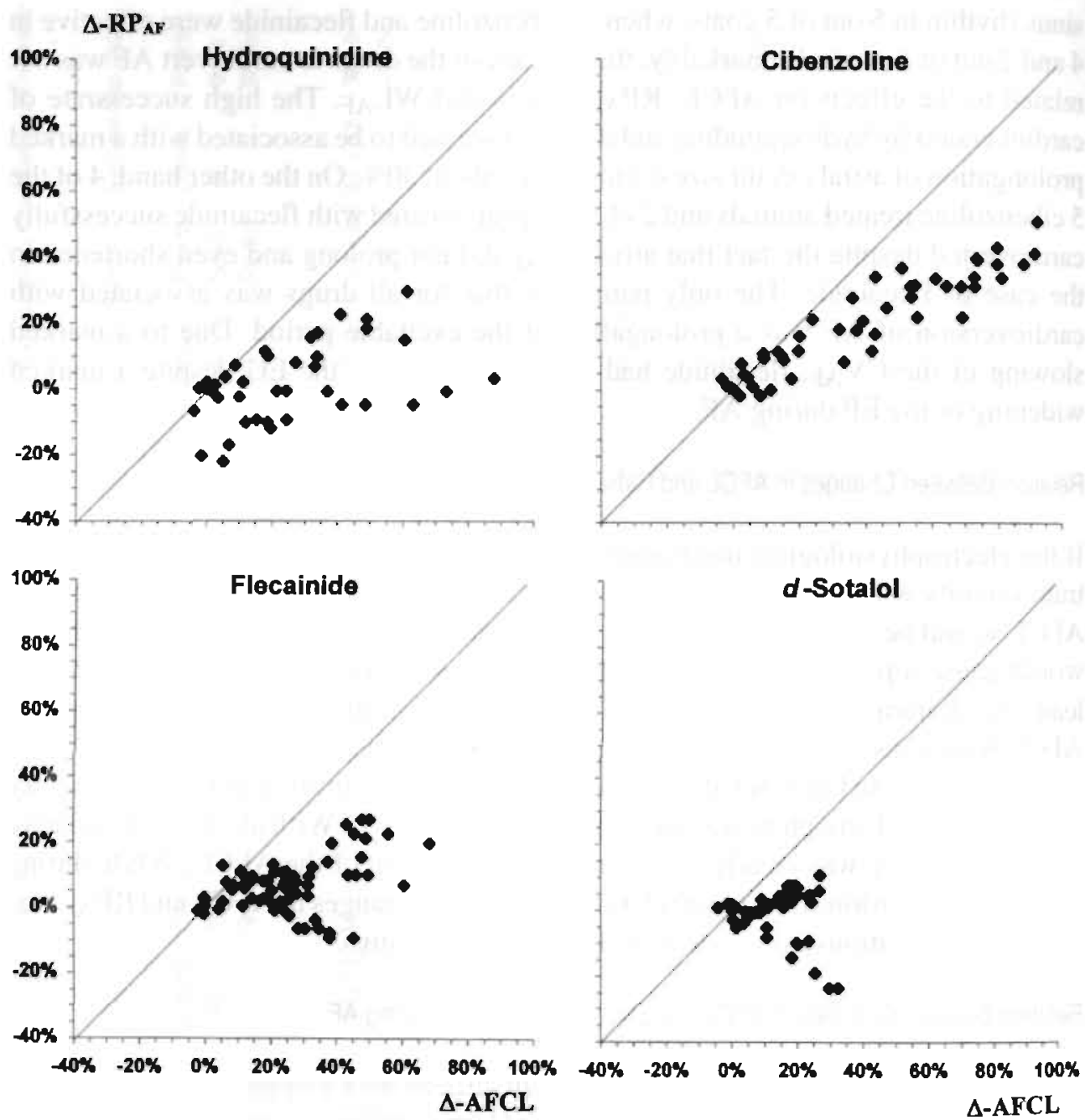

Figure 8. Correlation between relative changes in atrial fibrillation cycle length ( $\triangle D$-AFCL: horizontal axis) and atrial refraciory period during AF ( $\triangle-R P_{A F}$, vertical axis). Data for all drugs are from 5 goats. In each panel all individual data points as determined during the continuos infusion of the drugs are given. See text description.

excitable gap. The most pronounced effects on the excitable period were observed with $d$-sotalol and flecainide (slopes 3.8 and 3.6). On the other hand (Fig 11), the excitable gap was most markedly widened by $d$-sotalol and hydroquinidine (slopes 4.5 and 3.2). Flecainide and cibenzoline, increased the EG with about the same amount as the AFCL (slopes 1.3 and 0.9 respectively) In summary, due to the relatively small effects of $d$-sotalol and flecainide on RPAF, these drugs were most effective in prolonging the EP during AF. On the other hand, $d$-sotalol and hydroquinidine had relatively small effects on $\mathrm{CV}_{\mathrm{AF}}$ and as a result most effective widened the $E G_{\mathrm{AF}}$. 

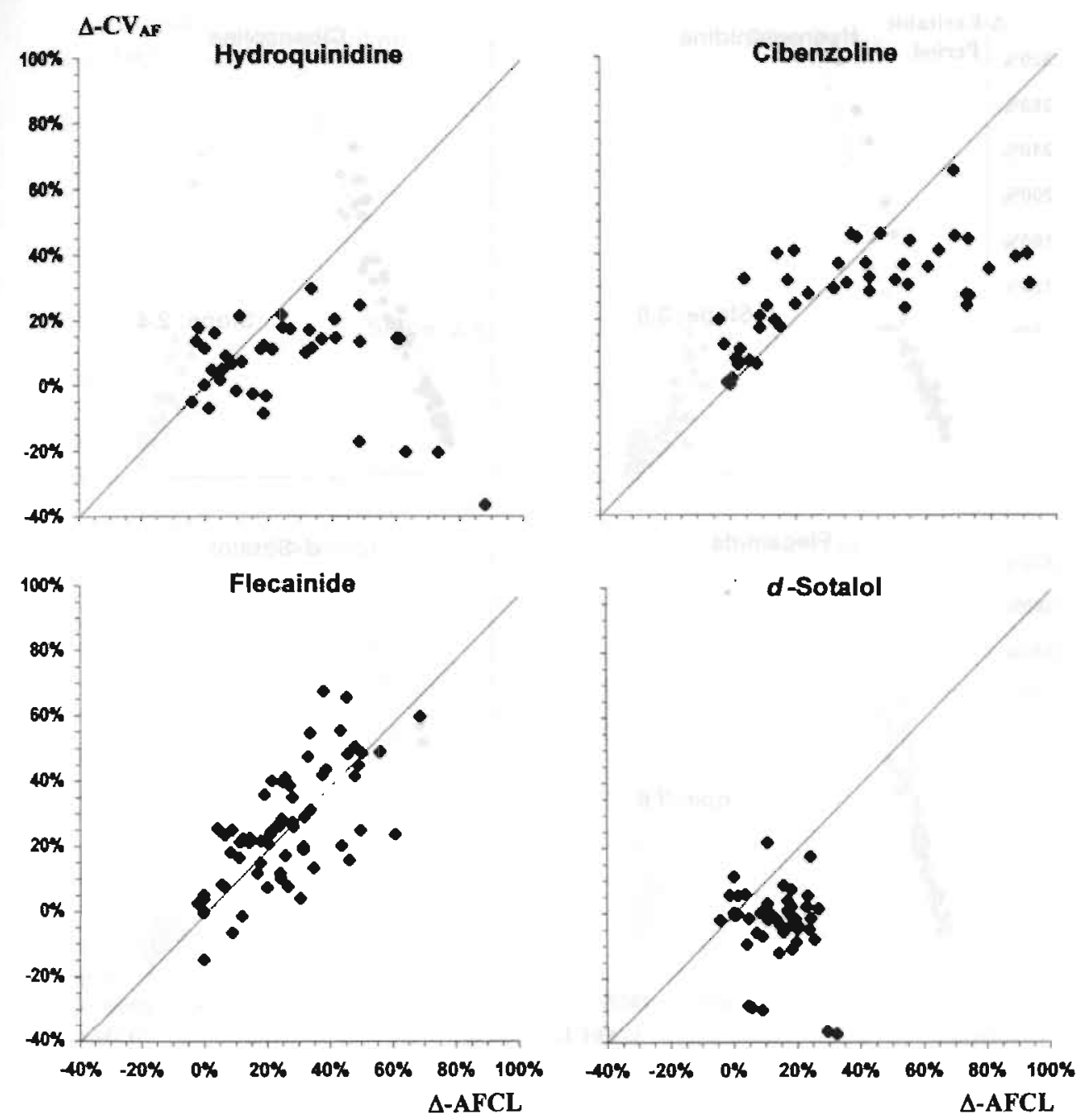

Figure 9. Correlation between the relative changes in atrial fibrillation cycle length ( $\triangle$-AFCL; horizontal axis) and atrial conduction velocity during entrainment of AF ( $\triangle-C V_{A F}$, vertical axis). Data for all drugs are from 5 goats. In each panel all individual data points as determined during continuous infusion of the drugs are givent. See text far further description.

Increase in Excitable Period and Excitable Gap by Drugs

Although all drugs seemed to widen the EP and/or EG during atrial fibrillation, the externally applied stimuli are artificial and might not represent the 'true' or functional excitable gap during atrial fibrillation. However, some other observations given below further support the concept of a drug-induced widening of the EP and EG during AF. In Fig 12 an example is given of a sudden acceleration of AF by a single early premature stimulus after administration of hydroquinidine. The tracing shows an 

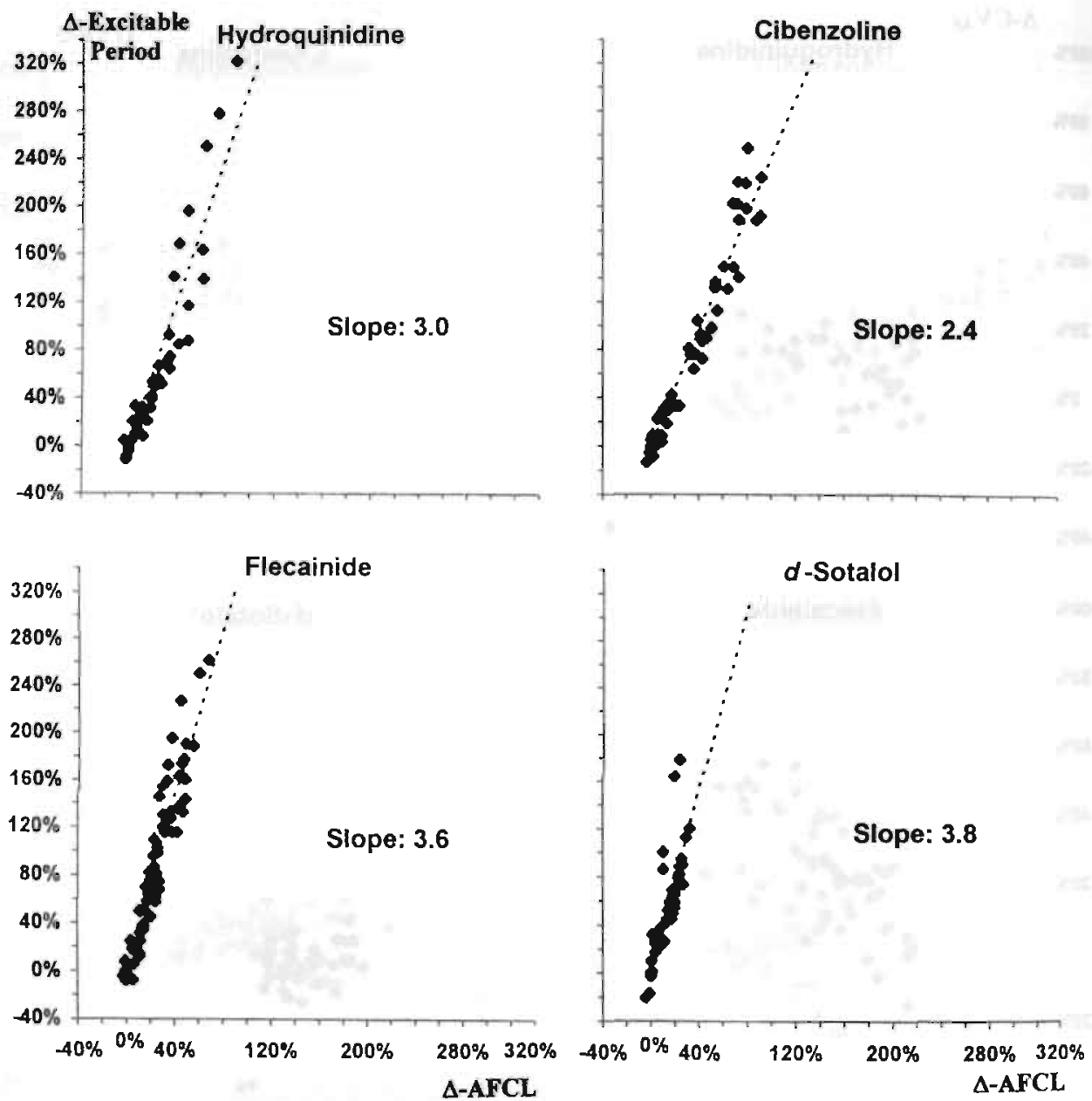

Figure 10. The correlation between the relative changes in AFCL and excitable period during AF. The dotted lines are linear regression lines. All drugs increased the excitable period during AF to a much larger extent than the AFCL. The relative increase in excitable period was largest for $d$-sotalol and flecainide (slope 3.8 and 3.6 ) and slightly smaller for hydroquinidine and cibenzoline (slope 3.0 and 2.4)

unipolar atrial electrogram recorded during $\mathrm{AF}$ at a distance of $4 \mathrm{~mm}$ from the site where a single premature stimulus was applied. After 40 minutes of hydroquinidine infusion $(0.2 \mathrm{mg} / \mathrm{kg} / \mathrm{min})$ the median AFCL had increased from $70 \mathrm{~ms}$ to $130-140 \mathrm{~ms}$. A premature stimulus was given during the measurement of the $\mathrm{RP}_{\mathrm{AF}}$. In the example shown, the stimulus with a coupling interval of $48 \mathrm{~ms}$ not only captured the atrium but suddenly and markedly accelerated the rate of AF. The plot at the bottom shows the relatively long AFCL of $130-140 \mathrm{~ms}$ was suddenly shortened by the stimulus to less than $70 \mathrm{~ms}$. This observation strongly supports the presence of a large drug-induced 'functional' excitable period during AF. 

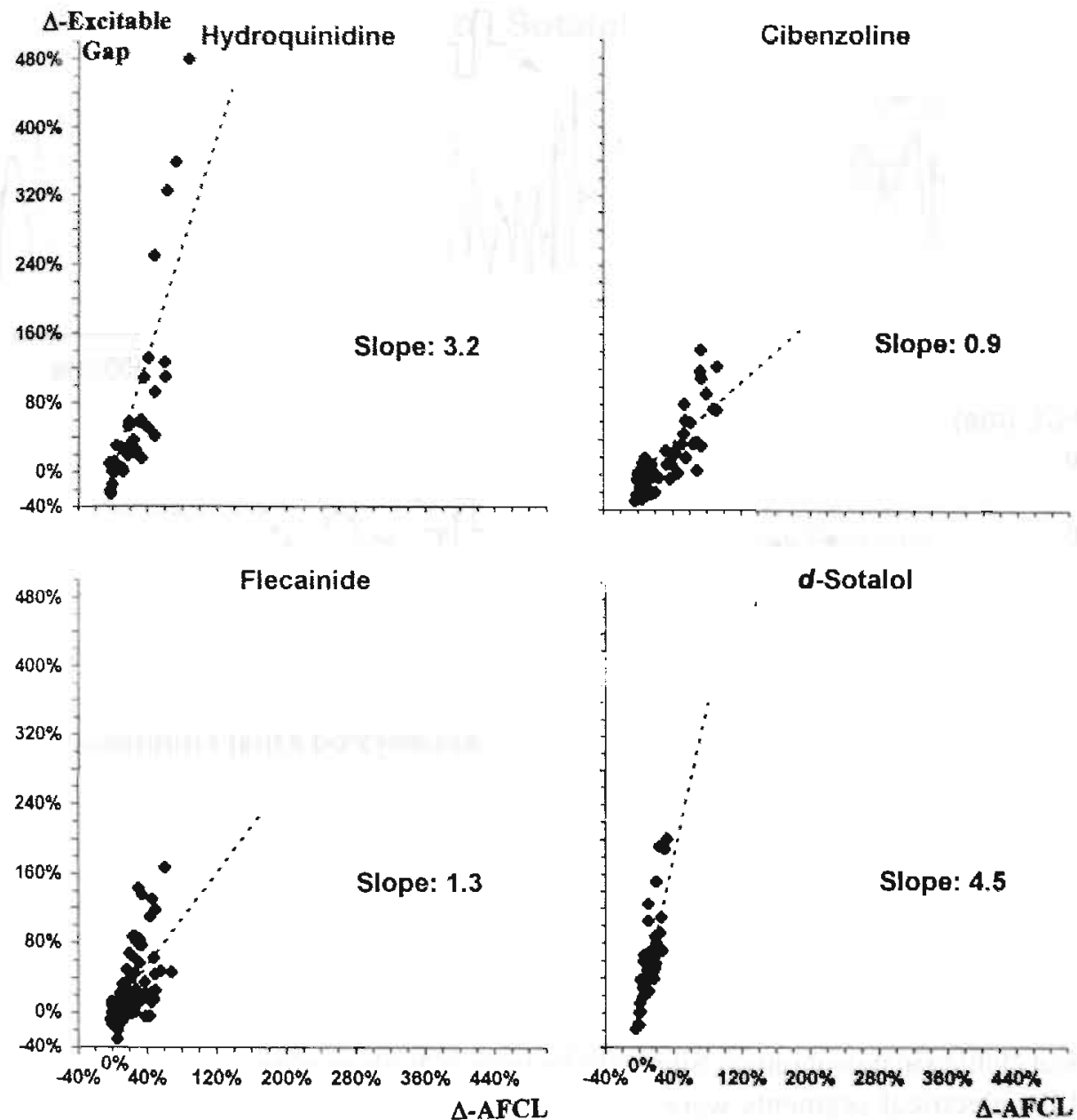

Figure 11. The correlation between the relative changes in AFCL and excitable gap during AF. $d$-Sotalo 3 and hydroquinidine widened the excitable gap most markedly, with slopes of 4.5 and 3.2 respectively. Due to a marked depression of the atrial conduction velocity during $\mathrm{AF}$, flecainide and cibenzoline had a relatively small effect on the excitable gap (slopes 1.3 and 0.9 ).

In Fig 13 an example of 'spontaneous acceleration' of AF is shown. In this case, $d$-sotalol $(0.2 \mathrm{mg} / \mathrm{kg} / \mathrm{min})$ had been administered for 55 minutes and the median AFCL was increased from $70 \mathrm{~ms}$ during control to $86 \mathrm{~ms}$ (histogram at bottom of Fig 13). However, the fibrillation rate fluctuated considerably and the AFCL sometimes became as long as 110-120 ms (upper tracing and left part of AFCL plot). However, the slow rate of AF did spontaneously accelerate within a few beats to an average AFCL of about $70 \mathrm{~ms}$ (lower tracing and right part of AFCL plot). During the slow phase of the arrhythmia (upper tracing) subsequent activations showed a rather similar morphology with a single steep deflection of high amplitude separated by long iso-electrical segments. However, during fast/accelerated AF there was a clear beat 

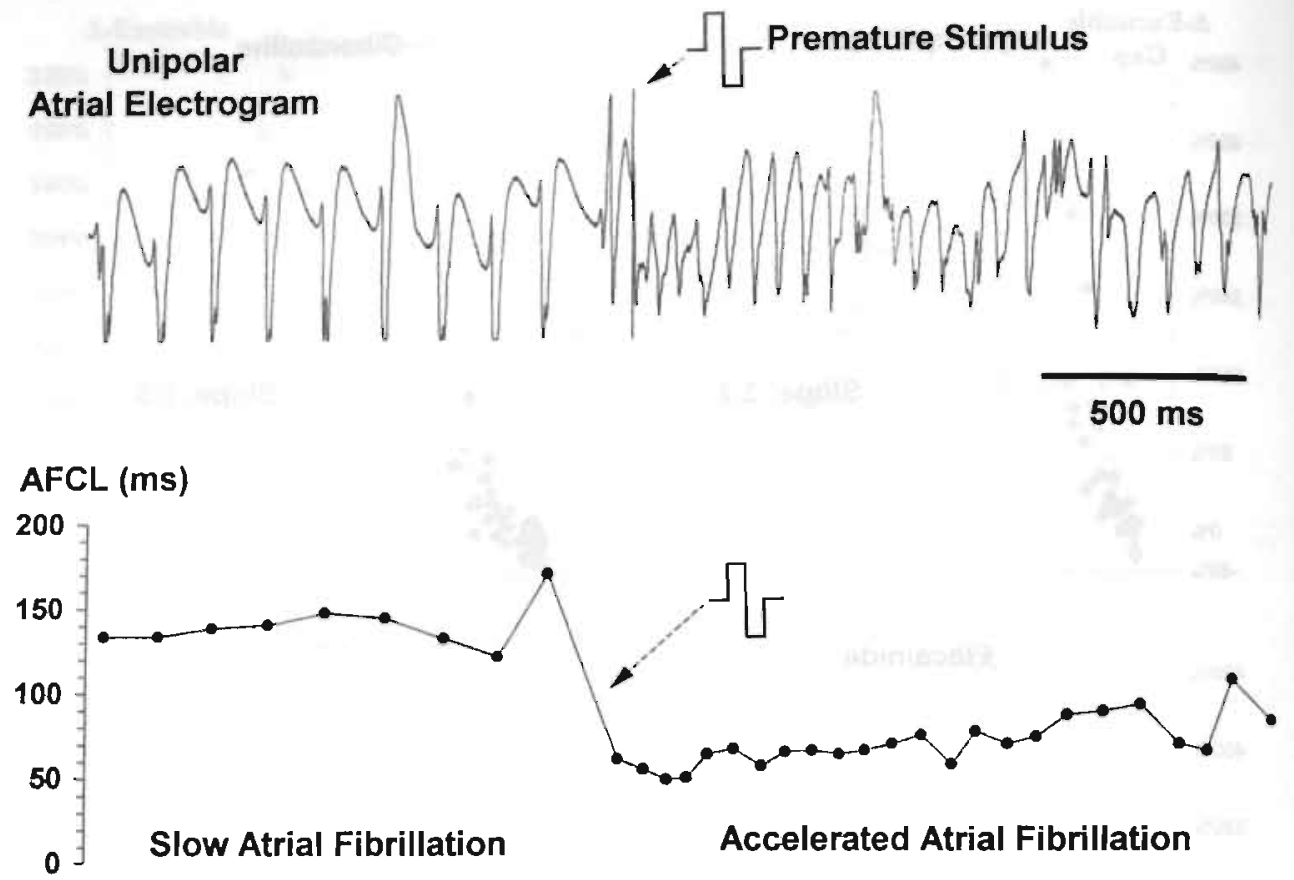

Figure 12. Acceleration of AF by a single premature stimulus after 40 minutes of hydroquinidine infusion ( 0.2 $\mathrm{mg} / \mathrm{kg} / \mathrm{min}$ ). The upper tracing shows an unipolar electrogram of AF recorded at $4 \mathrm{~mm}$ from the pacing site. The median AFCL had increased from $70 \mathrm{~ms}$ during control to $130-140 \mathrm{~ms}$. A single premature stimulus (coupling interval $48 \mathrm{~ms}$ ) captured the atrium and induced a marked acceleration of the rate of A.F. At the bottom an interval plot of the successive AF intervals is given during the acceleration of AF.

to beat change in morphology. Single deflections of high amplitude were less common and iso-electrical segments were shorter or had disappeared. These changes in the electrogram morphology suggest that, during slow AF the atrium was activated uniformly by broad wavefronts (type I fibrillation), ${ }^{15,16}$ while during rapid AF the activation becomes more complex (type II or III fibrillation). ${ }^{15,16}$ In this example the transition between slow and fast AF occurred frequently resulting in a bimodal histogram as shown at the bottom of Fig 13. 


\section{d - Sotalol}
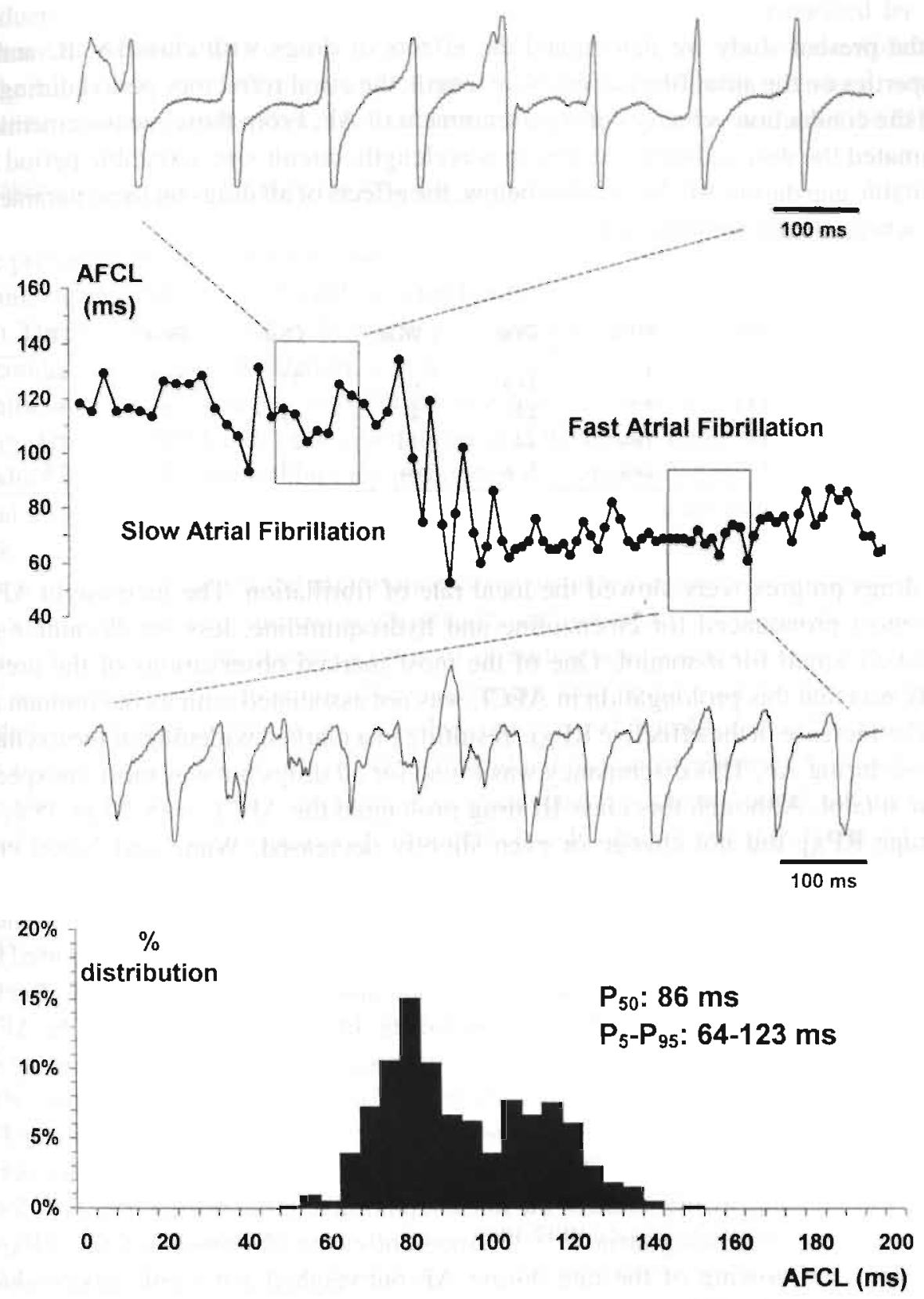

Figure 13. Spontaneous acceleration of AF after 55 minutes of $d$-sotalol administration $(0.2 \mathrm{mg} / \mathrm{kg} / \mathrm{min})$. Aithough the median AFCL was increased by the drug from $70 \mathrm{~ms}$ during control to $86 \mathrm{~ms}$ (histogram at bottom) the fibrillation rate fluctuated considerably and the AFCL sometimes became as long as 110-120 ms (upper tracing and left part of AFCL plot). However, the slow rate of AF did spontaneously accelerate within a few beats to an average AFCL of about $70 \mathrm{~ms}$ (lower tracing and right pan of AFCL plot). See text for further discussion. 


\section{Discussion}

In the present study we determined the effects of drugs with class IA, IC and III properties on the atrial fibrillation cycle length, the atrial refractory period during AF and the conduction velocity during entrainment of AF. From these measurements we estimated the drug induced changes in wavelength, circuit size, excitable period and excitable gap during AF. In the table below, the effects of all drugs on these parameters are schematically summarized.

\begin{tabular}{llllllll} 
& AFCL & RPAF & CV AF & WLAF & CS AF & EPAF & EG AF \\
\hline Hydroquinidine & $\uparrow \uparrow \uparrow$ & $\uparrow$ & $\downarrow \leftrightarrow$ & $\leftrightarrow$ & $\uparrow \uparrow$ & $\uparrow \uparrow \uparrow$ & $\uparrow \uparrow$ \\
Cibenzoline & $\uparrow \uparrow \uparrow$ & $\uparrow \uparrow$ & $\downarrow \downarrow$ & $\downarrow$ & $\leftrightarrow$ & $\uparrow \uparrow \uparrow$ & $\uparrow$ \\
Flecainide & $\uparrow \uparrow$ & $\uparrow \leftrightarrow$ & $\downarrow \downarrow$ & $\downarrow \downarrow$ & $\downarrow$ & $\uparrow \uparrow \uparrow$ & $\uparrow \leftrightarrow$ \\
$d$ Sotalol & $\uparrow$ & $\downarrow \leftrightarrow$ & $\uparrow \leftrightarrow$ & $\leftrightarrow$ & $\uparrow \uparrow$ & $\uparrow \uparrow \uparrow$ & $\uparrow \uparrow$ \\
\hline
\end{tabular}

All drugs progressively slowed the local rate of fibrillation. The increase in AFCL was most pronounced for cibenzoline and hydroquinidine, less for flecainide and relatively small for $d$-sotalol. One of the most marked observations of the present study was that this prolongation in AFCL was not associated with a concomitant and similar increase in the effective $\mathrm{RP}_{\mathrm{AF}}$, resulting in a marked widening of the excitable period during AF. This discrepancy was found for all drugs but was most unexpected for $d$-sotalol. Although this class III drug prolonged the AFCL with 20 to $25 \%$, the average RP $\mathrm{AF}_{\mathrm{AF}}$ did not change or even slightly decreased. Wang and Nattel et al. recently studied the mechanisms of action of several anti-fibrillatory drugs in a canine model of vagally mediated AF. Similar to our results, class I drugs were found to prolong the AFCL significantly more than $d, l$-sotalol $.8,9$ However, they reported that the AFCL prolongation was related to a comparable increase in the atrial effective refractory period as measured during rapid pacing. In contrast, in our study the AFCL prolongation was rather associated with an increase in the excitable period during AF. In some of the animals treated with $d$-sotalol and flecainide, the prolongation of the AFCL was even associated with a shortening of the atrial refractory period (see Figs 7 and 8 , and Tables 4 and 5). This paradoxical shortening of the refractory period might be explained by inversion of the rate adaptation of atrial refractoriness as found in chronically fibrillating atria. ${ }^{10,17-19}$ Apparently, the shortening of the $\mathrm{RP}_{\mathrm{AF}}$ in response to a slowing of the rate during AF outweighed a possible drug-induced prolongation of the $\mathrm{RP}_{\mathrm{AF}}$.

Drug-induced changes in intra-atrial conduction properties were estimated during stable entrainment of AF. The advantage of this method is that the conduction velocity is not affected by the natural beat to beat changes in AFCL, direction of wavefront propagation or by a varying degree of fragmentation during AF. Whereas cibenzoline and flecainide (class IC) both markedly slowed $\mathrm{CV}_{\mathrm{AF}}$ (Table 3 and 4), the effects of 
hydroquinidine on $\mathrm{CV}_{\mathrm{AF}}$ were only minor (Table 2). Apparently, the depression of conduction by this class IA drug was almost completely counterbalanced by the improvement of conduction as a result of the prolongation of the AFCL and a widening of the EP during AF. During $d$-sotalol infusion the $\mathrm{CV}_{\mathrm{AF}}$ slightly increased, which could be explained by the slowing of the fibrillation rate and the widening of the EPAF.

\section{Anti-fibrillatory Drugs do not Prolong the Atrial Wavelength During Chronic AF}

The present data show that the anti-fibrillatory actions of class IA, IC and III drugs during chronic AF are not based on a prolongation of the atrial wavelength (Tables 2-6). The increase of the $\mathrm{RP}_{\mathrm{AF}}$ by hydroquinidine was counterbalanced by the slowing of conduction during fibrillation, whereas $d$-sotalol did not affect both parameters significantly. As a result, the wavelength was not significantly affected by these two drugs. On the other hand, both cibenzoline and flecainide depressed the intra-atrial conduction velocity more than they prolonged the refractory period. As a result, the atrial wavelength during AF was actually shortened by these drugs with about 20 and $40 \%$.

Rensma et al. ${ }^{5}$ studied the importance of the atrial wavelength for the inducibility of atrial reentrant arrhythmias in chronically instrumented conscious dogs and reported that the anti-fibrillatory actions of quinidine and $d$-sotalol were based on a prolongation of the shortest possible wavelength with about $40-45 \%$. In subsequent studies these observations were extended and in 1991 Kirchhof et al. ${ }^{6}$ studied the anti-fibrillatory actions of ORG 7797 on the inducibility and stability of AF and related these drug effects to the electrophysiological changes during atrial pacing. The anti-fibrillatory actions of this experimental class IC drug seemed to be based on a prolongation of the wavelength at the maximal pacing rate with about $40 \%$ (prolongation of the minimal wavelength). More recently, these observations were extended by Wang and co-workers ${ }^{7-9}$ who concluded that the mechanism of the anti-fibrillatory action of procainamide, flecainide, propafenone, $d, l$-sotalol and ambasilide was based on a prolongation of the atrial wavelength at high atrial rates. Although the class IA and III agents exerted a reverse use-dependent effect on atrial refractoriness and prolonged the wavelength at slow rates more than at fast rates. class IC drugs caused a tachycardia-dependent increase in the atrial refractory period which outweighed the depression in conduction velocity and thus increased the wavelength at rapid rates. Mapping the activation of the atria during AF showed a significant reduction in the number of circuits and it was concluded that the anti-fibrillatory action of these drugs was primarily based on an increase in wavelength which resulted in an increase in the size and a decrease of the number of reentrant circuits, thus increasing the chances that reentry was interrupted and AF was terminated.

In the present study we could find no support for an important role of the atrial wavelength in the stability of AF. All four anti-fibrillatory drugs cardioverted chronic $\mathrm{AF}$ without any significant prolongation of the wavelength during AF (Table 6). In a previous study in chronically fibrillating goats, we showed that after successful 
pharmacological cardioversion of AF the wavelength was still abnormally short (7 $9 \mathrm{~cm})$. The presence of such a short wavelength after cardioversion was associated with a high inducibility of AF by a single premature stimulus up to $100 \%$ (see Chapter 6).

Possible Mechanisms of the Widening of the Excitable Period During Atrial Fibrillation by Class I and III drugs

Several studies have shown that during AF a small excitable period is present. 13,14 Mapping of the atrial activation pattern during AF has revealed that both functional and anatomical circuits are present during AF. $3,15,20,21$ The average width of the excitable period during $\mathrm{AF}$ is determined by the average excitable period in both functional (small excitable gap) and anatomical reentrant circuits (larger excitable gap) and by the relative contribution of these two kind of circuits during AF.

1) The EP in an anatomical reentrant circuit is determined by the difference between the average conduction time around the anatomical obstacle and the refractory period. Drugs that slow the conduction velocity can widen the EP by prolonging the revolution time around the anatomical obstacle. The observed prolongation of the $\mathrm{EP}_{\mathrm{AF}}$ by Class 1 drugs (especially IC) might thus be explained by a widening of the $\mathrm{EP}$ in anatomical reentrant circuits which may be present during $\mathrm{AF}$.

2) Functional reentrant circuits during AF can either be based on "leading circle reentry' 22 or on 'random reentry'. ${ }^{23}$ During leading circle reentry, the wavefront is running around a line of functional conduction block and has to make sharp U-turns at the pivoting points. If the amount of excitatory current of the small number of cells at the pivoting point is not sufficient to excite the larger number of cells around the corner, the wavefront has to postpone its turn, thereby introducing a small excitable period in the circuit. Drugs that depress the upstroke of the action potential (decrease in excitatory current) or increase the amount of current needed to be excited (excitability) will affect wavefront curvature and thus increase the EP. The widening of the $\mathrm{EP}_{\mathrm{AF}}$ might thus be explained by a depression of the upstroke of the action potential which is likely to occur after administration of class I drugs. Functional reentry during AF can also be based on random reentry, during which wavelets activate areas which previously have been activated by other wavelets. During this type of reentry an excitable gap may occur because cells, after restoring their excitability, have to wait until another wavelet reaches them to excite them again ( $\mathrm{EP}=$ waiting time). Drugs which decrease the number of wavelets that are present during AF, may increase the $E_{\mathrm{AF}}$ because the chance that a wavelet is directly available after restoration of excitability will be less. The widening of the EP $\mathrm{AF}_{\mathrm{AF}}$ by Class IA and III drugs (such as hydroquinidine and $d$-sotalol) might thus be explained by an increase in the average circuit size, and thus a decrease in the number of wavelets present during AF. Even if, during random reentry, a wavelet reenters another wavelet directly after restoration of the excitability, an excitable period may develop due to a beat to beat change in direction of subsequent activations during AF. While at the point of reentry the cycle 
length is more or less similar to the refractory period, at more distant sites the local $\mathrm{AF}$ cycle length is determined by the sum of the refractory period plus the antegrade and retrograde conduction times to and from the site of reentry (see Fig 10 of reference $\# 15$ for an illustration). In this case, Class I drugs can widen the $\mathrm{EP}_{\mathrm{AF}}$ by a depression of the conduction velocity which increases the antegrade and retrograde conduction times from the site of reentry ( $\mathrm{EP}=$ conduction time).

3) An additional reason for a widening of the $\mathrm{EP}_{\mathrm{AF}}$ may be that drugs decrease the number of functional reentrant circuits (which usually have a relatively small EP) and increase the number of anatomical reentrant circuits (which have a relatively large EP) during AF. A widening of the wavefront curvature may increase the size of a functional circuit to such an extend that anatomical obstacles become incorporated within the circuit (shift from functional to anatomical circuit). In this case, the circuit size and the EP will increase to a much larger extend than would be expected on the effects on wavefront curvature alone. Thus, a widening of the excitable period during AF by class I and III drugs can be the result of: 1) a slowing of the conduction velocity in anatomic circuits, 2) an increase in the conduction delay of functional circuits at sharp U-turns (leading circle reentry), 3) a prolongation of the average waiting time during random reentry or a prolongation of the conduction time to and from the site of random reentry, or 4) a shift from functional to anatomical reentrant circuits.

Is a Widening of the Excitable Period During AF Anti-fibrillatory?

Although. hydroquinidine, cibenzoline, flecainide and $d$-sotalol were all effective in cardioverting chronic AF, they exerted different effects on the AFCL, RPAF, CV $\mathrm{AF}$, $\mathrm{WL}_{\mathrm{AF}}$ and $\mathrm{CS}_{\mathrm{AF}}$. The only effect that these four drugs had in common was that they all widened the excitable period during AF. This observation suggests that the widening of the excitable period might be important for the anti-fibrillatory action of these drugs. According to Moe's multiple wavelet hypothesis, the stability of atrial fibrillation is determined by the number of wavelets that is present during AF. If only a small number of wavelets is present during AF the chances for simultaneous die out are relatively high, whereas with a large number of wavelets present these chances are low. Several studies have shown that during AF the number of wavelets is varying considerably and that the average number of wavelets depends on the dynamic balance between dying out of old wavelets and the genesis of new ones. ${ }^{3,15,24}$

A widening of the excitable period might be anti-fibrillatory because it may prevent the genesis of new wavelets. Computer simulations and mapping studies have shown that new wavelets can be formed when existing waves divide around areas of functional conduction block. 3,15,24 Functional conduction block during AF will occur if the local AF-interval becomes shorter than the local refractory period. If a wavelet encounters such an area of local refractoriness, it may fractionate thereby increasing the number of wavelets during AF. On the other hand, in the presence of a wide excitable period during $\mathrm{AF}$, the chance that a wavelet will encounter an area of functional conduction block is very small. As a result, fractionation of wavelets may 
occur less frequently which is likely to prevent the genesis of new wavelets. Recent observations by Wang et al. ${ }^{8}$ might support a role of an EP in the termination of AF. They reported that during AF 'block in a critical zone led to recovery of the remaining atrial tissue, with consequent rapid, symmetrical activation precluding the possibility of further reentrant cycles."

\section{Acknowledgments}

The authors would like to thank Dr. N. Kormoss from Continental Pharma/Searle Belgium for supplying the ampuls of Cipralan ${ }^{\circledR}$ (cibenzoline) and Dr. C. Mouton Dorey from Laboratoires Houdé for supplying Serecor ${ }^{\circledR}$ (hydroquinidine). The advice and discussion of Clifford Garratt is greatly acknowledged.

\section{References}

1 Moe GK, Abildskov JA: Atrial fibrillation as a self-sustaining arrhythmias independent of focal discharge. Am Heart J 1959:58:59-70

2 Moe GK: On the multiple wavelet hypothesis of atrial fibrillation. Arch Int Pharmacodyn Ther 1962;140:183-188

3 Allessie MA, Lammers WJEP, Bonke FIM, Hollen SJ: Experimental evaluation of Moe's multiple wavelet hypothesis of atrial fibrillation. in Zipes DP, Jalife J (eds): Cardiac Electrophysiology and Arrhythmias. NY. Grune \& Stratton, 1985, pp 265-275

4 Smeets JLRM, Allessie MA, Lammers WJEP, Bonke FIM, Hollen SJ: The wavelength of the cardiac impulse and reentrant arrhythmias in isolated rabbit atrium. The role of heart rate, autonomic transmitters, temperature, and potassium. Circ Res 1986;58:96-108

5 Rensma PL, Allessie MA, Lammers WJEP. Bonke FIM. Schalij MJ: Length of excitation wave and susceptibility to reentrant atrial arrhythmias in normal conscious dogs. Circ Res 1988;62:395-410

6 Kirchhof CJHJ, Wijffels M, Brugada J, Planellas J, Allessie MA: Mode of action of a new class IC drug (ORG 7797) against atrial fibrillation in conscious dogs. J Cardiovasc Phamacol 1991:17:116-124

7 Wang Z. Page PL. Nattel S: Mechanism of flecainide's antiarrhythmic action in experimental atrial fibrillation. Circ Res 1992;71:271-287

8 Wang J, Bourne GW, Wang Z. Villemaire C. Talajic M, Nattel S: Comparative mechanisms of antiarthythmic drug action in experimental atrial fibrillation. Circulation 1993:88: 1030-1044

9 Wang J. Feng J. Nattel S: Class III antiarrhythmic drug action in experimental atrial fibrillation. Differences in reverse use dependence and effectiveness between d-Sotalol and the new antiarthythmic drug Ambasilide. Circulation 1994:90:2032-2040

10 Wijffels MCEF, Kirchhof CJHJ, Dorland R, Allessie MA: Atrial fibrillation begets atrial fibrillation. A study in awake chronically instrumented conscious goats. Circulation 1995:92:1954-1968

11 Wijffels MCEF, Kirchhof CJHJ, Dorland R. Power J, Allessie MA: Electrical remodeling due to autial fibrillation in chronically instrumented conscious goats. The role of neurohumoral changes, ischemia. atrial stretch and high rate of electrical activation. Circulation (accepted) 1996: (Chapter 4).

12 Allessie MA. Hoeks APG, Schmitz GML, Reneman RS: On-line mapping system for the visualization of the electrical activation of the heart. Int J Cardiac Imag 1986:2:59-63

13 Allessie MA, Kirchhof CJHJ. Scheffer GJ, Chorro FJ, Brugada J: Regional control of atrial fibrillation by rapid pacing in conscious dogs. Circulation 1991;84:1689-1697 
14 Kirchhof CJHJ, Chorro FJ, Scheffer GJ, Brugada J, Konings KTS, Zetelaki Z, Allessie MA: Regional entrainment of atrial fibrillation studied by high-resolution mapping in open-chest dogs. Circulation 1993:88:736-749

15 Konings KTS. Kirchhof CJHJ, Smeets JLRM, Wellens HJJ, Penn OC, Allessie MA: High-density mapping of electrically induced atrial fibrillation in humans. Circulation 1994;89:1665-1680

16 Wells JL. Karp RB, Kouchoukos NT, Maclean WAH, James TN, Waldo AL: Characterization of atrial fibrillation in man: Studies following open heart surgery. Pace 1978;1:426-438

17 Attuel P, Leclercq JF, Coumel P: Atrial electrophysiological substrate remodelling after tachycardia in patients with and without atrial fibrillation. Pace 1995:18:804(Abstract)

18 Attuel P, Childers RW, Cauchemez B, Poveda J, Mugica J, Coumel P: Failure in the rate adaptation of the atrial refractory period: its relationship to vulnerability. Int J Cardiol 1982:2:179-197

19 Boutjdir M, Le Heuzey J, Lavergne T, Chauvaud S, Guize L, Carpentier A. Peronneau P: Inhomogeneity of cellular refractoriness in human atrium: factor of arrhythmia? Pace 1986;9:1095-1100

20 Schuessler RB, Kawamoto T, Hand DE, Mitsuno M, Bromberg BI, Cox JL, Boineau JP: Simultaneous epicardial and endocardial activation sequence mapping in the isolated canine right atrium. Circulation 1993;88:250-263

21 Cox JL, Canavan TE, Schuessler RB, Cain ME, Lindsay BD, Stone CM, Smith PK, Corr PB, Boineau JP: The surgical treatment of atrial fibrillation. II. Intraoperative electrophysiologic mapping and description of the electrophysiologic basis of atrial flutter and atrial fibrillation. $J$ Thor Card Surg 1991;101:406-426

22 Allessie MA, Bonke FIM, Schopman FJG: Circus movement in rabbit atrial muscle as a mechanism of tachycardia. III. The "leading circle" concept: A new model of circus movement in cardiac tissue without the involvement of an anatomical obstacle. Circ Res 1977;41:9-18

23 Hoffman BF, Rosen MR: Cellular mechanisms for cardiac arrhythmias. Circ Res 1981;49:1-15

24 Moe GK, Rheinboldt WC, Abildskov JA: A computer model of atrial fibrillation. Am Heart $J$ 1964:67:200-220 



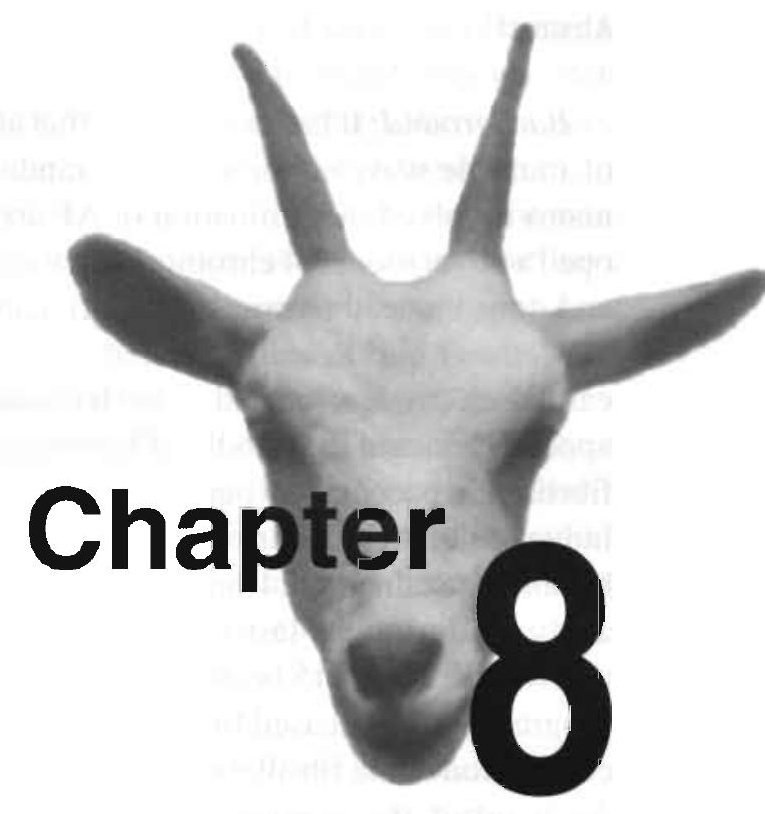

\section{On the Electrophysiological Mechanisms of Spontaneous and Cibenzoline-Induced Termination of Atrial Fibrillation in the Goat}

Francisco J. Chorro

Maurits C.E.F. Wijffels

Rick Dorland

Frans Mast

Maurits A. Allessie

This study was presented in part at the $I^{\text {st }}$ congress of the Federation of European Physiological Societies, 9-12 september 1995, Maastricht, The Netherlands. (Eur. J. Physiol (Pflügers Arch) 1995;430(4):RI11) 


\section{Abstract}

Background: It has been shown that atrial fibrillation (AF) is based on the presence of multiple wavelets propagating randomly through the atria. However the mechanisms involved in termination of AF are still poorly understood. Recently we developed a novel model of chronic AF in the goat in which the mechanisms of spontaneous and drug-induced termination of AF can be studied.

Methods and Results: Twelve goats were chronically instrumented with 27 epicardial electrodes, located at the left and right atrial free wall, the right and left atrial appendages, and the bundle of Bachmann. Chronic AF was induced by an automatic fibrillation pacemaker (burst pacing, $50 \mathrm{~Hz}, 1$ second). After a few days of continuous induction of $\mathrm{AF}$ the paroxysms of $\mathrm{AF}$ lasted for several minutes. After 1-3 weeks AF became sustained ( 24 hours). Electrograms recorded from 5 different areas were analyzed during the last 12 seconds of spontaneous or cibenzoline-induced termination of AF. Ten to 15 beats prior to spontaneous termination, the fibrillation intervals progressively increased from $113 \pm 7$ to $165 \pm 24 \mathrm{~ms}$ ( $\mathrm{p}<0.001$ ). During the last 3 beats, conduction of the fibrillation waves was increased from $68 \pm 8$ to $99 \pm 10 \mathrm{~cm} / \mathrm{s}(\mathrm{p}<0.01)$. As a result the average estimated circuit size increased from $8 \pm 1$ to $16 \pm 2 \mathrm{~cm}$ $(\mathrm{p}<0.001)$. Infusion of cibenzoline during chronic AF prolonged the AF intervals from $108 \pm 11$ to $176 \pm 59 \mathrm{~ms}(\mathrm{p}<0.05)$ and decreased the conduction velocity from $66 \pm 7$ to $51 \pm 16 \mathrm{~cm} / \mathrm{s}$ (n.s.). Cardioversion of AF by cibenzoline was preceded by the same phenomena as observed during spontaneous termination of paroxysmal AF, i.e. a progressive lengthening of the fibrillation interval to $240 \pm 60 \mathrm{~ms}(\mathrm{p}<0.05)$ and an increase in conduction velocity to $60 \pm 18 \mathrm{~cm} / \mathrm{s}$ (n.s.), resulting in an increase of the estimated circuit size from $8 \pm 2$ to $14 \pm 5 \mathrm{~cm}(\mathrm{p}=0.07)$.

Conclusions: Spontaneous and drug-facilitated termination of AF are preceded by a sudden, progressive increase in AF cycle length and conduction velocity. The resulting increase in estimated atrial circuit size from about $7-8 \mathrm{~cm}$ to $14-16 \mathrm{~cm}$ is causing termination of AF.

\section{Introduction}

Atrial fibrillation (AF) is a common arrhythmia in man, its incidence greatly increasing with age resulting in a prevalence of 2 to $4 \%$ in the population over 60 years of age. ${ }^{1-3}$ It often starts as paroxysmal atrial fibrillation but after some time the propensity of atrial fibrillation to terminate spontaneously diminishes and the arrhythmia becomes sustained. ${ }^{1,4}$ Although some of the electrophysiologic mechanisms underlying atrial fibrillation have been elucidated, still little is known about the mechanisms involved in spontaneous or drug-induced termination of AF. On the basis of computer simulations, in 1962 Moc proposed that atrial fibrillation is based on multiple wavelets propagating randomly through the atria. 5.6 Later, mapping studies both in animals and 
in humans have confirmed this hypothesis. ${ }^{7-10}$ Termination of atrial fibrillation is thought to be dependent on the statistical chance that the various wandering wavelets will die out simultaneously. If the average number of wavelets is small, there is a good chance that atrial fibrillation will self-terminate. On the other hand, if there are many wavelets present in the atria, the chances that they will all die out at the same time becomes negligible and atrial fibrillation will be sustained. In this respect we have emphasized the critical role of the atrial wavelength and suggested that prolongation of the wavelength of the fibrillating wavelets might be one of the possible mechanisms of termination of AF. ${ }^{11,12}$ This concept was supported by recent studies from Nattel's laboratory, ${ }^{13,14}$ showing that termination of AF by flecainide was associated with a decrease in the number of fibrillation wavelets. On the other hand, Swiryn's group ${ }^{15}$ failed to find evidence of progressive fusion of wavelets prior to termination of $\mathrm{AF}$ in man, and they concluded that: "Atrial fibrillation usually terminates directly to sinus rhythm and does so abruptly and without forewarning" and that: "Consistent trends toward more regular cycle lengths, alternating long and short cycle lengths, or progressively longer cycle lengths were not observed". 15

Recently we have developed a chronically instrumented goat model of atrial fibrillation in which electrograms can be recorded from multiple sites of the atria. ${ }^{16}$ In the present study we analyzed the electrograms recorded from 5 different parts of the atria during the last 12 seconds of spontaneous and drug-induced termination of $\mathrm{AF}$.

The objectives of the present study were 1) to determine whether termination of AF was preceded by a specific pattern of changes in atrial fibrillation cycle lengths, 2) to measure the beat-to-beat conduction velocities and changes in direction of the fibrillation waves prior to termination of $\mathrm{AF}, 3$ ) to monitor the effects of increasing dosages of a class IC drug (cibenzoline) on the characteristics of atrial fibrillation, and 4) to compare the pattern of spontaneous termination of AF with the events associated with pharmacological cardioversion by cibenzoline.

\section{Methods}

The conscious goat model of atrial fibrillation.

Twelve goats weighing between 46 and $67 \mathrm{~kg}$ were used lor this study. Animal handling was performed according to the guiding principles of the American Society of Physiology and approved by the Animal Investigation Committee of the University of Limburg. The goats were anaesthetized with Nesdonal ${ }^{\circledR}$ (Thiopental, $15 \mathrm{mg} / \mathrm{kg}$ ) and ventilated by Halothane ${ }^{\circledR}(1-2 \%)$ and a $1: 2$ mixture of $\mathrm{O}_{2}$ and $\mathrm{N}_{2} \mathrm{O}$. A left intercostal thoracotomy was made and the pericardium was opened to expose the heart. A silicon strip (Silastic ${ }^{\circledR}$, Dow Corning) of $10 \times 1.2 \mathrm{~cm}$, containing 15 unipolar platinum recording electrodes (diameter $1.5 \mathrm{~mm}$, inter-electrode distance $6-10 \mathrm{~mm}$ ) was guided through the anterior transverse sinus between the atria and the aortic root 


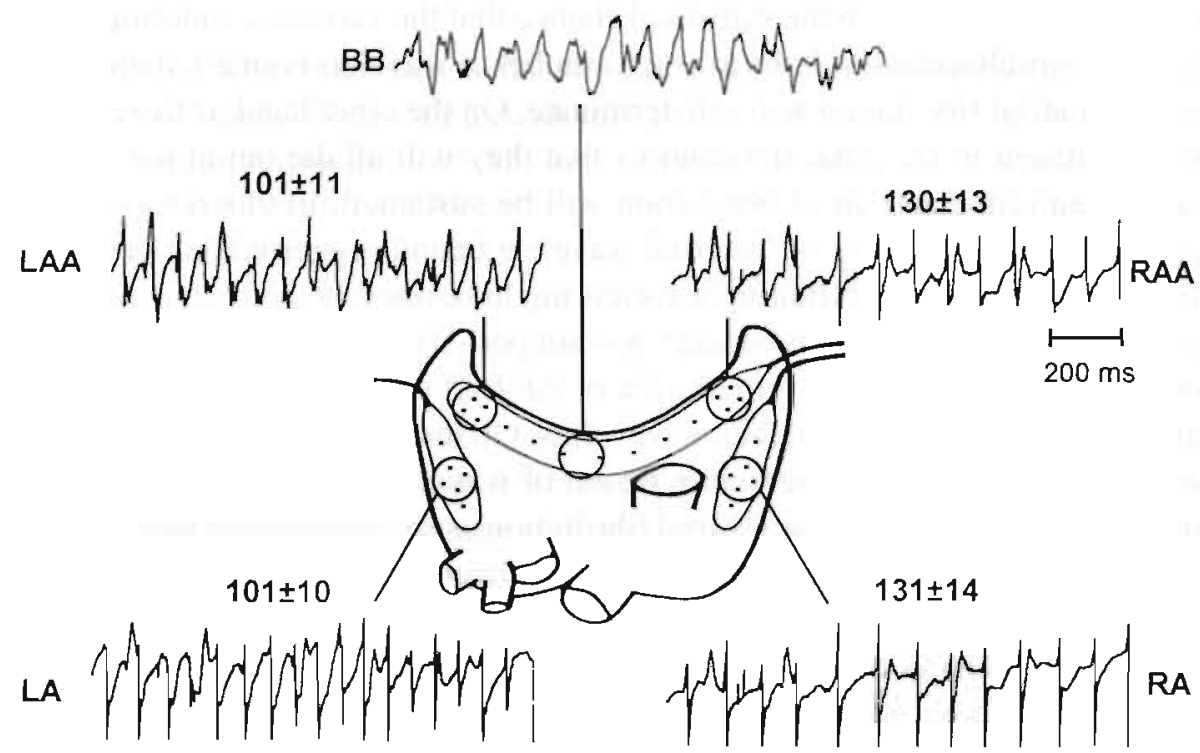

Figure 1. Unipolar fibrillation electrograms recorded at 5 different areas from the atria (BB, bundle of Bachmann; LAA, left atrial appendage; RAA, right atrial appendage; $L A$, left atrial free wall; RA, right atrial free wall). The mean \pm SD of the local atrial fibrillation cycles are given at the top of each electrogram. In total 27 epicardial electrodes were implanted on the atria. One silicon strip containing 15 electrodes was covering the bundle of Bachmann from the left to the right atrial appendage. Two other silicon strips, each containing 6 electrodes, were sutured to the free. wall of the right and left atria. The encircled quadruples of electrodes (inter-electrode distance 6 mm) were used to measure the conduction velocities of the fibrillation waves (LAA, RAA. L.A. RA). At the bundle of Bachmann (BB) only conduction times between two neighboring electrodes (inter-electrode distance $6 \mathrm{~mm}$ ) was measured.

and sutured to the tips of both atrial appendages. In addition, two smaller silicon strips of $3 \times 1.2 \mathrm{~cm}$, each containing 6 electrodes, were sutured to the lateral walls of the right and left atria (Fig 1). After approximation of the pericardium and closure of the thorax, the electrode leads were tunneled subcutaneously to the neck and exteriorized by a 30-pin connector (Lemosa ${ }^{\circledR}$, outer diameter $10 \mathrm{~mm}$ ). Three silver plates (diameter $25 \mathrm{~mm}$ ) were left subcutaneously to serve as grounding and indifferent electrodes and to record a precordial electrocardiogram. Post-operatively the animals received buprenorfine (Temgesic ${ }^{(\mathbb{*})}$, Reckitt \& Colman, Hull England) for 1-3 days. Ampicillin $(1000 \mathrm{mg})$ was given prophylactically both before and after surgery.

About 3 weeks after surgery the goats were connected to an external automatic atrial fibrillator. ${ }^{16}$ The external automatic fibrillator consisted of a personal computer connected to a stimulator (Medtronic, SP3084). The software continuously analyzed one of the atrial electrograms and as soon as sinus rhythm was detected, a 1-second burst of biphasic stimuli (duration $2 \mathrm{~ms}$, interval $20 \mathrm{~ms}$, strength 4 times diastolic threshold) was delivered to a pair of atrial electrodes. By these automatic bursts of stimuli, atrial fibrillation could be maintained continuously 24 hours a day, 7 days a week. As previously described, this procedure caused a progressive shortening of 
atrial refractoriness and a gradual increase in the duration of the induced episodes of atrial fibrillation. While during control electrically induced AF usually terminated spontaneously within a few seconds, after 1-2 days of AF the paroxysms of AF lasted for several minutes. Usually after 1-3 weeks of maintained AF atrial fibrillation became sustained ( 24 hours). ${ }^{16}$

A total of nine spontaneous terminations of AF was analyzed in 7 goats. The duration of these paroxysms of $\mathrm{AF}$ varied between 4 and 23 minutes and were recorded after 1 to 8 days of artificially maintained AF. In 6 other goats (except one in which also spontaneous termination was analyzed) the pharmacological conversion of sustained fibrillation by Cipralan ${ }^{(3)}$ (cibenzoline $10 \mathrm{mg} / \mathrm{ml}$, Searle) was studied. Cipralan ${ }^{\circledR}$ was administered by successive boli of $0.5 \mathrm{mg} / \mathrm{kg}$ i.v. ( 3 goats), or by a continuous infusion of $0.2 \mathrm{mg} / \mathrm{kg} / \mathrm{min}$ ( 3 goats). The total duration of AF in these goats was $17 \pm 12$ days and the duration of the last episode of $\mathrm{AF}$ that was cardioverted by Cipralan ${ }^{\circledR}$ varied between 1 and 29 days (mean $11 \pm 10$ ).

Data acquisition and analysis

At the day of the experiment the 30-pole connector in the neck of the animals was connected to a multichannel recording unit 17 and all 27 unipolar electrograms (gain 400; bandwidth 1-500 Hz) were continuously stored on tape together with a precordial electrocardiogram. The characteristics of the last 12 seconds prior to termination of $\mathrm{AF}$ were analyzed at five different areas of the atria, the left and right atrial free wall. the right and left atrial appendages, and the bundle of Bachmann (Fig 1). The following parameters were measured on a beat-to-beat basis: 1) local fibrillation interval, 2) local conduction time, 3) local conduction velocity, 4) change in direction of wave propagation. Local activation times were determined from the steepest negative deflection of the unipolar electrograms. Fibrillation interval histograms were made from one electrode at each of the five areas. Conduction times were measured between two neighboring electrodes (interelectrode distance $6 \mathrm{~mm}$ ). The regional direction and velocity of propagation was measured at 4 areas (right and left appendages and the right and left free atrial walls) by calculating the vector of conduction in quadruples of electrodes $6 \mathrm{~mm}$ apart. The quadruples were divided into two triangles and the vector of each triangle was calculated. The average of the two vectors was taken as the average direction and conduction velocity in the area of $6 \times 6 \mathrm{~mm}$. Only calculated velocities in the range between 10 and $180 \mathrm{~cm} / \mathrm{s}$ were taken into account. Both very low and very high calculated values were discarded because they do not represent an actual conduction velocity. Very low values point to the occurrence of local intra-atrial conduction block between the 4 recording electrodes, whereas very high values may result either from collision or epicardial breakthrough of fibrillation waves.

Data are presented as mean \pm standard deviation unless specified otherwise. Statistical analysis was performed by the paired or unpaired Student's $t$-test. A p-value of less than 0.05 was considered to be statistically significant. 


\section{Results}

\section{Characteristics of Atrial Fibrillation}

In Fig 1 an example is shown of the unipolar electrograms recorded from 5 different areas of the atria during paroxysmal atrial fibrillation. In this case atrial fibrillation had been induced repetitively during 2 days and as a result the paroxysms of AF now lasted for more than 20 minutes. The mean fibrillation interval at the different locations varied between $101 \pm 10 \mathrm{~ms}$ (left atrium) and $131 \pm 14 \mathrm{~ms}$ (right atrial free wall). As can be seen the electrograms showed clear beat-to-beat variations in configuration, but most of the time consisted of a single negative deflection separated by a short iso-electric segment, indicating that the different areas of the atria were still activated relatively uniformly by broad activation waves (Type I fibrillation). ${ }^{10,18}$ Because at this stage fragmented electrograms occurred only rarely, local activation times could be derived without much uncertainty from the fibrillation electrograms.

In Tables 1 and 2 the characteristics of paroxysmal and sustained atrial fibrillation are listed. After the automatic fibrillation pacemaker had maintained AF for $3 \pm 2$ days, the induced paroxysms of AF lasted between 4 and 23 minutes (mean $7.8 \pm 5.9$ ) (Table 1). In each goat the fibrillation cycle length was measured at five atrial sites (right and left appendage, right and left free wall. bundle of Bachmann). The numbers in Tables 1 and 2 represent the average values \pm SD of the measurements at these 5 atrial sites. In the total group of 9 paroxysms of AF, the mean and median atrial fibrillation cycle length was $113 \pm 7 \mathrm{~ms}$. The temporal variation in fibrillation cycle length was expressed by the difference between the 5th and 95th percentile (P5-P95) and by the standard deviation of the local fibrillation interval histogram. During paroxysmal AF, the $P_{5-95}$ and the SD of the fibrillation cycle length were $52 \pm 10 \mathrm{~ms}$ and $17 \pm 3$ ms respectively.

After atrial fibrillation had been maintained for an average of $17 \pm 12$ days (Table 2 ), the duration of the episodes of atrial fibrillation had dramatically increased to more than $11 \pm 10$ days. The mean and median fibrillation cycle length of sustained AF were $107 \pm 11$ and $109 \pm 12 \mathrm{~ms}$. The P5-95 and SD of the AF-interval histograms were $51 \pm 15$ and $17 \pm 5 \mathrm{~ms}$. There were no statistically significant differences between these characteristics of paroxysmal and sustained atrial fibrillation.

\section{Atrial Fibrillation Intervals prior to Spontaneous Termination}

Fig 2 shows an electrogram recorded from the free wall of the left atrium during the last 47 cycles of $A F$, together with a sequential plot of the last 120 fibrillation intervals prior to spontaneous termination of AF. Up to the last 20 beats prior to termination, AF showed the usual temporal variation in fibrillation intervals with a median value of $103 \mathrm{~ms}$ and a $P_{5-95}$ of $37 \mathrm{~ms}$. However about 2-3 seconds before conversion to sinus rhythm, this pattern suddenly changed and the atrial fibrillation intervals started to prolong progressively up to more than $200 \mathrm{~ms}$. In Fig 3 the mean fibrillation intervals 
Table 1. Characteristics of Paroxysmal Atrial Fibrillation

\begin{tabular}{lllllllll}
\hline & $\begin{array}{l}\text { Duration } \\
\text { of AF } \\
\text { Goat \# }\end{array}$ & $\begin{array}{l}\text { Duration } \\
\text { Paroxysm } \\
\text { (Min) }\end{array}$ & $\begin{array}{l}\text { Mean AF } \\
\text { Interval } \\
\text { (ms) }\end{array}$ & $\begin{array}{l}\text { Median AF } \\
\text { Interval } \\
\text { (ms) }\end{array}$ & $P_{5}$ & $P_{95}$ & $P_{5}-P_{95}$ & $\begin{array}{l}\text { Sd of AF } \\
\text { Interval }\end{array}$ \\
\hline 1 & 1 & 7.5 & $118 \pm 7$ & $118 \pm 8$ & $94 \pm 10$ & $140 \pm 10$ & $46 \pm 10$ & $14 \pm 3$ \\
2 & 8 & 8.0 & $119 \pm 3$ & $118 \pm 3$ & $99 \pm 8$ & $138 \pm 11$ & $39 \pm 18$ & $14 \pm 7$ \\
3 & 3 & 4.5 & $123 \pm 11$ & $123 \pm 12$ & $97 \pm 9$ & $145 \pm 12$ & $49 \pm 7$ & $16 \pm 2$ \\
3 & 3 & 4.2 & $111 \pm 7$ & $109 \pm 7$ & $78 \pm 14$ & $150 \pm 16$ & $72 \pm 19$ & $23 \pm 7$ \\
4 & 1 & 6.6 & $104 \pm 15$ & $104 \pm 16$ & $81 \pm 11$ & $124 \pm 21$ & $44 \pm 14$ & $16 \pm 4$ \\
4 & 1 & 5.5 & $105 \pm 11$ & $103 \pm 11$ & $79 \pm 13$ & $136 \pm 17$ & $57 \pm 19$ & $18 \pm 6$ \\
5 & 1 & 5.2 & $115 \pm 10$ & $117 \pm 10$ & $88 \pm 10$ & $143 \pm 16$ & $55 \pm 18$ & $18 \pm 5$ \\
6 & 2 & 23.0 & $117 \pm 15$ & $118 \pm 14$ & $91 \pm 19$ & $141 \pm 21$ & $49 \pm 21$ & $15 \pm 6$ \\
7 & 3 & 5.5 & $109 \pm 9$ & $109 \pm 8$ & $79 \pm 8$ & $136 \pm 12$ & $56 \pm 13$ & $19 \pm 4$ \\
& & & & & & & & 17 \\
Mean & 3 & 7.8 & 113 & 113 & 87 & 139 & 52 & 17 \\
Sd & 2 & 5.9 & 7 & 7 & 9 & 7 & 10 & 3 \\
\hline
\end{tabular}

AF, Atrial Fibrillation. Sd, Standard deviation; In each goat the AF interval was measured at 5 atrial sites (right and left atrial appendage, right and left atrial free wall and Bachmann's bundle). The mean values and standard deviations of the mean, median, low and high p-values of these 5 atrial sites are given. The Sd of AF interval represents the standard deviation of the local AF interval histogram.

Table 2. Characteristics of Sustained Atrial Fibrillation

\begin{tabular}{lllllllll}
\hline Goat \# & $\begin{array}{l}\text { Duration } \\
\text { of AF } \\
\text { (Days) }\end{array}$ & $\begin{array}{l}\text { Duration } \\
\text { Episode } \\
\text { (Min) }\end{array}$ & $\begin{array}{l}\text { Mean AF } \\
\text { Interval } \\
\text { (ms) }\end{array}$ & $\begin{array}{l}\text { Median AF } \\
\text { Interval } \\
\text { (ms) }\end{array}$ & $P_{5}$ & $P_{95}$ & $P_{5}-P_{95}$ & $\begin{array}{l}\text { Sd of AF } \\
\text { Interval }\end{array}$ \\
\hline 5 & 26 & 15 & $110 \pm 7$ & $109 \pm 6$ & $92 \pm 7$ & $128 \pm 10$ & $37 \pm 5$ & $14 \pm 4$ \\
8 & 32 & 29 & $116 \pm 18$ & $118 \pm 22$ & $86 \pm 11$ & $137 \pm 25$ & $51 \pm 20$ & $17 \pm 6$ \\
9 & 21 & 12 & $120 \pm 13$ & $122 \pm 12$ & $86 \pm 13$ & $148 \pm 14$ & $62 \pm 7$ & $21 \pm 2$ \\
10 & 10 & 4 & $109 \pm 4$ & $108 \pm 3$ & $73 \pm 16$ & $143 \pm 6$ & $69 \pm 20$ & $24 \pm 8$ \\
11 & 1 & 1 & $102 \pm 6$ & $106 \pm 7$ & $69 \pm 11$ & $123 \pm 8$ & $54 \pm 15$ & $18 \pm 5$ \\
12 & 11 & 6 & $88 \pm 4$ & $88 \pm 4$ & $72 \pm 2$ & $103 \pm 9$ & $32 \pm 10$ & $10 \pm 3$ \\
Mean & 17 & 11 & 107 & 109 & 80 & 130 & 51 & 17 \\
Sd & 12 & 10 & 11 & 12 & 9 & 16 & 15 & 5 \\
\hline
\end{tabular}

AF, Atrial Fibrillation. Sd, Standard deviation; In each goat the AF interval was measured at 5 atrial sites (right and left atrial appendage, right and left atrial free wall and Bachmann's bundle). The mean values and standard deviations of the mean, median, low and high p-values of these 5 atrial sites are given. The Sd of AF interval represents the standard deviation of the local AF interval histogram. 
$89122107=116$

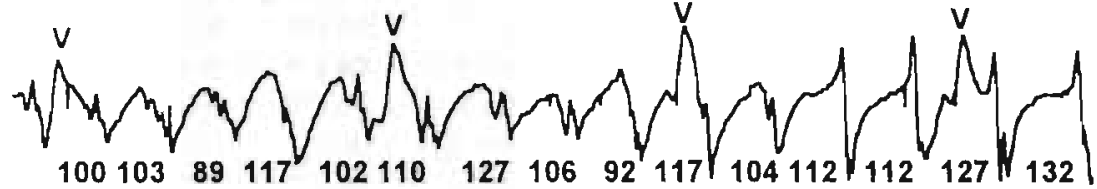

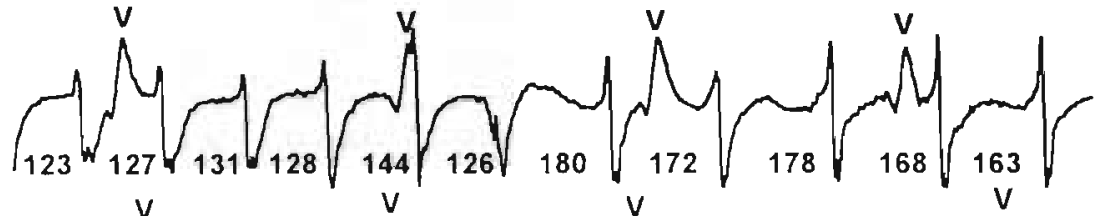

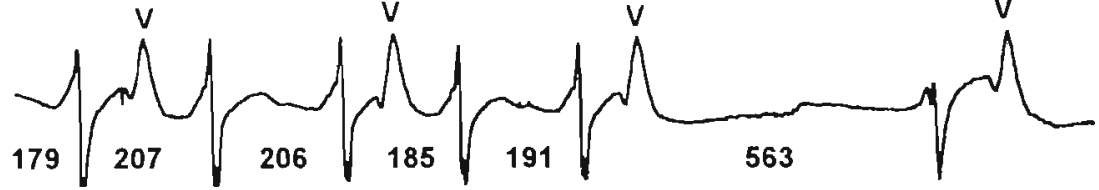

AF $\longrightarrow$ Sinus Rhythm

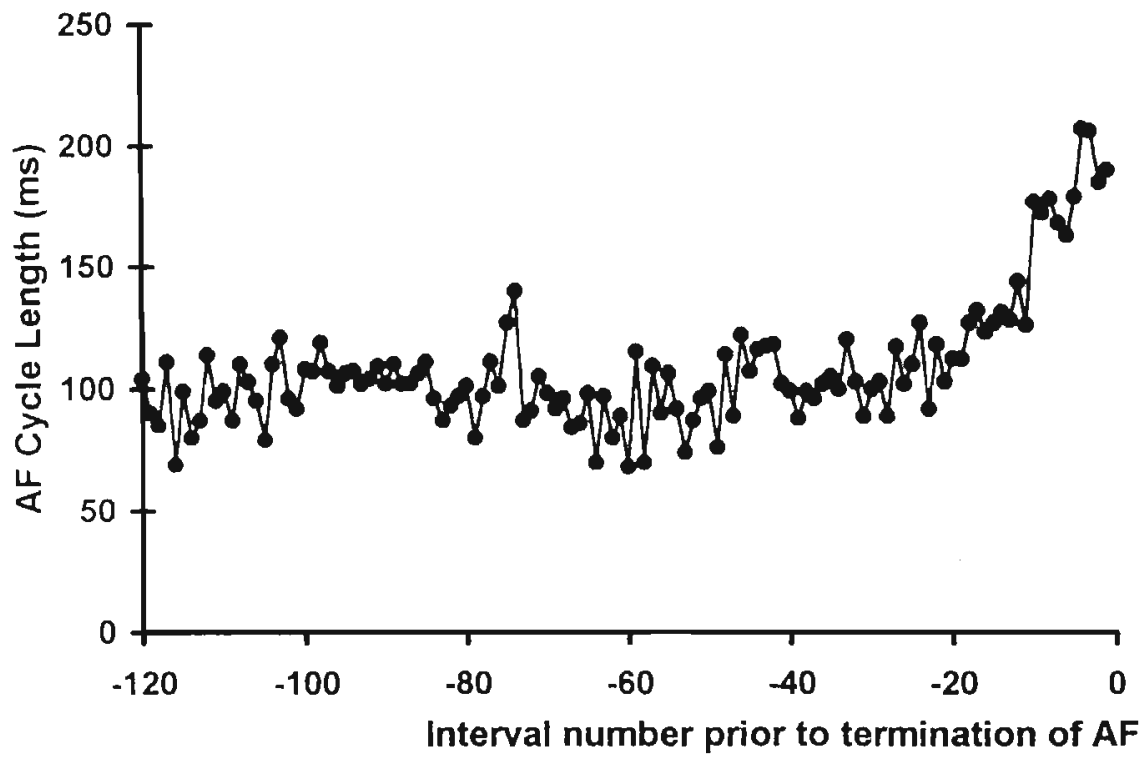

Figure 2. Progressive slowing of the rate of atrial fibrillation prior to conversion to sinus rhythm. Upper panel: A single unipolar electrogram recorded from the left atrial free wall during the last 47 cycles before spontaneous termination of AF. The individual fibrillation cycles are given in milliseconds. ( $V=$ ventricular complex $)$. Lower panel: Sequential plot of the last 120 local fibrillation intervals before spontaneous termination of AF. 

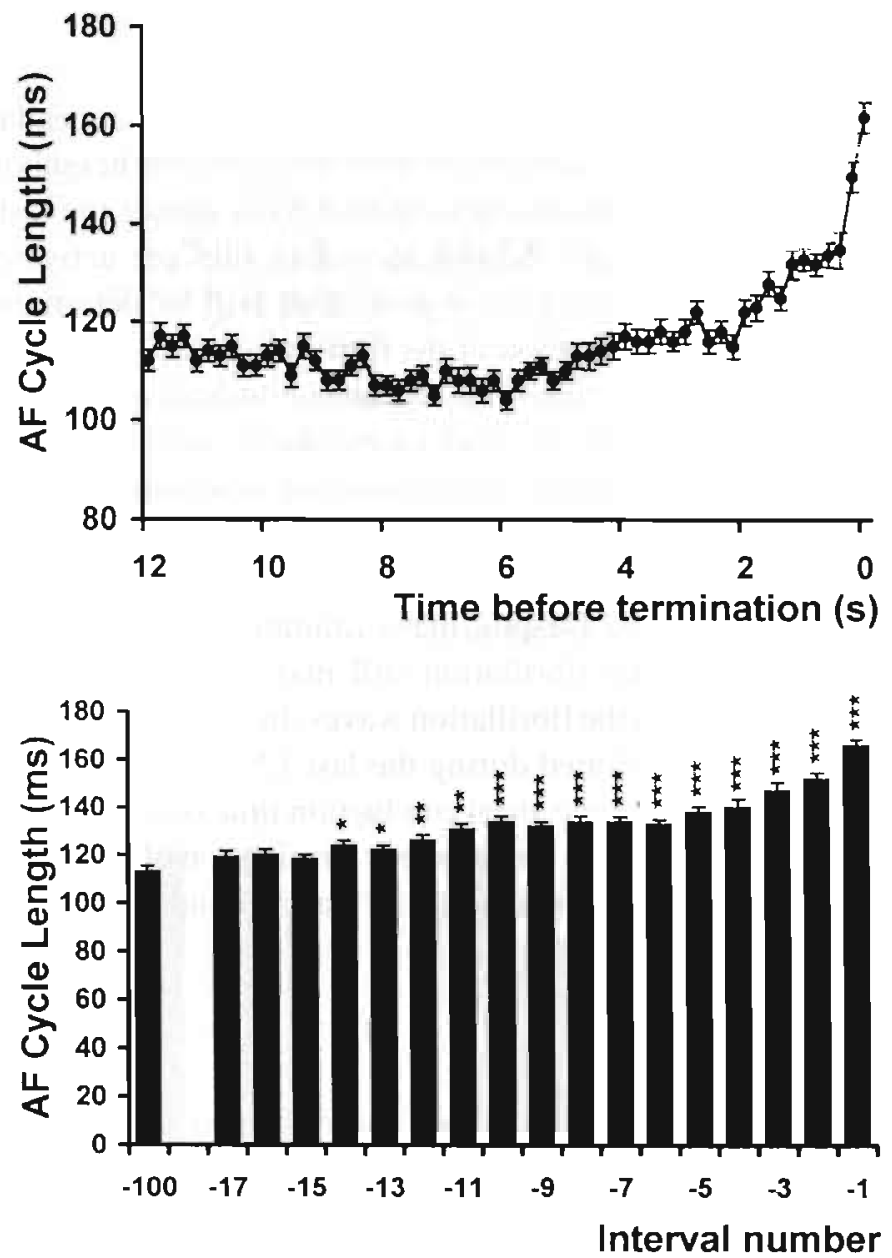

Figure 3. Progressive prolongation of AF cycle length 2-3 seconds before spontaneous termination of atrial fibrillation. The data points are the mean values of the local fibrillation intervals at 5 different atrial sites during termination of 9 paroxysins of AF. In the lower panel the AF cycles are plotted on a beat-to-beat basis. The last 14 beats before termination were longer than during ongoing AF. (*p<0.05; ** $p<0.01 ; * * * 0<0.001)$.

at the five recording sites of all 9 paroxysms of AF are plotted during the last 12 seconds of AF. On a beat-to-beat basis, the 14th interval prior to spontaneous conversion to sinus rhythm was the first cycle to be statistically prolonged (lower panel). The average cycle lengths at the 5 recording sites of the last three cycles before termination of AF were $148 \pm 10,153 \pm 6$, and $165 \pm 7 \mathrm{~ms}$ (SEM), compared to 113 $\pm 2 \mathrm{~ms} 12$ seconds before termination of $\mathrm{AF}(\mathrm{p}<0.001)$. 


\section{Local Conduction Times}

In 5 different areas (right and left free wall, right and left appendages, bundle of Bachmann), the differences in activation time between two neighboring electrodes (distance $6 \mathrm{~mm}$ ) was measured on a beat-to-beat basis during the last 12 seconds of atrial fibrillation. Assuming that the two recording sites are activated by the same fibrillation wave, the difference in activation time will be determined both by the velocity and direction of propagation of the fibrillation waves. Only if the impulse is conducted parallel to the electrodes, the difference in activation time will represent the true conduction velocity. In all other cases (due to an oblique orientation of the wavefront relative to the electrodes), the conduction time will overestimate the actual conduction velocity. On the other hand the actual average conduction velocity during AF may be underestimated by local conduction block of the fibrillation waves between the two recording electrodes. Despite these limitations, measurement of the local conduction time during atrial fibrillation still may be useful to detect changes in conduction characteristics of the fibrillation waves. In Fig 4 the atrial conduction times at the 5 recording sites are plotted during the last 12 seconds of the 9 paroxysms of AF. During stable AF the average atrial conduction time over a distance of $6 \mathrm{~mm}$ was about $10 \mathrm{~ms}$. Immediately before spontaneous termination of AF the conduction time became shorter. During the last three beats intra-atrial conduction time was shortened to less than $5 \mathrm{~ms}(\mathrm{p}<0.05)$.

\section{Direction and Velocity of Fibrillation Waves}

In the right and left atrial free walls and the right and left atrial appendages the conduction vectors of the fibrillation waves were measured during the last 12 seconds of AF. In Fig 5 the average conduction velocity and beat-to-beat changes in direction (delta angle) are plotted during the last 12 seconds of AF. During stable fibrillation the average conduction velocity was $68 \pm 2 \mathrm{~cm} / \mathrm{s}$ (SEM.). About 3 seconds before termination of AF the average conduction velocity started to increase (upper left panel). During the last beats the conduction velocity of the fibrillation waves had increased to about $100 \mathrm{~cm} / \mathrm{s}(\mathrm{p}<0.001)$ (lower left panel). The right panels of Fig 6 show the average beat-to-beat changes in direction of the fibrillation waves (delta angle). During ongoing fibrillation the average change in direction between two successive fibrillation waves was $56 \pm 3$ degrees (mean \pm SEM). About 2 seconds before termination of AF the beat to beat variation in direction of fibrillation waves started to decrease. During the last 3 beats the delta angle was $37 \pm 4,41 \pm 5$, and 35 \pm 5 degrees (mean \pm SEM) respectively $(p<0.05)$.

In Table 3 all measurements during spontaneous termination of the 9 paroxysms of AF are listed. In the calculation of the conduction velocities a lower and upper limit of respectively 10 and $180 \mathrm{~cm} / \mathrm{s}$ was taken into account and vectors outside these limits were discarded. If a lower limit of $30 \mathrm{~cm} / \mathrm{s}$ was applied, the calculated conduction velocities were not different indicating that slow conduction or intra-atrial conduction 

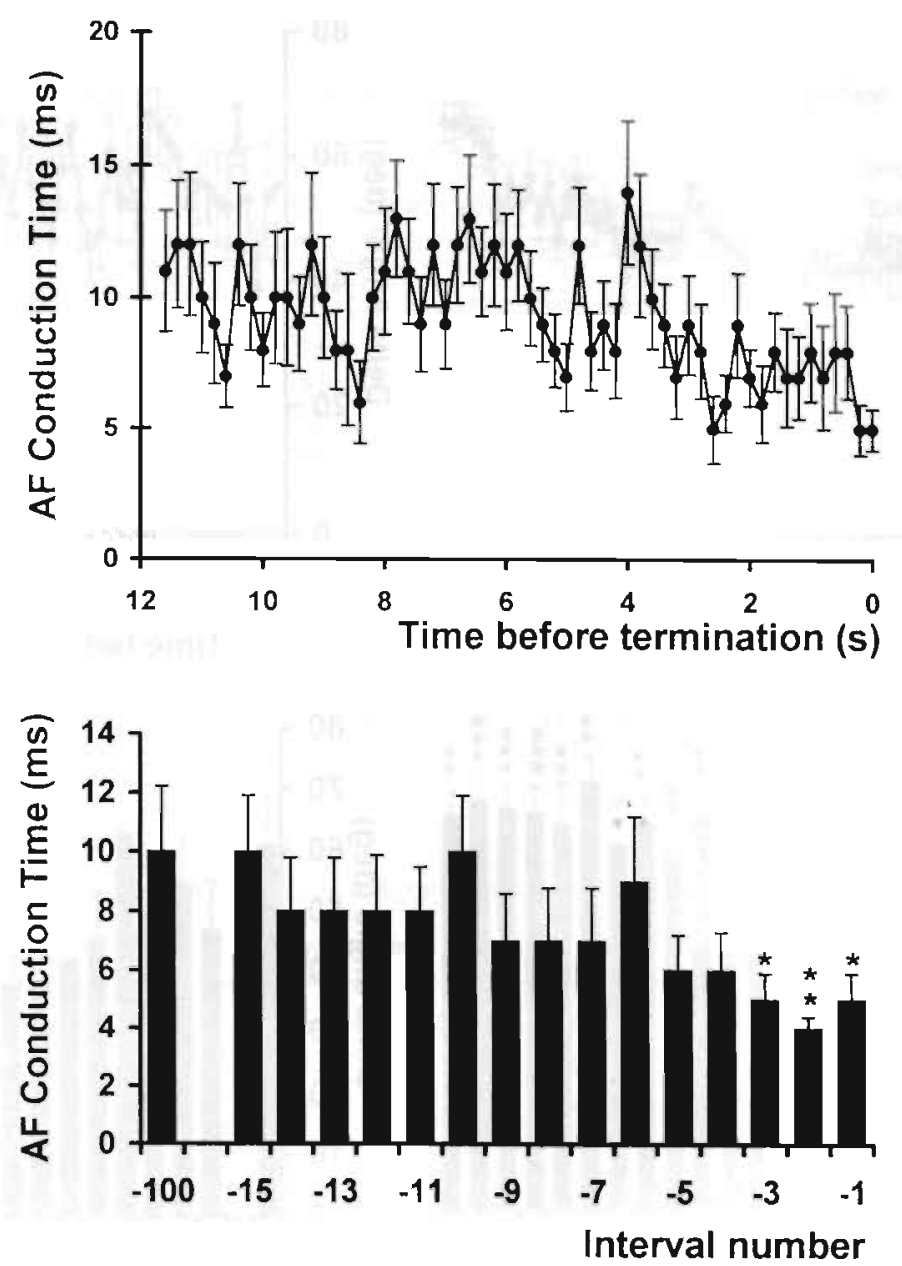

Figure 4. Shortening of intri-atrial conduction time before spontaneous termination of $\mathrm{AF}$ (inter-electrode distance $6 \mathrm{~mm}$ ). The upper panel shows the mean $\mathrm{AF}$ conduction times at 5 atrial areats during the last 12 seconds before termination of 9 episodes of AF. In the lower panel the mean AF conduction times are plotted on a beat-to-beat basis. The last three beats prior to termination showed statistically significant shorter conduction times. $\left({ }^{*} \mathrm{p}<0.05 ;{ }^{* *} \mathrm{p}<0.01\right)$.

block did not occur at the 4 recorded areas. On the basis of the local conduction velocity at the 4 atrial areas and the associated fibrillation cycle length, the size of the reentrant circuits during AF was calculated as:

Circuit Size $=$ Conduction Velocity $\times$ AF Cycle Length .

The average circuit size during ongoing AF estimated in this way wals $8 \pm 1 \mathrm{~cm}$. During the last three cycles before termination of AF the calculated reentrant circuit size 

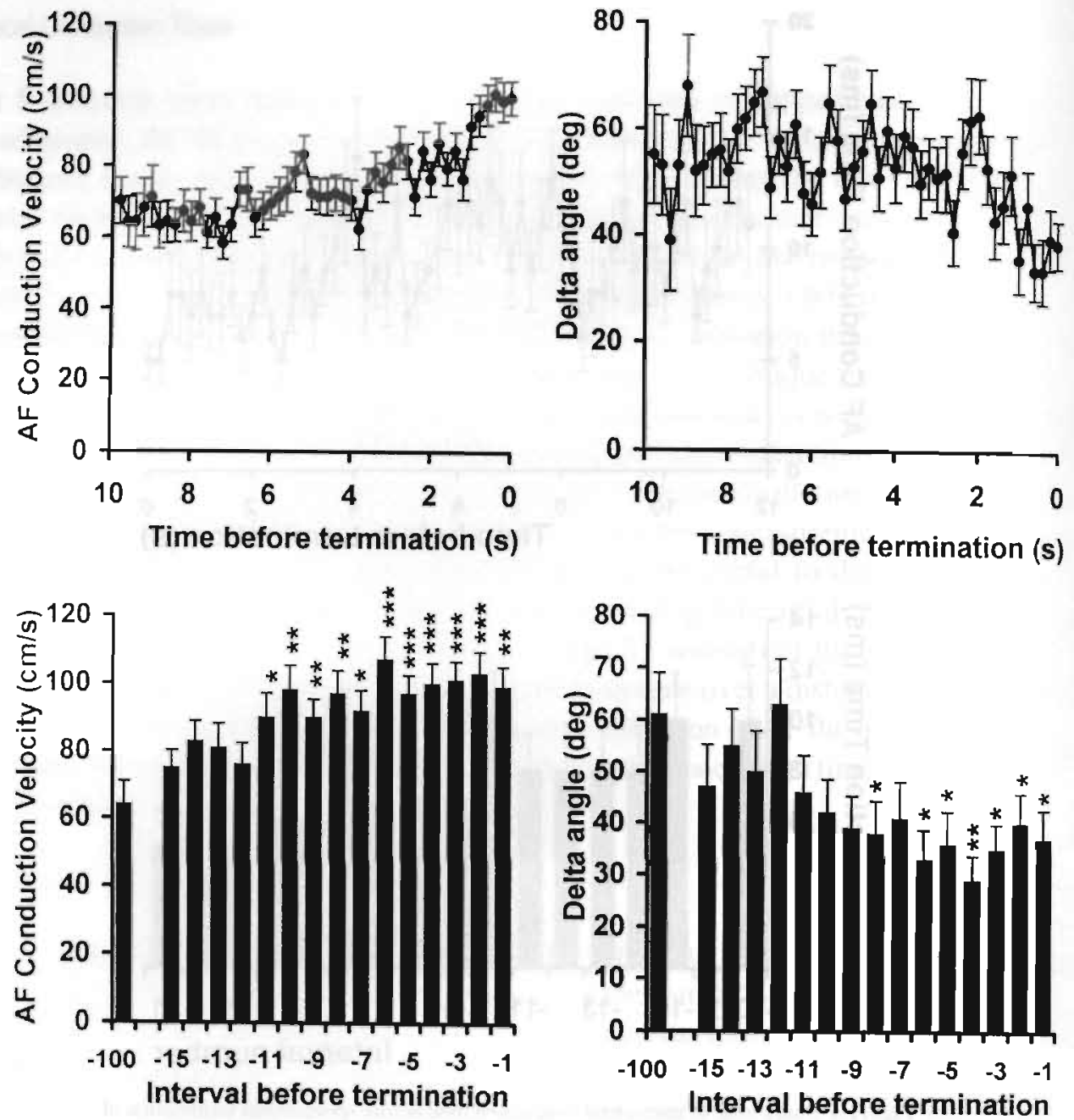

Figure 5. Average intratatrial conduction velocity and delta angle of the fibrillation waves prior to spontaneous termination of AF as measured from the conduction vector in 4 atrial areas of $6 \times 6 \mathrm{~mm}$. Shortly before conversion to sinus rhythm the conduction velocity increased from 86 to $99 \mathrm{~cm} / \mathrm{s}$. During the last 11 cycles conduction velocity was statistically significant different. The beat to beat changes in direction of the fibrillation waves diminished from 56. 10 less than 40 degrees (right panels). (* $p<0.05 ; * * p<0.01$; $^{* * *} p<0.001$ ). 
Table 3. Changes in Fibrillation Prior to Spontaneous Termination of AF

\begin{tabular}{|c|c|c|c|c|c|c|c|c|c|c|c|c|c|c|c|}
\hline \multirow[b]{2}{*}{ Goat H } & \multicolumn{5}{|c|}{ Ongoing Atrial Fibrillation } & \multicolumn{5}{|c|}{ Third Last Beat } & \multicolumn{5}{|c|}{ Second Last Bea: } \\
\hline & $\begin{array}{l}\text { AF } \\
\text { Int } \\
m s\end{array}$ & $\begin{array}{l}\text { Cond } \\
\text { Time } \\
\mathrm{ms}\end{array}$ & $\begin{array}{l}\text { Cond } \\
\text { Veloc } \\
\mathrm{cm} / \mathrm{s}\end{array}$ & $\begin{array}{l}\text { Delta } \\
\text { Ang } \\
\text { deg }\end{array}$ & $\begin{array}{l}\text { Cire } \\
\text { Size } \\
\mathrm{cm}\end{array}$ & $\begin{array}{l}\text { AF } \\
\text { Int } \\
m s\end{array}$ & $\begin{array}{l}\text { Cond } \\
\text { Time } \\
\text { ns }\end{array}$ & $\begin{array}{l}\text { Cond } \\
\text { Veloc } \\
\mathrm{cn} / \mathrm{s}\end{array}$ & $\begin{array}{l}\text { Delta } \\
\text { Ang } \\
\text { deg }\end{array}$ & $\begin{array}{l}\text { Circ } \\
\text { Size } \\
\mathrm{cm}\end{array}$ & $\begin{array}{l}\mathrm{AF} \\
\text { int } \\
\mathrm{ms}\end{array}$ & $\begin{array}{l}\text { Cond } \\
\text { Time } \\
\mathrm{ms}\end{array}$ & $\begin{array}{l}\text { Cond } \\
\text { Veloc } \\
\mathrm{cm} / \mathrm{s}\end{array}$ & $\begin{array}{l}\text { Della } \\
\text { Ang } \\
\text { deg }\end{array}$ & $\begin{array}{l}\text { Cire } \\
\text { Size } \\
\mathrm{cm}\end{array}$ \\
\hline 1 & 118 & 13 & 83 & 49 & 10 & 187 & 4 & 112 & 21 & 21 & 172 & 6 & 99 & 30 & 17 \\
\hline 2 & 119 & 8 & 71 & 43 & 8 & 114 & 8 & 67 & 35 & 8 & 139 & 4 & 87 & 38 & 12 \\
\hline 3 & 123 & 8 & 71 & 50 & 9 & 153 & 5 & 100 & 56 & 15 & 135 & 5 & 102 & 17 & 14 \\
\hline 3 & 111 & 10 & 60 & 66 & 7 & 165 & 4 & 94 & 41 & 16 & 166 & 3 & 90 & 47 & 15 \\
\hline 4 & 104 & 10 & 63 & 62 & 6 & 130 & 3 & 110 & 36 & 14 & 166 & 3 & 113 & 62 & 19 \\
\hline 4 & 105 & 10 & 61 & 71 & 6 & 131 & 6 & 65 & 14 & 9 & 162 & 3 & 70 & 58 & 11 \\
\hline 5 & 115 & 14 & 76 & 56 & 9 & 120 & 9 & 126 & 49 & 15 & 133 & 4 & 124 & 50 & 16 \\
\hline 6 & 117 & 11 & 64 & 44 & 7 & 201 & 6 & 104 & 43 & 21 & 175 & 7 & 106 & 22 & 19 \\
\hline 7 & 109 & 16 & 64 & 60 & 7 & 133 & 6 & 95 & 35 & 13 & 130 & 4 & 120 & 49 & 16 \\
\hline Mean & 113 & 11 & 68 & 56 & 8 & $148^{* *}$ & $6^{*}$ & $97^{\prime *}$ & $37^{*}$ & $15^{\prime \prime}$ & $153^{*}$ & $4^{* *}$ & $101^{\cdots \cdots}$ & $41^{\circ}$ & $15^{m *}$ \\
\hline SD & 7 & 3 & 8 & 10 & 1 & 30 & 2 & 20 & 13 & 5 & 18 & 1 & 17 & 16 & 3 \\
\hline
\end{tabular}

" $p<0.05 ;$;* $p<0.01 ; * * p<0.001$.

Table 3. (Continued) Changes in Fibrillation Prior to Spontaneous Termination of AF

\begin{tabular}{|c|c|c|c|c|c|c|c|c|c|}
\hline \multirow[b]{2}{*}{ Goat \# } & \multicolumn{5}{|c|}{ Last Beat } & \multicolumn{4}{|c|}{ Sinus Rhythm } \\
\hline & $\begin{array}{l}\text { AF } \\
\text { Int } \\
\mathrm{ms}\end{array}$ & $\begin{array}{l}\text { Cond } \\
\text { Time } \\
\mathrm{ms}\end{array}$ & $\begin{array}{l}\text { Cond } \\
\text { Veloc } \\
\mathrm{cm} / \mathrm{s}\end{array}$ & $\begin{array}{l}\text { Delta } \\
\text { Ang } \\
\text { deg }\end{array}$ & $\begin{array}{l}\text { Circ } \\
\text { Size } \\
\mathrm{cm}\end{array}$ & $\begin{array}{l}\text { Sinus } \\
\text { Int } \\
\mathrm{ms}\end{array}$ & $\begin{array}{l}\text { Cond } \\
\text { Time } \\
\mathrm{ms}\end{array}$ & $\begin{array}{l}\text { Cond } \\
\text { Veloc } \\
\mathrm{cm} / \mathrm{s}\end{array}$ & $\begin{array}{l}\text { Delta } \\
\text { Ang } \\
\text { deg }\end{array}$ \\
\hline 1 & 156 & 5 & 110 & 17 & 17 & 477 & 4 & 121 & 10 \\
\hline 2 & 151 & 6 & 101 & 26 & 15 & 462 & 3 & 108 & 5 \\
\hline 3 & 192 & 6 & 101 & 50 & 19 & 548 & 4 & 105 & 4 \\
\hline 3 & 173 & 8 & 93 & 39 & 16 & 541 & 4 & 106 & 9 \\
\hline 4 & 182 & 3 & 93 & 67 & 17 & 359 & 3 & 97 & 20 \\
\hline 4 & 156 & 3 & 91 & 14 & 14 & 363 & 6 & 101 & 11 \\
\hline 5 & 134 & 4 & 90 & 30 & 12 & 547 & 5 & 122 & 12 \\
\hline 6 & 204 & 6 & 95 & 29 & 19 & 538 & 5 & 110 & 10 \\
\hline 7 & 140 & 6 & 119 & 42 & 17 & 478 & 3 & 130 & 26 \\
\hline Mean & $165^{\star \star *}$ & $5^{*}$ & $99^{* *}$ & $35^{* *}$ & $16^{* * * *}$ & 479 & 4 & 111 & 12 \\
\hline SD & 24 & 2 & 10 & 17 & 2 & 75 & 1 & 11 & 7 \\
\hline
\end{tabular}

" $p<0.05 ; " p<0.01:{ }^{* * *} p<0.001$. 
increased markedly to $15 \pm 5,15 \pm 3$, and $16 \pm 2 \mathrm{~cm}$. This was due to the combination of a prolongation of AF cycle length and an increase in conduction velocity.

\section{Relationship between AF Cycle Length and Conduction}

In Fig 6 the average changes in conduction time, conduction velocity, beat-to-beat variation in direction, and estimated circuit size during termination of the 9 paroxysms of AF, are plotted in relation to the changes in fibrillation cycle length. The data points within the dotted box were recorded during stable fibrillation, whereas the data points outside the box represent the mean values of the last 15 beats prior to termination. Linear regression lines were calculated through these last 15 points, using the average values during sustained $\mathrm{AF}$ as its origin. There was a clear correlation between the progressive prolongation of AF cycle length prior to termination and shortening of conduction time $\left(\mathrm{r}^{2}=0.92\right)$, increase in conduction velocity $\left(\mathrm{r}^{2}=0.89\right)$ and decrease in delta angle $\left(r^{2}=0.80\right)$ of the fibrillation waves. Assuming that the conduction velocity during $\mathrm{AF}$ at the four atrial sites is representative for conduction in other areas of the atria, the average length of the circuitous pathways of the fibrillation waves can be estimated by the product of conduction velocity and fibrillation cycle length. During sustained atrial fibrillation (dotted box) the estimated circuit size varied between 7 and $9 \mathrm{~cm}$ (lower right panel). During the last 15 beats before termination of $\mathrm{AF}$, the estimated circuit size progressively increased to a value of $16 \mathrm{~cm}$ during the last beat of atrial fibrillation $\left(r^{2}=0.97\right)$.

\section{Cardioversion of Chronic Atrial Fibrillation by Cibenzoline}

Cibenzoline is a class IC anti-arrhythmic drug which decreases the rate of rise of phase 0 and the amplitude of the action potential. In addition cibenzoline also exhibits Class III and IV effects. ${ }^{19,20}$ The effects of cibenzoline on atrial fibrillation was measured in 6 goats. In this series, the mean total duration of atrial fibrillation was $17 \pm 12$ days, whereas the episode that was actually cardioverted by cibenzoline had lasted for 11 \pm 10 days. The mean fibrillation cycle length of chronic AF was $107 \pm 11 \mathrm{~ms}$ (see Table 2). Cibenzoline was administered intravenously in consecutive boli of 0.5 $\mathrm{mg} / \mathrm{kg}$ ( 3 goats) or by continuous infusion of $0.2 \mathrm{mg} / \mathrm{kg} / \mathrm{min}$ ( 3 goats). In Fig 7 and Table 4 the effects of cibenzoline are given. Twelve seconds before cardioversion, the drug had slowed down the rate of atrial fibrillation from an average cycle length of $108 \pm 11$ to $176 \pm 59 \mathrm{~ms}(\mathrm{p}<0.05)$. During ongoing fibrillation, the conduction velocity of the fibrillation waves was clearly depressed, the average difference in activation time between two electrodes $6 \mathrm{~mm}$ apart increasing from $11 \pm 2 \mathrm{~ms}$ to $15 \pm 3 \mathrm{~ms}$ (p $<0.05$ ) (upper right panel). The mean AF conduction velocity as measured at the 4 quadruples of electrodes during control was $66 \pm 7$ compared to $51 \pm 16 \mathrm{~cm} / \mathrm{s}$ after cibenzoline $(p=0.10)$ (lower left panel). The beat to beat changes in direction of the fibrillation waves (delta angle) was $58 \pm 8$ during control and $50 \pm 12$ after cibenzoline 

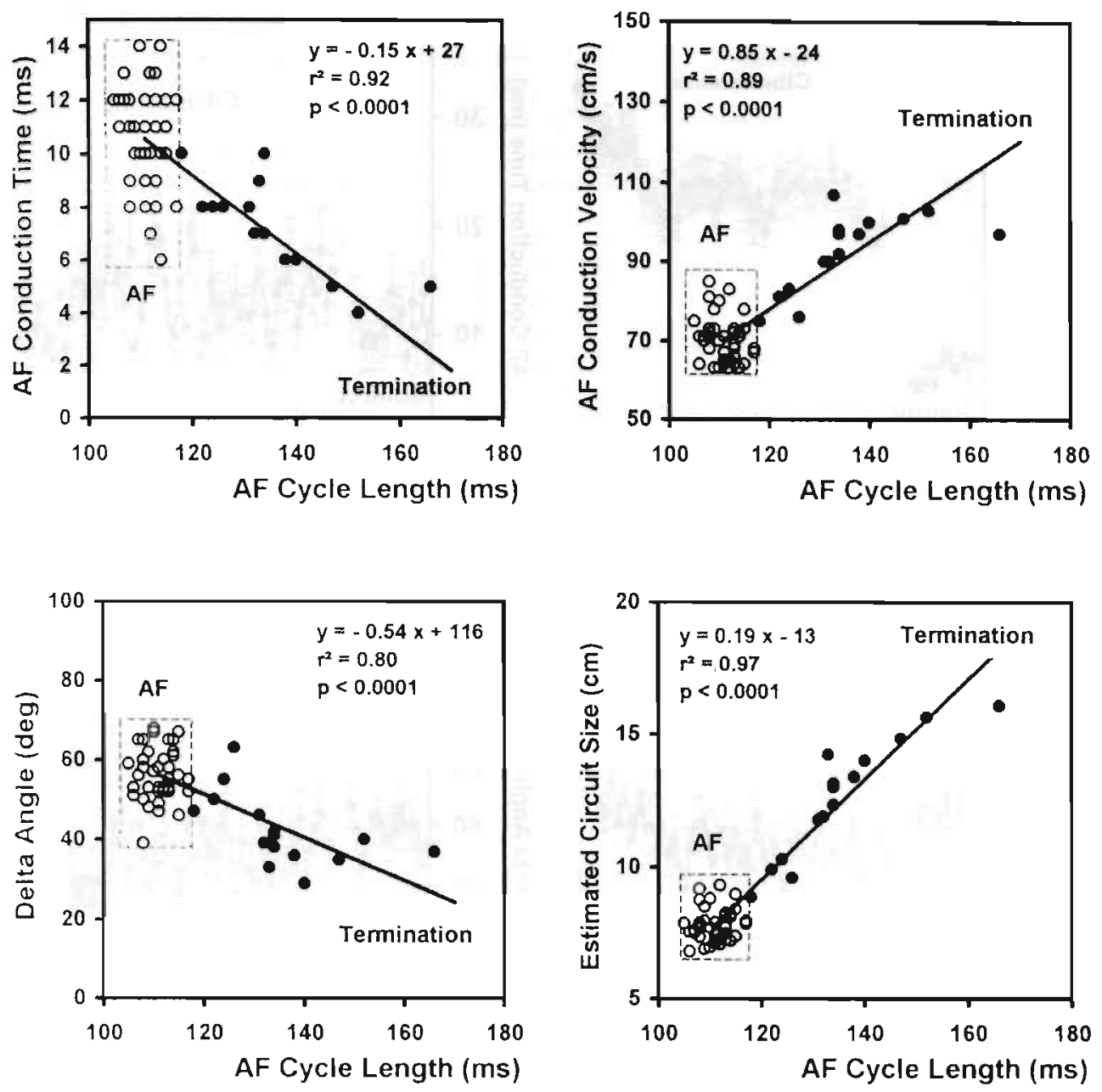

Figure 6. Correlation between progressive prolongation of the AF cycle length prior to termination and AF conduction time, conduction velocity, delta angle and estimated circuit size. The dotted boxes contain data points during ongoing atrial fibrillation. The data points outside the box were obtained during the last 15 bents before termination. Linear regression lines were calculated through these last 15 points, using the average value during ongoing atrial fibrillation as its origin. See text for description.

( $\mathrm{p}=0.16$ ) (lower right panel). The average $R R$ interval lengthened from $380 \pm 62$ to $445 \pm 129$ ms (n.s.) (not shown).

In Fig 8 the various changes by cibenzoline are related to the changes in AF cycle length. Interestingly, cardioversion of AF by cibenzoline was preceded by the same phenomena as observed during spontaneous termination of AF (compare Fig 6). During the last 13 beats prior to cardioversion by cibenzoline, the AF cycle length progressively prolonged from $176 \pm 59$ to $240 \pm 60 \mathrm{~ms}$ ( $\mathrm{p}<0.05$ ). Paradoxically. shortly before cardioversion by a class IC drug, the conduction velocity of the fibrillation 

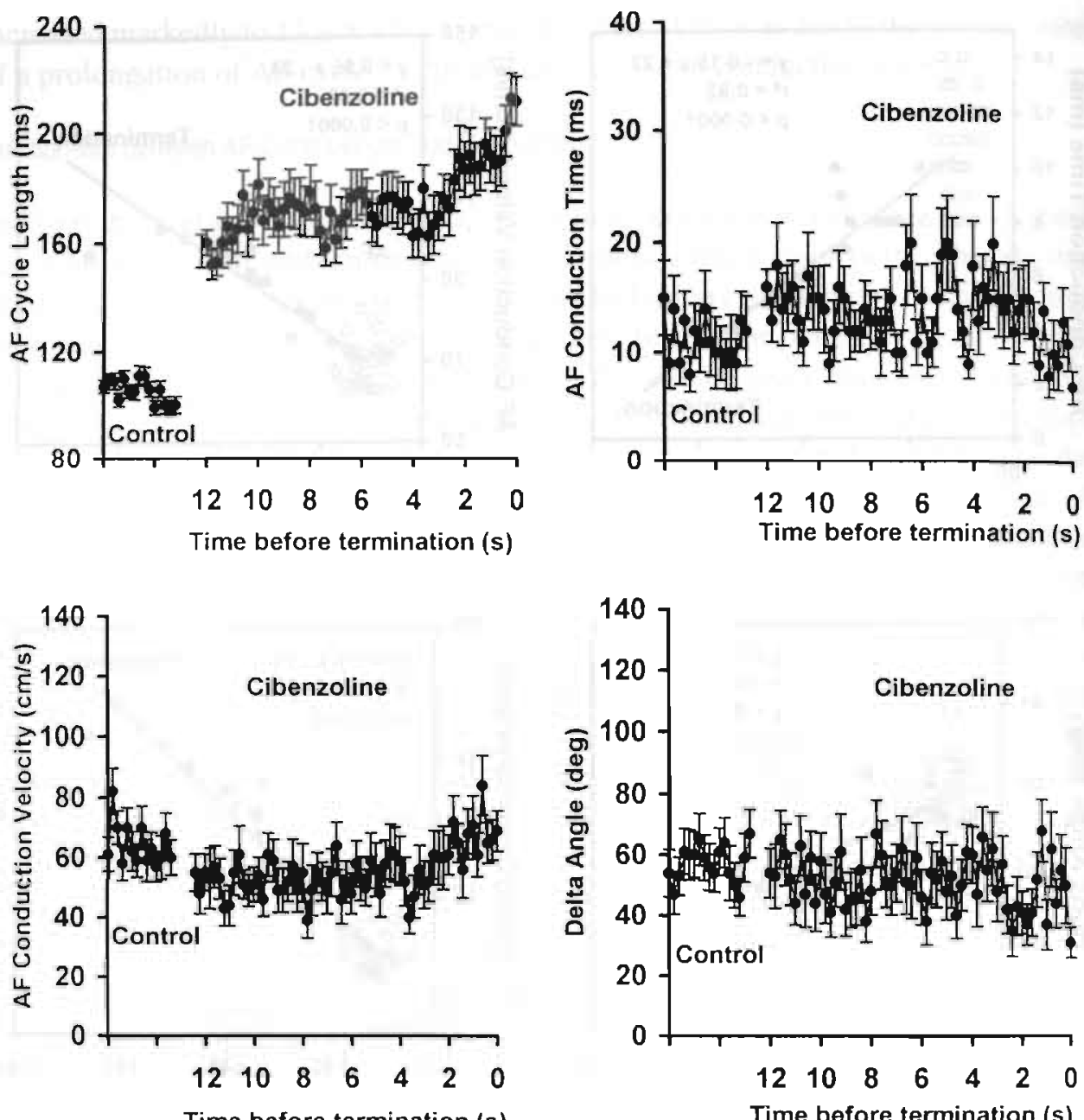

Time before termination (s)

Time before termination (s)

Figure 7. Cardioversion of chronic AF by cibenzoline. In the 4 panels the effects of cibenzoline on AF cycle length, intra-atrial conduction time, AF conduction velocity, and delta angle of the fibrillation waves are plotted during the last 12 seconds before termination of AF. There was a dose dependent increase in AF cycle length and slowing of AF conduction. Note that, like during spontaneous termination of paroxysmal AF, again a 'spontaneous' progressive prolongation of $\mathrm{AF}$ interval occurred (upper left panel) associated with an increase in conduction velocity (lower left panel).

waves increased from $51 \pm 16 \mathrm{~cm} / \mathrm{s}$ to $60 \pm 18 \mathrm{~cm} / \mathrm{s}(\mathrm{p}=0.32$ ). The delta angle between the last 2 beats prior to cardioversion decreased from $50 \pm 12$ to $30 \pm 5$ degrees $(\mathrm{p}<0.01)$. The estimated circuit size during chronic fibrillation was increased slightly by cibenzoline from an average of $7 \pm 1$ to $8 \pm 2 \mathrm{~cm}$. This increase in circuit size was limited, because the effect of the prolongation of AF cycle length on circuit size was counteracted by the concomitant decrease in conduction velocity. However, just before cardioversion the estimated circuit size markedly increased. Like during 


\begin{tabular}{|c|c|c|c|c|c|c|c|c|c|c|c|c|c|c|c|}
\hline \multirow[b]{2}{*}{ Goat \# } & \multicolumn{5}{|c|}{ Chronic Atrial Fibrillation } & \multicolumn{5}{|c|}{ After Cibenzoline. } & \multicolumn{5}{|c|}{ Last Beat } \\
\hline & $\begin{array}{l}\text { AF } \\
\text { int } \\
m s\end{array}$ & $\begin{array}{l}\text { Cond } \\
\text { Time } \\
\mathrm{ms}\end{array}$ & $\begin{array}{l}\text { Cond } \\
\text { Veloc } \\
\mathrm{cm} / \mathrm{s}\end{array}$ & $\begin{array}{l}\text { Delta } \\
\text { Ang } \\
\text { deg }\end{array}$ & $\begin{array}{l}\text { Circ } \\
\text { Size } \\
\mathrm{cm}\end{array}$ & $\begin{array}{l}\text { AF } \\
\text { Int } \\
m s\end{array}$ & $\begin{array}{l}\text { Cond } \\
\text { Time: } \\
\text { ms }\end{array}$ & $\begin{array}{l}\text { Cond } \\
\text { Veloc } \\
\mathrm{cm} / \mathrm{s}\end{array}$ & $\begin{array}{l}\text { Deita } \\
\text { Ang } \\
\text { deg }\end{array}$ & $\begin{array}{l}\text { Circ } \\
\text { Size } \\
\mathrm{cm}\end{array}$ & $\begin{array}{l}\text { AF } \\
\text { Int } \\
\mathrm{ms}\end{array}$ & $\begin{array}{l}\text { Cond } \\
\text { Time } \\
\mathrm{ms}\end{array}$ & $\begin{array}{l}\text { Cond } \\
\text { Veloc } \\
\mathrm{cm} / \mathrm{s}\end{array}$ & $\begin{array}{l}\text { Delta } \\
\text { Ang } \\
\text { deg }\end{array}$ & $\begin{array}{l}\text { Circ } \\
\text { Size } \\
\mathrm{cm}\end{array}$ \\
\hline 5 & 110 & 10 & 72 & 57 & 8 & 161 & 18 & 58 & 55 & 9 & 182 & 8 & 46 & 36 & 8 \\
\hline 8 & 116 & 11 & 69 & 53 & 8 & 148 & 18 & 37 & 55 & 5 & 264 & 13 & 77 & 29 & 20 \\
\hline 9 & 120 & 8 & 54 & 63 & 6 & 143 & 13 & 57 & 65 & 8 & 262 & 6 & 73 & 32 & 19 \\
\hline 10 & 109 & 12 & 62 & 61 & 7 & 173 & 18 & 60 & 51 & 10 & 220 & 15 & 49 & 30 & 11 \\
\hline 11 & 102 & 13 & 70 & 68 & 7 & 136 & 13 & 68 & 39 & 9 & 176 & 6 & 78 & 28 & 14 \\
\hline 12 & 88 & 11 & 67 & 44 & 6 & 293 & 12 & 27 & 33 & 8 & 334 & 8 & 36 & 22 & 12 \\
\hline Mean & 108 & 11 & 66 & 58 & 7 & $176^{*}$ & $15^{*}$ & 51 & 50 & 8 & $240^{*}$ & $g^{* *}$ & 60 & 30 & 14 \\
\hline SD & 11 & 2 & 7 & 8 & 1 & 59 & 3 & 16 & 12 & 2 & 60 & 4 & 18 & 5 & 5 \\
\hline
\end{tabular}

" $p<0.05 ; * p<0.01$.

Table 4. (Continued) Cibenzoline-Induced Termination of AF

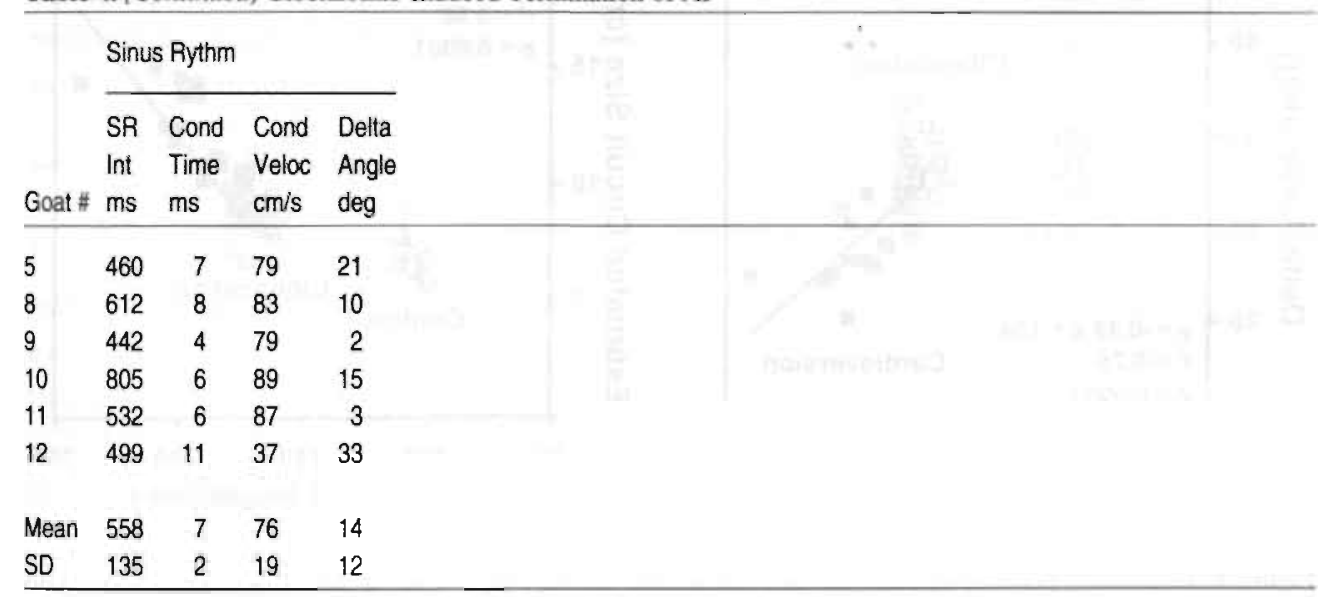

spontaneous termination of $\mathrm{AF}$, a progressive beat to beat increase in fibrillation cycle length was associated with an increase in conduction velocity. As a result the estimated size of the intra-atrial reentrant pathways increased to $14 \pm 5 \mathrm{~cm}$ just before cardioversion occurred. 

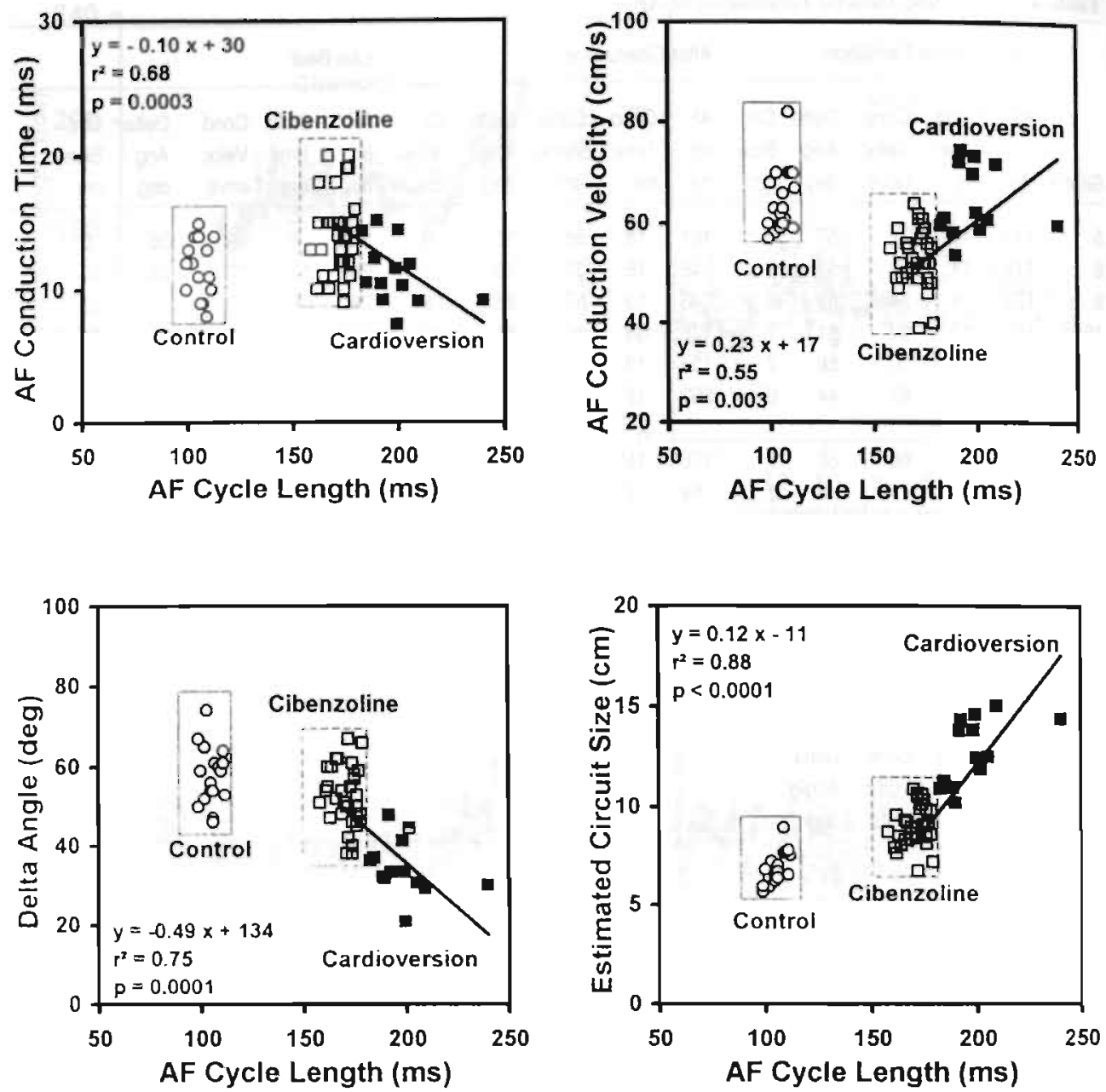

Figure 8. Correlation between changes in AF cycle length by cibenzoline and AF-conduction time. conduction velocity, delta angle and estimated circuit size. The data points in the solid boxes represent the values during chronic AF prior to infusion of Cibenzoline. The data points in the dotted boxes were recorded during the last minute before cardioversion of AF by cibenzoline. The data points outside the dotted box represent the last 13 beats before termination of AF. Cibenzoline caused a dose dependent prolongation of AF cycle length associated with an increase in conduction time, a slowing in conduction velocity, a slight decrease in delta angle and a small increase in estimated circuit size (compare values in solid and dotted boxes). Like during spontaneous termination of paroxysmal AF (compare Fig 6). also cardioversion of chronic AF by cibenzoline was preceded by a 'spontaneous' progressive increase in Af cycle length, conduction velocity and estimated circuit size. The linear regression lines were calculated from the last 13 points before termination and the mean value of the data points within the dotted box. 


\section{Discussion}

The key observation of this study is, that both spontaneous and pharmacological conversion of $\mathrm{AF}$ is preceded by a progressive prolongation of $\mathrm{AF}$ cycle length together with an increase in conduction velocity of the fibrillation waves. This is not easy to understand on the basis of a reentrant mechanism, nor is it clear what the cause and effect relationship between these two forewarning signs might be.

Although the cycle length of AF is for the largest part composed of the atrial refractory period, recent studies have shown that during $\mathrm{AF}$ also a short excitable gap exists. ${ }^{9,21,22}$ A lengthening of the AF-interval therefore may be due either to prolongation of the atrial refractory period or to a widening of the excitable gap. Because we were not able to directly measure the refractory period or the excitable gap during termination of $\mathrm{AF}$, at this point we can only speculate about the possible implications of an increase in the refractory period or a widening of the excitable gap for termination of AF. Since mapping studies have shown that both functional as well as anatomical circuits can be operative during atrial fibrillation, ${ }^{7,8,10}$ and because anisotropic tissue properties of the atria may play an important role, ${ }^{23,24}$ below we will consider the effects of changes in refractory period, excitable gap, and conduction velocity on different types of reentry.

\section{Progressive Increase in Refractory Period?}

In a large anatomical circuit with a fully excitable gap, prolongation of the refractory period initially will have no effect on the rate of the arrhythmia. Only when the excitable gap becomes so narrow that the fibers in the reentrant circuit can only partially restore their excitability, the conduction velocity of the circulating impulse will decrease and as a result, the cycle length of the reentrant arrhythmia will prolong. In smaller anatomical circuits with only a partially excitable gap, prolongation of the refractory period will slow down the arrhythmia right away, because a shortening of the excitable gap will further decrease the time for recovery of excitability and thus further depress conduction velocity. If the gap between the head and the tail of the reentrant impulse becomes too narrow, the circulating impulse will be eventually blocked and the arrhythmia will terminate.

The cycle length of both leading circle reentry ${ }^{25}$ and random reentry $y^{26}$ is primarily controlled by the refractory period, and a progressive lengthening of the atrial refractory period thus will result in progressive slowing of the arrhythmia. ${ }^{11,25,27,28}$ During atrial fibrillation the atrial refractory period may vary by changes in autonomic tone ${ }^{29}$ or the amount of stretch of the atrial wall. ${ }^{30-32}$ The rate adaptation of the atrial refractory period may also play an important role, and especially at higher rates variations in beat to beat interval may cause oscillations in the refractory period. Irregularities in AF cycle length thus might be associated with beat to beat variations in the refractory period, a short cycle being followed by a shorter and a long cycle followed by a longer refractory period. When the gain of such a positive feed back 
mechanism is high, atrial fibrillation might be unstable. A casual long AF cycle length (for instance due to the absence of a nearby wandering wavelet) will then be followed by a long refractory period and this in turn will increase the likelihood that the next cycle will be long also. In this way a progressive beat to beat prolongation of AF cycle length might occur which (due to the concomitant increase in wavelength) will lead to termination of AF. The possible role of a diminished rate adaptation of the refractory period in stabilizing atrial fibrillation has been suggested by Attuel et al. and Le Heuzey et al. ${ }^{33-35}$ These investigators showed that in patients with chronic atrial fibrillation the adaptation of the atrial refractory period to changes in heart rate was lost. Interestingly, this was also true in our goat model of sustained AF in which the normal rate adaptation of the refractory period was even inversed (i.e. the refractory period became shorter at longer cycle length). ${ }^{16}$ When the adaptation of the refractory period to changes in heart rate is lost, a spontaneous increase in AF cycle length obviously will no longer lead to an increase in refractory period. This may stabilize the fibrillatory process because long AF cycles are no longer followed by a longer refractory period. As a result, the odds will be against a progressive prolongation of AF cycle length, which in the present study was found to be a primary event in termination of atrial fibrillation. A progressive prolongation of the refractory period also would not explain the increase in conduction velocity which we found to be associated with termination of AF. If an increase in AF cycle length is due to a lengthening of the refractory period, the time for the atrial fibers to restore their excitability would remain the same, and despite the slowing in rate of AF, the fibrillation waves would continue to propagate through partially excitable tissue with the same depressed velocity.

\section{Progressive Widening of the Excitable Gap?}

The obscrvation that the prolongation of AF cycle length preceding termination of $\mathrm{AF}$ is associated with a concomitant increase in conduction velocity of the fibrillation waves rather points to a widening of the excitable gap. Depending on the type of reentry, the mechanisms that lead to a widening of the excitable gap are different.

In anatomical reentry the excitable period is determined by the difference between the duration of the refractory period and the revolution time around the anatomic obstacle. In this situation the excitable period can get longer by: 1) A shortening of the refractory period, 2) an increase in the size of the anatomical circuit, or 3) a decrease in the average conduction velocity around the circuit. In the present context the first possibility can be ignored, since it will not be associated with a prolongation of the reentrant cycle length. The second mechanism might be involved if the rate of a reentrant arrhythmia suddenly gets lower or when one arrhythmia converts to another (for instance the transition from fibrillation to flutter). In case of a progressive beat to beat increase in cycle length however, this does not seem a very likely mechanism, since it is hard to imagine how a series of beat-to-beat increases in size of an anatomical circuit might occur. At first sight, also the third possibility seems to be 
excluded since termination of $\mathrm{AF}$ was associated with an increase rather than a decrease in conduction velocity of the fibrillation waves. However, this mechanism should still be seriously considered in case of an anatomical circuit comprising an area of slow conduction. If the segment of slow conduction becomes further depressed, the average conduction velocity around the circuit might decrease (causing a slowing of the arrhythmia), whereas in the non-depressed parts of the circuit the conduction may actually speed up (as a consequence of the slowing in rate). Thus a progressive Wenckebach-like slowing of conduction in part of the circuit may lead to a progressive slowing of the arrhythmia associated with a progressive increase in conduction velocity in other parts of the heart.

Under some circumstances, also in leading circle reentry a short excitable gap may exist. In this type of reentry there is no anatomic obstacle which forces the impulse to travel in a longer circuit than necessary. Instead the impulse is circulating around a central line of functional conduction block created by the circulating impulse itself, and the revolution time of the impulse will be determined by its own refractory period. In a combined numerical and biological study Cabo et al. have demonstrated that the curvature of the wave front plays an important role in propagation in two-dimensional cardiac muscle and that changes in curvature may cause slow conduction or block. ${ }^{36}$ Thus, if reentrant circuits are very small, or if the wavefront is making a sharp U-turn at the ends of a central line of block (for instance due to tissue anisotropy), the local curvature at the pivot point will be very high and, as a result, the excitatory current generated by the cells at the crest of the wave will be dissipated in the large wedge of tissue ahead. In particular when a wavefront tries to make a sharp U-turn around a line of block oriented parallel to the fiber orientation, the turning wave will face a very low impedance at the pivot point due to the low coupling resistance of the longitudinal fibers. If the amount of current generated by the cells at the pivot point is not enough to depolarize the fibers around the pivot point to their threshold value, the wave will not be able to make a sharp U-turn. In stead the impulse will make a wider turn around the pivot point with a much lower curvature of its wavefront. The resulting conduction delay at the turning points by such an impedance mismatch, will create a short excitable gap in the reentrant circuit. ${ }^{36-39}$ The width of this partially excitable gap will depend on the safety factor for conduction. If the safety for conduction is still high, the excitable gap may be very small. However, if the current generated by the myocardium is diminished (depressed action potential), or the amount needed to excite the fibers is increased (excitability), the excitable gap may become wider. It is difficult to say, what in this case the net effect on the conduction velocity of fibrillation waves will be. At one hand lowering of the safety factor will lower the conduction velocity, whereas on the other hand a decrease in the rate of fibrillation and the associated widening of the excitable gap will increase the conduction velocity.

During random reentry (when a wave is reentering the tail of another wave), there are two reasons why an excitable gap may exist: 1) After the fibers have recovered 
their excitability, another wave may not always immediately be available to excite them, and an excitable gap simply arises because the cells have to wait until one of the other wavelets has reached them. 2) Even if a fibrillation wave reenters the tail of another wave immediately after the end of its refractory period, an excitable gap will arise at more remote areas. Due to the opposite direction of the reentering waves, the local cycle lengths will be determined by the sum of the cycle length at the site of random reentry plus the antegrade and retrograde conduction times to and from that point of reentry (for an illustration see Fig 10 of reference \#10).

The excitable gap during random reentry thus is a complex phenomenon, not only varying from site to site and from cycle to cycle, but also being determined by multiple variables like the local refractory period, intra-atrial conduction velocity and the number of waves. The number of wandering waves seems to be the major determinant of the duration of the excitable gap during random reentry. The more wavelets are present, the higher the chance that one of them will be in the immediate neighborhood as soon as the fibers have restored their excitability and thus the average 'waiting time' will be short. On the other hand, if for any reason the number of wavelets gets smaller, the average waiting time will get longer and consequently, on the average, the excitable period will be prolonged.

\section{Estimated Size of Intra-atrial Circuits during AF}

The maximal number of reentering fibrillation waves during AF is determined by the size of the atria and the length of the intra-atrial circuits. In the series of experiments given in Table 3 the AF waves had a mean cycle length of $113 \mathrm{~ms}$ and an average conduction velocity of $68 \mathrm{~cm} / \mathrm{s}$. Thus, during an average cycle length, the AF waves propagated over a distance of $7.7 \mathrm{~cm}$ Simplifying the compli-cated patterns of excitation during AF to circular-shaped circuits, the diameter of these circuits then can be estimated to be about $2-3 \mathrm{~cm}$. Prior to spontaneous termination of $\mathrm{AF}$, both $\mathrm{AF}$ cycle length and intra-atrial conduction velocity progressively increased to a value of $165 \mathrm{~ms}$ and $99 \mathrm{~cm} / \mathrm{s}$ during the last beat before termination. Assuming that no areas of slow conduction were involved, the last reentrant pathway thus must have had a length of more than $16 \mathrm{~cm}$ and a diameter of more than $5 \mathrm{~cm}$.

\section{The Effects of Cibenzoline}

Infusion of cibenzoline increased the average fibrillation interval from $108 \pm 11$ to $176 \pm 59 \mathrm{~ms}$ and at the same time slowed the velocity of the fibrillation waves from $66 \pm 7$ to $51 \pm 16 \mathrm{~cm} / \mathrm{s}$. Because an increase in cycle length and a decrease in conduction velocity have opposite effects on the size of a reentrant circuit, the estimated length of the fibrillation circuits increased only slightly from 7 to $8 \mathrm{~cm}$ (see Table 4). Like during spontaneous termination of atrial fibrillation, also during cardioversion by cibenzoline, the actual conversion to sinus rhythm was preceded by a 'spontaneous' progressive slowing of the rate of fibrillation. Likewise, this slowing 
of the rate of fibrillation was associated with an increase in conduction velocity of the fibrillation waves. And again, during the last fibrillatory cycles the length of the circuitous pathway of the fibrillation waves dramatically increased. With an average last fibrillation interval of $240 \mathrm{~ms}$ and a conduction velocity of $60 \mathrm{~cm} / \mathrm{s}$ (Table 4), the last intra-atrial circuits must have been as long as $14 \mathrm{~cm}$ (diameter about $5 \mathrm{~cm}$ ). Given the size of the atria, such a long estimated length of the last intra-atrial circuit makes it understandable that fibrillation could no longer perpetuate itself. However we like to emphasize that the estimation of the size of the fibrillation circuits is based on the assumption that no areas of slow atrial conduction were involved.

\section{Mechanisms of Termination of AF}

Since in 1959 Moe and coworkers demonstrated that AF is a self-sustaining arrhythmia independent of focal discharge, it has been generally accepted that the stability of the fibrillatory process depends on the number of wavelets which are wandering through the myocardium. ${ }^{5,7}$ Later we have emphasized the role of the wavelength of the atrial impulse for initiation and termination of AF. ${ }^{12}$ Because the wavelength determines the maximum number of wavelets that can be present in the atria, drugs that prolong the wavelength are considered to possess anti-fibrillatory properties. Nattel and coworkers have studied the mechanisms through which various antiarrhythmic drugs like flecainide, procainamide, propafenone and sotalol cardiovert atrial fibrillation in dogs subjected to vagal nerve stimulation. ${ }^{13,14,40}$ They concluded that: "antiarrhythmic drugs terminate experimental AF by increasing the wavelength for reentry at rapid rates, leading to a reduction in the number of functional reentry circuits and, eventually, failure of reentrant excitation." 14 After Kirchhof et al. had shown that an experimental class IC drug (ORG 7797) preferentially prolonged the atrial refractory period at higher pacing rates, ${ }^{41}$ Nattel's laboratory demonstrated that flecainide caused a tachycardia-dependent increase in atrial effective refractory period, outweighing the depression in conduction velocity and thus increasing the wavelength. ${ }^{13}$ By mapping the activation of the atria during AF with an array of 112 bipolar electrodes, they found a significant reduction in the number of circuits after 5 minutes of flecainide infusion and a further decrease immediately prior to termination of $\mathrm{AF}$, the size of the intra-atrial circuit(s) being clearly increased just before $\mathrm{AF}$ terminated. ${ }^{13}$ Brugada et al. ${ }^{42}$ studied the effects of a single intravenous dose of cibenzoline in 20 patients with spontaneous and induced atrial fibrillation. In 18 of 20 patients, AF (mean cycle length $147 \pm 34 \mathrm{~ms}$ ) was converted into a regular flutter with a cycle length of $302 \pm 34$ ms. In one patient undergoing a 'corridor' operation, epicardial mapping of both atria during administration of cibenzoline showed fusion of multiple wavelets into a single broad wavefront around the caval veins. Instead of contributing the anti-fibrillatory effects of cibenzoline to a prolongation of the atrial wavelength, they proposed that this transformation of random reentry into ordered reentry was primarily due to the depression of intra-atrial conduction leading to conduction block of the fibrillating waves and reduction of the number of waves. 
The observation in our present study that termination of AF was associated with an increase in cycle length and conduction velocity of the fibrillation waves, suggests that conversion of AF was not primarily due to an increase in wavelength but to a progressive widening of the excitable gap. As has been discussed above, there are several possible mechanisms for a widening of the excitable gap, depending on the type of reentry involved. A sudden widening of the excitable gap may be the result of a sudden increase in size of the reentrant pathway. This may happen if smaller functionally determined circuits are interrupted, either by chance or under the influence of a drug, and are replaced by larger waves traveling around one or more of the atrial anatomical obstacles. In such a case it will depend on the number of the anatomical circuits and their cycle length, whether 'fine' fibrillation is transferred into 'coarse' AF, or whether AF will be converted into flutter. A more gradual widening of the excitable gap may occur by 1) a progressive conduction delay in an area of depressed conduction incorporated in an anatomical circuit, 2) widening of the U-turn at the pivot points of functional anisotropic reentry, or 3) a progressive decrease in the number of wavelets during random reentry.

Although none of these explanations can yet been excluded, in our opinion the last possibility offers the most likely hypothesis for the supposed widening of the excitable gap associated with spontaneous or drug-induced termination of atrial fibrillation.

Limitations

A clear limitation of the present study is that no activation maps were obtained and that no direct information is as yet available about the spatio-temporal variations in refractory period and excitable gap during AF. Therefore, most of what has been discussed above remains speculative and -as Moe liked to saly - must be regarded as 'a piece of arm-chair physiology'. Before we can decide upon the different roles played in termination of fibrillation by 'depression of the action potential', 'prolongation of the wavelength', and 'widening of the excitable gap', techniques have to be developed to actually measure the excitable gap during AF.

Acknowledgments

We are grateful to Dr. N. Kormoss from Continental Pharma/Searle (Belgium) for his enthusiastic support, and to the Con selleria de Cultura de Valencia for supporting a 4-month stay of Dr. F.J.Chorro at the Department of Physiology of the University of Limburg.

\section{References}

1 Godtredsen J: Arrial fibrillation; etiology, course and prognosis. A follow-up study of 1212 cases. Copenhagen, Munksgaard, 1975. 
2 Kannel WB, Abbott RD, Savage DD, McNamara PM: Epidemiologic features of chronic atrial fibrillation: the Framingham study. $N$ Engl I Med 1982;306:1018-1022

3 Petersen P. Godtfredsen J: Atrial fibrillation: a review of course and prognosis. Acta Med Scand $1984 ; 216: 5-9$

4 Kopecky SL, Gersh BJ, McGoon MD, Whisnant JP, Holmes DR, Ilstrup DM, Frye RL: The natural history of lone atrial fibrillation: a population based study over three decades. $N$ Engl $I$ Med 1987;317:669-674

5 Moe GK, Abildskov JA: Atrial fibrillation as a self-sustaining amhythmias independent of focal discharge. Am Heart $J$ 1959:58:59-70

6 Moe GK. Rheinboldt WC, Abildskov JA: A computer model of atrial fibrillation. Am Heart $J$ 1964;67:200-220

7 Allessie MA, Lammers WJEP, Bonke FIM, Hollen SJ: Experimental evaluation of Moe's multiple wavelet hypothesis of atrial fibrillation. in Zipes DP, Jalife J (eds): Cardiac Electrophysiology and Arrhythmias. NY, Grune \& Stratton, 1985, pp 265-275

8 Cox JL, Canavan TE, Schuessler RB, Cain ME, Lindsay BD, Stone CM, Smith PK, Corr PB, Boineau JP: The surgical treatment of atrial fibrillation. II. Intraoperative electrophysiologic mapping and description of the electrophysiologic basis of atrial flutter and atrial fibrillation.J Thor Card Surg 1991;101:406-426

9 Kirchhof CJHJ, Chorro FJ. Scheffer GJ, Brugada J, Konings KTS, Zetelaki Z, Allessie MA: Regional entrainment of atrial fibrillation studied by high-resolution mapping in open-chest dogs. Circulation 1993;88:736-749

10 Konings KTS, Kirchhof CJHJ, Smeets JLRM, Wellens HJJ, Penn OC, Allessie MA: High-density mapping of electrically induced atrial fibrillation in humans. Circulation 1994;89:1665-1680

11 Smeets JLRM, Allessie MA. Lammers WJEP, Bonke FIM, Hollen SJ: The wavelength of the cardiac impulse and reentrant arrhythmias in isolated rabbit atrium. The role of heart rate, autonomic transmitters, temperature. and potassium. Circ. Res 1986:58:96-108

12 Rensma PL. Allessie MA. Lammers WJEP, Bonke FIM. Schalij MJ: Length of excitation wave and susceptibility to reentrant atrial arrhythmias in normal conscious dogs. Circ Res 1988:62:395-410

13 Wang Z, Page PL, Nattel S: Mechanism of flecainide's antiarrhythmic action in experimental atrial fibrillation. Circ Res 1992;71:271-287

14 Wang J, Boume GW, Wang Z, Villemaire C, Talajic M, Nattel S: Comparative mechanisms of antiarrhythmic drug action in experimental atrial fibrillation. Circulation 1993:88:1030-1044

15 Sih HJ, Ropella KM, Swiryn S, Gerstenfeld EP. Sahakian AL: Observations from intra-atrial recordings on the termination of electrically induced atrial fibrillation in humans. Pace 1994;17:1231-1242

I6 Wijffels MCEF, Kirchhof CJHJ, Dorland R, Allessie MA: Atrial fibrillation begets atrial fibrillation. A study in awake chronically instrumented conscious goats. Circulation 1995:92:1954-1968

17 Allessie MA. Hoeks APG. Schmitz GML. Reneman RS: On-line mapping system for the visualization of the electrical activation of the heart. Int J Cardiac Imag 1986:2:59-63

18 Wells JL, Karp RB, Kouchoukos NT, Maclean WAH, James TN, Waldo AL: Characterization of atrial fibrillation in man: Studies following open heart surgery. Pace 1978;1:426-438

19 Browne KF, Prystowksky EN, Zipes DP, Chilson DA, Heger JJ: Clinical efficacy and electrophysiologic effects of Cibenzoline therapy in patients with ventricular arrhythmias. J Am Coll Cardiol $1984: 3: 857-864$

20 Holk M, Osterrieder W: Inhibition of the myocardial Ca2+ inward current by the class I antiarrhythmic agent Cibenzoline. Clin Pharmacol Ther 1987;41:537-545

2I Allessie MA, Kirchhof CJHJ, Scheffer GJ, Chorro FJ, Brugada J: Regional control of atrial fibrillation by rapid pacing in conscious dogs. Circulation 1991;84:1689-1697

22 Kalman JM. Olgin JE, Karch MR. Lesh MD: Regional entrainment of atrial fibrillation in man. J Cardiovasc Electrophysiol, in press, 1996 
23. Spach MS, Miller WT, Dolber PC, Kootsey JM, Sommer JR, et al: The functional role of structural complexities in the propagation of depolarization in the atrium of the dog: cardiac conduction disturbances due to discontinuities of effective axial resistivity. Circ Res 1982:50:175-191

24 Spach MS, Dolber PC: Relating extracellular potentials and their derivatives to anisotropic propagation at a microscopic level in human cardiac muscle. Evidence for electrical uncoupling of side-to-side fiber connections with increasing age. Circ Res 1986;58:356-371

25 Allessie MA, Bonke FIM, Schopman FJG: Circus movement in rabbit atrial muscle as a mechanism of tachycardia. III.The "leading circle" concept: A new model of circus movement in cardiac tissue without the involvement of an anatomical obstacle. Circ Res 1977;41:9-18

26. Hoffman BF, Rosen MR: Cellular mechanisms for cardiac arrhythmias. Circ Res 1981:49:1-15

27 Allessie MA, Bonke FIM, Lammers WJEP: The effects of carbamylcholine, adrenaline, ouabain, quinidine and verapamil on circus movement tachycardia in isolated segments of rabbit atrial myocardium. in Kulbertus HE (ed): Reentrant arrhythmias. Mechanisms and treatment. Lancaster, M.TP Press Limited, 1977, pp 63-71

28 Farges JP, Faucon G. Lievre M, Ollagnier M: Relationship between atrial and ventricular rates of fibrillation and cardiac contractile tissue effective refractory periods in the dog. Br J Pharmacol 1978:63:587-591

29 Coumel P. Attuel P, Lavallee J, Flammang D, Leclercq JF, Slama R: Syndrome d'arythmie auriculaire d'origine vagale. Arch Mal Coeur 1978;71:645-656

30 Solti F, Vecsey T, Kekési V, Juhász-Nagy A: The effect of atrial dilatation on the genesis of atrial arrhythmias. Cardiovasc Res 1989:23:882-886

31 Calkins H, El-Atassi R, Kalbfleisch S, Langberg J. Morady F: Effects of an acute increase in atrial pressure on atrial refractoriness in humans. Pace 1992;15:1674-1680

32 Klein LS, Miles WM, Zipes DP: Effect of atrioventricular interval during pacing or reciprocating tachycardia on atrial size, pressure, and refractory period. Contraction-excitation feedback in human atrium. Circulation 1990:82:60-68

33 A.tuel P. Childers RW, Cauchemez B, Poveda J, Mugica J, Coumel P: Failure in the rate adaptation of the atrial refractory period: its relationship to vulnerability. Int J Cardiol 1982:2:179-197

34 Attuel P, Childers RW. Haissaguerre M, Leclercq J, Mugica J, Coumel P: Failure in the rate adaptation of the atrial refractory periods: new parameter to assess atrial vulnerability. Pace 1984:7:1382

35 Le Heuzey J, Boutjdir M, Gagey S, Lavergne T, Guize L: Cellular aspects of atrial vulnerability, in Attuel P. Olsson SB. Schlepper M (eds): The atrium in Health and Disease. Mount Kisco, Futura Publishing, 1989. pp 81-94

36 Cabo C. Pertsov AM, Baxter WT, Davidenko JM, Gray RA, Jalife J: Wave-front curvature as a cause of slow conduction and block in isolated cardiac muscle. Circ Res 1994;75: 1014-1028

37 Allessie MA, Schalij MJ, Kirchbof CJHJ, Boersma LVA, Huyberts MSP, Hollen SJ: Experimental electrophysiology and arrhythmogenicity. Anisotropy and ventricular tachycardia. Eur Heart $J$ 1989:;0 (suppl E):2-8

38 Boersma LVA, Buggada J, Kirchhof CJHJ, Allessie MA: Mapping of reset of anatomic and functional reentry in anisotropic rabbit ventricular myocardium. Circulation 1994:89:852-862

39 Wit AL. Allessie MA: Functional models of reentry: a comparison of anisotropic and leading circle reentry, in Waldo AL, Touboul P (eds): Arrial flutter. Armonk, New York, Futura Publishing Company, 1996.

40 Wang J. Feng J. Nattel S: Class III antiarrhythmic drug action in experimental atrial fibrillation. Differences in reverse use dependence and effectiveness between d-Sotalol and the new antiarrhythmic drug Ambasilide. Circulation 1994:90:2032-2040

41 Kirchhof CJHJ, Wijffels M, Brugada J, Planellas J, Allessie MA: Mode of action of a new class IC drug (ORG 7797) against atrial fibrillation in concious dogs. J Cardiovasc Pharmacol 1991:17:116124

42 Brugada J, Gursoy S, Brugada P. Atie J, Guiraudon GM. Andries E: Cibenzoline transforms random re-entry into ordered re-entry in the atria. Eur Heart J 1993;14:267-272 


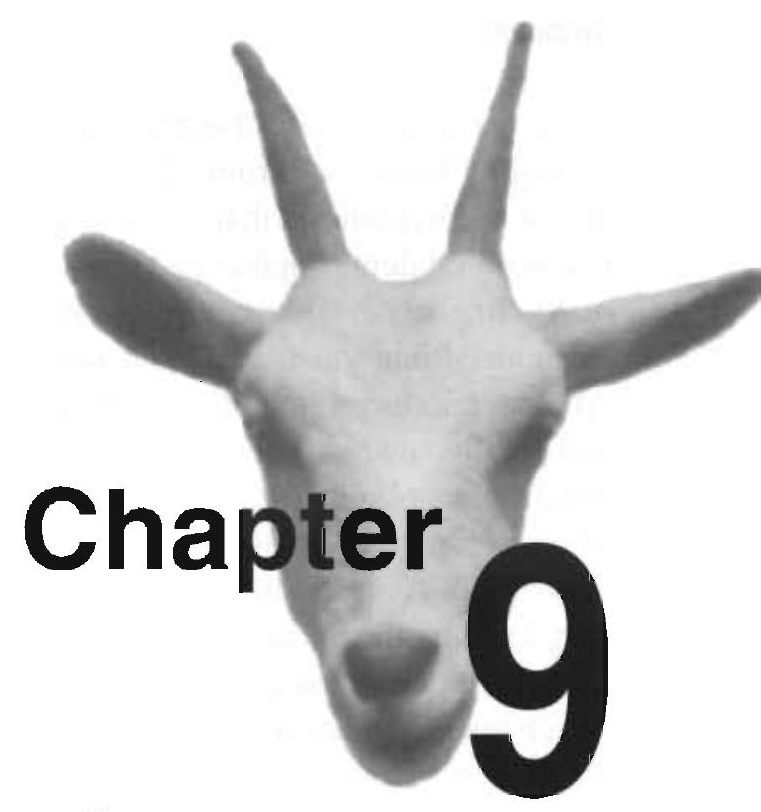

General Discussion; Possible Implications 


\section{Synopsis}

The present thesis describes the electrophysiological effects of Atrial Fibrillation (AF) in healthy hearts of chronically instrumented goats. The initial aim of the study was to test the hypothesis that 'Atrial Fibrillation begets Atrial Fibrillation', which was based on epidemiological and clinical observations suggesting a progressive nature of AF. In goats that had been in normal sinus rhythm during their whole life, AF could be induced but was usually self-terminating within a few seconds. However, when $\mathrm{AF}$ was reinduced repetitively, the duration of $\mathrm{AF}$ episodes increased progressively and finally, within a few weeks of pacing, led to the development of chronic AF. Electrophysiological studies revealed a dramatic shortening of the atrial effective refractory period (AERP) while no significant depression in intra-atrial conduction was found. As a result, the atrial wavelength was shortened which could at least in part explain the increased propensity for AF. In addition, the shortening of the refractory period was much more pronounced at slow heart rates than at fast rates which resulted in an attenuation or sometimes even inversion of the physiological rate adaptation of refractoriness. While in normal (sinus rhythm) hearts, the refractory period prolongs in response to a slowing of the heart rate, now the refractory period failed to prolong and sometimes became even shorter when heart rate was slowed down.

The shortening of the atrial refractory period seemed not to be caused by a higher activity of the autonomic nervous system, ischemia of the atrial myocardium or by increased blood levels of the atrial natriuretic factor (ANF). Although acute atrial stretch by volume loading did not shorten the AERP, it could not be excluded completely that chronic atrial stretch for days or weeks is involved in the process of electrical remodeling. Finally, the high rate of atrial activation itself as is present during AF seemed to be the trigger for the AF-induced shortening of the refractory period. After 1-2 days of rapid pacing (interval $180-200 \mathrm{~ms}$ ) the atrial refractory period had not only shortened at all heart rates but also the adaptation to changes in heart rates became attenuated or reversed.

After AF had become chronic, the efficacy of several anti-fibrillatory agents with class IA, IC and III properties was studied, revealing some new findings. Although all drugs were effective in cardioversion of chronic AF, none of the drugs prolonged atrial wavelength at slow rates and the reinducibility of AF by a single early premature stimulus remained as high as $66 \%$ for cibenzoline to $100 \%$ for hydroquinidine, flecainide and $d$-sotalol. Interestingly, also the class III drug $d$-sotalol, which has a clear reverse use-dependency failed to prolong the refractory period at slow rates and the AERP remained as short as $71 \pm 19 \mathrm{~ms}$. The prolongation of the atrial refractory period by cibenzoline to $123 \pm 30 \mathrm{~ms}$ seemed promising, however due to the drug's depression of conduction velocity cibenzoline failed to prolong the atrial wavelength and the inducibility still remained as high as $66 \%$. 
In this thesis we also describe the electrophysiological effects of anti-fibrillatory drugs during chronic atrial fibrillation. The effects on AF cycle length, refractory period during $\mathrm{AF}$ and conduction velocity during entrainment of AF were measured to estimate the drug-induced changes in atrial wavelength, circuit size and excitable period (in ms) and excitable gap (in $\mathrm{cm}$ ) during AF. Similar to previous studies, all drugs prolonged the AF cycle length and were effective in cardioversion of AF. However, all class IA, IC and III drugs tested failed to prolong the atrial wavelength during $\mathrm{AF}$, which up to now was considered the mechanism of their anti-fibrillatory action. Although at least some of the anti-fibrillatory actions of hydroquinidine and $d$-sotalol could be attributed to a prolongation of the circuit size during AF, cibenzoline did not change circuit size while flecainide even shortened the circuit size considerably despite clear anti-fibrillatory effects of both drugs. The key observation in these experiments was that all drugs prolonged the AF cycle length considerably more than the atrial refractory period during AF. As a result, the excitable period during AF became wider. Next to a prolongation of wavelength and circuit size, this widening of the excitable period thus may be an important anti-fibrillatory property. We hypothesized that a wide excitable period plays a destabilizing role in the balance between genesis of new wavelets and dying out of old wavelets, which together determine the number of wavelets that is present during AF. New wavelets are usually formed by division of existing waves around areas of (functional) conduction block and a long excitable period may prevent the occurrence of functional conduction block and by that prevent the genesis of new wavelets.

Implications for Future Experimental Research

The observations as described in the present thesis evoke a number of questions that should be addressed in future studies. Up to now we do not know what channels are involved in the AF-induced shortening of the atrial refractory period and action potential duration. Theoretically these effects can be caused either by a decrease in inward current or an increase in outward current. The maladaptation of the atrial refractoriness might give us some clues about the possible channels involved. Several studies have indicated that the stimulation/up-regulation of transient outward currents, ${ }^{1,2}$ ATP-regulated potassium currents, ${ }^{3}$ or acetylcholine activated potassium channels, ${ }^{4,5}$ or the depression/down-regulation of calcium currents ${ }^{2,6}$ can cause a shortening of refractoriness which is more pronounced at slow rates. Although in our goat studies, the role of ATP-regulated potassium channels and acetylcholine activated potassium channels for the AF-induced shortening of atrial refractoriness seemed rather unlikely, future studies using isolated atrial myocytes from fibrillating atria are needed to elucidate this observation. Once the 'atrial fibrillation' channel is identified, it may open the possibility for the development of specific blockers or openers (in case of down-regulation) which may provide an alternative basis for the development of anti-fibrillatory drugs. 
Theoretically, the stimuli responsible for the development of electrical remodeling can be different from the factors responsible for maintenance of the electrically remodeled state. Intra-cellular changes in $\mathrm{Na}^{+}$or $\mathrm{Ca}^{2+}$ ions being a result of the high rate of electrical activation during AF or rapid pacing 7,8 might be the trigger for upor down-regulation of ion-channels. Especially if one is concerned about the prevention of electrical remodeling, it will be important to know the stimuli that are involved. Chatelain et al. reported a down-regulation of $\mathrm{Ca}^{2+}$-channels in response to an isoproterenol induced intracellular $\mathrm{Ca}^{2+}$ overload, which was prevented after blocking the $\mathrm{Ca}^{2+}$ channels with SR 33557. More direct evidence that $\mathrm{Ca}^{2+}$ overload might serve as an intra-cellular stimulus for the AF-induced shortening of atrial refractoriness was recently provided by Tieleman et al. ${ }^{9}$ showing that the process of electrical remodeling can be delayed by the $\mathrm{Ca}^{2+}$ channel blocker verapamil.

The repetitive induction of atrial fibrillation resulted in a progressive increase in the duration of AF-episodes which was associated with a marked shortening of atrial refractoriness and an attenuation or reversion of its adaptation to changes in heart rate. However, due to an increase in both atrial vulnerability and stability of AF, the changes in atrial refractory period could only be followed directly during the first 2-4 days of AF. Previous studies ${ }^{10-12}$ showed a good correlation between the local fibrillation interval and the local refractory period suggesting that the AF-interval can be used as an index of local refractoriness. The measurements of the AF-interval allowed us to follow the time course in changes in refractoriness for a much longer period of time. The observed changes in AF-interval indicated that during the first 24 hours of AF atrial refractoriness shortened with about $2 \mathrm{~ms}$ per hour, during the following days with only a few milliseconds per day while after about 6 days a new steady state in atrial refractoriness was reached. In contrast, the stability of atrial fibrillation continued to increase after the first week of maintained AF and in many goats AF became chronic after more than 2-4 weeks of pacing. This discrepancy in time course of the shortening of the AF-interval / "atrial refractoriness" and the increase in stability of AF indicates that also other factors may be involved in the development of chronic AF. Future research is needed to solve the following questions:

1) Does the refractory period further shorten after the first days of AF? The local atrial fibrillation interval did not shorten significantly anymore after the first 6 days of AF. However, as shown by Allessie et al. and Kirchhof et al. ${ }^{13.14}$ during AF a small excitable gap can be present indicating that the median AF-interval is certainly not equal to the atrial refractory period. In addition, in the present thesis it was shown that the prolongation of the AF-interval by anti-fibrillatory drugs was not associated with similar changes in the atrial refractory period during AF. Using the techniques enabling the measurement of the refractory period during AF itself or during stable entrainment of AF would allow to follow the changes in refractory period during a much longer time-course and even during chronic $\mathrm{AF}$.

2) What is the role of maladaptation of atrial refractorine'ss for the perpetuation of $A F$ ? The physiological rate adaptation may play a role in the spontaneous termina- 
tion of AF. During AF, the interval varies on a beat to beat basis which is likely to be associated with concomitant variations in the local refractory period. If a long AF-interval is followed by a long refractory period, the likelihood for the next AF-interval to be long is increased as well. Such a positive feed-back mechanism might form the basis for the observed progressively increasing AF-intervals prior to the termination of AF. However, if during atrial fibrillation the rate adaptation of the refractory period is lost or even reversed, a long interval will now be followed by a short refractory period, making another long interval more unlikely. Some preliminary studies, in which the refractory period could be measured during entrainment of (sustained) AF indicated that the adaptation of atrial refractoriness indeed was attenuated. These experiments could be extended by using a single stimulus during $\mathrm{AF}$ to relate the refractory period directly to the immediately preceding AF-interval. Analysis of the length of subsequent AF-intervals might be used to show a positive feedback mechanism of long intervals in AF of recent onset (long interval more likely followed by another long interval) while this feedback mechanism might be lost in chronic AF (long interval more likely to be followed by a short interval).

3) Is their a role for (local) depression of atrial conduction properties? As previously mentioned, AF did not depress the intra-atrial conduction velocity during the initial 2-4 days of AF during which electrophysiological studies still could be performed. Also after cardioversion of chronic atrial fibrillation, the conduction velocity along Bachmann's bundle was only moderately depressed and because these effects were not reversible it could not be established whether these changes were the result of AF or the effect of the long-term implantation of the electrodes. Recently van der Velden et al. (personal communication) studied the distribution of connexin (Cx) 40 and 43 (gap junction proteins) in tissue samples taken from atria of goats in sinus rhythm and of goats in chronic AF. It was found that the expression pattern of $\mathrm{Cx} 43$ was unchanged, while the pattern for $\mathrm{Cx} 40$ showed sinall discontinuities in areas of $100-600 \mu \mathrm{m}$. In the same study, in five goats the atrial conduction velocity in the free wall of the right atrium was measured during slow pacing, both before implantation of the electrodes and after $136 \pm 44$ weeks of maintained AF, by high resolution mapping (240 electrodes, inter-electrode distance $2.5 \mathrm{~mm}$ ). Although, these islets of Cx40 deprived cells did not change the average atrial conduction velocity in the right atrial free wall ( $84 \pm 12 \mathrm{~cm} / \mathrm{s}$ in sinus rhythm goats versus $88 \pm 6 \mathrm{~cm} / \mathrm{s}$ in chronically fibrillating goats), they still may play a role in the occurrence of micro-reentry during AF which might be important for the perpetuation of AF.

4) What is the role of the sinus node and the atrio-ventricular node in chronic AF? Several studies have indicated that the sinus node plays an important role in the occurrence and perpetuation of AF. Clinically, atrial fibrillation is more commonly observed in patients with sick sinus syndrome. ${ }^{15,16} \mathrm{It}$ has been demonstrated that sinus node reentry and sinus reciprocation can occur, ${ }^{17,18}$ and that suppression of the sinus node and/or AV-node reduces the inducibility and stability of AF. ${ }^{19-21}$ Furthermore, Kirchhof has shown that during $A F$, a considerable amount of fibrillation waves 
originated from the sinus node area. ${ }^{22,23}$ It was suggested that these impulses, which were most likely based on sino-atrial reciprocation, might be of importance for the perpetuation of $\mathrm{AF}$, especially by 'restarting' the fibrillation process in case of nearby spontaneous termination of AF. Although in the present thesis the role of the sinus node in the development of chronic AF was not determined, in a few goats we observed very long sinus node recovery times after spontaneous cardioversion of AF (pauses of 4 seconds versus a normal sinus rhythm interval of 400-600 ms). Future experiments in which the sinus node function is followed during maintained $\mathrm{AF}$, or experiments in which the sinus node region is isolated, might reveal the significance of sinus node dysfunction during $\mathrm{AF}$ and elucidate its role for the perpetuation of $\mathrm{AF}$.

5) What is the role of chronic atrial stretch? In the present studies, acute atrial stretch did not cause a significant shortening of atrial refractoriness. However, this does not exclude that more prolonged atrial stretch might affect the propensity for AF. Stretch can affect the substrate for AF in many different ways. Dilatation of the atria increases the atrial surface area which may allow more wavelets to be present at the same time. Stretch can also favor the perpetuation of AF by shortening the refractory period and action potential duration, ${ }^{24-26}$ depression of the atrial conduction properties, ${ }^{27-29}$ or by increasing the inhomogeneity in electrophysiological properties. ${ }^{30,31}$ The role of atrial dilatation was not extensively studied in the present thesis and several experiments might be designed to determine its possible involvement in the development of chronic AF. Of special interest are the recent observations by Borgers and Ausma et al. ${ }^{32,33}$ showing that in cells from chronically fibrillating goat atria similar changes occur as seen in ventricular hibernating cells. In fibrillating atrial myocardium a loss of myofibrils and intra-cellular accumulation of glycogen was found. Next to the dramatic shortening of the action potential by AF which is likely to prevent $\mathrm{Ca}^{2+}$-ions to enter the cell, these morphological changes might explain the temporary atrial paralysis after cardioversion of chronic $\mathrm{AF}^{34-36}$ The loss of atrial contractility during chronic $\mathrm{AF}$ might also facilitate recurrences of $\mathrm{AF}$ and favor its perpetuation. The acute induction of $\mathrm{AF}$ is associated with an increase in wall stiffness and a decrease in compliance 37,38 which will prevent marked atrial dilatation in response to an increase in atrial pressure. ${ }^{37-39}$ However, in chronically fibrillating atria a loss of contractility might result in marked dilatation in response to already relatively small increases in atrial pressure. Although some studies showed a clear relationship between the occurrence and recurrence of atrial fibrillation and atrial size, ${ }^{40-42}$ at this moment the exact role of dilatation and hibernation in recurrence and perpetuation of the arrhythmia are not known.

Implications for Clinical Research and Possible Clinical Implications

The linding that AF induces electrophysiological changes in the atrial myocardium which favor the perpetuation of the arrhythmia might also play a role in humans. Clinically, it has been reported that the efficacy of anti-arrhythmic drugs is much higher in recent onset AF ( $<24$ hours) than for AF of longer duration. ${ }^{43-46}$ Directly 
after cardioversion of AF the atrial rate suddenly slows from $400-600$ beats per minute to $70-120$ beats per minute and due to the maladaptation of atrial refractoriness the refractory period fails to prolong or even can get shorter. Such a dangerously shon refractory period, which is only reversible within a few days of sinus rhythm, may play an important role in the recurrence of AF which is so common during the first days to weeks after successful cardioversion. ${ }^{47-49}$ Although, anti-fibrillatory drugs are useful in prevention of relapses to AF, ${ }^{50-53}$ the long-term maintenance of sinus rhythm remains a difficult clinical problem. In the present thesis all anti-fibrillatory drugs were successful in cardioversion of chronic AF; however they failed to prolong the wavelength at slow rates after successful cardioversion and could not prevent the reinduction of AF. Surprisingly, also the class III agent $d$-sotalol, failed to prolong the atrial refractory period which might suggest that electrical remodeling may change the electrophysiological effects of anti-fibrillatory drugs. The diminishing efficacy of drugs in AF of longer duration and the high rate of relapses after successful cardioversion might be explained by such a process of electrical remodeling. These observations stress the importance of testing anti-fibrillatory drugs in electrical remodeled atria and stress the importance of developing new drugs which are effective in prolonging the atrial refractory period and wavelength in electrically remodeled hearts.

Another clinical observation in which the process of electrical remodeling may play a role is that paroxysmal AF often deteriorates into chronic AF. ${ }^{54-57}$ Although this transition partly may depend on the progression of an underlying heart disease, it also occurs in patients with lone AF 54.57 and seems to be related to the frequency and duration of the episodes of AF.54,56 Some recent studies have provided more direct evidence that electrical remodeling may also play a role in humans but further clinical research is needed before one can draw any conclusions. Attuel et al. ${ }^{58}$ and Daoud et al. ${ }^{59}$ reported that short episodes of rapid atrial pacing or atrial fibrillation induced in humans shortened the atrial refractory period and attenuated its physiological rate adaptation. In addition, the shortened atrial refractory period was associated with a longer duration of the induced episodes of AF. So, if electrical remodeling also in humans contributes to the perpetuation of the arrhythmia, this may have several important implications. As previously mentioned, electrical remodeling may play a role in the diminishing efficacy of anti-fibrillatory drugs, in the frequent recurrences of AF after successful cardioversion and in the transition from paroxysmal to chronic AF. Paroxysms of AF can shorten the refractory period to such an extend that the next episode of AF is more casily induced and will last longer. On the other hand, the reversibility of this process implicates that electrical remodeling does not play a role in patients with infrequent and relatively short episodes of AF. The fact that the effects of electrical remodeling were reversible within a few days of sinus rhythm implicates that restoration and maintenance of sinus rhythm can have important anti-fibrillatory effects. Cardioversion of paroxysmal AF should be performed as soon as possible, because the longer AF lasts, the more stable it will be and the more difficult it will be cardioverted. However, directly after cardioversion the refractory period will still be 
very short and relapses of AF thus should be anticipated. Especially during the first days after cardioversion, it might be useful to monitor these patients or to instruct them carefully to come to the hospital immediately when AF reoccurs. With such a strategy, the process of electrical remodeling might be halted and long-term maintenance of sinus rhythm may be achieved. Some evidence to support this strategy was provided by a study of Crijns et al. ${ }^{49}$ who reported that serial anti-arrhythmic drug treatment increased the 2-year cumulative percentage of patients free of AF or atrial flutter from $31 \%$ to $63 \%$. Further clinical studies evaluating the effects of such a strategy on the long-term maintenance of sinus rhythin seem warranted.

On the other hand, it should not be forgotten that patients often have an underlying heart disease which provides a substrate for AF. In patients with markedly dilated atria. ischemic heart disease or vagally or adrenergically mediated AF, the role of electrical remodeling might be insignificant and in these different groups of patients the relative contribution of electrical remodeling should be studied. In our goat studies, the AF-induced shortening of atrial refractoriness seemed not to be mediated by changes in the autonomic nervous system, acute stretch, ischemia or ANF, implicating that interventions directed against these factors does not seem warranted in patients with $\mathrm{AF}$.

\section{References}

1 Giles WR, van Ginneken ACG: A transient outward current in isolated cells from crista terminalis of rabbit heart. J Physiol 1985;368:243-264

2 Ruiz-Petrich E, Leblane $\mathrm{N}$ : The mechanism of the rate-dependent changes of the conducted action potential in rabbit ventricle. Can J Physiol Pharmacol 1989;67:780-787

3 Bril A, Man RY: Effects of the potassium channel activator, BRL 34915, on the action potential characteristics of canine cardiac Purkinje fibers. J Pharmacol Exp Ther 1990;253:1090-1096

4 Wang Z. Fage PL, Nattel S: Mechanism of flecainide's antiarrhythmic action in experimental atrial fibrillation. Circ Res 1992:71:271-287

5 Wang J, Bourne GW, Wang Z, Villemaire C, Talajic M, Nattel S: Comparative mechanisms of antiarrhythmic drug action in experimental atrial fibrillation. Circulation 1993;88:1030-1044

6 Boyett MR. Fedida D: The effect of heart rate on the membrane currents of isolated sheep Purkinje fibres. I Physiol 1988;399:467-491

7 Cohen CJ. Fozzard HA. Sheu SS: Increase in intracellular sodium ion activity during stimulation in mammalian cardiac muscle. Circ Res 1982:50:651-662

8 Langer GA: Calcium exchange in dog ventricular muscle: relation to frequency of contraction and maintenance of contractility. Circ Res 1965:17:78-89

9 Tieleman RG, de Langen CDJ, van der Woude HJ, Grandjean JG, Bel KJ, Wijffels MCEF, Allessie MA, Crijns HJGM: Reduction of electrical remodeling of the atrium by verapamil. Circulation 1995;92:I-754(Abstract)

10 Lammers WJEP, Allessie MA, Rensma PL: The use of fibrillation cycle length to determine spatial dispersion in electrophysiological properties and to characterize the underlying mechanism of fibrillation. New Trends Arrhythm 1986:2:109-112

11 Opthof T, Ramdat Misier AR, Coronel R, Vermeulen JT, Verberne HJ, Frank RGJ, Moulijn AC, Capelle van FJL, Janse MJ: Dispersion of refractoriness in canine ventricular myocardium: effects of sympathetic stimulation. Circ Res 1991;68:1204-1215 
12 Ramdat Misier AR, Opthof T, Heme I van NM, Defat JJAM. Bakker de JMT, Janse MI, Capelle van FJL: Increased dispersion of "refractoriness" in patients with idiopathic paroxysmal atrial fibrillation. JAm Coll Cardiol 1992:19:1531-1535,

13 Allessie MA, Kirchhof CJHJ, Scheffer GJ, Chorro FI, Brugada J: Regional control of atrial fibrillation by rapid pacing in conscious dogs. Circulation 1991;84:1689- 1697'

14 Kirchhof CJHJ. Chorro FJ, Scheffer GJ. Brugada J, Konings KTS, Zetelaki Z. Allessie MA: Regional entrainment of atrial fibrillation studied by high-resolution mapping in open-chest dogs. Circulation 1993:88:736-749

15 Bigger JT, Reiffel JA: Sick simus syndrome. Ann Rev Med 1979;30:91-118

16 Ferrer MI: The sick sinus syndrome. Circulation 1973;47:635-641

17 Allessie MA, Bonke FIM: Direct demonstration of sinus node reentry in the rabbit heart. Circ Res $1979 ; 44: 557-568$

18 Han J, Malozzi MA, Moe GK.: Senoatrial reciprocation in the isolated rabbit heart. Circ Rex 1968;22:355-362

19 Assume K, Shinmura H, Shimizu K, Iwane H: Significance of the sino-atrial node on mechanism of occurrence of atrial fibrillation. Jpn Heart J 1972:13:84-98

20 Nadeau RA, Roberge FA, Billette J: Role of the sinus node in the mechanism of cholinergic atrial fibrillation. Circ Res 1970;27:129-138

21 Scherf D, Terranova R: Mechanisms of auricular flutter and fibrillation. Am J Physiol 1949;159: 137. 142

22 Kirchhof CJHJ: The simus node and atrial fibrillation. Maastricht The Netherlands: University of Limburg, 1989;(Thesis)

23 Kirchhof CJHJ, Allessie MA, Bonke FIM: The sinus node and atrial arrhythmias. Ann N Y Acad Sci 1990;591:166-177

24 Solti F, Vecsey T, Kekési V, Juhász-Nagy A: The effect of atrial dilatation on the genesis of atrial arthythmias. Cardiovasc Res 1989:23:882-886

25 Ravelli F, Allessie MA: Atrial stretch decreases refractoriness and induces atrial fibrillation in the isolated rabbit heart. Circulation 1995;92:I-754(Abstract)

26 Le Grand B, Hatem S, Deroubaix E, Couétil JP, Coraboeuf E: Depressed transient outward and calcium currents in dilated human atria. Cardiovasc Res 1994;28:548-556

27 Hordof AJ, Edie R, Malm JR, Hoffman BF, Rosen MR: Electrophysiologic properties and response to pharmacologic agents of fibers from diseased human atria. Circularion 1976;54:774-779

28 Ten Eick RE. Singer DH: Electrophysiologic properties of diseased human atrium. I.Low diastolic potential and altered cellular response to potassium. Circ Res 1979:44:545

29 Mary-Rabine L, Albert A, Pham TD, Hordof AJ, Fenoglio JJ, Jr., Malm JR, Rosen MR: The relationship of human atrial cellular electrophysiology to clinical function and ultrastructure. Circ Res 1983;52:188-199

30 Isobe F. Schuessler RB. Mitsuno M. Nitta T, Cronin CS, Boineau JP, Cox JL: High atrial pressure directly affects the dispersion of refractoriness and the inducibility of atrial fibrillation. Circulation 1993;88:I-326(Abstract)

31 Satoh T, Zipes DP: The duration of atrial refractoriness in the thin region of the canine right atrium. exceeds refractoriness in the thick region. Circulation 1995:92:I-755(Abstract)

32 Borgers M, Ausma J, Wijffels M. Allessie M: Atrial fibrillation in the goat: a model for chronic hibemating myocardium. Circulation 1994;90:1-467(Abstract)

33 Ausma J, Wijffels M, Ramaekers F, Allessie M, Borgers M: Atrial fibrillation in the goat: A model for dedifferentation of cardiomyocytes. Eur J Physiol (Pfligers Arch) 1995;430:R111 (Abstract)

34 Ikram $\mathrm{H}$, Nixon PGF. Arcan T: Left atrial function after electrical conversion to sinus rhythm. $\mathrm{Br}$ Heart J 1968;30:80-83

35 Van Gelder IC, Crijns HJGM, Blanksma PK. Landsman MLJ, Posma JL, Van Den Berg MP, Meijler FL. Lie KI: Time course of hemodynamic changes and improvement of exercise tolerance after cardioversion of chronic atrial fibrillation unassociated with cardiac valve disease. Am J Cardiol $1993 ; 72: 560-566$ 
36 Manning WJ, Silverman DI, Katz SE, Riley MF, Come PC, Doherty RM, Munson JT, Douglas PS: Impaired left atrial mechanical function after cardioversion: relation to the duration of atrial fibrillation. J Am Coll Cardiol 1994;23:1535-1540

37 Leistad E, Christensen G, Ilebekk A: Effects of atrial fibrillation on left and right atrial dimensions, pressures, and compliances. Am J Physiol 1993;264:H1093-H1097

38 White CW, Kerber RE, Weiss HR, Marcus ML: The effects of atrial fibrillation on atrial pressurevolume and flow relationships. Circ Res 1982;51:205-215

39 Wijffels MCEF, Kirchhof CJHJ, Dorland R, Power J, Allessie MA: Electrical remodeling due to atrial fibrillation in chronically instrumented conscious goats. The role of neurohumoral changes, ischemia, atrial stretch and high rate of electrical activation. Circulation (submitted) 1996;

40 Henry WL, Morganroth J, Pearlman AS, Clark CE, Redwood DR, Itscoitz SB, Epstein SE: Relation between echocardiographically determined left atrial size and atrial fibrillation. Circulation 1976;53:273-279

41 Davies MJ, Pomerance A: Pathology of atrial fibrillation in man. Br Hearl J 1972;34:520-525

42 Brodsky MA, Allen BJ: Factors determining maintenance of sinus rhythm after chronic atrial fibrillation with left atrial dilatation. Am J Cardiol 1989;63:1065-1068

43 Crozier IG, Ikram H, Kenealy M, Levy L: Flecainide acetate for conversion of acute supraventricular tachycardia to sinus rhythm. Am J Cardiol 1987;59:607-609

44 Crijns HJGM, Wijk van LM, Gilst van WH, Kingma HJ, Van Gelder IC, Lie KI: Acute conversion of atrial fibrillation to sinus rhythm: clinical efficacy of flecainide acetate. Comparison of two regimes. Eur Heart $J$ 1988:9:634-638

45 Suttorp MJ, Kingma HJ, Jessurun ER, Lie-A-Huen L, van Hemel NM, Lie KI: The value of class IC antiarrhythmic drugs for acute conversion of paroxysmal atrial fibrillation or flutter to sinus rhythm. J Am Coll Cardiol 1990:16:1722-1727

46 Suttorp MJ, Kingma JH, Lie-A-Huen L, Mast EG: Intravenous flecainide versus verapamil for acute conversion of paroxysmal atrial fibrillation or flutter to sinus rhythm. Am J Cardiol 1989:63:693-696

47 Resnekov L, McDonald L: Appraisal of electroconversion in treatment of cardiac dysrhythmias. $\mathrm{Br}$ Heart $J$ 1968:30:786-811

48 Bjerkelund C, Orning O: An evaluation of DC shock treatment of atrial arrhythmias. Acta Med Scand 1968;184:481-491

49 Crijns HJGM, Van Gelder IC, Gilst van WH, Hillege H, Gosselink M, Lie KI: Serial antiarrhythmic drug treatment to maintain sinus rhythm after electrical cardioversion for chronic atrial fibrillation or atrial flutter. Am J Cardiol 1991;68:335-341

50 Coplen SE, Antman EM, Berlin JA, Hewitt P, Chalmers TC: Efficacy and safety of quinidine therapy for maintenance of sinus rhythm after cardioversion. A meta-analysis of randomized control trials. Circulation 1990;82:1106-1116

51 Gosselink MAT, Crijns HJGM, Van Gelder IC, Hillige H, Wiesfeld ACP, Lie KI: Low-dose amiodarone for maintenance of sinus rhythm after cardioversion of atrial fibrillation or flutter. JAMA 1992:267:3289-3293

52 Rasmussen $\mathrm{K}$, Wang $\mathrm{H}$, Fausa $\mathrm{D}$ : Comparative efficiency of quinidine and verapamil in the maintenance of sinus rhythm after DC conversion of atrial fibrillation. A controlled clinical trial. Acta Med Scand (Suppl) 1981;645:23-28

53 Juul-Moller S, Edvardsson N, Rehnqvist-Ahlberg N: Sotalol vs. quinidine for the maintenance of sinus rhythm after direct current conversion of atrial fibrillation. Circulation 1990;82:1932-1939

54 Godtfredsen J: Atrial fibrillation: etiology, course and prognosis. A follow-up study of 1212 cases. 1975:(Abstract)

55 Godtfredsen J: Atrial fibrillation: course and prognosis. A follow-up study of 1212 cases, in Kulbertus HE, Olsson SB, Schlepper M (eds): Atrial Fibrillation. Mölndal, Sweden, Lindgren and Soner, 1982, pp 134-145

56 Parkinson J. Campbell M: Paroxysmal auricular fibrillation. A record of two hundred patients. $Q J$ Med 1930;24:67-100 
57 Kopecky SL, Gersh BJ, McGoon MD, Whisnant JP, Holmes DR, Ilstrup DM, Frye RL: The natural history of lone atrial fibrillation: a population based study over three decades. $N$ Engl J Med 1987;317:669-674

58 Attuel P, Leclercq JF, Coumel P: Atrial electrophysiological substrate remodelling after tachycardia in patients with and without atrial fibrillation. Pace 1995;18:804(Abstract)

59 Daoud EG, Niebauer M, Bogun F, Castellani M, Chan KK, Goyal R., Harvey M, Man CK, Strickberger SA, Morady F: Atrial fibrillation induced shortening of atrial refractoriness in humans. Circulation [995;92:I-404(Abstract) 



\section{Summary}

In chapter 1 the background to the present study is given. Atrial fibrillation is the most common arrhythmia in man with a prevalence of $0.4 \%$ in the total population, $4 \%$ in cardiac patients and $40 \%$ in patients with overt heart failure. From clinical and epidemiological studies it has been known that AF has a progressive nature. In patients, AF often starts as short paroxysms which gradually increase in duration, finally deteriorating into chronic $\mathrm{AF}$. Additional evidence for the progressive nature of the arrhythmia is that the success rate of cardioversion by anti-fibrillatory drugs and the successful maintenance of sinus rhythm afterwards are much higher if the arrhythmia has persisted for only a short time. A possible explanation for the progressive nature of $\mathrm{AF}$ is a deterioration in underlying heart disease (e.g. valvular disease, coronary heart disease). It was the aim of this present study to test the alternative hypothesis that atrial fibrillation itself causes progressive electrophysiological changes to the atrial myocardium which favor the initiation and perpetuation of the arrhythmia. In order to evaluate the latter hypothesis an animal model was developed. Goats were chronically instrumented with multiple epicardial electrodes which made it possible to maintain atrial fibrillation continuously and to follow the changes in electrophysiological properties (atrial refractoriness and intra-atrial conduction velocity). In chapter 1 the effects of maintenance of atrial fibrillation on the duration of AF-episodes as measured in the first goat are given.

In chapter 2 a historical overview, mechanisms and determinants of atrial fibrillation are given. In chapter 3 the electrophysiological effects of maintenance of $\mathrm{AF}$ are described in more detail. In goats that had been in normal sinus rhythm during their whole life, AF could be induced but was usually self-terminating within a few seconds. However, when AF was reinduced repetitively for 24 hours a day and 7 days a week, the duration of AF-episodes increased progressively and finally in almost all goats AF became chronic (duration more than 24 hours) within 2-4 weeks. Electrophysiological studies revealed that the dramatic increase in stability of AF was accompanied by a progressive shortening of the AF-interval and a shortening of the atrial effective refractory period. At higher heart rates the shortening of the AERP was less pronounced resulting in an attenuation or sometimes even inversion of the physiological rate adaptation of atrial refractoriness. While in normal (sinus rhythm) hearts, the refractory period prolonged in response to a slowing of heart rate, now the refractory period failed to prolong and sometimes became even shorter when heart rate was slowed down. Because no significant changes in the intra-atrial conduction velocity were found during the first few days of $\mathrm{AF}$, the atrial wavelength (product of refractory period and conduction velocity) shortened dramatically as well. The shortening of atrial wavelength was associated with an increase in not only the stability 
of AF but also with an increase in the inducibility of AF by a single early premature stimulus from $24 \%$ to $76 \%$ (after 24 hours of AF).

In chapter 4 the possible stimuli for the AF-induced shortening of atrial refractoriness (electrical remodeling) are evaluated. The shortening of atrial refractoriness seemed not to be mediated by a higher activity of the autonomic nervous system, ischemia of the atrial myocardium or by increased levels of the atrial natriuretic factor (ANF). Although acute volume loading did not shorten atrial refractoriness, it could not be excluded that more chronic atrial stretch can be involved in the process of electrical remodeling. Finally, the high rate of atrial activation itself turned out to be the trigger for the AF-induced shortening and inversion of the rate adaptation of the AERP.

Becuuse the AF induced shortening of the AERP is most likely to be due to changes in the duration of the action potential, monophasic action potentials were recorded in normal sinus rhythm goats and in goats in which AF had become chronic (chapter 5). Similar to the effects on atrial refractoriness, AF caused a shortening and inversed rate adaptation of the atrial action potential duration.

In chapters 6,7 and 8 the effects of class IA, IC and III anti-fibrillatory drugs in this model of chronic AF are studied. Hydroquinidine (class IA), cibenzoline (class IC with additional class III and IV effects). flecainide (class IC) and $d$-sotalol (class III) were all effective in the cardioversion of chronic AF. Sinus rhythm was restored by these drugs in $86,86,67$ and $92 \%$ of the goats respectively. Side-effects of these drugs were seen in $14,43,56$ and $8 \%$ of the goats. Although all drugs were effective in termination of chronic AF, none of the drugs prolonged the atrial wavelength at slow heart rates which remained as short as $5.7-8.8 \mathrm{~cm}$ versus $17.4 \mathrm{~cm}$ in sinus rhythm goats. As a result, the reinducibility of AF by a single early premature stimulus remained as high as $67-100 \%$ (chapter 6). Measurements of the AERP and the atrial conduction velocity during $\mathrm{AF}$ revealed that the anti-fibrillatory effects of class IA, IC and III drugs is not based on a prolongation of the atrial wavelength during $A F$, which previously has been considered to be the mechanism of their action. (chapter 7). The key observation in these experiments was that all drugs prolonged the AF-interval considerably more that the atrial refractory period during AF. As a result, the excitable period widened progressively by $100-200 \%$, which may be an important anti-fibrillatory property. In chapter 8 the changes in AF interval and conduction velocity just prior to termination of AF are studied. It was concluded that spontaneous and drug-facilitated termination of AF are preceded by a sudden progressive increase in the AF interval and atrial conduction velocity. This resulted in an increase in estimated circuit size (product of AF interval and conduction velocity) from $7-8 \mathrm{~cm}$ to $14-16 \mathrm{~cm}$ which preceeds the termination of AF.

Finally, in the last chapter of this thesis (chapter 9) the possible implications and some of the limitations of this study are discussed.

In summary, repetitive induction of atrial fibrillation in healthy hearts of chronically instrumented goats leads to a progressive increase in the stability and inducibility 
of atrial fibrillation ("AF begets AF"). These changes were associated with a dramatic shortening of the atrial effective refractory period (electrical remodeling) which seemed to be caused by the high rate of atrial activation during AF. These findings may provide a good explanation for the clinically observed progressive nature of the arrhythmia. Although some recent studies have provided evidence that electrical remodeling may also play a role in humans, it should not be forgotten that patients often have an underlying heart disease which provides an additional substrate for AF. As a consequence the precise role of electrical remodeling is unclear at present and future studies addressing this subject are needed. The second part of the thesis shows that the anti-fibrillatory properties of drugs are not necessarily based on a prolongation of the atrial wavelength, which up to now was considered to be the mechanism of their action. Although drugs were efficient in cardioversion of chronic AF, they failed in successful preventing arrhythmia reinduction. These studies have provided new insight into the pathophysiology of atrial fibrillation and anti-fibrillatory drug actions and are likely to stimulate development of more effective therapy for this common arrhythmia. 



\section{Samenvatting}

Het hart is een holle spier die circa 70 maal per minuut samentrekt en daarmee het bloed door het lichaam pompt. Iedere contractie van de hartspier wordt voorafgegaan door een electrische stimulatie van de afzonderlijke spiercellen. Deze electrische stimulatie wordt verzorgd door een electrische prikkel die in de sinusknoop ontstaat, een structuur gelegen in het rechter atrium (boezem), en van daaruit wordt voortgeleid over de beide atria, via de atrioventriculaire knoop (AV-knoop) naar de beide ventrikels (kamers) van het hart. Dit proefschrift richt zich op atriumfibrilleren (AF) een zeer frequent voorkomende ritmestoornis bij de mens. Tijdens atriumfibrilleren worden de beide atria niet meer op de normale regelmatige wijze geactiveerd door de sinusknoop (frequentie 70 slagen per minuut), maar zijn er talrijke kriskras door elkaar lopende kringstroompjes aanwezig die de atria zeer snel en zeer onregelmatig activeren met een frequentie van circa 400-600 slagen per minuut. Hoewel de AV-knoop slechts een deel van deze slagen voorgeleidt, verloopt ook de activatie van de kamers te snel en volstrekt onregelmatig met 100-160 slagen per minuut. De afwezigheid van een gecoördineerde atriumcontractie en het te snelle en onregelmatige kamerritme geven klachten van hartkloppingen en een verminderde inspanningstolerantie. $\mathrm{Bij}$ patiënten met atriumfibrilleren staat het bloed in de oortjes van de atria vrijwel stil, waardoor de kans op vorming van bloedstolsels (trombi) en daarmee de kans op trombo-embolische complicaties wordt verhoogd.

Hoofdstuk 1 beschrijft de achtergrond van de huidige studie. Atriumfibrilleren heeft een prevalentie van circa $0.4 \%$ in de totale bevolking, $4 \%$ bij hartpatiënten en $40 \%$ bij patiënten met hartfalen. Uit klinische en epidemiologische studies is gebleken dat AF een progressief verlopende aandoening is, die aanvankelijk slechts aanvalsgewijs optreedt om later over te gaan in een chronische vorm. Ook is bekend dat AF nog veel gemakkelijker te stoppen is (met geneesmiddelen of door electroshock) en de kans op een recidief nog veel kleiner is, wanneer de ritmestoornis slechts kort geleden is ontstaan (bijvoorbeeld $<24$ uur). Op grond van deze waarnemingen rees de vraag of dit progressieve verloop van AF het gevolg is van de progressie van een onderliggende hartaandoening (zoals een klepgebrek of kransslagaderlijden) of dat $\mathrm{AF}$ zelf electrofysiologische of structurele veranderingen van de boezem veroorzaakt die het chronisch worden van AF kunnen verklaren. Om deze laatste hypothese te toetsen werd een proefdiermodel ontwikkeld. Door in geiten op het oppervlak van beide atria meerdere elektrodes te implanteren, werd het mogelijk AF op te wekken en de electrofysiologische eigenschappen van de atria (refractaire periode en geleidingssnelheid) in de tijd te vervolgen. In hoofdstuk I wordt het effect getoond van het herhaaldelijk opwekken van atriumfibrilleren zoals bestudeerd in de allereerste geit. 
Nadat in hoofdstuk 2 een historisch overzicht van atriumfibrilleren wordt gegeven en de determinanten van de ritmestoornis worden besproken, worden in hoofdstuk 3 de electrofysiologische effecten van atriumfibrilleren in meer detail bestudeerd. Indien AF opgewekt wordt in geiten, die hun gehele leven in sinus ritme geweest zijn, stopt deze ritmestoornis gewoonlijk binnen enkele seconden. Echter, door met behulp van een automatische fibrillatie pacemaker AF continu te onderhouden (gedurende 24 uur per dag en 7 dagen per week), neemt de duur van de afzonderlijke episodes van AF progressief toe, hetgeen in vrijwel alle geiten binnen 2-4 weken resulteert in chronisch AF (duur meer dan 24 uur). Deze dramatische toename in de stabiliteit van AF gaat gepaard met een verkorting van het activatie-interval (tijd tussen twee opeenvolgende activaties) tijdens $\mathrm{AF}$ en een verkorting van de atriale effectieve refractaire periode (AERP). Omdat tijdens hogere hartfrequenties de verkorting van de AERP minder uitgesproken is treedt er een afzwakking of soms zelfs een inversie op van de normale frequentie-afhankelijke verkorting van de AERP. Terwijl in normale (sinus ritme) harten de AERP verlengt wanneer het hartritme vertraagt, bleek na 2-4 dagen van onderhouden van atriumfibrilleren de refractaire periode niet meer te verlengen en soms zelfs te verkorten indien het hartritme werd vertraagd. Tijdens de eerste dagen van $\mathrm{AF}$ treden er geen veranderingen op in de intra-atriale geleidingssnelheid, waardoor ook de atriale golflengte (produkt van de refractaire periode en de geleidingssnelheid) fors afneemt. De afname van de atriale golflengte werd niet alleen met een toename in de stabiliteit van AF geassocieerd maar ook met een toename van de induceerbaarheid van AF door een enkele extra-stimulus van $24 \%$ tot $76 \%$ (na 24 uur AF).

In hoofdstuk 4 komen de mogelijke stimuli voor de verkorting van de AERP door AF ("electrical remodeling") aan de orde. De verkorting van de AERP blijkt niet veroorzaakt te worden door veranderingen van het autonome zenuwstelsel, zuurstofgebrek van de atria, atriale rek of verhoogde bloedspiegels van de atriale natriuretische factor. Daarentegen blijkt de hoge atriale ontladingsfrequentie zèlf de stimulus voor de verkorting en de inversie van de frequentie-afhankelijkheid van de AERP.

Daar de door AF-geïnduceerde verkorting van de refractaire periode het meest waarschijnlijk berust op een verkorting van de duur van de actiepotentiaal werden zowel in sinusritme geiten als in geiten waarin chronisch atriumfibrilleren werd geïnduceerd, monofasische actiepotentialen geregistreerd (hoofdstuk 5). Het blijkt dat, vergelijkbaar met de effecten op de refractaire periode, $\mathrm{AF}$ zowel een verkoning als een inversie van de frequentie-afhankelijkheid van de duur van de actiepotentiaal geeft.

De hoofdstukken 6, 7 en 8 beschrijven de effecten van diverse klasse IA, IC en III anti-aritmica in dit proefdiermodel van chronisch atriumfibrilleren. Zowel hydroquinidine (klasse IA) als cibenzoline (klasse IC met additionele klasse III en IV effecten), flecainide (klasse IC) en $d$-sotalol (klasse III) zijn zeer effecticf in cardioversie van chronisch atriumfibrilleren. Sinus ritme werd hersteld in respectievelijk 86, 86,67 en $92 \%$ van de geiten. Bijwerkingen van deze geneesmiddelen werden gezien in respectievelijk 14. 43, 56 en $8 \%$ van de geiten. Ondanks hun effectiviteit in 
terminatie van AF wordt de AERP (gemeten tijdens trage hartfrequenties) door deze geneesmiddelen nauwelijks verlengd en/of de atriale geleidingssnelheid sterk vertraagd waardoor de atriale golflengte (het produkt van de AERP en de geleidingssnelheid) abnormaal kort blijft $(5.7-8.8 \mathrm{~cm}$, versus $17.4 \mathrm{~cm}$ tijdens controle). De abnormaal korte golflengte werd gecorreleerd met een hoge reïnduceerbaarheid van AF (67-100\%) (hoofdstuk 6). Bij metingen van de AERP en de geleidingssnelheid tijdens AF blijkt dat het anti-fibrillatoire effect van klasse IA, IC en III anti-aritmica niet berust op een verlenging van de golflengte tijdens AF, zoals voorheen in andere studies werd gesuggereerd (hoofdstuk 7). De progressieve verlenging van het AF-interval en het anti-fibrillatoire effect van deze geneesmiddelen werd geassocieerd met een progressieve verwijding van de exciteerbare periode tijdens AF (verschil tussen AF- interval en de refractaire periode) met $100-200 \%$. In hoofdstuk 8 wordt beschreven dat zowel de spontane als de cibenzoline-geïnduceerde terminatie van atriumfibrilleren wordt voorafgegaan door een plotselinge en progressieve toename van het AF-interval en de geleidingssnelheid tijdens atriumfibrilleren. Een toename in de geschatte circuit lengte (produkt van AF-interval en geleidingssnclheid) van $7-8 \mathrm{~cm}$ tot $14-16 \mathrm{~cm}$ gaat vooraf aan de terminatie van $\mathrm{AF}$.

Het proefschrift wordt afgesloten met een algemene discussie (hoofdstuk 9) waarin de mogelijke (klinische) implicaties en beperkingen van het huidige onderzoek worden weergegeven.

Samenvattend kunnen we stellen dat het herhaaldelijk opwekken van atriumfibrilleren in gezonde harten van chronisch geïnstrumenteerde geiten aanleiding geeft tot een progressieve toename in de induceerbaarheid en stabiliteit van atriumfibrilleren ("AF begets AF"). De AF-geïnduceerde verkorting van de refractaire periode ("electrical remodeling") speelt hierbij een zeer belangrijke rol. De bevindingen van dit proefschrift kunnen een goede verklaring geven voor de klinische waarneming dat atriumfibrilleren een progressief verlopende ritmestoornis is. Aan de andere kant moeten we niet vergeten dat, patiënten met atriumfibrilleren vaak een onderliggende hart-of vaatziekte hebben, die een additioneel substraat kan vormen voor atriumfibrilleren. Hoewel sommige klinische studies inmiddels aanwijzingen geven voor het optreden van electrical remodeling bij patiënten, is de significantie van onze bevindingen in patiënten met onderliggende hart- of vaatziekten nog niet geheel duidelijk. Toekomstig onderzoek zal de relevantie moeten aantonen. Het tweede deel van dit proefschrift laat zien dat de anti-fibrillatoire effecten van geneesmiddelen niet noodzakelijk gerelateerd zijn aan een verlenging van de atriale golflengte tijdens AF, hetgeen tot nu toe beschouwd werd als het werkingsmechanisme van deze geneesmiddelen. Bovendien werd gevonden dat geneesmiddelen heel effectief kunnen zijn in het termineren van chronisch AF terwijl zij falen in de preventie van reïnductie van de ritmestoornis. Deze bevindingen verschaffen ons nieuwe inzichten in de pathofysiologie van atriumfibrilleren en de mechanismen van anti-fibrillatoire geneesmiddelen en vormen een stimulus voor het ontwikkelen van effectievere therapieën voor deze veelvoorkomende ritme-stoornis 



\section{Nawoord}

Het is al weer meer dan 8 jaar geleden dat ik, in het derde jaar van mijn studie geneeskunde, voor de eerste keer in aanraking kwam met de wetenschap en de "Electrofysiologie". Ik weet nog goed dat ik destijds niet inzag waarom zo'n wetenschapsstage 6 weken moest duren; een week of twee voor enkele proefjes, het uitwerken van de data en het opschrijven hiervan leken mij ruimschoots voldoende. Niets bleek echter minder waar! Hoewel, het mij inmiddels duidelijk is dat het verrichten van wetenschappelijk onderzoek een zeer tijdrovende bezigheid is, is deze optimistische inschatting van wat er in een korte tijd allemaal gedaan kan worden, mij ook bij de afronding van dit promotieonderzoek blijven achtervolgen. Dat dit tot vele frustraties bij mijzelf en de mensen in mijn directe omgeving geleid heeft moge duidelijk zijn. Uitspraken als "eind november", "bijna klaar", "misschien kom ik zondag nog", "het begint al ergens op te lijken" of "nog even twee tabellen uitprinten" bleken achteraf gewoon gelogen en slechts bruikbaar voor het oppeppen van mijn eigen gemoed. Nu het boekje eindelijk af is (ik kan het nog steeds niet geloven), kan ik zeggen dat ik met een fijn gevoel op de afgelopen jaren terug kan kijken. Een dankwoord aan eenieder die een bijdrage heeft geleverd aan de totstandkoming van dit proefschrift is dan ook zeker op zijn plaats. Een aantal mensen zou ik in het bijzonder willen bedanken.

Allereerst mijn promotor Prof M.A. Allessie. Beste Maurits, om met jou te mogen werken is een grote eer, een unieke ervaring en ik ben jou dan ook veel dank verschuldigd. Je drang naar perfectie, je kritische houding en je analyserend vermogen zijn haast door niemand te evenaren en vormen de basis voor dit proefschrift. De continue stroom ain nieuwe (meestal goede) ideeën werkte na enige gewenning inspirerend en motiverend. Dat deze eigenschappen aanleiding gaven tot het keer op keer veranderen van protocollen, de opstelling van de apparatuur of de opzet van een paper ben ik inmiddels al lang weer vergeten. Ik hoop dat we in de toekomst even vruchtbaar en prettig kunnen blijven samenwerken.

Dr. Kirchhof. Beste Charles. al tijdens mijn wetenschapsstage was jij mijn begeleider en mocht ik altijd in die mooie grote bruine leren stoel zitten. Gedurende het eerste jaar van mijn O.I.O.-schap nam jij de dagelijkse begeleiding voor je rekening. Je ontembare inzet en het ogenschijnlijke plezier dat jij hieraan beleefde waren een grote steun en werkten zeer stimulerend. Zelfs als ik in het weekend voor problemen stond was jij bereid de straat even over te steken (dat kon vroeger nog) om mij uit de brand te helpen. Ik hoop dat ook wij, in de toekomst weer eens als vanouds samen kunnen experimenteren.

De leden van de beoordelingscommissie, prof. dr. H.J.J. Wellens, dr. H.J.G.M. Crijns, prof. dr. M.J. Janse, prof. dr. R.S. Reneman, prof. dr. H.A.J. Struijker Boudier 
bedankt voor de bereidheid het manuscript kritisch door te lezen en om op de verdediging van mijn proefschrift aanwezig te zijn.

Mijn paranimfen Rick Dorland en Marc Bemelmans. Rick, het feit dat jij, een rasechte Feyenoord fan bent heeft mij niet kunnen weerhouden jou als paranimf te benoemen. Jij verrichtte een groot deel van de experimenten en stond jarenlang aan mijn zijde. Dit uurtje zal er ook nog wel bij kunnen! Je tenue en schoenen (kistjes) zul je even aan moeten passen maar misschien weet je daarna niet meer beter. Beste Marc, als een van mijn beste vrienden vind ik het heel leuk dat ook jij op deze dag aan mijn zijde wil staan. De laatste jaren weet ik je steeds meer te waarderen en ik hoop dat onze vriendschap een lang leven beschoren is.

Een speciaal woord van dank gaat naar Lucas Boersma. Beste Lucie Baby, via het hockey-eftal volgde ik jou weg naar de electrofysiologie. Je aanwezigheid in het lab stond immer garant voor een gezellige sfeer en bracht een gezonde concurrentiestrijd tussen de atrium- en ventrikelboys teweeg (jammer dat je steeds verloor!). Ik hoop dat we in de komende jaren onder jouw bezielende leiding samen met Zwoelie en Janice, BTV, Marc en Maya nog af en toe wat ontspannende avonturen kunnen ondernemen.

En dan de jongens en meisjes van het electrofysiologie lab oftewel "The Team of Rick Dorland": Frans Mast bedankt voor de vele programmeer-avonturen (je wist nooit wat voor een versie van het stimulusprogramma je nu weer kreeg). Matthijs Killian voor het capturen, Lucie van der Zee voor de roddel-uitjes naar de slager, Peter Danse (de Waalse Nar) voor de hernieuwde strijdlust tussen de atrium en ventrikelboys, Joost Frederiks voor het abstract formulier (AHA '93) en Karen Konings voor van alles en nog wat. Het komisch duo Jut en Jul (Jan Hollen en Frits Schmitz) verdienen een aparte vermelding want zonder jullie bestaat er geen laboratorium voor de electrofysiologie. De technische ondersteuning bij het vervaardigen en repareren van de apparatuur was voor mij onmisbaar (als jullie beiden op vakantie gingen, waren Rick en ik altijd extra voorzichtig om maar geen oscilloscoop en/of prikkelkast op te blazen). Het opblazen van die ene prikkelkast zal ik overigens nooit vergeten, Jan bedankt!

De afgelopen jaren is het lab werkelijk overstroomd met buitenlandse gasten. Many thanks! Clifford Garratt for the discussions and the most helpful comments on preparing the manuscript. Gavier Chorro, Jean-Claude Deharo, Kai Haberl, John Power, Flavia Ravelli, Michael Reiter and Docter Who for the pleasant company and all the scientific support.

De andere collegae van de vakgroep Fysiologie, voor het jarenlang dulden van die heerlijke "geitenlucht". De dames van het secretariaat, met name Claire Bollen, voor de secretarieële ondersteuning. Ruud Kruger, Ferenc Verhulst, Jo Habets en Theo van de Nagel voor de kundige handjes op de OK en het "lenen" van de diverse goederen (tondeuses, infuuspompen etc.). 
In de afgelopen jaren heb ik het genoegen gehad met vele mensen van andere vakgroepen en universiteiten te mogen samenwerken. Marc Vos, Marieke de Groot en Jet Beekman voor de hulp bij het registreren van MAPjes en de totstandkoming van hoofdstuk 5. Prof. dr. M. Borgers, beste Marcel en Jannie Ausma, eenmaal op het pad van beland van het hibernerende geiten atrium was jullie kar (overladen met een grenzeloos enthousiasme) niet meer te stoppen. Robert Tieleman en Cees de Langen, ondanks de taalbarièrre (Groningers zijn niet te verstaan) gaf jullie aanwezigheid altijd aanleiding tot een gezellige sfeer, succes met jullie eigen onderzoekslijn die nu zijn vruchten begint af te werpen. Robert, tevens bedankt voor de verwerking van de ANF-data. Prof. dr. H.J. Jongsma en Huub van der Velden, Prof. dr. J. de Goede en Bart Hoekstra, voor al de wetenschappelijke discussies.

De mensen van de centrale proefdiervoorzieningen, met name Ton van de Boogaard, Birgit Kusters, Huub Simons, Frans Slangen, Mai en Joyce voor de deskundige hulp, advies en de verzorging van de geiten.

Hier wil ik ook enkele woorden van dank richten aan mijn ouders. Jullie hebben mij van kinds af aan gestimuleerd in mijn studie, de afronding van dit proefschrift is mede aan jullie te danken. Jullie stonden altijd klaar om mij advies te geven, of mijn Nederlandse taal te corrigeren. Jullie doorzettingsvermogen is een voorbeeld voor velen.

Lieve Marieke, mijn dank voor jou is natuurlijk niet in enkele woorden te vatten. Het afgelopen jaar heb ik niet alleen je computer in beslag genomen maar heb ik jou en ons huishouden volledig verwaarloosd. Mijn besonges (uitlopende tijdsplanningen, nachtelijke print-avonturen, de overgang naar de vakgroep Cardiologie) moeten jou menigmaal tot wanhoop hebben gedreven. Bedankt voor de bemoedigende woorden, de correctie van de manuscripten en het luisterende oor indien ik volledig ontdaan of gestressed hier een beroep op deed. Nu mijn proefschrift achter de rug is hoop ik wat meer vrije tijd voor jou te hebben, bij de afronding van je eigen promotie-onderzoek wens ik je heel veel succes en kun je in ieder geval een volledig beroep op mij doen.

Natuurlijk wil ik ook eenieder bedanken die ik hier (in alle drukte om dit nawoord nog op tijd naar de drukker te krijgen) vergeten ben en die zijn naam nog steeds niet heeft gevonden (dit is namelijk meestal een van de belangrijkste redenen om een dankwoord te lezen). 



\section{Curriculum Vitae}

$\begin{array}{ll}\begin{array}{l}4 \text { november } 1967 \\ 1979-1985\end{array} & \begin{array}{l}\text { Geboren te Maastricht } \\ \text { Gymnasium- } \beta \text {, Stedelijke Scholengemeenschap } \\ \text { te Maastricht }\end{array} \\ 1985 & \text { Start studie Geneeskunde, Rijksuniversiteit Limburg } \\ 1986 & \text { Propedeutisch examen Geneeskunde } \\ 1988-1989 & \text { Student-assistentschap vakgroep Fysiologie } \\ 1989 & \text { Doctoraal examen Geneeskunde } \\ 1991 & \text { Artsexamen. Met Genoege'n } \\ 1992-1996 & \text { O.I.O., Fysiologie, Rijksuniversiteit Limburg } \\ \text { juni 1996 tot heden } & \text { AGNIO, Cardiologie, Academisch Ziekenhuis } \\ & \text { Maastricht }\end{array}$




\section{Publications}

\section{Papers}

C Kirchhof, MCEF Wiffels, J Brugada, J Planellas, M Allessie. Mode of action of a new class Ic drug (ORG 7797) against atrial fibrillation in conscious dogs. J Cardiovasc Pharmacol 1991;17:1 16-124.

MA Allessie, MCEF Wijffels, CJHJ Kirchhof. Experimental models of arrhythmias: toys or truth ? Eur Heart J 1994;5(supplement A):2-8.

MCEF Wiiffels, CJHJ Kirchhof, LVA Boersma, R Dorland, MA Allessie. Atrial fibrillation begets atrial fibrillation. New trends in arrhythmias 1993;IX (2):147-152.

MCEF Wiiffels, CJHJ Kirchhof, R Dorland, MA Allessie. Atrial fibrillation begets atrial fibrillation. A study in awake chronically instrumented goats. Circulation 1995;92:1954-1968.

MA. Allessie, KTS Konings, CJHJ Kirchhof and MCEF Wijffels. Electrophysiological mechanisms of perpetuation of atrial fibrillation. Am J Cardiol 1995;77:10A-23A.

MCEF Wijffels, CJHJ Kirchhof, R Dorland, J Power, MA Allessie. Electrical remodeling due to atrial fibrillation in chronically instrumented conscious goats. The role of neurohumoral changes, ischemia, atrial stretch and high rate of electrical activation. Accepted Circulation 1996

RG Tieleman, CDJ de Langen, IC van Gelder, PJ de Kam, J Grandjean, KJ Bel, MCEF Wijffels, MA Allessie, HJGM Crijns. Verapamil reduces tachycardia induced electrical remodeling of the atria. Accepted Circulation 1996

\section{Chapters}

MA Allessie, MCEF Wiiffels, CJHJ Kirchhof. Electrical remodelling of the atria by atrial fibrillation. A possible explanation for post-fibrillation paralysis. In H Crijns, J Kingma, J Viersma (eds.): Heart Failure: From conduction to contraction. Dordrecht, The Netherlands, Kluwers. 1994, pp 11-19.

MCEF Wijfels, CJHJ Kirchhof, LVA Boersma, R Dorland, MA Allessie. Atrial fibrillation begets atrial fibrillation. In M Allessie, R Campbell, B Olsson (eds.): Atrial fibrillation: Mechanisms and therapeutic strategies. Mount Kisco, New York, Futura Publishing Company Inc, 1994, pp 195-201.

CJHJ Kirchhof, MCEF Wiiffels, MA Allessie. Pace termination of atrial fibrillation. In M Allessie, R Campbell, B Olsson (eds.): Atrial fibrillation: Mechanisms and therapeutic strategies. Mount Kisco, New York, Futura Publishing Company Inc. 1994, pp 251-271.

M Allessie, K Konings, MCEF Wijffels. Electrophysiological mechanisms of atrial fibrillation. In JP Dimarco, EN Prystowsky (eds.): Atrial Arrhythmias. State of the art. Armonk, New York, Futura Publishing Company Inc. 1995. pp 155-I61.

MCEF Wiiffels, CJHJ Kirchhof. R Dorland, MA Allessie. Electrical remodeling due to atrial fíbrillation. In MA Allessie, M Fromer (eds.): Atrial and ventricular fibrillation. Mechanisms and device therapy. Armonk, New York, Futura Publishing Company Inc. 1996, pp. in press.

JM Power, MCEF Wijffels, J Kalman, MA Allessie. Electrical conversion of atrial fibrillation. In MA Allessie, M Fromer (eds.): Atrial and ventricular fibrillation. Mechanisms and device therapy Armonk, New York, Futura Publishing Company Inc. 1996, pp. in press.

\section{Abstracts}

C Kirchhof, MCEF Wiiffels, J Planellas, M Allessie. Mode of anti-fibrillatory action of ORG 7797. The Faseb Joumal 1990;4(3):A454. 
M Allessie, C Kirchhof, MCEF Wiiffels. Estimation of the wavelength of the electrical impulse during atrial fibrillation. The Faseb Journal 1990;4(3): A681.

C Kirchhof, MCEF Wiiffels, J Planellas, L Boersma, M Allessie. Mode of anti-fibrillatory action of ORG 7797. Circulation 1990;82(4):III-529.

MCEF Wiiffels, C Kirchhof, K. Konings, M Allessie. Artificially maintained atrial fibrillation causes chronic atrial fibrillation in conscious goats. Eur J Physiol (Pflügers Arch) 1992;420:R89.

MCEF Wijffels, $\mathrm{C}$ Kirchhof, $\mathrm{K}$ Konings, M Allessie. Artificially maintained atrial fibrillation causes chronic atrial fibrillation in conscious goats. Eur J Physiol (Pflügers Arch) 1992;421:R43.

MCEF Wijffels, C Kirchhof, L Boersma, M Allessie. Atrial fibrillation begets atrial fibrillation. Eur $J$ Physiol (Pflügers Arch) 1993;424:R10.

L Boersma, Z Zetelaki, J Brugada, J Frederiks, MCEF Wijffels, C Kirchhof, M Allessie. Non-sustained ventricular tachycardia is terminated spontaneously by shifting of the reentrant circuit to the boundary of the heart. Eur J Physiol (Pflügers Arch) 1993;424:R2.

MCEF Wijffels, C Kirchhof, J Frederiks, L Boersma, M Allessie. Atrial fibrillation begets atrial fibrillation. Circulation 1993;88(part 2):I-18.

L Boersma, Z Zetelaki, J Frederiks, MCEF Wijffels, J Brugada, C Kirchhof, M Allessic. Two different mechanisms of spontaneous termination of polymorphic ventricular tachycardia in isolated rabbit hearts. Circulation 1993;88(part 2):I-117.

MCEF Wijffels, R Dorland, C Kirchhof, $\mathrm{M}$ Allessie. Electrophysiological effects of atrial fibrillation in conscious goats. Journal of Physiology 1994;479P:70P.

MCEF Wijffels, C Kirchhof, J Frederiks, L Boersma, M Allessie. Atrial fibrillation begets atrial fibrillation. Baylor Cardiac Arrhythmia Center: International Digest 1994;2(1):9.

MCEF Wijffels, R Dorland, C Kirchhof, M Allessie. What causes electrical remodelling of the atria due to atrial fibrillation? Circulation 1994;90(4;part2):I-41.

M Borgers, J Ausma, MCEF Wijffels, M Allessie. Atrial fibrillation in the goat: a model for chronic hibernating myocardium. Circulation 1994:90(4;part 2):I-467.

J Power, MCEF Wiiffels, R Dorland, and M Allessie. Defibrillation in a caprine model of chronic atrial fibrillation. Pace 1995; 18 (part II):809.

J Ausma, MCEF Wiiffels, F Ramaekers, M Allessie, M Borgers. Atrial fibrillation in the goat: A model for dedifferentation of cardiomyocytes Eur J Physiol (Pflügers Arch) 1995;430(4):R111.

F Mast, FJ Chorro, MCEF Wiiffels, R Dorland, MA Allessie. Change in estimated circuit size during spontaneous termination of atrial fibrillation. Eur J Physiol (Pflügers Arch) 1995:430(4):R112.

MJP Killian, F Mast, MCEF Wijfels, MA Allessie. Measurement of the atrial refractory period and the width of the excitable gap during sustained atrial fibrillation in the goat. Eur J Physiol (Pflügers Arch) 1995:430(4):R144.

J Ausma, MCEF Wijffels, F Ramaekers, M Allessie, M Borgers. Disruption of cardiomyocyte cohesion in chronic fibrillating atria of the goat. Eur J Physiol (Pflügers Arch) 1995;430(4):R144.

MCEF Wijffels, C Kirchhof, R Dorland, M Killian, F Mast, M Allessie. Effectiveness of Cibenzoline versus Flecainide in terminating sustained atrial fibrillation in goats. Eur J Physiol (Pflügers Arch) 1995;430(4):R145.

MCEF Wiiffels, KTS Konings, CJHJ Kirchhof, R Dorland, F Mast, MA Allessie. Changes in circuit size during the development of sustained atrial fibrillation. Circulation 1995;92(8):I-753.

RG Tieleman, CDJ de Langen, HJ van der Woude, JG Grandjean, KJ Bel, MCEF Wijffels, MA Allessie, HJGM Crijns. Reduction of electrical remodeling of the atrium by verapamil. Circulation 1995;92(8):I-754.

CDJ de Langen, RG Tieleman, HJ van der Woude, JG Grandjean, KJ Bel, MCEF Wijffels, MA Allessie, HJGM Crijns. Delayed recovery of atrial refractoriness after atrial tachycardia in the goat. Circulation 1995:92(8):1-755.

J Ausma, M Borgers, MCEF Wijffels, F Ramaekers, M Allessie. Chronic atrial fibrillation induces changes in cardiomyocyte phenotype. J Mol Cel. Cardiol 1996;28(5):A80.

M Borgers, F Thoné, J Ausma, MCEF Wijffels, M Allessie. Structural changes of atrial myocardium after chronic atrial fibrillation in the goat; J Mol Cell Cardiol 1996;28(5):A23. 
J Ausma, MCEF Wiffels, M Allessie, F Ramaekers, M Borgers. Dedifferentiation of cardiomyocytes in a model of chronic atrial fibrillation. Eur Heart J 1996; 17 (Abstract suppi):522.

MCEF Wijffels, R Dorland, MJP Killian, F. Mast, MA Allessie. Pharmacological conversion of chronic atrial fibrillation. Circulation 1996;94(8):I-351

F Mast, MJP Killian, MCEF Wiiffels, R Dorland, MA Allessie. A new method to measure the excitable gap during atrial fibrillation by single stimuli. Circulation 1996;94(8):I-351

$\mathrm{L}$ van der Zee, MCEF Wijffels, R Dorland, MA Vos, MA Allessie. Atrial fibrillation induced shortening of the monophasic action potental in the goat. Circulation 1996;94(8):I-556

M Borgers, J Ausma, F Thone, L Wouters, MCEF Wijffels, MA Allessie. Structural changes of atrial myocardium after chronic atrial fibrillation in the goat. Circulation 1996:94(8):I-593

RG Tieleman, CDJ de Langen, JG Grandjean, IC van Gelder, PJ de Kam, MCEF Wiiffels, HJGM Crijns. Regional differences in pacing induced electrical remodeling of the atria and recovery from electrical remodeling induces increased dispersion of refractoriness. Circulation 1996;94(8):I-352

HMW van der Velden, M van Zijverden, MJA van Kempen, MCEF Wijfels, WA Groenewegen, MA Allessie, HJ Jongsma. Abnormal expression of the gap junction protein connexin 40 during chronic atrial fibrillation in the goat. Circulation 1996;94(8):I-593 

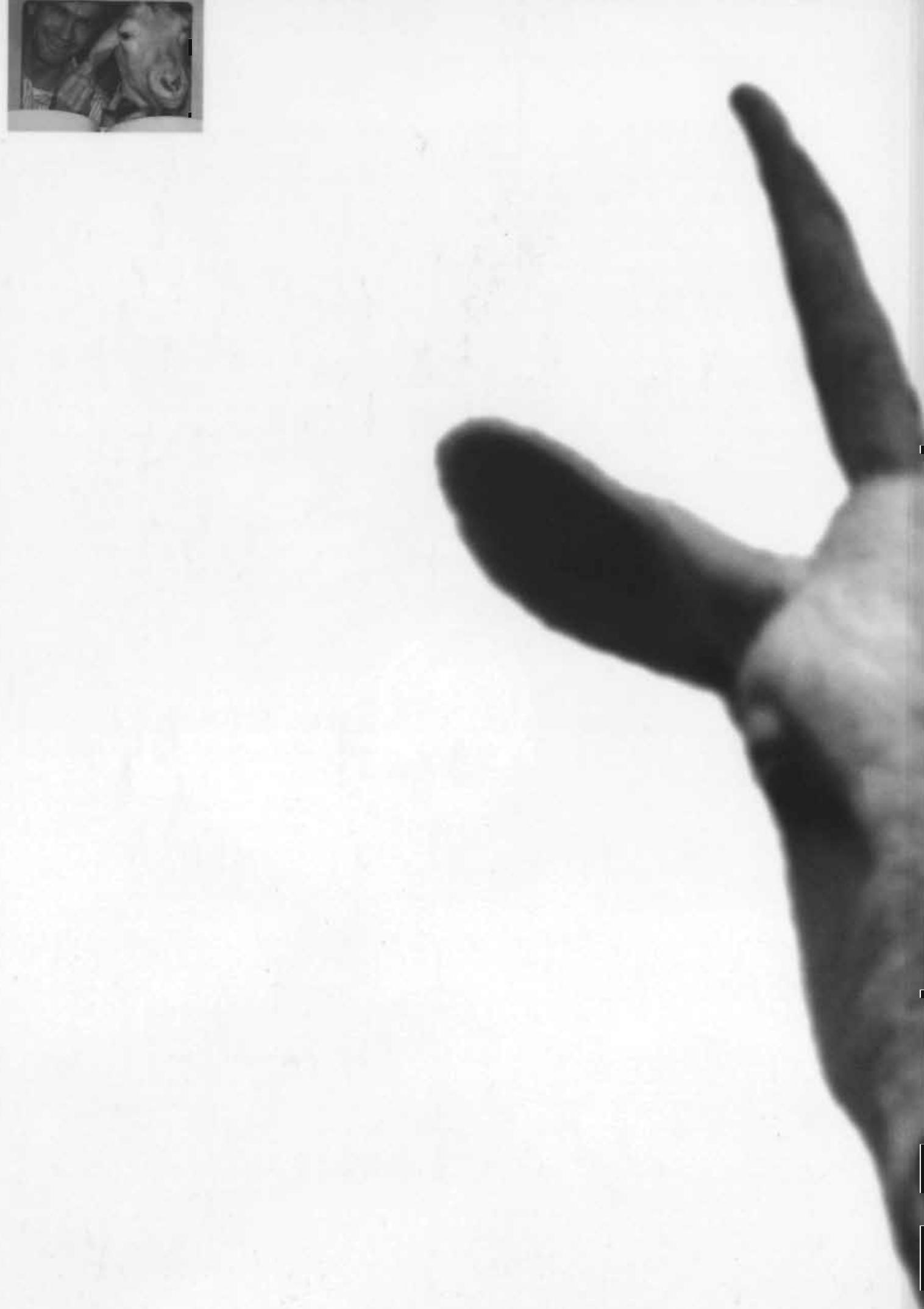